\title{
Investigation of Coal Syngas Impurity Tolerance of Alternative Cermet SOFC Anodes
}

Phil Gansor

West Virginia University

Follow this and additional works at: https://researchrepository.wvu.edu/etd

\section{Recommended Citation}

Gansor, Phil, "Investigation of Coal Syngas Impurity Tolerance of Alternative Cermet SOFC Anodes" (2012). Graduate Theses, Dissertations, and Problem Reports. 4857.

https://researchrepository.wvu.edu/etd/4857

This Thesis is protected by copyright and/or related rights. It has been brought to you by the The Research Repository @ WVU with permission from the rights-holder(s). You are free to use this Thesis in any way that is permitted by the copyright and related rights legislation that applies to your use. For other uses you must obtain permission from the rights-holder(s) directly, unless additional rights are indicated by a Creative Commons license in the record and/ or on the work itself. This Thesis has been accepted for inclusion in WVU Graduate Theses, Dissertations, and Problem Reports collection by an authorized administrator of The Research Repository @ WVU. For more information, please contact researchrepository@mail.wvu.edu. 


\title{
Investigation of Coal Syngas Impurity Tolerance of Alternative Cermet SOFC Anodes
}

\author{
Phil Gansor \\ Thesis submitted to the Benjamin M. Statler College of Engineering and Mineral \\ Resources \\ at West Virginia University \\ in partial fulfillment of the requirements \\ for the degree of \\ Master of Science
in
Mechanical Engineering \\ Edward M. Sabolsky, Ph.D., Chair \\ John Zondlo, Ph.D. \\ Xueyan Song, Ph.D.
}

Department of Mechanical and Aerospace Engineering

Morgantown, West Virginia

2012

Keywords: SOFC, coal syngas, phosphine, $\mathrm{H}_{2} \mathrm{~S}$

Copyright 2012 Phil Gansor 


\section{Abstract \\ Investigation of Coal Syngas Impurity Tolerance of Alternative Cermet SOFC Anodes}

Phil Gansor

Solid Oxide Fuel Cells (SOFC's) have the potential for producing highly efficient energy through conversion of chemical energy to electrical energy at high temperatures $\left(>600^{\circ} \mathrm{C}\right)$. Until recently, pure hydrogen fuel $\left(\mathrm{H}_{2}\right)$ is the prime fuel used within these devices. However, the high processing costs associated with clean hydrogen production combined with the abundance of available fossil fuels within the United States has opened the door for research on alternative fuels to power these cells. Among the biggest obstacles associated with this concept are the contaminants that are present in raw fuels such as natural gas or coal. While gas-cleanup technology is continually improving, parts per million (ppm) concentrations of species such as hydrogen sulfide $\left(\mathrm{H}_{2} \mathrm{~S}\right)$ and phosphine $\left(\mathrm{PH}_{3}\right)$ prove to be harmful to the traditional nickel-yttrium stabilized zirconia (Ni/YSZ) anode due primarily to the interactions with the Ni catalyst. In this work, a nickel-gadolinium doped ceria (Ni/GDC) anode is processed with a GDC barrier layer between the anode and electrolyte for evaluation in $\mathrm{H}_{2} \mathrm{~S}$-laden $\mathrm{H}_{2}$ and coal derived synthesized gas (syngas). Additionally, a novel $\mathrm{Sr}_{2} \mathrm{MgMoO}_{6-\delta} / \mathrm{GDC}$ anode (both electrolyte supported and anode supported) is developed for testing in fuels containing both $\mathrm{H}_{2} \mathrm{~S}$ and $\mathrm{PH}_{3}$. The central findings of this work are that the Ni/GDC anode with a GDC barrier layer can remain stable in syngas fuel with $100 \mathrm{ppm} \mathrm{H}_{2} \mathrm{~S}$. The same cell showed relatively high stability in wet $\mathrm{H}_{2}$ fuel with up to $1000 \mathrm{ppm} \mathrm{H}_{2} \mathrm{~S}$ without significant degradation and the barrier layer was shown to be essential to this stability. Specifically, the barrier layer helps to prevent nickel oxidation near the anode-electrolyte interface and to electrochemically oxidize the sulfur for additional power production. Also, the $\mathrm{Sr}_{2} \mathrm{MgMoO}_{6-\delta} / \mathrm{GDC}$ composite anode showed much improved tolerance to $10 \mathrm{ppm} \mathrm{PH}_{3}$ than the traditional Ni/YSZ cermet anode with the major cause of degradation being localized de-lamination at the anode/electrolyte interface and densification and de-lamination of the Pt contact from the anode. Unlike the Ni/YSZ anode, the SMM anode constituents were not found to be chemically reactive with $\mathrm{P}$ for our operating conditions. 


\section{Dedication}

I wish to dedicate this work to my loving family, friends, and most especially to God without whom none of this work would be worthwhile. 


\section{Acknowledgements}

I would like to express a great deal of thanks to my research advisor, Dr. Edward Sabolsky, for the countless hours he has dedicated to the furthering of my education both in the classroom and in the laboratory. Without this guidance, completion of the project would not have been possible. Mrs. Kathy Sabolsky must also be thanked for all of time and expertise that she provided in the lab over the past couple of years. I gained a great deal of knowledge from both Dr. and Mrs. Sabolsky throughout the course of this project that no doubt will serve me well in my future endeavors. A special thanks also goes out to the other members of my committee, Dr. Xueyan Song and Dr. John Zondlo, who were both kind enough to lend their expertise with fuel cells to increase the value of the work in this thesis. An additional thanks to Dr. Zondlo is necessary for allowing a majority of the work presented in this thesis to be conducted in his laboratory. I also would like to acknowledge Mrs. Adrianne McGraw for her assistance with micro-structural SEM imaging and Mr. Engin Ciftyurek and Mr. Joshua Mullenax for their help with material characterization. Most especially, I owe thanks to Dr. Chunchuan Xu for all of the invaluable assistance he provided with regards to fuel cell testing and organization of data. His efforts have resulted in a couple of publications on the work in this thesis which have benefitted those in the group as well as the rest of the scientific community. I finally would like to thank my father, (Mike Gansor), mother (Julie Gansor), brother (Steve Gansor), and sister (Jennifer Mone) for their unwavering support throughout the completion of my studies. 


\section{Table of Contents}

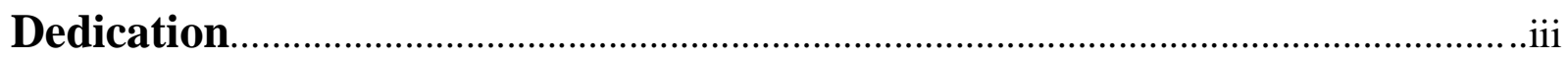

Acknowledgements .............................................................

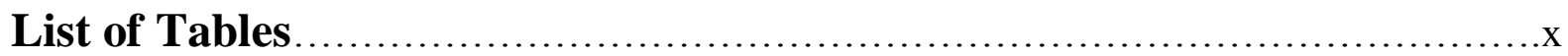

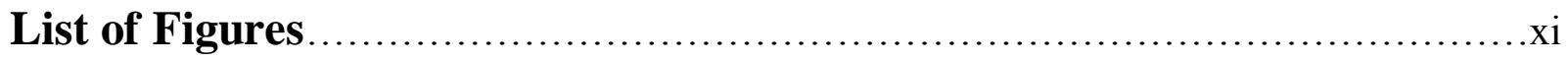

Chapter 1- Introduction ........................................................

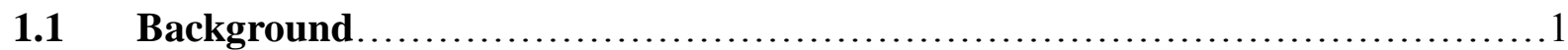

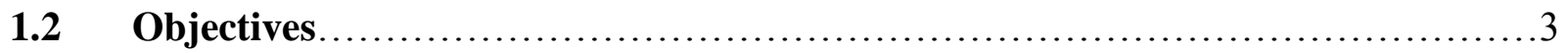

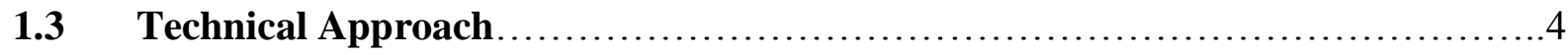

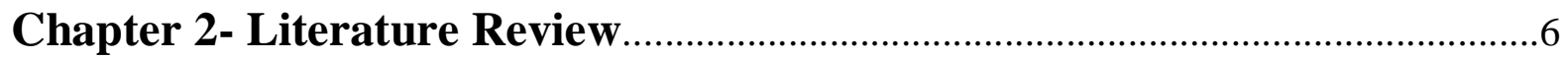

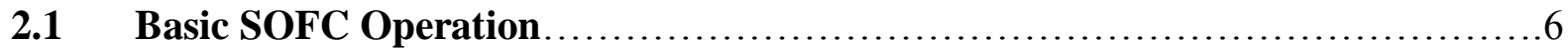

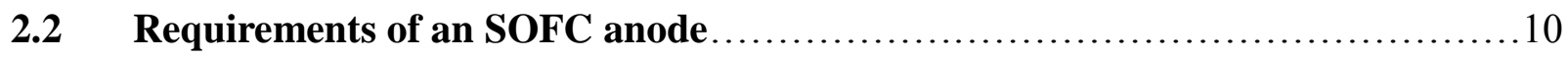

2.2.1 Coefficient of Thermal Expansion ......................................10

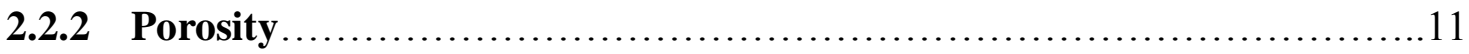

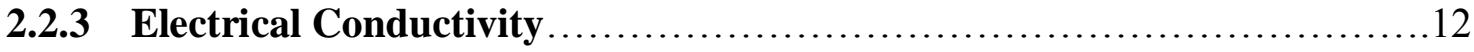

2.2.4 Catalytic Activity and Chemical Stability ..............................13

$2.3 \quad$ Cell Evaluation Techniques..................................................

2.3.1 I-V-P Performance Curves......................................... 14

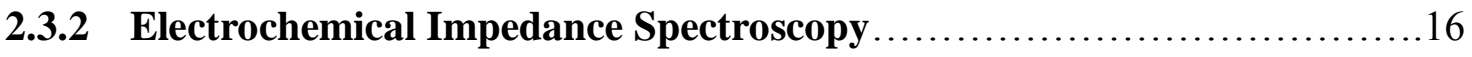

2.4 Conventional Ni/YSZ Anode Operating in Syngas Fuel........................17

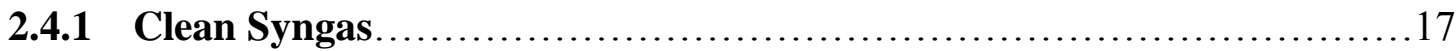




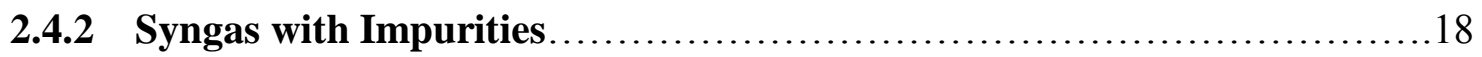

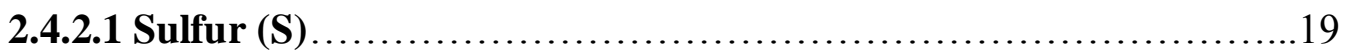

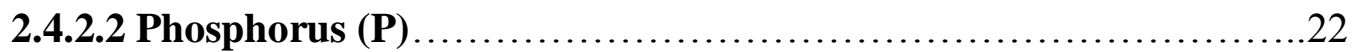

2.5 Alternative Anode Approach for Mitigating Impurity Degradation ...............23

2.5.1 The Nickel/Gadolinium-Doped Ceria (Ni/GDC) Anode....................24

2.5.2 The Fluorite-Structured GDCAnode .........................................................25

2.5.3 Other Non-Nickel Based Compositions..............................25

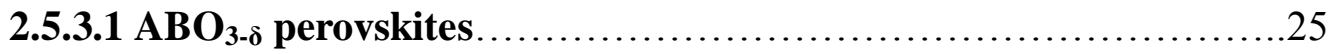

2.5.3.2 The Double Perovskite Anode.................................2 27

2.6 Basic Cell Architectures and Processing .....................................2

2.6.1 The Electrolyte Supported Cell Architecture ...........................28

2.6.1.1 Electrolyte Processing .......................................28

2.6.1.2 Barrier-Layer/Electrode Application (Screen-printing)............32

2.6.2 Anode-supported Cell Architecture and Processing Issues.................32

Chapter 3- Nickel Based Anode Impurity Evaluations.........................34

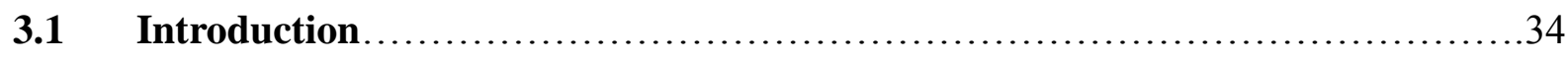

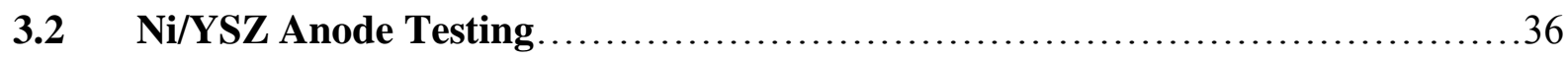

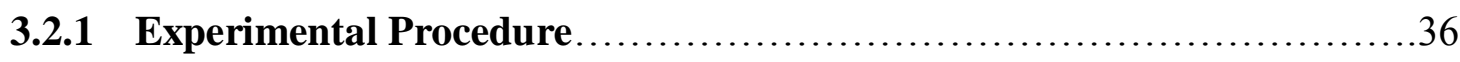

3.2.1.1 Cell Fabrication......................................................

3.2.2.2 Cell Testing Setup ............................................. 38

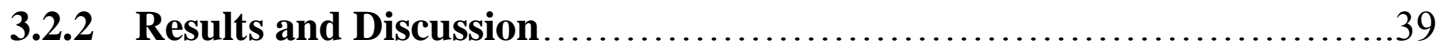

3.2.2.1 Baseline Testing for the Ni/YSZ Anode.......................39 
3.2.3 Conclusions................................................... 45

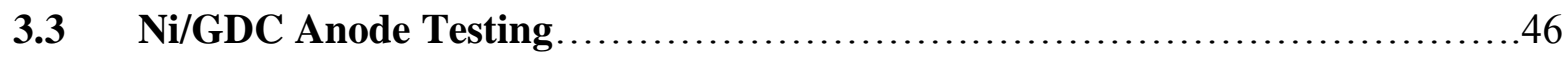

3.3.1 Experimental Procedure.......................................46

3.3.1.1 Cell Fabrication........................................46

3.3.1.2 Cell Test Setup........................................46

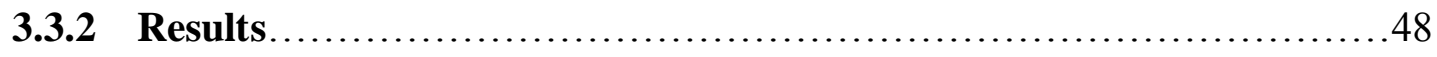

3.3.2.1 Ni-GDC-10 anode with/without a GDC barrier layer............48

3.3.2.2 Ni-GDC-20 anode with a GDC barrier layer......................52

3.3.2.3 Reference Electrode and Cell Impedance.........................55

3.3.2.4 Morphology, Structural and Chemical Analysis...............61

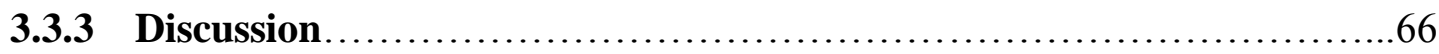

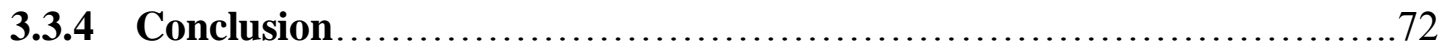

Chapter 4: Phosphine Impurity Evaluations of Alternative Composite SOFC

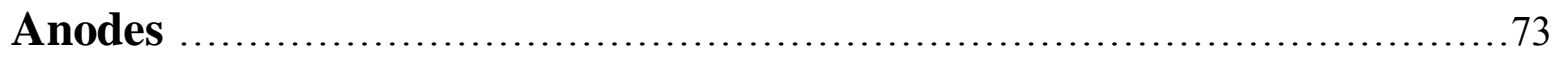

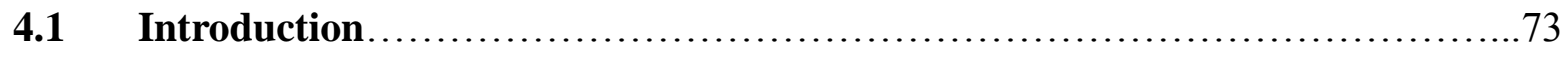

4.2 $\mathrm{PH}_{3}$ Impurity Tolerance of $\mathrm{Sr}_{2} \mathrm{MgMoO}_{6-\delta} / \mathrm{GDC}$ Composite Anodes ............76

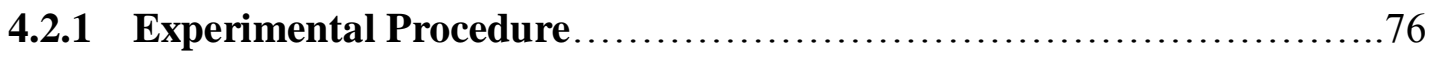

4.2.1.1 $\mathrm{Sr}_{2} \mathrm{MgMoO}_{6-\delta}$ Powder Preparation........................76

4.2.1.2 Electrolyte/GDC Preparation and Processing ..................... 77

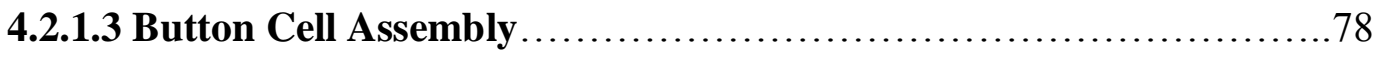

4.2.1.4 Fuel Cell Testing ........................................... 78 


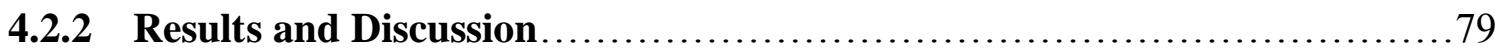

4.2.2.1 Initial performance of the SMM anode in clean $\mathbf{H}_{2}$ fuel.............79

4.2.2.2 Performance of SMM/GDC anode in clean $\mathrm{H}_{2}$ fuel and clean coal

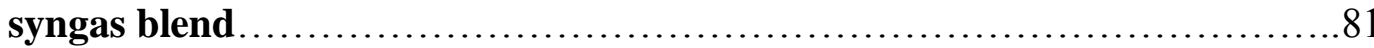

4.2.2.3 Performance of $\mathrm{SMM} / \mathrm{GDC}$ anode in $\mathrm{H}_{2}$ with $10 \mathrm{ppm} \mathrm{PH}_{3} \ldots \ldots \ldots . . .83$

4.2.2.4 XPS/EDS analysis........................................... 90

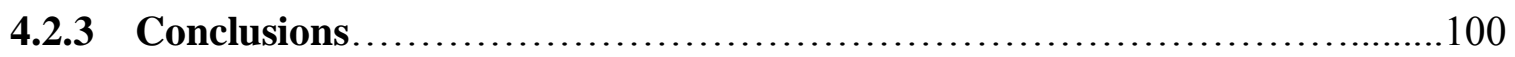

4.3 In Situ Formation of a Solid Oxide Fuel Cell (SOFC) Cermet Anode by $\mathrm{NiWO}_{4}$

Reduction............................................................... 101

4.3.1 Experimental Procedure ................................................. 103

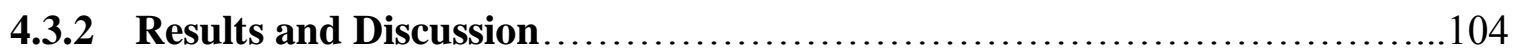

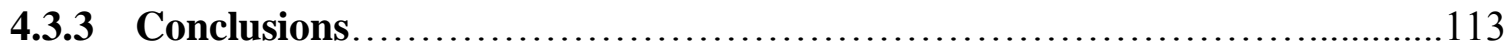

Chapter 5- $\mathrm{A} \mathrm{Sr} \mathrm{Sr}_{2} \mathrm{MgOO}_{6-\delta} / \mathrm{Gd}_{0.1} \mathrm{Ce}_{0.9} \mathrm{O}_{2}$ Anode Supported SOFC ...........115

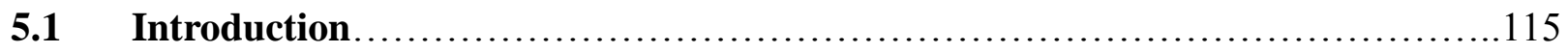

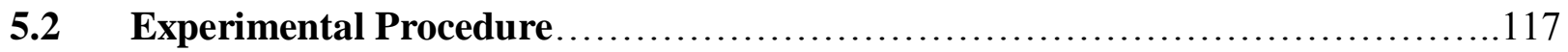

5.2.1 Anode Support Fabrication ………………….......................................117

5.2.1.1 Tape Casting and Hot Pressing ..................................117

5.2.1.2 Sample Bisquing ............................................... 117

5.2.3 Electrolyte/Cathode Application ...................................... 118

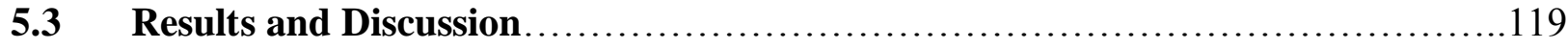

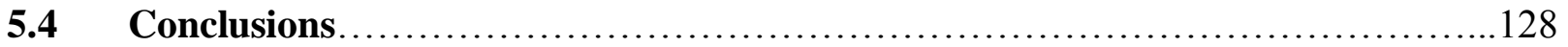


Chapter 6-Thesis Conclusions and Future Work.................................129

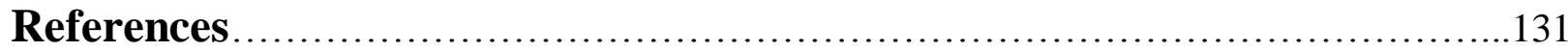




\section{List of Tables}

Table 1: CTE's for SOFC Components from Room Temp to $1000^{\circ} \mathrm{C}[29] \ldots \ldots \ldots \ldots . . . . . . .11$

Table 2: Performance for various in house Ni/YSZ anodes...........................39

Table 3: Summary of the impedance spectra for cell-4 in $\mathrm{H}_{2}$ and clean syngas [112].......57

Table 4: Max power densities for both SMM and GDC anode........................79

Table 5: Final burnout temperature profile for the SMM/GDC anode support...............122

Table 6: Molybdenum weight loss percentages for various firing temperatures.............123 


\section{List of Figures}

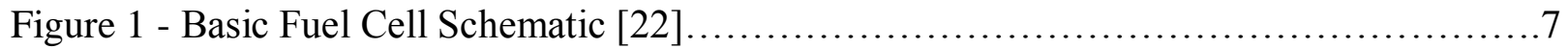

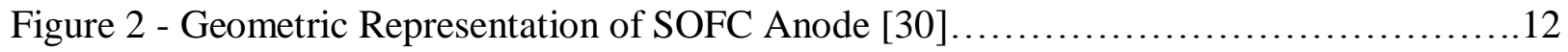

Figure 3 - Characteristic SOFC I-V curve............................................ 14

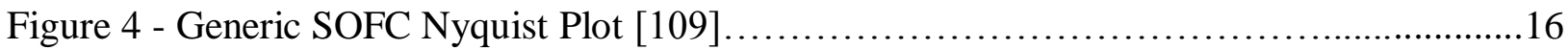

Figure 5 - Voltage vs time plot for sulfur adsorption to Ni-surface..........................20

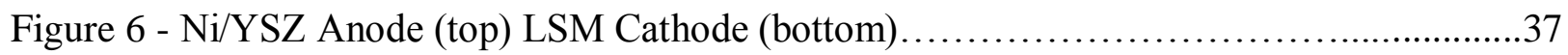

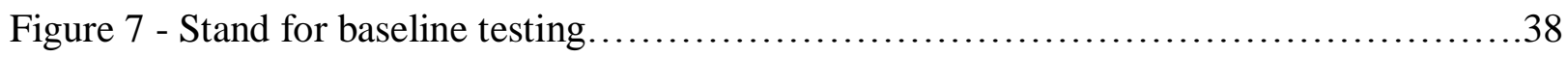

Figure 8 - Comparison of ionic conductivities between YSZ and GDC $\ldots \ldots \ldots \ldots \ldots \ldots \ldots . \ldots 40$

Figure 9 - Power density for the Ni/YSZ anode in clean syngas $\ldots \ldots \ldots \ldots \ldots \ldots \ldots \ldots \ldots \ldots . \ldots . \ldots \ldots$

Figure $10-\mathrm{Ni} / \mathrm{YSZ}$ anode response to syngas $+20 \mathrm{ppm} \mathrm{H}_{2} \mathrm{~S} \ldots \ldots \ldots \ldots \ldots \ldots \ldots \ldots \ldots \ldots . \ldots . \ldots \ldots$

Figure $11-$ EIS plot for the Ni/YSZ anode in syngas $+20 \mathrm{ppm}_{2} \mathrm{~S} \ldots \ldots \ldots \ldots \ldots \ldots \ldots \ldots \ldots . \ldots \ldots$

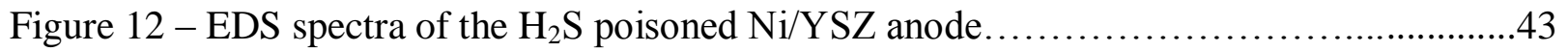

Figure 13 - SEM images of Ni/YSZ anode in a) clean syngas and b) syngas +20

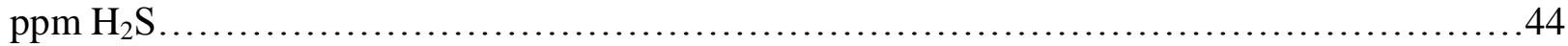

Figure $14-\mathrm{Ni} / \mathrm{YSZ}$ anode in response to $10{\mathrm{ppm} \mathrm{PH}_{3} \ldots \ldots \ldots \ldots \ldots \ldots \ldots \ldots \ldots \ldots \ldots \ldots \ldots \ldots \ldots \ldots \ldots \ldots \ldots}$

Figure 15 - (a) The cell contact configuration and (b) the cell testing setup

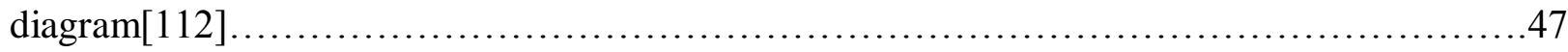

Figure 16 - Performance of cell-1 and its area specific resistances (ASR) in clean syngas and syngas with $100 \mathrm{ppm} \mathrm{H}_{2} \mathrm{~S}$.

Figure 17 - Performance of cell-2 and its area specific resistances (ASR) in clean syngas and

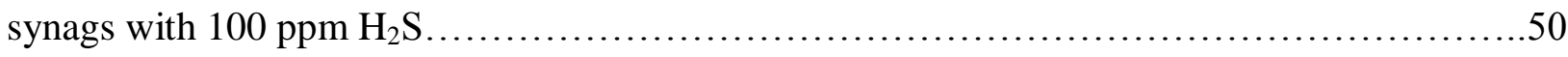


Figure 18 - Performance of cell-3 and its ASR in clean syngas and syngas with 100 ppm $\mathrm{H}_{2} \mathrm{~S}$.

Figure 19 - Performance of cell-4 in (a) wet $\mathrm{H}_{2}$, (b) wet $\mathrm{H}_{2}+100 \mathrm{ppm}_{2} \mathrm{~S}$, and (c) syngas with/without $100 \mathrm{ppm}_{2} \mathrm{~S}$ during the first $100 \mathrm{~h}$, then the cell was recovered in $\mathrm{H}_{2}$, and (d) $\mathrm{H}_{2}+\mathrm{N}_{2}, \mathrm{H}_{2}+200$ ppm $\mathrm{H}_{2} \mathrm{~S}$, (e) $\mathrm{H}_{2}+500$ ppm $\mathrm{H}_{2}$ and (f) $\mathrm{H}_{2}+1000 \mathrm{ppm} \mathrm{H}_{2} \mathrm{~S}$ testing. 52

Figure 20 - The voltage and ASR of cell-5 versus testing time. .53

Figure 21 - The cell voltage and ASR versus testing time of cell-6

(with the Ni-GDC-20 barrier layer in the anode).

Figure 22 - The impedance spectra of cell-4 under $200 \mathrm{~mA} \mathrm{~cm}{ }^{-2}$ current

bias in wet $\mathrm{H}_{2}$.

Figure 23: The impedance spectra of cell-4 under $200 \mathrm{~mA} \mathrm{~cm}{ }^{-2}$ current bias in wet $\mathrm{H}_{2}$ with 100 ppm $\mathrm{H}_{2} \mathrm{~S}$. .56

Figure 24: The impedance spectra of cell-4 under $200 \mathrm{~mA} \mathrm{~cm}{ }^{-2}$ current bias in clean syngas.

Figure 25: The impedance spectra of cell-4 under $200 \mathrm{~mA} \mathrm{~cm}{ }^{-2}$ current bias in syngas with 100

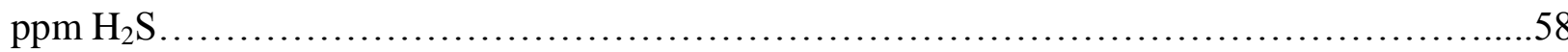

Figure 26: The impedance spectra of cell-4 under $200 \mathrm{~mA} \mathrm{~cm}^{-2}$ current bias in $\mathrm{H}_{2}$ with 0,100 ppm, 200 ppm, 500 ppm and 1000 ppm $\mathrm{H}_{2} \mathrm{~S}$ impurity.

Figure 27: The impedance spectra of cell-4 under $200 \mathrm{~mA} \mathrm{~cm}{ }^{-2}$ current bias in $\mathrm{H}_{2}$ with $0,16 \%$, $25 \%, 50 \%, 75 \%$ and $84 \% \mathrm{~N}_{2}$.

Figure 28: The total polarization resistance $\mathrm{R}_{\mathrm{t} \rho}$ of the cell-4 versus $\mathrm{H}_{2} \mathrm{~S}$ concentration (ppm) and $\mathrm{N}_{2}(\mathrm{~mol} \%)$ concentration in $\mathrm{H}_{2}$ fuel. .61 
Figure 29: SEM images for cell-6 of (a) the poisoned Ni-GDC in the anode interface, (b) the clean reduced $\mathrm{Ni}-\mathrm{GDC}$ in the anode interface.

Figure 30: SEM images for cell-6 of the Ni particles in the contact paste on the top surface of the anode: (a) at $1 \mathrm{k}$ magnification and (b) at $20 \mathrm{k}$ magnification.

Figure 31: EDS spectra of (a) the Ni paste, (b) Ni particles in the anode interface, (c) Ni-GDC anode interface and (d) GDC particles in the anode interface.

Figure 32: The depth profile of XPS spectra on the Ni surface of the $\mathrm{H}_{2} \mathrm{~S}$ poisoned cell. The oxidized S peak at $169-170 \mathrm{eV}$ is only significant on the top Ni surface. The un-oxidized S peak is detectable at $8 \mathrm{~nm}$ depth from the Ni surface. .64

Figure 33: The depth profile of XPS spectra of the $\mathrm{H}_{2} \mathrm{~S}$ poisoned cell Ni surface.

Figure 34: XPS spectra of the $\mathrm{H}_{2} \mathrm{~S}$ poisoned top surface of the Ni paste and (b) GDC-20 barrier layer on the cell. The oxidized S peak at $169.85 \mathrm{eV}$ is only significant on the GDC-20 barrier layer.

Figure 35: A conceptualization of the cell anode and electrolyte active interface showing that (a) the $\mathrm{Ni}$ is slowly oxidized by $\mathrm{O}^{2-}$ at the active interface and (b) the GDC layer is suppressing the $\mathrm{NiO}$ formation at the active interface [112].... .68

Figure 36: XRD spectra for the $\mathrm{Sr}_{2} \mathrm{MgMoO}_{6-\delta}$ anode calcined at different temperatures in a 5\% $\mathrm{H}_{2} / \mathrm{N}_{2}$ atmosphere. (*) denotes the secondary $\mathrm{SrMoO}_{4}$ phase. .76

Figure 37: Fuel cell fixture schematic used in current-voltage-power (J-V-P) testing in this work [113] .78

Figure 38: Performance of the pure GDC anode in $3 \%$ wet $\mathrm{H}_{2}$. .80 Figure 39: (J-V-P) performance for SMM/GDC composite anode in wet $\mathrm{H}_{2}\left(3 \% \mathrm{H}_{2} \mathrm{O}\right)$.... .81

Figure 40: Voltage vs. time for the electrolyte-supported SOFC with a SMM/GDC anode tested at constant current density $\left(0.25 \mathrm{~A} \mathrm{~cm}^{-2}\right)$ in a) $\mathrm{H}_{2}+3 \% \mathrm{H}_{2} \mathrm{O}$ and b) clean syngas at $800^{\circ} \mathrm{C} \ldots . .82$ 
Figure 41: Cell voltage and resistance vs. time for the electrolyte-supported SOFC with a SMM/GDC anode tested at $800^{\circ} \mathrm{C}$ and at constant current density $\left(0.25 \mathrm{~A} \mathrm{~cm}^{-2}\right)$ in a) $\mathrm{H}_{2}+3 \%$

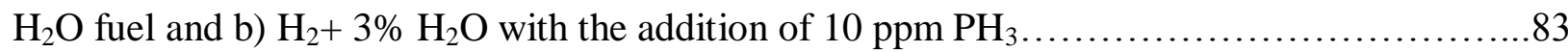

Figure 42: Voltage vs. Time plot for the SMM/GDC composite anode in wet $\mathrm{H}_{2}$ for $160 \mathrm{~h} \ldots \ldots .84$

Figure 43: J-V-P performance of SOFC with SMM/GDC anode in wet $\mathrm{H}_{2}$ before $\mathrm{PH}_{3}$

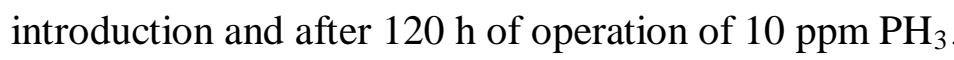

Figure 44: Comparison of the performance at constant current density $\left(0.25 \mathrm{~A}-\mathrm{cm}^{-2}\right)$ in wet $\mathrm{H}_{2}$ and with addition of 10 ppm $\mathrm{PH}_{3}$ between Ni-YSZ anode cell and SMM/GDC anode cell......86

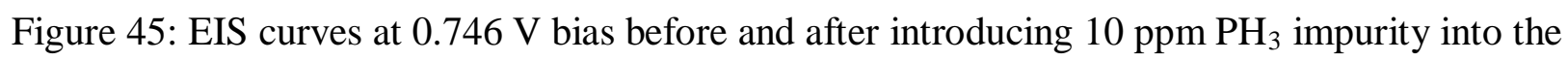

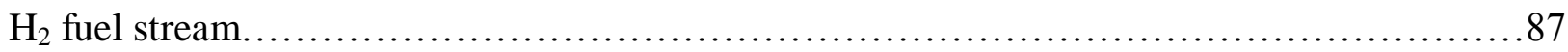

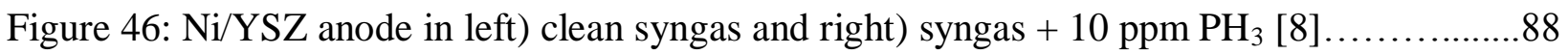

Figure 47: SEM micrographs of the SMM/GDC anode after testing in A) wet $\mathrm{H}_{2}$ and B) wet $\mathrm{H}_{2}$

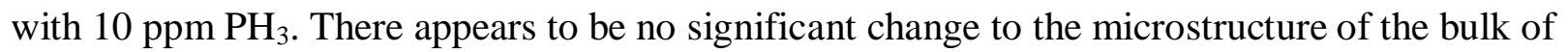
the anode.

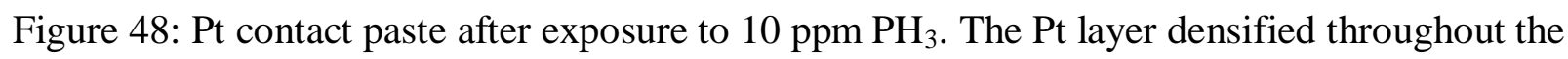
course of this test....

Figure 49: SEM micrograph of the active anode/electrolyte interface after $\mathrm{PH}_{3}$ poisoning test for the SMM/GDC composite anode. .90

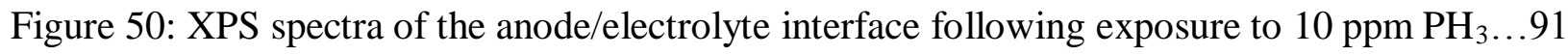

Figure 51: An enhanced view of the XPS spectra with no change in signal at $192 \mathrm{eV}$ where the P 2s peak would be expected .92

Figure 52: An enhanced view of the XPS signal in the $134 \mathrm{eV}$ range corresponding to the $\mathrm{Sr} 3 \mathrm{~d}$ signal. This signal also corresponds to the $\mathrm{P} 2 \mathrm{p}$ peak and thus is not adequate for elemental qualification 
Figure 53: EDS scan of the anode/electrolyte interface. The scan has a well defined Sr peak and a very weak signal for $\mathrm{P}$. 93

Figure 54: XPS peaks of the clean reduced raw Sr powder...........................94

Figure 55: XPS peaks of the clean reduced raw Mg powder...........................95

Figure 56: XPS peaks of the clean reduced raw Mo powder............................ 96

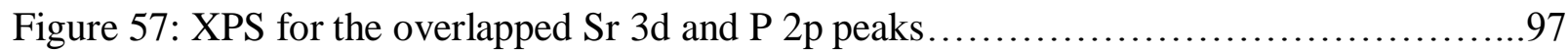

Figure 58: XPS for the Sr 3p spectra for the poisoned sample........................ 97

Figure 59: $\mathrm{Mg} 2 \mathrm{p}$ peak for the poisoned $\mathrm{MgO}$ sample $\ldots \ldots \ldots \ldots \ldots \ldots \ldots \ldots \ldots \ldots \ldots \ldots \ldots . \ldots \ldots$

Figure 60: P 2p peak for the poisoned $\mathrm{MgO}$ sample..................................98

Figure 61: Mo 3d spectra for the poisoned $\mathrm{PH}_{3}$ samples................................99

Figure 62: XPS spectra for the Mo 3d and P 2p regions for a solid MoP hydro-desulfurizaiton

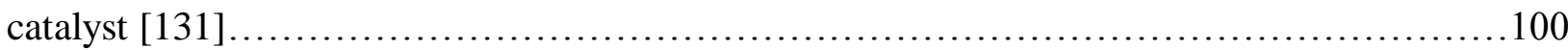

Figure 63: $\mathrm{XRD}$ of the $\mathrm{NiWO}_{4}$ anode before reduction............................... 105

Figure 64: XRD of the reduce anode after $48 \mathrm{~h}$ in $3 \%$ wet $\mathrm{H}_{2}$. (x) corresponds to $\alpha-\mathrm{W}$ and (*) to

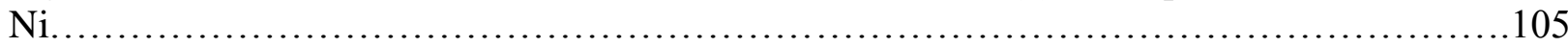

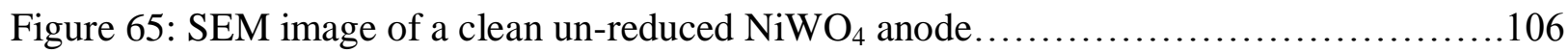

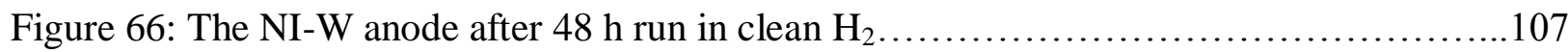

Figure 67: Cell potential -power density-current density performance for an electrolyte-supported $\mathrm{SOFC}$ button cell at $800^{\circ} \mathrm{C}$ for the following defined compositions....................... 108

Figure 68: Cell voltage as function of time for an electrolyte-supported SOFC button cell with a $\mathrm{NiWO}_{4} / \mathrm{GDC}$ anode tested at a current density of $0.15 \mathrm{~A}-\mathrm{cm}^{-2}$ at $800^{\circ} \mathrm{C} \ldots \ldots \ldots \ldots \ldots \ldots \ldots \ldots \ldots \ldots . .110$

Figure 69: EIS data for the $\mathrm{NiWO}_{4} / \mathrm{GDC}$ anode before and after impurity addition...........111

Figure 70: XPS survey scan for the $\mathrm{NiWO}_{4}$ poisoned sample $\ldots \ldots \ldots \ldots \ldots \ldots \ldots \ldots \ldots \ldots \ldots 112$

Figure 71: XPS scan for the P 2p peak............................................... 112

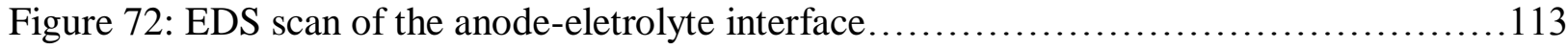

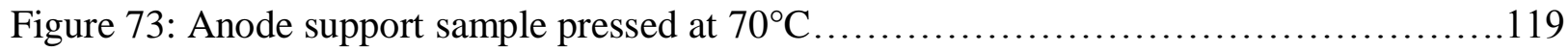

Figure 74: Anode support sample heated at excessive rate resulting in 'pillowing'............120 
Figure 75: Macroscopic cross-section of the anode support showing good lamination of pressed

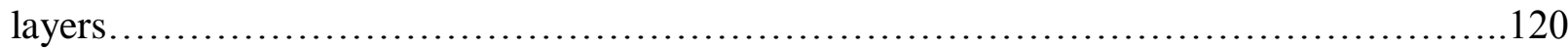

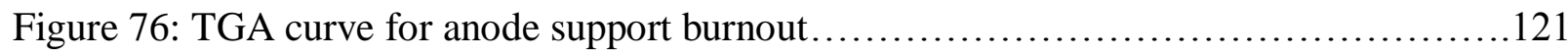

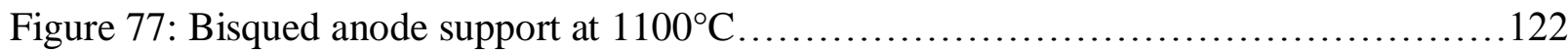

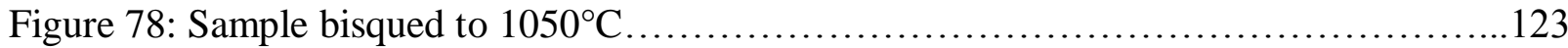

Figure 79: The handprinted GDC electrolyte layer after firing to $1250 \mathrm{C}$ for $2 \mathrm{~h} \ldots \ldots \ldots \ldots 125$

Figure 80: The SEM images showing density of the anode support at a) the interface (left) and b)

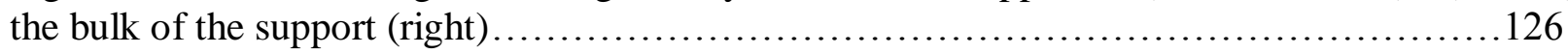

Figure 81: SEM image of the GDC electrolyte after 5 sol-gel coatings and firing to 800C....127

Figure 82: Electroyte after 15 coatings and 2 sintering runs to $800^{\circ} \mathrm{C} \ldots \ldots \ldots \ldots \ldots \ldots \ldots \ldots$ 


\section{Chapter 1- Introduction}

\subsection{Background}

With an ever increasing need for cheap, eco-friendly energy sources, fossil fuels have garnered a lot of attention over the past several decades. Several billion government dollars have been allocated for clean coal research over the past ten years [1]. Most recently in August 2010, the US Department of Energy made public a new initiative known as the US-China Clean Advanced Coal Technology Consortium, where the primary emphasis will be on clean burning methods and clean coal technology [2]. A device that is capable of utilizing this clean coal and converting its energy from chemical to useable electrical energy is the Solid Oxide Fuel Cell (SOFC) [3].

The SOFC has several advantages over other energy systems. For one, they convert the energy from fuel to electricity at high efficiencies [4]. Another positive is that the fuel cell does not require a combustion process which is good from both an emissions and safety standpoint. And arguably the biggest advantage is that they are capable of operating on several different types of fuel, including hydrogen, methane, natural gas, and perhaps most importantly from a geographic perspective, coal derived synthesized gas (syngas) [5]. The syngas is developed through a gasification process that takes the raw coal and converts it into an applicable gaseous form. Syngas varies in composition, but generally consists of $\mathrm{H}_{2}, \mathrm{CO}, \mathrm{CO}_{2}, \mathrm{H}_{2} \mathrm{O}$, and trace amounts of $\mathrm{N}_{2}$. In general, the respective ranges are 15-65\% for $\mathrm{H}_{2}, 20-50 \%$ for $\mathrm{CO}, 5-30 \%$ for $\mathrm{CO}_{2}$, and $0-40 \% \mathrm{H}_{2} \mathrm{O}$ [46]. This particular fuel, though promising, presents issues that prevent the fuel cell from becoming a more widely accepted source of electrical generation.

One of these issues that will be a main area of focus of this research is the degradation of the SOFC anode upon exposure to the trace elemental impurities within syngas. Some of the major harmful elements that syngas contains are arsenic (As), chlorine $(\mathrm{Cl})$, mercury $(\mathrm{Hg})$, phosphorus (P), and sulfur (S). These are elements that are incapable of being completely removed via gas cleanup [6]. While gas cleanup technologies are advancing, research has been conducted to show that as little as parts per billion ( $\mathrm{ppb}$ ) levels of phosphine $\left(\mathrm{PH}_{3}\right)$ within the gas 
stream are capable of degrading the typical Nickel-Yttrium Stabilized Zirconia (Ni/YSZ) anode within a matter of hours [7]. Prior research has shown that there are multiple modes of anode degradation for phosphorus. For one, the phosphorus can form secondary, non-conductive phases with nickel. Another reported mode of degradation for the Ni/YSZ anode is the migration of Ni to the anode surface thus limiting both gas diffusion and sites for electrochemical oxidation of the fuel. Overall, the Ni/YSZ cell has shown no ability to resist cell degradation and depending on the type of cell support architecture (electrolyte vs. anode) or fuel $\left(\mathrm{H}_{2}\right.$ vs coal syngas), total cell failure takes place in anywhere from 30 hours to 400 hours [8].

In the case of another more abundant contaminant in gasified coal, hydrogen sulfide $\left(\mathrm{H}_{2} \mathrm{~S}\right)$, both reversible and un-reversible damage has been observed through previous works [912]. Sulfur surface adsorption has been shown to be reversible when cycling sulfur in and out of the fuel stream; whereas, irreversible changes have been seen primarily due to a loss of the percolation of the Ni particles nearest the anode/electrolyte interface at higher concentrations of $\mathrm{H}_{2} \mathrm{~S}$ [13]. Unlike phosphorus, some tolerance to sulfur poisoning in the short term has been achieved with different catalysts, most notably doped cerias [14-16]. However, no such work has been done to suggest that a nickel-ceria anode can operate for several hundred hours in sulfur containing fuels without loss in performance. 


\subsection{Objectives}

The primary emphasis of this research will be to investigate various anode materials that are potentially tolerant to ppm levels of and hydrogen sulfide and phosphine. Fabrication and processing of these materials will all be done in-house and testing will be conducted on YSZ electrolyte supported cells. The long range goal of these efforts will be to identify anode composition(s) that do not lose electrical power capacity for over 10,000 hours while running with these impurities. Both nickel-based and non-nickel-based anodes will be evaluated in both hydrogen and syngas containing fuels with impurities to establish potential tolerance and/or tolerance levels. A novel anode-supported cell will also be processed for the non-nickel based composition to demonstrate the potential of running the cell in a fuel stream that contains both contaminates which has not been shown previously. In reality, an anode should be co-tolerant which is what would be required for commercial application of fuel cells running on coal. In-situ characterizations for all fuel cells will be made by monitoring the electrochemical impedance spectrum of the full cell and ex-situ characterizations will be made using scanning electron microscope (SEM), Energy Dispersive X-Ray (EDX), X-Ray Diffraction (XRD), and X-Ray Photoelectron Spectroscopy (XPS) techniques. 


\subsection{Technical Approach}

This project will first attempt to identify anode architectures that feature $\mathrm{Ni}$ as the primary metal catalyst. Several works in recent years have suggested that the substitution of the standard YSZ ion conductor in the anode cermet with gadolinium-doped ceria (GDC) may be a better option for cells operating on fuels other than pure $\mathrm{H}_{2}$, as it suppresses carbon coking [17] and offers better tolerance to $\mathrm{H}_{2} \mathrm{~S}$. This material exhibits much higher ionic conductivity than YSZ at our standard SOFC operating temperature $\left(800^{\circ} \mathrm{C}\right)$ which increases cell performance. Additionally, the GDC has been suggested to catalyze the oxidation of sulfur, a process like $\mathrm{H}_{2}$ oxidation that generates electrons. However, this material has shown to react with the adsorbed S species on the anode particles to form ceria oxy-sulfides which can cause degradation to the cell at high $\mathrm{H}_{2} \mathrm{~S}$ concentrations [17].

With this insight, the goal will be to develop a Ni/GDC anode on a YSZ electrolytesupported substrate. Also, knowing that irreversible degradation to the cell in sulfur-containing fuels occurs primarily at the anode/electrolyte interface, incorporation of a dense GDC barrier layer between the electrodes and the electrolyte is believed to improve overall tolerance. Parametric studies on the effect of this barrier layer, the fuel composition, the level of Gddoping, and sulfur concentration will be carried out in a systematic fashion to assess the viability of this anode composition for fuels containing sulfur. Comparative work with the Ni/YSZ cell in this environment will help to demonstrate the improved performance of the Ni/GDC anode.

Another composition evaluated for potential use as an SOFC anode that has never been reported on before is $\mathrm{NiWO}_{4}$. The advantage of this composition is that is has the potential to insitu form a homogeneous matrix of $\mathrm{Ni}+\mathrm{WO}_{\mathrm{x}}$ as reduction from the wolframite structure occurs readily [18]. This homogeneous mix of ionic and electronically conductive particles could optimize triple phase boundary sites and thus maximize performance. An additional benefit for evaluating this material is that it has demonstrated ability to sense $\mathrm{H}_{2} \mathrm{~S}$ and also de-sulfurize hydrocarbon fuels [19]. Polarization curves and post-test analysis will be used to determine what happens to the composition at SOFC operating temperature in reducing atmospheres as well as its functionality as an anode. Anode compositions incorporating YSZ and GDC will help to improve overall cell performance in a wet $\mathrm{H}_{2}$ atmosphere. Finally, this novel anode is tested in

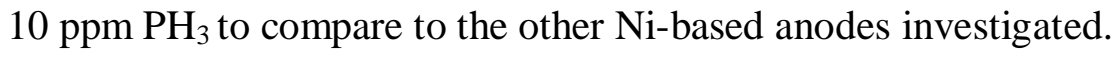


The next phase of the project will be to determine how the SOFC operates in fuels with $\mathrm{PH}_{3}$ contaminant for a relatively new anode material that does not utilize nickel. The $\mathrm{Sr}_{2} \mathrm{MgMoO}_{6-\delta}(\mathrm{SMM})$ anode is a double-perovskite that has achieved relatively high power densities with low degradation $(<12 \%)$ in the presence of sulfur over a $200 \mathrm{~h}$ testing interval [20]. With this exists the possibility of an anode that can tolerate realistic levels of $\mathrm{PH}_{3}$ and $\mathrm{H}_{2} \mathrm{~S}$ simultaneously without harming the microstructure and performance of the cell. Without thermodynamic analysis available for the possible interactions between phosphorus and each of the anode constituents, an experimental approach will be taken to assess this composition. The first will be to synthesize the powder using a solid-state method. Next will be the incorporation of GDC into the anode matrix to increase the overall ionic conductivity. With this new SMM/GDC composite, fuel cell tests will be carried out in clean fuels to demonstrate stability

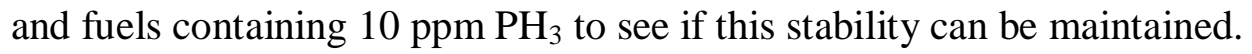

The final phase of this project will be to develop an anode-supported cell for this SMM/GDC composite and conduct similar testing. The motivation for this is primarily for performance purposes as this will make it possible to significantly reduce the thickness of the electrolyte which is responsible for most of the ohmic resistance of the cell. The difference between the electrolyte-supported cell and the novel anode support will be the electrolyte used. A GDC electrolyte will be used via a (screen-printing or spin-coating) method as to avoid possible reactions between the $\mathrm{Sr}$ and $\mathrm{Zr}$ that are likely at the $800^{\circ} \mathrm{C}$ operating temperature [21]. 


\section{Chapter 2- Literature Review}

This chapter summarizes recent work that has been published in this particular area of SOFC research. The first section will provide an overview of the basic operation of the SOFC, important characteristics of an SOFC anode, and methods of cell evaluation. The next section will discuss previous impurities work that has been conducted on the standard Ni/YSZ anode for some of the key contaminants within coal syngas. Subsequent sections will overview alternative cermet anodes as well as mixed ion-electron conductors that have been developed to help mitigate the poisoning effects. Finally, the two different cell architectures explored in this work will be reviewed.

\subsection{Basic SOFC Operation}

The SOFC operates by supplying a given fuel to the anode and air to the cathode and separating the two electrodes by a dense ion-conducting electrolyte. At SOFC operating temperatures, the electrolyte is capable of efficiently supplying oxygen ions to the anode where it can react with the fuel and produce water and free electrons. The overall reaction of the fuel cell operating with pure hydrogen as the fuel can be seen in equation 1 :

$$
\mathrm{H}_{2}+1 / 2 \mathrm{O}_{2} \rightarrow \mathrm{H}_{2} \mathrm{O}
$$

More telling however are the two half reactions that govern SOFC operation along with the associated enthalpy of formation, $\Delta \mathrm{H}(\mathrm{T})$, at $800^{\circ} \mathrm{C}$.

$$
\begin{array}{lll}
\text { Anode } & \mathrm{H}_{2}+\mathrm{O}^{2-} \rightarrow \mathrm{H}_{2} \mathrm{O}+2 \mathrm{e}^{-} & \Delta \mathrm{H}\left(800^{\circ} \mathrm{C}\right)=-242 \mathrm{~kJ} / \mathrm{mol} \\
\text { Cathode } & 1 / 2 \mathrm{O}_{2}+2 \mathrm{e}^{-} \rightarrow \mathrm{O}^{2-} & \Delta \mathrm{H}\left(800^{\circ} \mathrm{C}\right)=0 \mathrm{~kJ} / \mathrm{mol}
\end{array}
$$

The cathode reaction represents the reduction of oxygen and consumption of electrons to form oxygen ions which migrate through the electrolyte. The anode half-reaction represents the 
oxidation of hydrogen to produce both water and two electrons [22]. This is often referred to as a Membrane Electrode Assembly (MEA) and when connected to an external load, the electron flow from these half-reactions can be captured to generate useable energy as seen in the diagram below.

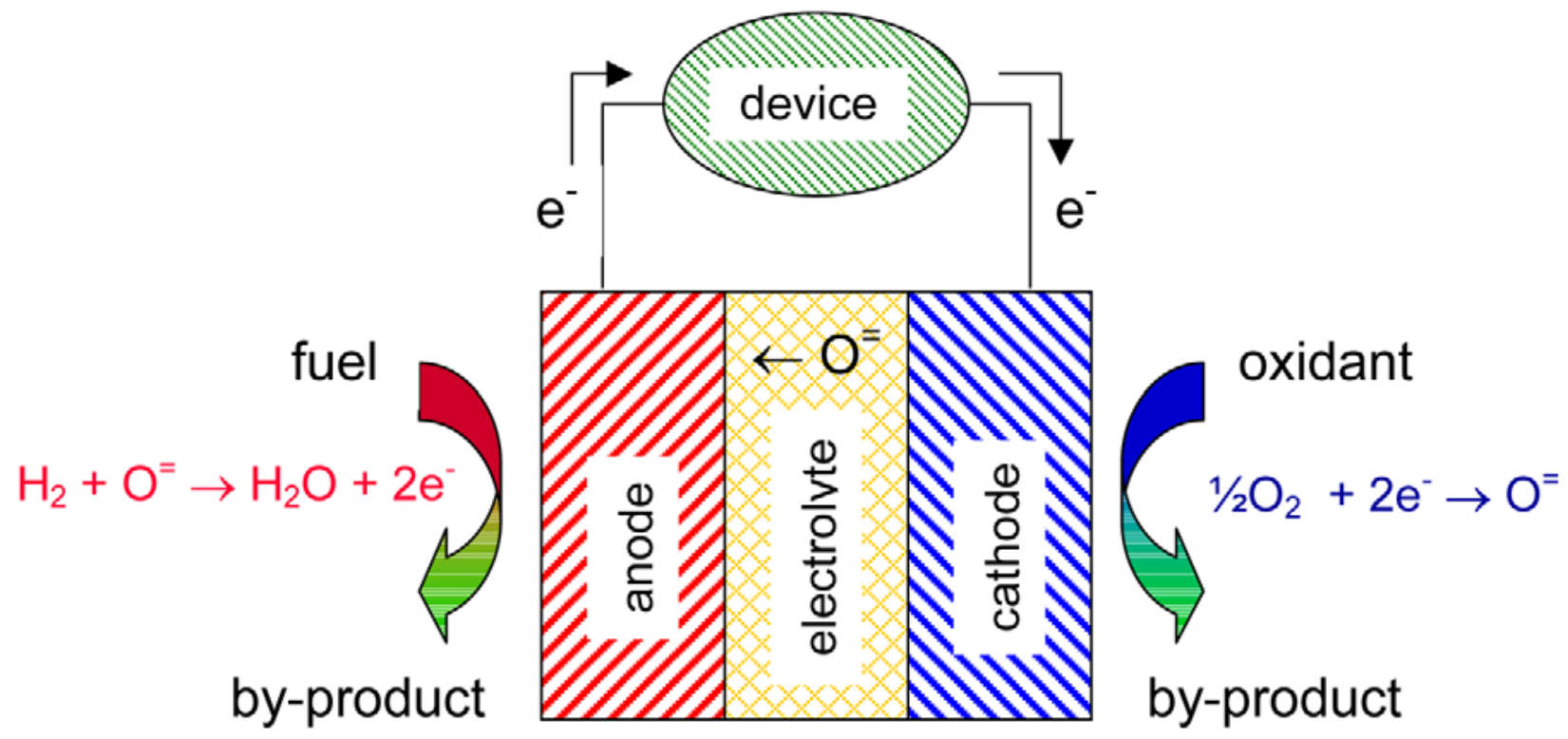

Figure 1: Basic Fuel Cell Schematic [22].

The electrochemical oxidation of the fuel takes place in areas within the anode known as the triple phase boundaries (TPB). The TPB region represents the confluence of the three different species required to produce the electrons. These are the metal phase, the ion phase, and the gaseous phase. The metal phase serves two purposes. The first is to catalyze the reaction between the fuel and oxygen ions. This is where Ni metal is a great candidate due to its high catalytic potential and its relative affordability in comparison to other metals such as Pt or Au. It is important however that the Ni particles be fully reduced at the triple phase boundary locations as $\mathrm{NiO}$ is not nearly as catalytically active [23]. The second purpose is for electron transport out of the anode to the external source. Ni has an electronic conductivity upwards of $10^{3} \mathrm{~S} \mathrm{~cm}^{-1}$ at $800^{\circ} \mathrm{C}$ in an oxygen depleted environment which allows for efficient export of electrons [24]. The ion phase present at the TPB is the YSZ for the traditional anode. It supplies the oxygen ions to the site and also helps to prevent $\mathrm{Ni}$ agglomeration over time at SOFC operating temperatures. 
YSZ is a good ionic conductor and is also stable in different environments. The final phase is the fuel gas phase, which consists of fuel and reaction products. The best fuel cell anode will be the one that allows for the most places for these three to unite. A homogeneous mix of Ni and YSZ will result in the most available surface area in the matrix to carry out the reaction.

Several previous research projects have been conducted on SOFC's running on pure hydrogen, demonstrating very high power densities and long term stability. Power densities in excess of $1 \mathrm{~W}-\mathrm{cm}^{-2}$ have been achieved by using a conventional Ni/YSZ anode, a YSZ electrolyte, and a LSM/YSZ cathode [25]. Long term stability has also demonstrated long term stability in humidified $\mathrm{H}_{2}$ for several hundred hours using galvanostatic measurement techniques for the same composition [26]. While these results are promising for the SOFC, the requisite of pure hydrogen leaves much to be desired. In order to make the SOFC a viable source of largescale power generation, those types of cell specifications will need to be achieved using cheaper and more readily available fuels. Sources such as natural gas, bio-mass, and gasified coal are of great abundance in the United States which makes it possible to have a cheap, endless supply of fuel.

The primary difference in operating the SOFC with alternative fuels is the presence of carbonic species. In the case of hydrocarbons, fuel is reformed catalytically to form carbon monoxide and hydrogen (syngas). The carbon monoxide acts as a fuel much like hydrogen to form $\mathrm{CO}_{2}$ via electrochemical oxidation and subsequently generate electrons. The $\mathrm{CO}$ oxidation equation and overall anodic reaction for a typical syngas composition is:

$\begin{array}{lll}\text { CO Oxidation } & \mathrm{CO}+1 / 2 \mathrm{O}_{2} \rightarrow \mathrm{CO}_{2} & \Delta \mathrm{H}\left(800^{\circ} \mathrm{C}\right)=-189 \mathrm{~kJ} / \mathrm{mol} \\ \text { Net Fuel Cell Reaction } & \mathrm{O}_{2}+\mathrm{CO}+\mathrm{H}_{2} \rightarrow \mathrm{CO}_{2}+\mathrm{H}_{2} \mathrm{O} & \Delta \mathrm{H}\left(800^{\circ} \mathrm{C}\right)=-431 \mathrm{~kJ} / \mathrm{mol}\end{array}$

One of the advantages of a high temperature SOFC is that there is no need for an expensive external reformer; rather, the fuel can be reformed inside the system which greatly increases overall efficiency. However, a major problem that exists with internal reforming is carbon deposition onto the anode surface from hydrocarbon pyrolysis. This is particularly devastating for the nickel-based anode. Carbon deposition has deleterious effects to the anode by 
covering the surface and limiting both gas diffusion and electro-catalysis as well as causing physical destruction to the microstructure. This effect can be combated by injection of steam into the system. Equation 5 shows the reaction that governs carbon formation and Equation 6 shows how this formation is inhibited by introduction of steam into the system. These reactions are applicable for any order hydrocarbon, where $\mathrm{n}$ is a positive integer.

Hydrocarbon Pyrolysis $\quad \mathrm{C}_{\mathrm{n}} \mathrm{H}_{2 \mathrm{n}+2} \rightarrow \mathrm{nC}+(\mathrm{n}+1) \mathrm{H}_{2}$

Steam Reformation

$$
\mathrm{C}_{\mathrm{n}} \mathrm{H}_{2 \mathrm{n}+2}+\mathrm{nH}_{2} \mathrm{O} \rightarrow \mathrm{nCO}+(2 \mathrm{n}+1) \mathrm{H}_{2}
$$

Favorability towards syngas formation results in increased likelihood of long term stability without solid carbonaceous buildup. The ratio of steam to carbon is very important in maximizing $\mathrm{H}_{2}$ production and minimizing hydrocarbon pyrolysis and the Boudouard equation.

Boudouard Reaction $\quad 2 \mathrm{CO} \rightarrow \mathrm{C}+\mathrm{CO}_{2} \quad \Delta \mathrm{H}\left(800^{\circ} \mathrm{C}\right)=-189 \mathrm{~kJ} / \mathrm{mol}$

$\mathrm{H}_{2}$ production is maximized by keeping the water-gas shift reaction to the right, which requires higher steam levels than stoichiometrically necessary.

Water-Gas Shift Reaction $\quad \mathrm{CO}+\mathrm{H}_{2} \mathrm{O} \rightarrow \mathrm{CO}_{2}+\mathrm{H}_{2} \quad \Delta \mathrm{H}\left(800^{\circ} \mathrm{C}\right)=-38.6 \mathrm{~kJ} / \mathrm{mol}$

Though not practical, it has been suggested that the optimal steam to carbon ratio is at least 2:1 for operation at temperatures in excess of $800^{\circ} \mathrm{C}$ [27].

The overall syngas composition is dependent on gasification methods and the source itself [28], but in literature they are generally reported in terms of the following content: $\mathrm{H}_{2}, \mathrm{CO}$, $\mathrm{CO}_{2}$, and $\mathrm{H}_{2} \mathrm{O}$. Seeing as the open circuit voltage (OCV) is dependent on the gradient of oxygen across the electrolyte, the lower $\mathrm{P}_{\mathrm{H} 2}$ present in the anode when running on syngas makes the OCV lower and ultimately the maximum performance lower. This makes optimization of the anode materials and microstructure even more of a necessity for these conditions. From a thermodynamic standpoint, the SOFC viewed in terms of the free enthalpy of reaction of the fuel with the oxidant, which is described in detail in a later section. Specifically at $800^{\circ} \mathrm{C}$, the 
theoretical OCV's for the humidified hydrogen oxidation reaction $\left(3 \% \mathrm{H}_{2} \mathrm{O}\right)$ and the syngas reactions are $1.10 \mathrm{~V}$ and $0.978 \mathrm{~V}$ respectively.

\subsection{Requirements of an SOFC Anode}

The SOFC anode's efficiency is dependent on several material and structural requirements. These include proper matching of coefficient of thermal expansions (CTE), porosity, electrical conductivity, catalytic activity, and chemical stability. Each of these play an integral role in optimizing the rates of reaction outlined above that generate electrical power. If any of these qualities are insufficient or become insufficient during operation, then the performance of the cell can become compromised. Unfortunately, in the case of SOFC operation with hydrocarbon fuel and impurities, these requirements are more difficult to sustain than operating with pure hydrogen fuel.

\subsubsection{Coefficient of Thermal Expansion (CTE)}

The first important quality of the SOFC anode is that the coefficient of thermal expansion (CTE) should be compatible for all components. This is because most SOFC applications have a need for cycling between ambient temperature and the operating temperature. A large mismatch between these coefficients can result in macroscopic damage to the cell either during fabrication or during operation. The CTE can be calculated using a dilatometer, which is a device that measures changes in volume of a material in response to a physical or chemical process. In this case that process is temperature variation. The coefficients should be compatible for not only the electrode and electrolyte, but also for the electrical contact, whether it be a metallic interconnect in the case of a stack or contact paste for a single cell test. A list of CTE's for the conventional SOFC with some of the traditional interconnect materials can be seen in Table 1 [29]. 
Table 1: CTE's for SOFC Components from Room Temp to $1000^{\circ} \mathrm{C}$ [29].

\begin{tabular}{lll}
\hline Component & Material & CTE $\left(10^{-6} \mathrm{~K}^{-1}\right)$ \\
\hline Cathode & $(\mathrm{La}, \mathrm{Sr}) \mathrm{MnO}_{3}$ & $11-14$ \\
Electrolyte & Yttria-stabilized $\mathrm{ZrO}_{2}$ (YSZ) & 10.5 \\
Anode & Ni-YSZ-Cermet & $11-12$ \\
Interconnection & $(\mathrm{La}, \mathrm{Sr}) \mathrm{CrO}_{3}$ & 11 \\
& Cr-based ODS alloy & $9-10$ \\
& Ferritic steel & $10-15$ \\
\hline
\end{tabular}

It can be seen that pretty good matches exist between each of these components for the standard SOFC. Nickel itself has a high CTE of $\alpha=13.3 \times 10^{-6} \mathrm{~K}^{-1}$, which is not a good match to the CTE of YSZ. The high CTE in comparison to YSZ is one of the many reasons for using a Ni-YSZ cermet anode. The mixture of the two provides a much more compatible CTE with the electrolyte which allows for much easier thermal processing. It is in the case of trying to incorporate more exotic electrode or electrolyte compositions where the CTE compatibility can become a significant problem. This is also a much larger problem in the case of fabricating an anode supported cell which involves the co-sintering of the anode and electrolyte. If the rate of volume shrinkage as a function of temperature for each component is not similar all the way up to the onset of sintering, then warping and cracking of the cells becomes inevitable.

\subsubsection{Porosity}

Another essential quality of the SOFC anode is that it be porous enough for easy gas diffusion to the active sites where the electrochemical oxidation of the fuel takes place. This takes place at the TPB locations within the anode matrix. Figure 2 provides a visual representation of a typical anode matrix and the passageway necessary for good fuel delivery, where the green represents the Ni, dark blue the YSZ, and light blue is porosity [30]. 


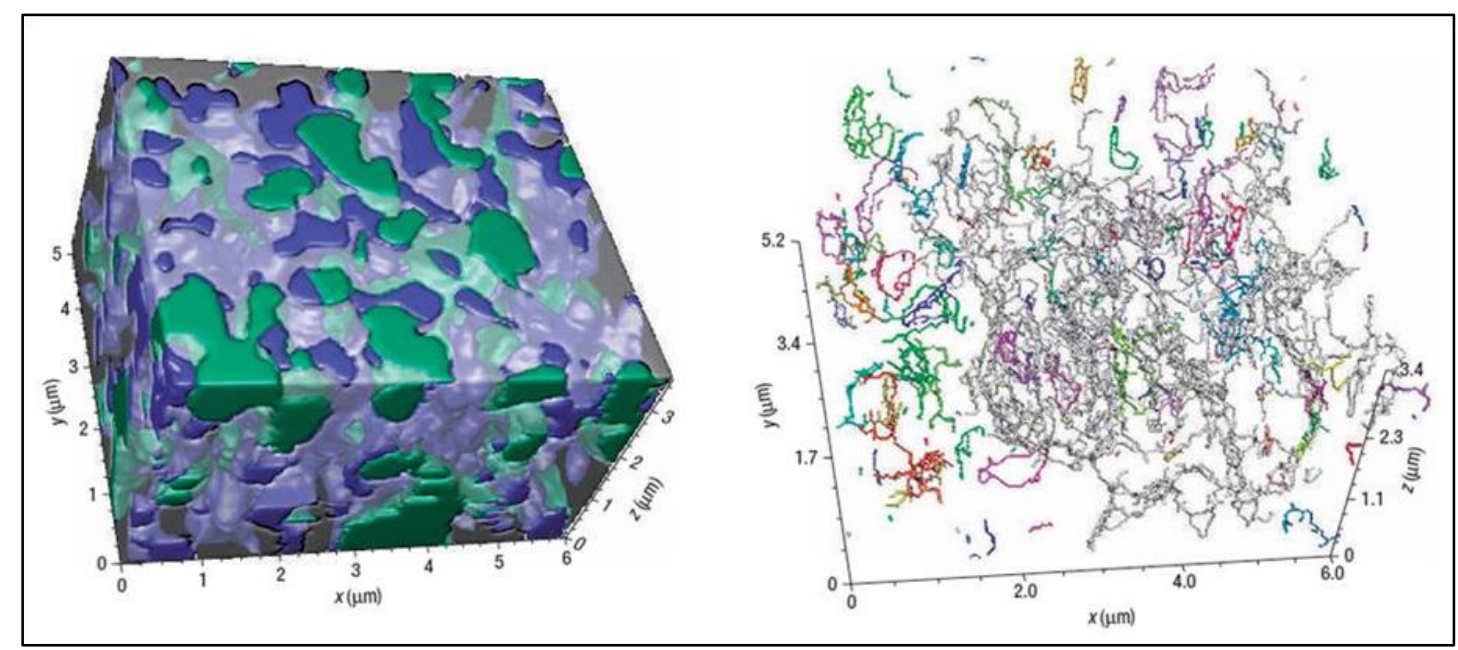

Figure 2: Geometric Representation of SOFC Anode [30].

One way to limit this reaction would be if the pores were to become clogged. This is where the YSZ in the anode matrix plays another role in addition to creating a three-dimensional pathway for oxygen ion flow. The YSZ also helps to prevent coarsening of the Ni over time at SOFC operating temperatures. The first anodes ever investigated were pure metals like Ni and Pt that lost all porosity over time and ultimately delaminated completely from the electrolyte [31]. This agglomeration greatly decreases gas permeability through the anode and thus limiting cell efficiency. In addition to particle agglomeration, carbon deposition on the anode surface as well as possible contaminant interactions with nickel can cause a great decrease in the porosity.

\subsubsection{Electrical Conductivity}

In order for the fuel cell to generate electrical power, there must be a continuous pathway in three dimensions for the electrons to migrate from the chemical reaction site at the anode surface to the external source. With the long distance of travel for these electrons due to the high surface area of the electrolyte, a metallic mesh current collector is often used to minimize this travel time and thus decrease overall cell resistance [32]. The high electrical conductivity of Ni at SOFC operating temperatures minimizes the resistance of the cell towards electron transport. The issue of the electrical network is more important in the case of anode supported architecture 
where macroscopically there is a larger distance (nearly 300-600 $\mu \mathrm{m}$ mean free path) compared to roughly $30-70 \mu \mathrm{m}$ in an electrolyte-supported SOFC design.

\subsubsection{Catalytic Activity and Chemical Stability}

In order to ensure rapid production of electrons at the TPB's, a good catalyst is required. $\mathrm{Ni}$ metal is an excellent promoter of fuel oxidation for long periods of time. However, if the $\mathrm{Ni}$ were to become oxidized either during high current fluxes or as a result of impurity introduction, the reaction rates decrease significantly. Not only is it imperative that anode stability be maintained in highly reducing environments, but it also must hold with respect to the electrolyte and the current collection path. If over time the contact is altered between either of these two interfaces, then cell efficiency is compromised. This problem is avoided for the Ni/YSZ anode when utilizing YSZ as the electrolyte in pure $\mathrm{H}_{2}$ fuel. The chemical stability issues for the anode arise when using alternative fuels with different oxygen partial pressures and trace impurities. Most importantly for coal-based fuel is the changes to the chemical makeup that arise during when introducing small concentrations of impurities such as S or P. The changes to the SOFC anode in response to these are among the primary focuses of this thesis.

\subsection{Cell Evaluation Techniques}

In order to assess the overall performance of the fuel cell and specifically the anode, there are two primary methods that are often used. Current-Potential-Power Density (I-V-P) curves and impedance spectroscopy are quantitative techniques that can offer valuable information on the efficiency of the cell as well as diagnose where the shortcomings in the circuit are located. 


\subsubsection{I-V-P Performance Curves}

The most common method scientists use to measure SOFC performance is the I-V curve. To generate the curve, data points are collected from open circuit conditions (i.e. no current flux across the cell), through maximum current until all of the potential across the cell is depleted. A characteristic I-V curve can be seen in Figure 3.

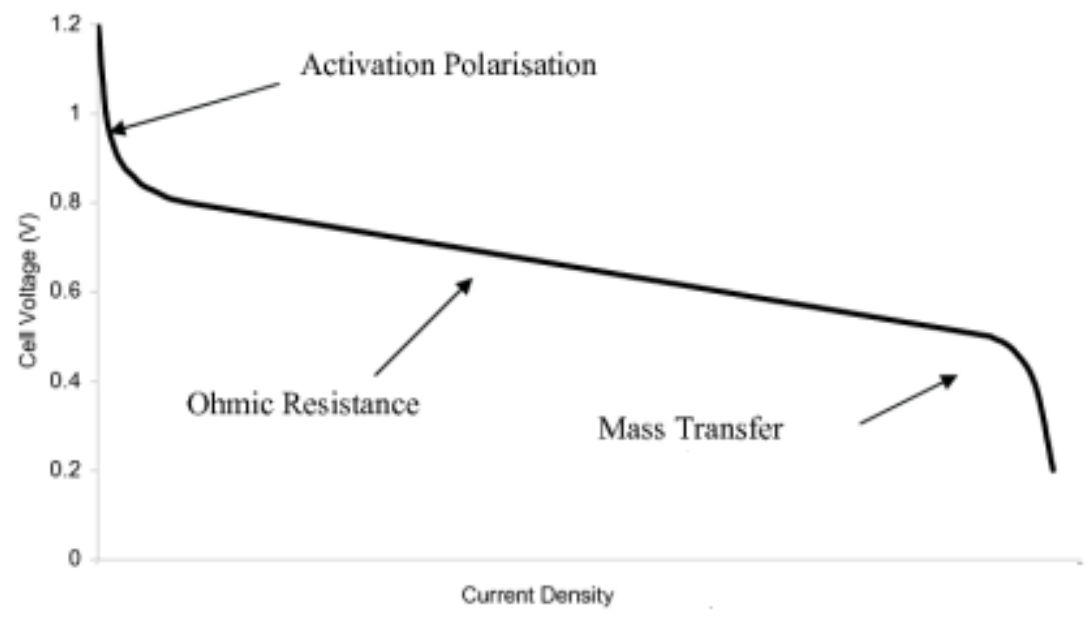

Figure 3: Characteristic SOFC I-V curve.

The polarization, which is essentially the voltage loss corresponding to current density, can be broken down into three categories that scientists use to characterize a fuel cells' operation. These three polarizations are: ohmic polarization, concentration polarization, and activation polarization. Under open circuit conditions, the cell potential exists due to the low partial pressure of oxygen that exists on the anode side. The equilibrium potential can be calculated from knowledge of the thermodynamics of the reaction in question. One first determines the change in Gibbs free energy, $\Delta \mathrm{G}$, for the given reaction. For the hydrogen oxidation reaction, the equilibrium potential is given by $-\Delta \mathrm{G} / \mathrm{nF}$, where $\mathrm{n}$ is the number of electrons transferred in the reaction and F is Faraday's constant. For this reaction, the Gibbs free energy is [22, 33-34]:

$$
\Delta \mathrm{G}=\Delta \mathrm{G}^{\circ}(\mathrm{T})+\mathrm{RT} \ln \left(\left(\mathrm{PH}_{2} * \mathrm{PO}_{2}{ }^{1 / 2}\right) / \mathrm{PH}_{2} \mathrm{O}\right)
$$


where $\Delta G^{\circ}(T)$ is the Gibbs free energy of the reaction for the case when all species are in their standard states (atmospheric pressure, pure gas) and the pressures in the second term refer to the actural pressures in the fuel cell experiment. The $\Delta \mathrm{G}^{\circ}(\mathrm{T})$ is tabulated for most reactions of interest. For the hydrogen oxidation reaction, this value is $-242 \mathrm{KJ} / \mathrm{mol}+(45.8 \mathrm{~J} / \mathrm{mol}-\mathrm{K}) \times \mathrm{T}$, where $\mathrm{T}$ is the absolute temperature. This can calculate the standard Nernst potential, $\mathrm{E}^{\circ}(\mathrm{T})$, for a specific reaction [22]:

$$
\mathrm{E}^{\circ}(\mathrm{T})=\Delta \mathrm{G}^{\circ}(\mathrm{T}) / \mathrm{nF}
$$

For a SOFC under open circuit conditions where no current is run through the system, the measured potential should be the Nernst potential, with losses in this open circuit potential being attributed to leaks within the system. The other losses that are seen as a function current density are the ohmic polarization, the activation polarization, and the concentration polarization.

The ohmic polarization of a fuel cell is governed by Ohm's law, which basically relates voltage drop and current linearly. The drop in voltage as a result of ohmic polarization can be calculated directly by knowing the geometry and resistivities of the MEA components. The primary contributor here is the electrolyte due to YSZ's high ionic resistivity. However, the anode and cathode both contribute to the overall value and changes to the ohmic polarization over time are generally attributed to increases in the electrode resistance.

The concentration polarization is based on the diffusion capabilities of the electrodes. One of the important parameters used to define this polarization is the limiting current density, which is the current density where the partial pressure of the fuel at the reactive sites is near zero [35]. These potentials are due to the depletion of charge carrying reactants caused by slowed diffusion of fuel through the porous electrodes. The value of this limiting current density is determined by MEA component thicknesses and the diffusivities of the fuel and oxidant. At this current density, the slope of the I-V curve increases as the voltage approaches zero (as seen in the far right portion of the curve in Figure 3). Fortunately, the current density at which this occurs is almost always higher than the operating current density of an SOFC stack.

The activation polarization is related to the cells ability to promote charge transfer. These transfers involve either the conversion of a neutral species into an ion or vice versa both of which require the transfer of electrons. This portion of the overall resistance also describes ion or 
electron transport into the electrolyte or current collector, respectively. This polarization is the resistance of the cell towards this transfer. Essentially, it represents the problems that inhibit ideal reactions which occur at the TPB's and the electrode/electrolyte interfaces. This polarization is very much dependant on the electrode materials and their microstructure [35-36].

\subsubsection{Electrochemical Impedance Spectroscopy}

A better diagnostic tool for understanding SOFC efficiency is an impedance spectrometer. The strength of the method lies in the fact that by a small-signal perturbation, it reveals both the relaxation times and relaxation amplitudes of the various processes present in a dynamic system over a wide range of frequencies. Various polarizations exhibit different time dependence due to different origins of the kinetic processes involved. The response time for ohmic polarization is essentially zero, while the response time for concentration polarization is related to the relevant gas phase transport parameters, specifically diffusivity [36].

For a full SOFC test, the generic impedance spectra can be seen in a Nyquist plot. A characteristic Nyquist plot can be seen in Figure 4.

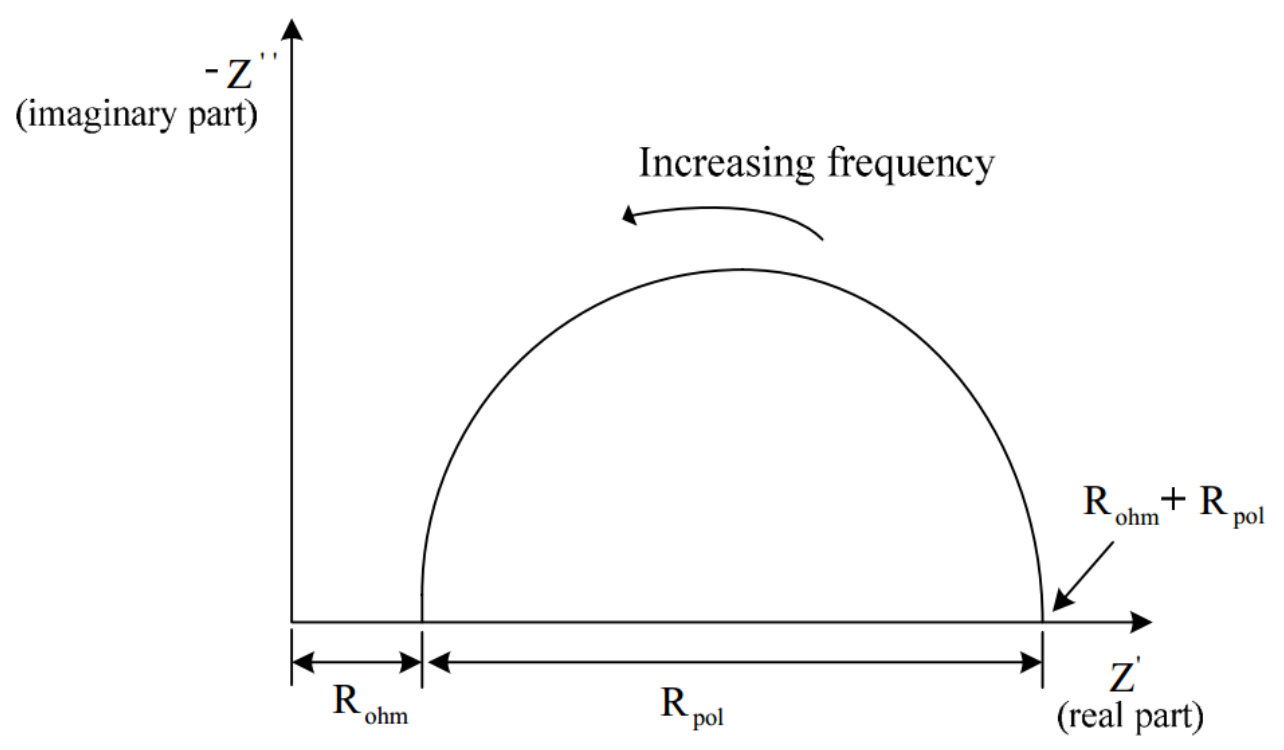

Figure 4: Generic SOFC Nyquist plot [109]. 
On this plot, there are several observations that can be made to come away with the most information. First, the x-axis represents the real axis and the y-axis the imaginary impedance. The intersection of the plot with the $\mathrm{x}$-axis is analogous to the ohmic resistance for the cell, or a zero time response. As you move from the left to the right along the plot beyond the intersection, the type of mechanism that are causes the resistance and reactance responses change. Nearest to the left of the plot are the processes that occur at high frequency. In the case of the SOFC, this is primarily attributed to charge transfer processes during the electrochemical reaction as well as electron transport out of the system. These are specifically related to the activation overpotentials

of the SOFC. The frequency values for this type of process can range from $10^{3}-10^{12} \mathrm{~Hz}$. The further to the right on the real axis, the slower the process speed. The spectra points there correspond primarily to concentration overpotentials associated with gas diffusion difficulties to the TPB locations. The frequencies associated with this process can range from as low as 0.05 $\mathrm{Hz}$ to $10^{3} \mathrm{~Hz}$ [129-130]. The length along the $\mathrm{x}$-axis of negative $\mathrm{y}$-values corresponds to the overall polarization resistance. The total cell resistance is equal to the ohmic resistance plus the polarization resistance.

And while a single Nyquist plot at a given instant can provide useful information, it is the change in impedance at different points in time of a SOFC test that are significant when conducting impurity testing. The technique of measuring impedance at different times during a poisoning test can help to diagnose changes to the cell and assess possible degradation mechanisms. Additionally, an AC or DC bias can be applied to the cell to simulate cell resistance during fixed loading. This can help assess the effect the oxygen flux across the cell has on cell resistance. This tool is essential for accurate cell analysis in sulfur and phosphorus impurity.

\subsection{Conventional Ni/YSZ Anode Operating in Syngas Fuels}

\subsubsection{Clean Syngas}

Cleanup methods for dirty fuels are improving all the time, making the concentrations of the impurities present more manageable as time passes. However, cleanup costs and the need for continual absorbent replacements in general make investigation of poison-tolerant anodes 
worthwhile. Additionally, clean syngas without trace impurity presence still presents problems to the Ni/YSZ cermet.

Trembly et al. [12,16] conducted SOFC single cell and short stack (2 planar cells in series) testing with coal syngas as the fuel. The single cell tests were run initially in a 50/50 $\mathrm{H}_{2} / \mathrm{N}_{2}$ mixture at $850^{\circ} \mathrm{C}$ for 100 hours in order to establish that their cells' performances were stable before introducing $\mathrm{CO}$ into the anode stream. Their results indicate that with their syngas mixture $\left(20 \% \mathrm{H}_{2}, 33 \% \mathrm{~N}_{2}, 29 \% \mathrm{CO}, 18 \% \mathrm{H}_{2} \mathrm{O}\right)$, only a $7 \%$ degradation was observed after nearly 300 hours of operation [12]. Similar experiments of the small stack testing indicate an area-specific resistance (ASR) rate increase nearly double that of a single cell test configuration. The authors attribute this increased rate of degradation to nickel or carbon buildup through the inlet passages of the manifold, as well as, the possible upstream fuel leakage, meaning that the MEA itself may be suitable for long-term syngas operation.

Ye et al. [37] conducted single cell tests on Ni/YSZ anode supported cells using syngas as a fuel and determined that high carbon monoxide levels within the stream led to electrode cracking and carbon coking. The decreased mass diffusion from this ultimately slowed down the systems electrochemical reaction rate. In an effort to counteract this, they coated the Ni/YSZ anode with $\mathrm{Cu}-\mathrm{CeO}_{2}$. This layer both served to catalyze the WGS reaction towards $\mathrm{H}_{2}$ production as well as prevent coking. The results for this impregnated cell showed stable operation in syngas for over $1000 \mathrm{hrs}$.

\subsubsection{Syngas with Impurities}

In addition to the degradation that can occur to the Ni/YSZ anode from carbon deposition, problems also arise when subjecting the anode materials to trace impurities present in coal. With the testing capabilities at WVU, sulfur and phosphorus are of particular interest. 


\subsubsection{Sulfur $(S)$}

Sulfur is one of the primary trace contaminants in syngas and has been shown to have a detrimental impact on the performance of the traditional Ni/YSZ SOFC anode with concentrations less as low as $100 \mathrm{ppm}$ [13]. The most common compound of sulfur formed on the product side of an SOFC gasifier is $\mathrm{H}_{2} \mathrm{~S}$ [38]. And while current gas cleanup technology can reduce the concentrations of $\mathrm{H}_{2} \mathrm{~S}$ in coal down to under $100 \mathrm{ppm}$, the expense is significant and could be avoided with the development of a sulfur tolerant anode. This would also eliminate the risk of possible cleanup stage failures or the need for absorbent replacement during operation.

Upon introduction of $\mathrm{H}_{2} \mathrm{~S}$ into the anode stream (regardless of concentration), there is an immediate increase in the cell's polarization. Figure 5 is a representation of the change in cell potential for a fixed current after introduction of $\mathrm{H}_{2} \mathrm{~S}$ into to the anode side of the SOFC.

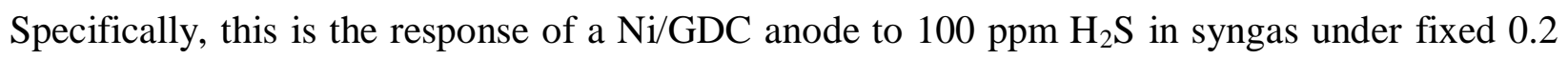
A-cm ${ }^{2}$ loading at $800^{\circ} \mathrm{C}$. For the first 30000 seconds, the cell is at this fixed current in clean syngas. The sharp drop corresponds to $\mathrm{H}_{2} \mathrm{~S}$ introduction into the fuel stream. Most of the drop in potential occurs within a matter of seconds, though it does take several minutes for the cell to completely level off. 


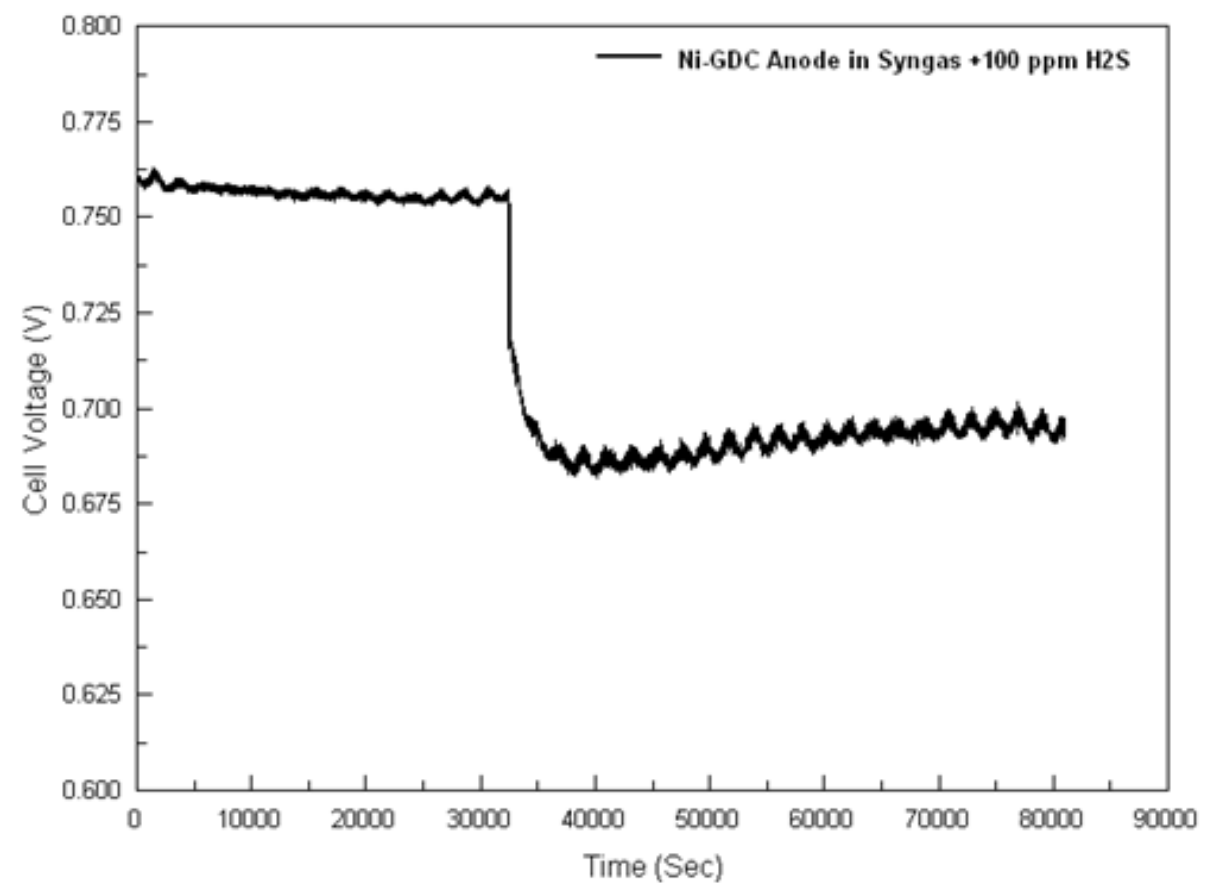

Figure 5: Voltage vs time plot a Ni-GDC anode in response to $100 \mathrm{ppm} \mathrm{H} 2 \mathrm{~S}$ in syngas describing the process of sulfur adsorption to Ni-surface.

Researchers have used the DC polarization techniques to show that this initial degradation step which takes place over a matter of minutes is due to surface adsorption of sulfur onto the catalytically active Ni particles [39]. This adsorption is only nanometers in thickness, but it decreases the catalytic potential of the $\mathrm{Ni}$ particles and also makes the particles more susceptible to re-oxidation during periods of high current flux. Fortunately, this initial degradation is recoverable upon removal of $\mathrm{H}_{2} \mathrm{~S}$ from the anode stream up to a certain concentration. Cheng et al. [40] showed that the increase in anode polarization resistance, rather than the drop in cell power output, should be used to describe the extent of sulfur poisoning when investigating the influence of cell voltage or current. If the drop in power output is used, then there is an apparent contradiction in the effect of potential or current density on the extent of poisoning, depending on whether the cell is operated under galvanostatic or potentiostatic control. For longer-term (several hours or more) exposure to a sulfur-containing fuel, a slow irreversible increase in ohmic resistance is sometimes observed [39]. The researchers suggest that this increase to the ohmic resistance is caused by formation of solid Ni-S phases, which are not as catalytically active nor electronically conductive. According to thermodynamic 
calculations, the most common phases to occur would be either $\mathrm{NiS}$ or $\mathrm{Ni}_{3} \mathrm{~S}_{2}$ as seen in equations 9 and 10.

$$
\begin{aligned}
& \mathrm{Ni}_{(\mathrm{s})}+\mathrm{S}_{(\mathrm{g})} \rightarrow \mathrm{NiS}_{(\mathrm{s})} \\
& 3 \mathrm{Ni}(\mathrm{s})+2 \mathrm{~S}(\mathrm{~g}) \rightarrow \mathrm{Ni}_{3} \mathrm{~S}_{2}(\mathrm{~s})
\end{aligned}
$$

However, it has been shown that under usual SOFC operating conditions, i.e., $\mathrm{pH}_{2} \mathrm{~S}<$ $100 \mathrm{ppm}$ at $\mathrm{T}>600{ }^{\circ} \mathrm{C}, \mathrm{Ni}_{3} \mathrm{~S}_{2}$ would spontaneously decompose to $\mathrm{Ni}$ and $\mathrm{H}_{2} \mathrm{~S}$ [41]. The authors have recently reported observations of surface reconstruction of $\mathrm{Ni}$ grains induced by $\mathrm{S}$ adsorption [42], causing step formation, which may be indicative of S dissolution in the surface of Ni. [43]. Because of contradictions like this, the actual mechanism for irreversible degradation to the Ni/YSZ anode is not completely understood. Several proposed mechanisms have been proposed, but very little has been substantiated.

To purely assess the impact of $\mathrm{H}_{2} \mathrm{~S}$ (not $\mathrm{C}$ ), some researchers have conducted testing in wet $\mathrm{H}_{2}$ environments rather than syngas. Experiments carried out by Lussier et al. [44] show that for levels of $\mathrm{H}_{2} \mathrm{~S}$ ranging from $200-500$ ppm, a decrease in cell performance can be detected in as little as one minute. They report that for short exposure times ( 1 hour), the anode can fully recover from the $\mathrm{H}_{2} \mathrm{~S}$ but that the degradation to the cell for longer time periods (>10 hours) is irreversible. Their post-mortem analysis indicated that much of the active area of the anode had become depleted of $\mathrm{Ni}$ which decreases TPB length throughout and thus reduces performance. They found that the Ni migrated towards the surface of the bulk anode layer. This work also showed that sulfur was completely removed from their system upon cool down in an inert environment, suggesting that Ni-S solid phase formation did not occur.

Kuhn et al. [45] showed that sulfur had a much larger impact on cells operating with $\mathrm{H}_{2} \mathrm{O}$ in the stream, though multiple anode reactions were evaluated. Their findings also showed that for 500 ppm concentrations of $\mathrm{H}_{2} \mathrm{~S}$ for 5 hours, losses in anode activity are attributable to anode surface reconstruction rather than a bulk $\mathrm{Ni}-\mathrm{S}$ phase. The tests were carried out with varying 
water contents and determined that increased water content has a more drastic impact on performance.

Cheng et al. [40] suggested that at higher amperages, the resistance due to sulfur poisoning is better at higher current levels. This was done by first measuring the anode polarization at open circuit conditions and measuring the change after $10 \mathrm{ppm} \mathrm{H}_{2} \mathrm{~S}$ at various potential levels. Their reasoning for this phenomenon is that sulfur is capable of being electrochemically oxidized at the TPB by the following reaction [39]:

$$
\mathrm{S}_{(\mathrm{ad})}+2 \mathrm{O}_{2-}=\mathrm{SO}_{2(\mathrm{~g})}+4 \mathrm{e}^{-}
$$

The theory is that for higher fluxes of oxygen, the adsorbed $\mathrm{S}$ acts as a fuel similar to $\mathrm{H}_{2}$ making it possible to remove sulfur from the system more readily.

\subsubsection{Phosphorus (P)}

Phosphorus is another trace specie within direct syngas that is gaining a lot of attention for researchdue to several recent reports suggesting that the slightest presence of phosphorus in the anode stream results in extreme cell degradation. This means that significant consequences to an SOFC stack would result if a fuel cleanup mishap should ever occur. This element is most commonly introduced to the anode as a part of phosphine $\left(\mathrm{PH}_{3}\right)$. However, thermodynamic calculations suggest that phosphorus can also appear as $\left(\mathrm{P}_{2} \mathrm{O}_{3}\right)_{2}$ [46]. The phosphorus is capable of deteriorating the performance just as with $\mathrm{H}_{2} \mathrm{~S}$, however, the mechanisms for degradation appear to be different. As such, the different mechanisms for degradation of the Ni/YSZ anode are briefly outlined.

Zhi et al. [47] investigated the way the diffusion and reaction rates were affected due to the presence of syngas containing ppm levels of $\mathrm{PH}_{3}$. Their findings indicate that the porous network of the anode was reduced which slowed down mass transfer. Their impedance measurements also showed a decrease in charge transfer during the same test. Finally, their postmortem XRD analysis showed the formation of $\mathrm{Ni}_{3}(\mathrm{PO})_{4}$ as well as $\mathrm{ZrP}_{2} \mathrm{O}_{7}$ which suggests that at as little as $10 \mathrm{ppm}$ concentrations and standard SOFC operating temperatures, phosphorus thermodynamically reacts with nickel and zirconium. 
Work by Marina et al. [48] identified several bulk nickel-phosphide phases for levels of $\mathrm{PH}_{3}$ as low as 500 parts per billion (ppb). These secondary phases included $\mathrm{Ni}_{3} \mathrm{P}, \mathrm{Ni}_{5} \mathrm{P}_{2}, \mathrm{Ni}_{2} \mathrm{P}$, and $\mathrm{Ni}_{12} \mathrm{P}_{5}$. At high temperatures, $\mathrm{Ni}_{3} \mathrm{P}$ was found to be the dominant phase. In addition to secondary phase formation, phosphorus was also identified at the anode/electrolyte interface. Additionally, their study showed no evidence of phosphorus reacting to form phases with Zr. Anode electrode polarization was found to be the most significant reason for degradation of their anode supported cells. An additional fact is that the concentration level of $\mathrm{PH}_{3}$ had little impact on rates of degradation for the anode supported cell. They also reported a much more pronounced increase in overpotential for electrolyte supported cells when subjected to phosphine. For the electrolyte supported cell, the entire anode was converted to Ni-P phases and the ohmic resistance increased significantly. Another publication by Marina [49] showed that 2 ppm $\mathrm{PH}_{3}$ levels led to irreversible damage, though some phosphorus poisoning was alleviated due to the oxidation of some phosphorus.

Most recently $\mathrm{Xu}$ et al. $[8,50]$ conducted tests on anode supported cells and subjected

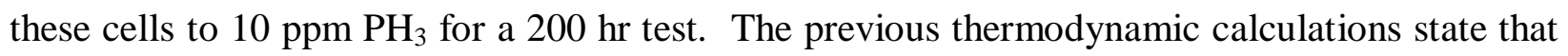
phosphorus has larger impact on cell degradation at lower temperatures, but their work shows higher rates of cell failure at higher temperatures and they attribute this to higher $\mathrm{PH}_{3}$ diffusion rates to the TPB. They also confirm that the composition of bulk phase formation is different depending on whether $\mathrm{H}_{2} \mathrm{O}$ was present. If so, the main phase is $\mathrm{Ni}_{5} \mathrm{P}_{2}$, otherwise the $\mathrm{Ni}_{12} \mathrm{P}_{5}$ is dominant.

\subsection{Alternative Anode Approach for Mitigating Impurity Degradation}

In recent years, several different groups have made efforts to address the fuel impurity problem through development of alternate anode materials. Most work has been focused on alternative anodes for sulfur, as it is contained in the highest concentrations in the most fuels. Many improvements have been made to the SOFC anode for $\mathrm{H}_{2} \mathrm{~S}$ impurity, though the results of this thesis seem to supersede that which is available in literature. It should also be noted that at this point, little to no work has been published on alternative anode response to phosphorus impurity. 


\subsubsection{The Nickel/Gadolinium-doped Ceria (Ni/GDC anode)}

Zhang et al. [10] make a comparison of the Ni/YSZ and Ni/GDC anode in the presence of $\mathrm{H}_{2} \mathrm{~S}$. They demonstrate that varying the concentration of sulfur from 5ppm to 700ppm has a much greater impact on anode potential for the Ni/YSZ anode compared to the Ni/GDC. They operated at a constant load of $0.2 \mathrm{~mA} / \mathrm{cm}^{2}$ over two hours and the decrease in potential was from $0.61 \mathrm{~V}$ to $0.37 \mathrm{~V}$ for Ni/YSZ and from $0.78 \mathrm{~V}$ to $0.72 \mathrm{~V}$ for Ni/GDC at $700 \mathrm{ppm}$. One key observation they make is that the poisoning effect is more pronounced at lower concentrations especially for the Ni/GDC composition, suggesting that sulfur oxidation may be supplying electrons through the GDC. The authors suggest that the mixed ion-electronic nature of GDC is responsible for this improved tolerance to $\mathrm{H}_{2} \mathrm{~S}$.

The substitution for YSZ with GDC in the anode matrix does offer several potential advantages. For one, GDC offers superior ionic conductivity to YSZ. This helps to combat the sulfur poisoning by increasing the rate at which oxygen ions are supplied to the remaining triple phase boundary locations. Additionally, it has been suggested that the Ni/GDC cermet can suppress both carbon coking and irreversible degradation to the TPB network [51-52]. Degradation for Ni/GDC anodes operating in $\mathrm{H}_{2} \mathrm{~S}$ laden fuels has been attributed to formation of ceria-oxysulfides [17]:

$$
2 \mathrm{CeO}_{2-\mathrm{x}}(\mathrm{s})+\mathrm{H}_{2} \mathrm{~S}(\mathrm{~g})+(1-2 \mathrm{x}) \mathrm{H}_{2}(\mathrm{~g}) \leftrightarrow \mathrm{Ce}_{2} \mathrm{O}_{2} \mathrm{~S}(\mathrm{~s})+2(1-\mathrm{x}) \mathrm{H}_{2} \mathrm{O}(\mathrm{g})(\mathrm{x}<0.5)
$$

This solid phase formation ultimately changes the microstructure and the electrochemical capabilities leading to cell failure. However, this formation does not occur at lower concentrations of $\mathrm{H}_{2} \mathrm{~S}$. Up until this critical concentration, the $\mathrm{CeO}_{2}$ essentially acts as an adsorbent to $\mathrm{H}_{2} \mathrm{~S}$ fuel. And though this has been suggested, no literature exists on optimization of the GDC throughout the anode composition. At the anode electrolyte interface, oxygen flux is at its highest, and if sulfur interferes with the reduction of $\mathrm{NiO}$ and subsequent fuel oxidation process, then microstructural changes to the TPB can occur leading to irreversible damage to the cell. With the previous literature suggesting that GDC can suppress local oxidation of $\mathrm{Ni}$ as well as potentially promoting the electrochemical reaction of $\mathrm{S}$ and $\mathrm{O}^{2-}$, the theory proposed in the first part of this thesis is that processing of a thin $(\sim 5 \mu \mathrm{m})$ barrier between the bulk anode and the electrolyte will enhance the cells overall ability to tolerate higher concentrations of $\mathrm{H}_{2} \mathrm{~S}$. 


\subsubsection{The Fluorite-Structured GDC Anode}

Marina et al. [53] investigated SOFC performance of a pure gadolinium-doped ceria (GDC) anode. They incorporated a thin layer of YSZ particles to aid in adhesion between the porous anode and the YSZ electrolyte. This also allowed for a lower sintering temperature of GDC to YSZ of only $1100^{\circ} \mathrm{C}$ With a standard lanthanum-doped strontium manganate (LSM) cathode and $\mathrm{H}_{2}$ as the fuel, they report a maximum power density of $470 \mathrm{~mW} / \mathrm{cm}^{2}$ at $1000{ }^{\circ} \mathrm{C}$. The cells were also run in $\mathrm{CH}_{4}$ for 1000 hours and during that time no carbon deposition was detected on the anode surface. The only downside is that the electro-catalytic activity of the GDC towards oxidation of $\mathrm{CH}_{4}$ was pretty low. The paper suggested that the fairly high performance levels seen in the work were attributed to the use of a porous platinum current collector and that without this the catalytic activity towards $\mathrm{CH}_{4}$ is much lower. Overall, the low catalytic level makes it an unlikely candidate as an MEA that can run on syngas making the Ni/GDC composite essential for long term high energy output.

\subsubsection{Other Non Nickel-Based Anode Compositions}

While many of the recent efforts in anode development have revolved around the nickel electro-catalyst due to its superior properties and affordability, some focus has been dedicated towards discovery of new anodes that either contain a different electrical conductor or are duel ion and electron conductors. There are multiple new compositions that do not contain nickel that have improved certain aspects of performance depending on the conditions.

\subsubsection{1 $\mathrm{ABO}_{3-\delta}$ perovskites}

In the standard Ni/YSZ cermet, the fluorite structure of YSZ makes it easy to accept oxygen vacancies. Combining this with a transition metal with multiple valence states and you get a possible alternative anode composition that has the fluorite structure alone with a transition metal in the B site and a stable rare earth or alkaline earth metal in the larger A site location. There is one inherent advantage with this concept, specifically that the necessity of a triple phase boundary between a particle that is solely an electronic conductor (i.e. Ni) and YSZ in a 
geometrically homogeneous matrix is not required. This potentially can eliminate a lot of problems with the ohmic resistance in the anode arising from poor contact between the two phases. With this mixed ion-electron conductor composition comes several constraints: 1) retention of electronic conductivity requires that the active redox couple on the $\mathrm{M}$ atom remain only partially reduced in the atmosphere at the anode, i.e. that the perovskite remains mixedvalent; 2) the active redox couple must have a low enough energy to accept electrons from $\mathrm{H}_{2}$ or hydrocarbon fuel in order to induce its dissociative chemisorption on the oxide surface; 3 ) catalytic activity requires an easy release of oxidized products from the surface as well as rapid replenishment of $\mathrm{O}^{2-}$ ions to the surface; 4) the oxygen vacancies that allow for $\mathrm{O}^{2-}$ ion conduction must not be ordered at SOFC operating temperature; 5) the thermal expansion must be compatible with that of the electrolyte [32]. If these can be maintained, then efficient power generation can be sustained.

Aguilar et al. [54] developed a $\mathrm{La}_{1-\mathrm{x}} \mathrm{Sr}_{\mathrm{x}} \mathrm{VO}_{3-\delta}$ (LSV) perovskite as an SOFC anode that can run in fuels containing very high levels of $\mathrm{H}_{2} \mathrm{~S}$ (up to $10 \%$ ). Oddly enough, they show that this anode shows favorability towards $\mathrm{H}_{2} \mathrm{~S}$ oxidation via equation 11 above rather than $\mathrm{H}_{2}$ oxidation. This implies that lower concentrations of $\mathrm{H}_{2} \mathrm{~S}$ that are more comparable to those found in gasified coal streams may not be suitable for this anode. The work also confirms low performance at for this fuel stream at $1000^{\circ} \mathrm{C}$ [55]. Also, LSV has poor redox stability due to the easy formation of $\mathrm{V}^{5+}$ valence state during oxidation which can ultimately lead to destruction of the perovskite structure [105]. This composition also readily forms $\mathrm{SrV}_{2} \mathrm{O}_{8}$, which is an insulator. Another perovskite that has shown promise as an $\mathrm{SOFC}$ anode is $\mathrm{SrTiO}_{3}$ [56-58]. Specifically, A-site donor doping with La has increased performance due to its trivalent stability and similar ionic radius to Barnett et al. [57] developed a $\mathrm{Sr}_{0.8} \mathrm{La}_{0.2} \mathrm{TiO}_{3}$ anode support with $\mathrm{Ni} / \mathrm{YSZ}$ active layers with $100 \mathrm{ppm}_{2} \mathrm{~S}$ in $\mathrm{H}_{2}$ and compared with the traditional Ni/YSZ anode and demonstrated stability for an $80 \mathrm{hr}$ testing period whereas a 15\% decrease was seen during this same time. They also ran the anode in natural gas and experienced no drop in potential, though the 6 hour exposure is rather short for verification of long-term tolerance. Marina et al. [58] showed that redox cycling did not adversely affect this anode of long periods but that the power density was rather low for their optimal La-doping concentration $\left(\mathrm{x}=0.4\right.$ for $\operatorname{Sr}_{1}$ $\left.{ }_{x} \mathrm{La}_{\mathrm{x}} \mathrm{TiO}_{3}\right)$. 


\subsubsection{The Double-Perovskite Anode}

The double-perovskite $\mathrm{Sr}_{2} \mathrm{MgMoO}_{6}(\mathrm{SMM})$ was recently proposed as an efficient SOFC anode using directly methane and natural gas fuels. A high electronic, redox stability and tolerance to sulfur species were reported for this anode material [20-21,59]. Additionally, modification of the double-perovskite $\mathrm{Sr}_{2} \mathrm{MgMoO}_{6}$ by $\mathrm{La}^{3+}$ substitution has been reported to improve the electro-catalytic properties for fuel oxidation though it has reported to be less chemically stable for long term operation [21,60-61]. Another big problem with this anode and the YSZ electrolyte is cation diffusion at the anode/electrolyte interface. Specifically, this diffusion occurs between the $\mathrm{Sr}$ and $\mathrm{Zr}$ forming $\mathrm{SrZrO}_{3}$ at as little as $1000^{\circ} \mathrm{C} .23$ wt- $\%$ of this phase was present without incorporation of a barrier layer at this temperature, which is the minimum required temperature for electrode adhesion. Smaller interactions between the SMM and a GDC electrolyte material can occur at temperatures in excess of $1250^{\circ} \mathrm{C}$, though they have not been quantified [21]. So, a GDC barrier layer between this anode and a YSZ electrolyte could be suitable for cells where the electrodes are adhered below this temperature. Power densities for this anode with a $\mathrm{La}_{0.8} \mathrm{Sr}_{0.2} \mathrm{Ga}_{0.8} \mathrm{Mg}_{0.2} \mathrm{O}_{3-\delta}$ (LSGM) in excess of $800 \mathrm{~mW}-\mathrm{cm}^{-2}$ in humidified $\mathrm{H}_{2}$ as well as moderate tolerance to $\mathrm{H}_{2} \mathrm{~S}$ have been achieved making the SMM anode a promising one for further investigation taking the above knowledge into consideration [32].

\subsection{Basic Cell Architectures and Processing}

With the focus of this thesis being the mitigation of SOFC's anode degradation, it is important to understand the typical ways that the anode is configured within the MEA and the advantages and disadvantages of each. In academic research, most materials' testing is confined to either an electrolyte-supported or anode-supported platform. In general, the electrolytesupported cell is preferred due to its simplistic fabrication process relative to the anode supported cell. However, the anode-supported cell offers the opportunity for superior performance using the same materials which makes it favorable for commercialization. 


\subsubsection{Electrolyte-supported Cell Architecture}

The simplest to fabricate is the electrolyte-supported cell. It has the advantage of being supported by the strongest and densest component of the MEA which minimizes the likelihood of failure due to mechanical cracking or leaking. The primary disadvantage is the increased thickness requirement of the electrolyte which prevents high power density production by increasing the ohmic resistance. Also, for the quick evaluation of many different anode compositions, this platform is best since a whole anode structure does not need to be reengineered to form the anode-support. This means that various anode compositions can be consistently tested without having to allocate a lot of time addressing ceramic processing difficulties. It is for these reasons that most experimental materials work is conducted on this platform, but commercialization of said materials are in configurations that allow for thinner electrolytes.

\subsubsection{Electrolyte Processing}

\section{Tape Casting}

The most common method for creating the dense YSZ electrolyte is tape casting. This method involves the horizontal translation of a liquid slurry where the thickness is controlled by a thin blade. This standard slurry has 5 major components: (1) The YSZ powder; (2) solvents; (3) dispersants; (4) binders; (5) plasticizers. These components are typically brought together via a milling process. Each of these components plays an integral role in assuring a homogenous tape.

\section{Solvents}

The YSZ particles are first mixed in a solvent-based medium for several hours on a ball milling machine. There two primary functions of the solvent is to create fluidity for the powder during the casting process as well as to uniformly dissolve the other additives throughout the powder. The selection of solvent is between water or an organic liquid. Both offer advantages and disadvantages depending on the type of application. For instance, if safety is of utmost 
concern than a water-based system would be preferred due to the high flammability of common organic solvents such as ethanol, toluene etc. Cost restrictions would also make water an attractive choice for a system solvent.

However, there are several characteristics that organic solvents possess that make it favorable for many tape casting processes. When the tape is cast along a carrying polymer material (e.g. mylar), the evaporation rate of the slurry plays an integral role in the homogeneity of the sample. The ability of a liquid to wet a solid is defined by the surface tensions of all three phases (solid, liquid, vapor). Mathematically, it is seen as:

$$
\operatorname{Cos} \theta=\left(\gamma_{\mathrm{sv}}-\gamma_{\mathrm{sl}}\right) / \gamma_{\mathrm{lv}}
$$

In order to achieve good wetting, a low angle is desired. Typically organic solvents are selected for they have much lower surface tensions, $\gamma_{1 v}$, than a water based solvent. For this reason, the solvent system employed for all the ceramic processing in this thesis contains a 50-50 mix of ethanol and xylene by weight, which have surface tensions of 23 and $28\left(10^{-3} \mathrm{~N} / \mathrm{m}\right)$ at room temperature respectively. These are both about one third the value of water $73\left(10^{-3} \mathrm{~N} / \mathrm{m}\right)$ which makes them more attractive options due to their increased ability to free the system of bubbles and other imperfections during milling [62].

\section{Dispersants, Binders, and Plasticizers}

Many times the particles in a solvent system have a tendency to aggregate or flocculate. This results in a heterogeneous matrix of particle sizes that will make $100 \%$ densification of the YSZ substrates upon sintering more difficult to achieve. To prevent this from occurring, most systems contain what is known as a dispersant, or an additive that helps increase the repulsive forces between two particles. These dispersants ultimately help to stabilize the systems particles and in general there are three different types that are considered for such an application: simple ions/molecules, low weight polymers, and surfactants.

The ion dispersants are most commonly used for aqueous systems and they form by dissolving of electrolyte solutions. Examples of this type of dispersant are $\mathrm{Na}_{2} \mathrm{SiO}_{3}$ and $\mathrm{HCl}$. These inorganic salts function by disassociating in water, where one charged ion adsorbs to the 
particle surface in tandem with an opposite charged diffuse layer. The result is electrostatic stabilization due to the repulsion of this 'double layer' that forms around the particle. The low weight polymer dispersants are an option as well and they consist of carbon chains with molecular weights on the order of hundreds of grams. Polystyrene and polyvinyl alcohol are examples of this type of dispersant.

While both of these options could potentially disperse the YSZ particles in the electrolyte slurry, the surfactant is the most appropriate choice. The surfactant is a short chain of organic atoms with an end that contains either an ionic or anionic functional head depending upon whether the solvent system is water or alcohol based. Stabilization mostly occurs by steric repulsion between the organic tails in the solvent [62]. For this work, a menhaden fish oil is used as the dispersant as it is commonly used in many oxide materials such as $\mathrm{Al}_{2} \mathrm{O}_{3}$ and $\mathrm{SrTiO}_{3}$ [63]. The last piece of the organic system is the binder, which is a long organic polymer chain that helps provide the mechanical strength for the green body before sintering. Poly-vinyl alcohol and poly-vinyl butyral are commonly used binders in SOFC electrolyte slurries.

\section{Doctor Blade Method}

After appropriate mixing of the slurry components through a ball milling process, the slurry is cast along a moving piece of stick-free polymer material that translates along a horizontal axis. An automated roller is used to create the translation and control the speed and a device called a doctor blade controls the tape thickness.

The tape thickness is very important in optimizing the subsequent thermal firing of the material. Most literature suggests individual layer thicknesses between 30-40 $\mu \mathrm{m}$ [64-65]. If the thickness increases beyond this then the more likely the slurry's components are to redistribute and create gradients. These gradients can result in particle agglomeration, poor gas permeation during thermal firing, and ultimately lead to ineffective substrates.

After casting, the tape is typically either punched or cut out into sheets for stacking. Multiple layers are often stacked together to create a single green substrate that is thick enough to adequately support the forces that result from sealing the cell. The solid electrolyte piece also 
benefits from multiple layers in the event that one of the layers has holes or imperfections. This helps to ensure a sufficient seal to fully separate the fuel and oxygen streams.

\section{Hot Pressing of Samples}

When utilizing the tape-casting method, an important step in obtaining a flat, dense substrate is hot pressing. The ultimate goal is to meld together the multiple layers into 1 layer, and for a given composition there exists a condition of temperature and pressure that achieves this. The temperature is based on knowing the glass transition temperature of your organics. For the organic system utilized for all ceramic processing in this work, a pressing temperature of 210 ${ }^{\circ} \mathrm{F}$ with a $70 \mathrm{kip}\left(99^{\circ} \mathrm{C}\right.$ and $\left.311 \mathrm{kN}\right)$ applied force was sufficient for proper melding of the different layers. It is important to not completely melt the organics as that will cause a heterogeneous distribution of organics and will change their properties causing problems during sintering.

\section{Sintering and Forging}

Once the laminates are pressed they are cut into the appropriate green size based on the shrinkage of the material. In the case of the YSZ laminates developed in this work, the shrinkage is approximately $23 \%$. In order to create a strong material that is fully dense, thermal treatment is required. It has been well documented that for full densification of $\mathrm{YSZ}$, a $1450^{\circ} \mathrm{C}$ minimum sintering temperature is required [66]. This temperature allows for full escape of organic species (typically by $400^{\circ} \mathrm{C}-500^{\circ} \mathrm{C}$ ) before sintering. Ideally, this evacuation of organics occurs without distorting the homogenized packing of the YSZ particles.

After this step, the higher temperature regime is where the densification of the particles into a functional ceramic occurs. There are three primary driving forces for sintering which are chemical reaction, external pressure, and most importantly to this case the curvature of the particle surfaces. The free surface energy associated with the porous YSZ network of particles in a finite volume serves as the driving mechanism to achieve a dense body that contains no free surface energy. At $1450^{\circ} \mathrm{C}$, this energy is dissipated and a dense substrate is the result. 
Although the substrate is fully dense, it might or might not be flat as additional frictional forces from the surface that the substrate sets on can cause different rates of shrinkage leading to potential bowing. If this bending occurs uniformly in a radial direction, then it can be salvaged by placing weights on the samples and heating to the sintering temperature which is a process known as forging. In this work, an identical $\mathrm{Al}_{2} \mathrm{O}_{3}$ setter to the one that the substrates were sintered on is used to flatten out the samples.

\subsubsection{Barrier-Layer/Electrode Application (Screen-printing)}

With the flat electrolyte piece is fabricated, the deposition of the GDC barrier layer is the next important step in completing the MEA assembly. This layer is placed onto both sides of the electrolyte and densification is achieved similarly. A screen-printing technique helps to control the thickness of the layer. The mesh size of the screen dictates the overall layer thickness and a rubber blade is drug across the sample at a controlled force and speed to generate the coating. For a 400 mesh grid, the resultant thickness is approximately $5 \mu \mathrm{m}$, which is the target thickness to serve its multiple purposes. The GDC layer on the cathode side serves to prevent interfacial diffusion between the strontium in the LSM cathode with the $\mathrm{Zr}$ in the electrolyte. On the anode side it has the additional function of helping to prevent degradation in response to coal impurities.

Much like the GDC barrier layer, the anode and cathode materials are screen-printed on using the same protocol. Only the thicknesses of the bulk layers are to be between 40 and $50 \mu \mathrm{m}$ so multiple prints of each are required. Plus for both sides, a thinner active site containing higher amounts of ion conducting species is generally incorporated to maximize TPB surfaces near the barrier layer making the multiple print method convenient. In general, the layers are applied according to their required sintering temperature from highest to lowest.

\subsubsection{Anode-supported Cell Architecture and Processing Issues}

In contrast to the electrolyte-supported cell which utilizes the dense, strong YSZ ceramic as its mechanical spine, this type rather uses the porous anode as the primary support. Much of 
the efforts in commercialization of fuel cells are being focused on this design for its increased power generating capabilities. This increased capability is primarily attributed to the decrease in required thickness of the electrolyte which decreases the overall ohmic resistance of the cell [36]. However, this architecture contains additional processing issues in comparison to the electrolytesupported configuration that need to be considered.

The electrolyte material is fabricated using a variety of methods including tape casting, vacuum slip casting, and wet powder spraying have been used with success [67]. The tape casting method is similar to that of the electrolyte-supported architecture described previously.

One big obstacle is that most of these membranes are fabricated by thermally treating the anode and electrolyte at the same time to create a half-cell. In order for this to work, the CTE values of the two materials must be similar. Sintering shrinkage is the biggest problem with this stage of ceramic processing. The thermodynamic driving forces associated with each material are related to their particle size and this variability leads to different shrinkage rates, the onset temperature for shrinkage, and the overall magnitude of shrinkage. Problems that arise from this include warping of the cell and/or micro-cracking both of which result in a useless cell. Utilizing the standard Ni/YSZ anode and YSZ electrolyte, several groups worldwide have developed firing protocols that leave the piece flat and free of micro-cracking.

Among the most common processes to achieve the anode/electrolyte half-cell is to first create the green anode support, either by casting and laminating, uniaxial pressing etc. This is followed by a process known as bisquing, which is a thermal treatment step that takes the sample up to the onset of sintering to provide enough mechanical strength for electrolyte deposition. For the $\mathrm{Ni} / \mathrm{YSZ}$ anode, this temperature ranges between $1000-1200^{\circ} \mathrm{C}$ [68-69]. With the bisqued sample, the electrolyte can then be applied by a spraying or printing technique. This composite structure is then sintered to the minimum temperature required for full electrolyte densification.

With the co-sintering of the anode and electrolyte components, there are a couple of primary concerns. The first is that for good gas diffusion to the active sites, porosity needs to be maintained even after the high temperature required for full electrolyte densification. To fulfill this carbon pore formers are incorporated by amounts ranging from $40-60 \%$ by volume. Carbon black, graphite, and starches are among the most commonly used materials to obtain this porous 
network [70-71]. The evacuation of this material leaves a porous, though uncontrolled microstructure that allows for appropriate mass transport all the while maintaining mechanical strength. A general processing methodology similar to this will be carried out for the SMM/GDC anode supported cell in Chapter 5.

\section{Chapter $3-\mathrm{H}_{2} \mathrm{~S}$ Impurity Tolerance Evaluations of Ni/GDC Cermet Anodes}

\subsection{Introduction}

Coal-derived syngas is a potential fuel source for the SOFC. However, the presence of volatile contamination containing $\mathrm{H}_{2} \mathrm{~S}, \mathrm{PH}_{3}, \mathrm{HCl}, \mathrm{AsH}_{3}, \mathrm{Sb}$, and $\mathrm{Hg}$ species in warm syngas can cause degradation of the SOFC performance [72]. Sulfur is one of the most abundant impurities in coal and after coal is gasified, with most of the sulfur appearing as $\mathrm{H}_{2} \mathrm{~S}$ in the syngas. The concentration could range from 0.1 to $1.6 \% \mathrm{H}_{2} \mathrm{~S}$ by volume in raw coal syngas derived from typical gasification systems [38,73]. Although commercial desulfurization techniques, such as adsorption and wet absorption at ambient temperature can remove $\mathrm{H}_{2} \mathrm{~S}$ down to $1 \mathrm{ppm}$ (a level which may not lead to SOFC degradation) the hot syngas from the gasifier has to be cooled, thereby reducing the overall thermal efficiency of the system. Some transition metal oxide desulfurization sorbents, such as $\mathrm{Cu}_{2} \mathrm{O}, \mathrm{ZnO}, \mathrm{NiO}, \mathrm{CoO}$ and $\mathrm{MnO}$, have been reported to yield as high as $99 \% \mathrm{H}_{2} \mathrm{~S}$ removal efficiency at temperatures over $600^{\circ} \mathrm{C}$ [73]. However, the warm gas cleanup technique would leave some level of $\mathrm{H}_{2} \mathrm{~S}$ in the syngas, perhaps as much as 50-100 ppm [74]. Therefore, the development of $\mathrm{H}_{2} \mathrm{~S}$ resistance in the Ni-based anode is still a meaningful target for a highly efficient SOFC energy system fueled by coal-derived syngas.

The poisoning mechanisms of $\mathrm{H}_{2} \mathrm{~S}$ on the Ni-based anode have been discussed and 
reported in the literature review. There are two primary mechanisms of $\mathrm{H}_{2} \mathrm{~S}$ poisoning on a Nibased anode have been identified, an initial rapid degradation phase which is reversible followed by a slow nonstop degradation phase which is irreversible. The initial $\mathrm{H}_{2} \mathrm{~S}$ poisoning mechanism is attributed to the adsorption of sulfur on the nickel which blocks the hydrogen reaction sites [75-77]. For the second degradation phase, there has been a discrepancy in the literature. Dong et al. reported that this degradation results from a chemical reaction which forms nickel sulfide and leads to the complete loss of Ni catalysis under typical SOFC operating conditions. Sasaki et al. proposed that the second degradation phase was associated with the oxidation of the Ni electrode catalysts. Thus, the goal of producing an $\mathrm{H}_{2} \mathrm{~S}$-tolerant, $\mathrm{Ni}$-based anode is to minimize the initial phase of cell degradation and prevent the cell from undergoing the irreversible degradation. The addition of ceria to a Ni-based anode has shown some $\mathrm{H}_{2} \mathrm{~S}$ resistance over that of the pure NiYSZ anode under conventional SOFC operation conditions [51,78]. For example, Trembly reported a Ni-GDC anode cell exposed to 200 240 ppm $\mathrm{H}_{2} \mathrm{~S}$ in syngas suffered only 10 12\% degradation for a $570 \mathrm{~h}$ test [12]. The $\mathrm{H}_{2} \mathrm{~S}$ tolerance of the Ni-GDC anode used in this case was not optimized by altering either the anode architecture or the GDC concentration. Changes of the GDC concentration and architecture of the cell anode may affect the overall cell resistance, the anode stability and the cell's tolerance of $\mathrm{H}_{2} \mathrm{~S}$ in the fuel. In the present work, different

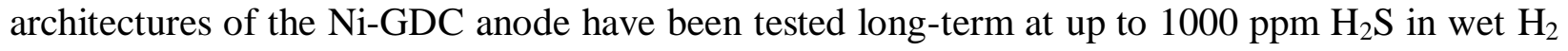
and $100 \mathrm{ppm}$ in syngas. According to the test results, the $\mathrm{H}_{2} \mathrm{~S}$ poisoning mechanisms on the Nibased SOFC and the $\mathrm{H}_{2} \mathrm{~S}$ tolerance afforded by the GDC barrier layer have been illustrated and discussed.

The work in this chapter begins with a brief confirmation of the previous literature that the standard Ni/YSZ cermet anode is not effective in sulfur or phosphorus containing fuels. An initial series of experiments optimizing the SOFC architecture are presented (both in text and appendices) to address a couple key problems that were initially encountered in this work: the significance of the barrier layer with both electrodes in regards to power density, adhesion of the anode materials to the YSZ electrolyte, the Ni/YSZ anode in fuels containing sulfur and phosphorus impurity.

The next section will address the viability of the Ni/GDC anode from above by testing several different parameters. First, the anode will be tested in $\mathrm{H}_{2} \mathrm{~S}$ impurity with and without the GDC barrier layer. Next, concentration limits of $\mathrm{H}_{2} \mathrm{~S}$ are established in both wet $\mathrm{H}_{2}$ and coal 
syngas environments. Also, changes to the ASR in response to various levels of $\mathrm{N}_{2}$ content within the stream are assessed. This set of experiments will demonstrate the viability of this anode for SOFC operation containing $\mathrm{H}_{2} \mathrm{~S}$. Also the Ni/GDC anode will be assessed in terms of $\mathrm{PH}_{3}$ tolerance.

\subsection{Ni/YSZ Anode Testing}

\subsubsection{Experimental Procedure}

The following section outlines the experimental procedures carried out in the fabrication and testing of the Ni/YSZ anode. It should be noted that subsequent experimental sections in this chapter will only highlight things not already covered in this section.

\subsubsection{Cell fabrication}

Button cells were fabricated by first taking 8-YSZ powder (Daiichi Kigenso Kagaku Kagyo Co. LTD) and preparing the electrolyte using standard tape-casting methods. First, one to two layers of alumina milling media were placed into a clean polystyrene bottle. The first additive to the bottle is the YSZ electrolyte powder. The solvent is then added, which consists of a 50/50 xylene/ethanol mixture by weight. Once added and lightly mixed by hand, the fish oil dispersant is added. The solvent + solid system without binders or plasticizers is then milled for 4 hours. After this initial milling, the plasticizers (polyalkalene glycol and benzyl butyl phthalate) and binder (poly-vinyl butyral) are added and milled overnight.

Tape casting using the doctor blade method was executed the following day. The thickness of the tape was controlled to $\sim 40 \mu \mathrm{m}$ and dried overnight. The samples were then cut into $4 \times 4$ inch sheets that are stacked into layers of 4 before being placed into vacuum seal bags for hot pressing. The hot pressing condition for YSZ is 70 kips force at $210^{\circ} \mathrm{F}$ for 15 minutes. This process creates a monolayer that is $150 \mu \mathrm{m}$ in green thickness. With shrinkage of the YSZ 
laminate being $\sim 23 \%$, the resultant substrates are between $100-120 \mu \mathrm{m}$ for these experiments. The tapes were cut to ensure a dense 1 inch circle to fit the testing stand.

The sintering schedule for YSZ densification was $2^{\circ} \mathrm{C} / \mathrm{min}$ to $600^{\circ} \mathrm{C}$ for a 1 hour hold, then $3^{\circ} \mathrm{C} / \mathrm{min}$ to $1450^{\circ} \mathrm{C}$ and a 2 hour hold, followed by a $5^{\circ} \mathrm{C} / \mathrm{min}$ cool down to room temperature. In the event that forging was required, the same $1450^{\circ} \mathrm{C}$ max temperature was needed by heating at a constant rate of $3^{\circ} \mathrm{C} / \mathrm{min}$ with appropriate weight in the form of $\mathrm{Al}_{2} \mathrm{O}_{3}$ setters.

The anode is next applied to the substrate. First, a 50/50 wt- $\%$ mixture of NiO and YSZ powder is printed down onto the electrolyte using a 325 mesh screen. This results in an active layer that is $\sim 10 \mu \mathrm{m}$ in thickness. This procedure was followed by a $40-\mu \mathrm{m}$ thick $70 / 30 \mathrm{wt}-\%$ using a 230 mesh screen. The composite was fired on at $1350^{\circ} \mathrm{C}$ for good adhesion. Lastly, a $10-$ $\mu \mathrm{m}$ thick LSM/GDC active cathode layer was printed and dried before adding a $40-\mu \mathrm{m}$ thick LSM current collector layer. This cathode assembly was sintered at $1100^{\circ} \mathrm{C}$ for 2 hours. Figure 6 shows a simple image of the electrodes on YSZ substrates after sintering.

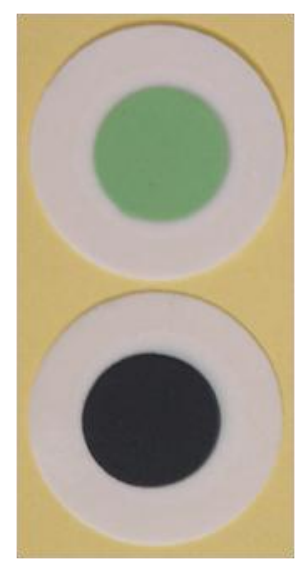

Figure 6: Ni/YSZ Anode (top) LSM Cathode (bottom).

All of the samples contained a GDC barrier layer on the cathode side to prevent $\mathrm{Sr}-\mathrm{Zr}$ interactions, and this layer was synthesized using a co-precipitation method. The same layer was applied to some of the anodes for comparative purposes. The layer was printed using a 400 count mesh for a thickness of $5 \mu \mathrm{m}$ and was fired on at $1350^{\circ} \mathrm{C}$. 


\subsubsection{Cell Testing Setup}

Figure 7 below shows a picture of the testing stand used for this initial baseline testing in wet $\mathrm{H}_{2}$.

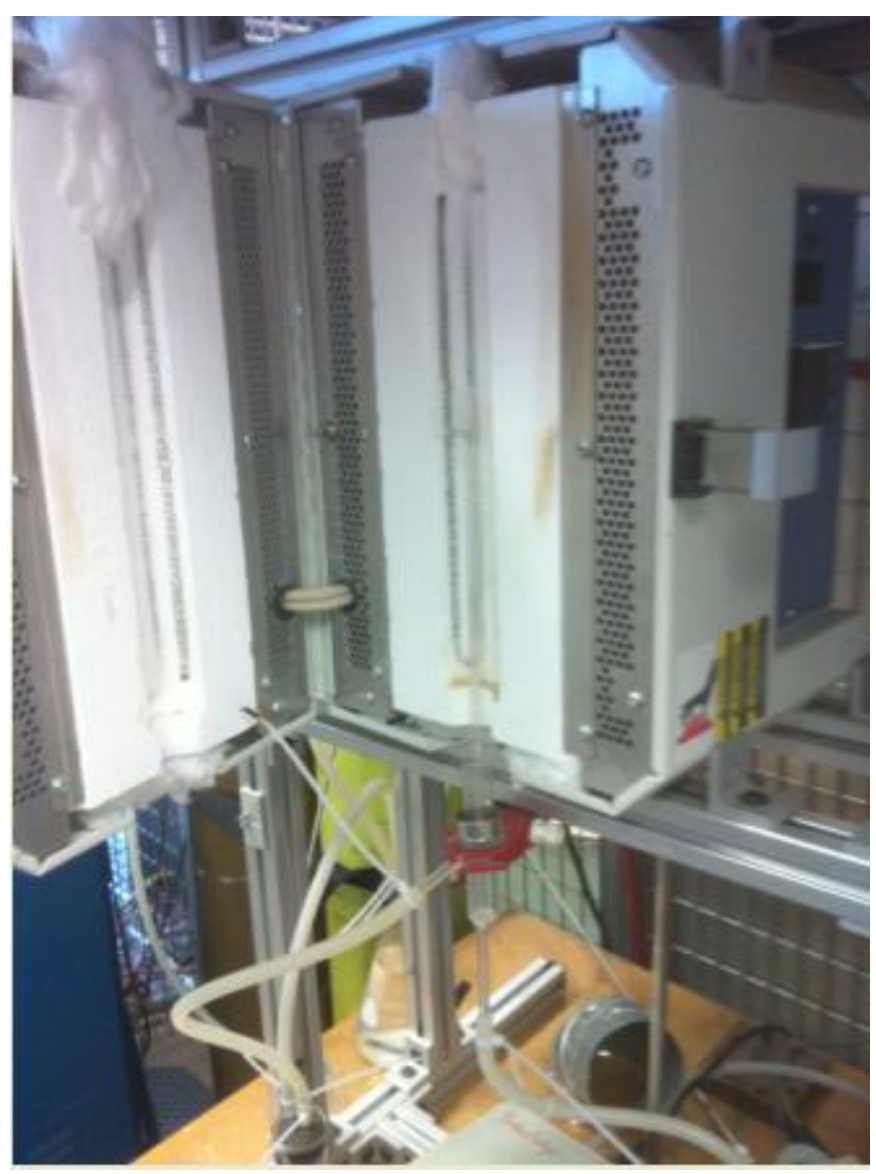

Figure 7: Stand for baseline testing.

The cells are mounted onto a 1 inch alumina tube and sealed with cement. Pt mesh and wires are used to draw current through the circuit and are contacted with Ni paste on the anode side and LSM paste on the cathode. These inks are porous in nature as they are only heated up to the $800^{\circ} \mathrm{C}$ testing condition as to not limit mass diffusion. The $\mathrm{Pt}$ is required as the melting point of a cheaper metal like silver is just above $800^{\circ} \mathrm{C}$ and it is prone to oxidation. Bubblers are used to simulate a wet $\mathrm{H}_{2}$ fuel environment $\left(3 \% \mathrm{H}_{2} \mathrm{O}\right)$ which is monitored by a flow meter and house air supplies the oxidant to the cathode where a mass flow controller (MFC). These baseline tests were brought to temperature $\left(800^{\circ} \mathrm{C}\right)$ in an inert environment over the course of 6 hours. Once at 
temperature, the anode is slowly reduced in $25 \%$ increments until full reduction after 2 hours. At this point, electrochemical performance curves can be obtained.

\subsubsection{Results and Discussion}

\subsubsection{Baseline Testing for the Ni/YSZ Anode}

Multiple tests for the Ni/YSZ anode were carried out without a GDC barrier layer on the anode side of the fuel cell and then with a $5 \mu \mathrm{m}$ layer. Table 2 shows the comparison of several SOFC tests in terms of power production at $800^{\circ} \mathrm{C}$ in a humidified $\mathrm{H}_{2}$ environment with a fuel flow of 50 standard cubic centimeters per minute (SCCM) and 100 SCCM air.

Table 2: Matrix of baseline Ni/YSZ anode tests in $3 \%$ wet $\mathrm{H}_{2}$.

\begin{tabular}{|c|c|c|c|c|c|}
\hline Sample & Active Anode & Anode Current Collector & Barrier Layer (Y/N) & OCV (V) & Max Power Density $\left(\mathrm{mWcm}^{-2}\right)$ \\
\hline 1 & Ni/YSZ (50/50 wt\%) & Ni/YSZ (70/30 wt\%) & No & 1.08 & 202 \\
\hline 2 & Ni/YSZ (50/50 wt\%) & Ni/YSZ (70/30 wt\%) & No & 1.078 & 222 \\
\hline 3 & Ni/YSZ (50/50 wt\%) & Ni/YSZ (70/30 wt\%) & No & 1.077 & 224 \\
\hline 4 & Ni/YSZ (50/50 wt\%) & Ni/YSZ (70/30 wt\%) & No & 1.069 & 196 \\
\hline 5 & Ni/YSZ (50/50 wt\%) & Ni/YSZ (70/30 wt\%) & No & 1.078 & 230 \\
\hline 6 & Ni/YSZ (50/50 wt\%) & Ni/YSZ (70/30 wt\%) & No & 1.077 & 200 \\
\hline 7 & Ni/YSZ (50/50 wt\%) & Ni/YSZ (70/30 wt\%) & Yes & 1.07 & 260 \\
\hline 8 & Ni/YSZ (50/50 wt\%) & Ni/YSZ (70/30 wt\%) & Yes & 1.077 & 255 \\
\hline 9 & $\mathrm{Ni} / \mathrm{YSZ}$ (50/50 wt\%) & Ni/YSZ (70/30 wt\%) & Yes & 1.074 & 266 \\
\hline 10 & $\mathrm{Ni} / \mathrm{GDC}(50 / 50 \mathrm{wt} \%)$ & Ni/YSZ (70/30 wt\%) & Yes & 1.068 & 336 \\
\hline 11 & $\mathrm{Ni} / \mathrm{GDC}(50 / 50 \mathrm{wt} \%)$ & Ni/YSZ (70/30 wt\%) & Yes & 1.068 & 312 \\
\hline 12 & Ni/GDC (50/50 wt\%) & Ni/YSZ (70/30 wt\%) & Yes & 1.066 & 305 \\
\hline
\end{tabular}

After multiple tests for each condition, it was clear that the GDC barrier layer played an integral role in increasing power production. Samples 1-6, which did not have a barrier layer had power densities of between 196 and $230 \mathrm{~mW}-\mathrm{cm}^{-2}$. Samples 7-9 however contained the same bulk anode composition with a $5 \mu \mathrm{m}$ GDC barrier and the average power density was closer to $260 \mathrm{~mW}-\mathrm{cm}^{-2}$. The theory is that the superior ionic conductivity allows for quicker fuel oxidation at the triple phase boundary locations leading to more efficient electron flow. Figure 8 shows a comparison of the ionic conductivities of YSZ and GDC. 


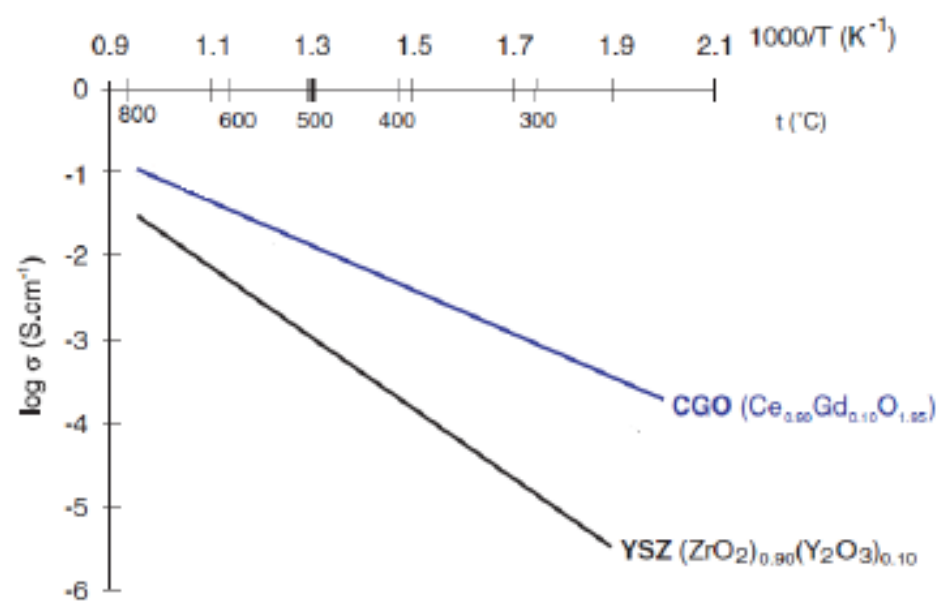

Figure 8: Comparison of ionic conductivities between YSZ and GDC [125].

Samples 10-12 in Table two were different in that they had an active layer comprised of a $\mathrm{Ni} / \mathrm{GDC}$ mixture rather than Ni/YSZ. The result was maximum power densities in excess of 300 $\mathrm{mW}-\mathrm{cm}^{-2}$. It is important to note that the electrolyte thickness, and thus initial ohmic resistance, were essentially the same for each test. The target thickness of $100 \mu \mathrm{m}$ was targeted during YSZ processing to ensure that changes to the performance were related to the electrodes and barrier layer. The reason GDC is avoided as the sole electrolyte material is that it has some electrical conductivity in reducing atmospheres which could result in electrical leaking across the membrane. This makes the strong YSZ electrolyte-support, which exhibits no electrical conductivity at $800^{\circ} \mathrm{C}$, plus a thin GDC layer an attractive architecture.

\subsubsection{Impurity Testing for the Ni/YSZ Anode}

With good performance demonstrated for the baseline composition, confirmation of previous literature in regards to impurity testing was needed to validate our methods. The first check was to see that this cell could in fact produce sufficient power in clean syngas, which contains lower partial pressures of $\mathrm{H}_{2}$ for the anode side and thus making the electrochemical reactions less efficient. Figure 9 shows that for our clean syngas blend $\left(\mathrm{H}_{2} 34 \%, \mathrm{CO} 31 \%, \mathrm{CO}_{2}\right.$ $19 \%, 16 \% \mathrm{H}_{2} \mathrm{O}$ ), about $210 \mathrm{~mW}-\mathrm{cm}^{-2}$ of power was produced which is more than enough for our purposes and competitive when taking the electrolyte thickness into account. This curve was 
taken at a time $2 \mathrm{~h}$ after reducing to syngas. The OCV of 0.965 is similar to other Ni/YSZ cells tested within the group using the same syngas blend.

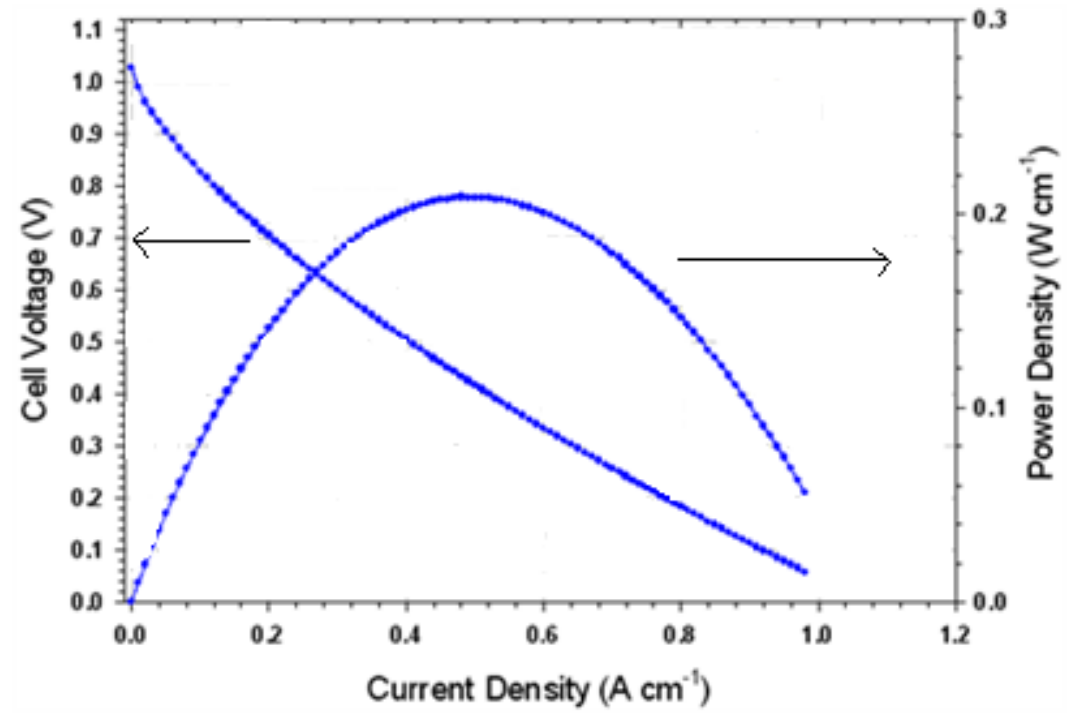

Figure 9: Power Density for Ni/YSZ anode in clean syngas.

The next check is to confirm the degradation of the Ni/YSZ anode in response to $\mathrm{H}_{2} \mathrm{~S}$ impurity. To do this, an identical cell was loaded first in wet $\mathrm{H}_{2} \mathrm{O}$ at $0.2 \mathrm{~A}-\mathrm{cm}^{-2}$ and $800^{\circ} \mathrm{C}$ and after a couple hours, 20 ppm $\mathrm{H}_{2} \mathrm{~S}$ was introduced into the stream. This can be seen in Figure 10. Also, the electrochemical impedance spectra for this cell at a point 10 hours after introduction of $20 \mathrm{ppm} \mathrm{H}_{2} \mathrm{~S}$ can be seen in Figure 11. The ohmic resistance of $0.555 \Omega \mathrm{cm}^{2}$ is higher than the 0.48-0.50 $\Omega \mathrm{cm}^{2}$ resistance that would be expected given the electrolyte thickness and YSZ material. This increase to the ohmic resistance is cause for the secondary irreversible degradation that Figure 11 displays. 


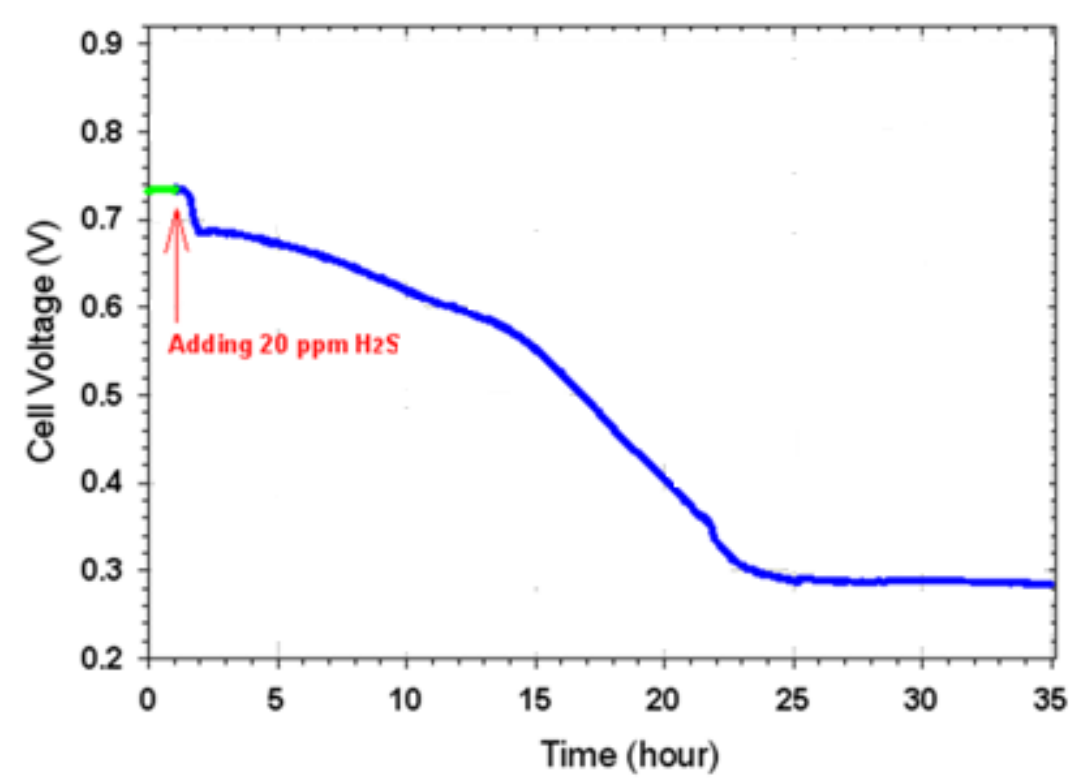

Figure 10: Ni/YSZ anode response to syngas+ $20 \mathrm{ppm} \mathrm{H}_{2} \mathrm{~S}$.

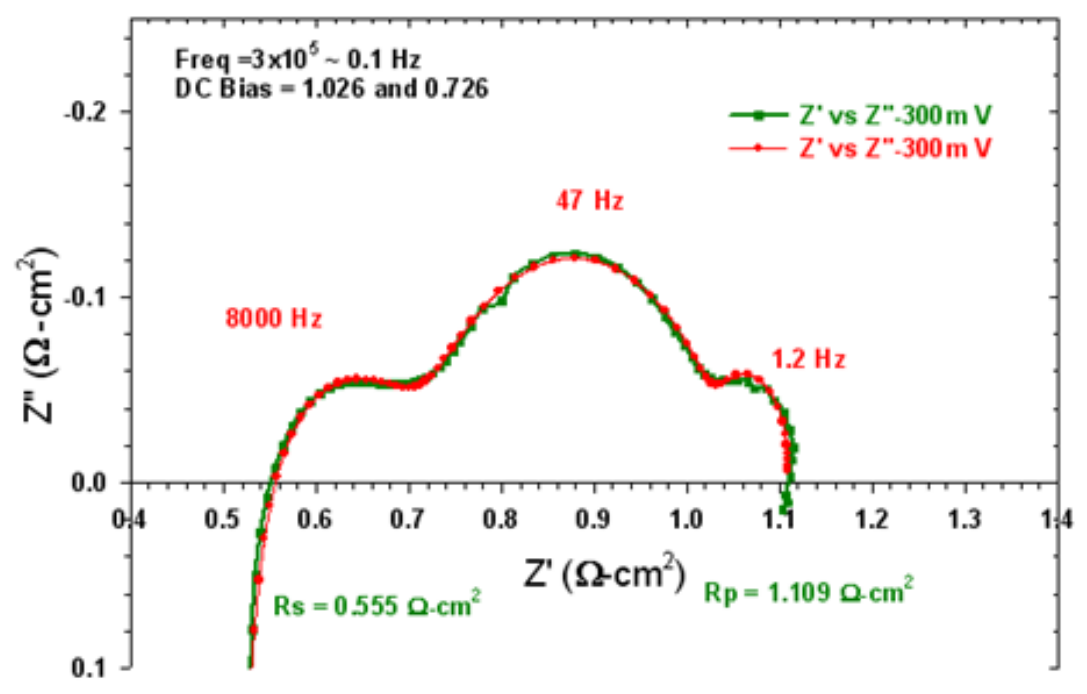

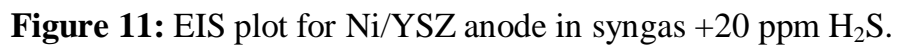

The initial drop corresponds to the adsorption of S onto the Ni particles, which occurs in a matter of a minute or two. The gradual secondary loss over the following 20 hours could be attributed to a few possible mechanisms. One could be carbon coking, which seems to be present based on the EDS plot in Figure 12 where a well defined, though small peak is seen. 
Additionally, local oxidation of the $\mathrm{Ni}$ near the anode-electrolyte interface could destroy the geometry of the triple phase boundary sites. Figure 13a shows a clean Ni/YSZ anode and Figure

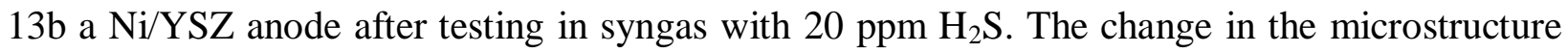
is indicative of either $\mathrm{Ni}-\mathrm{S}$ interactions or $\mathrm{Ni}$ oxidation. The flattening of the curve at the end could be explained by the decreased catalytic activity of $\mathrm{NiO}$ that stabilized throughout portions of the microstructure over this time. However, if Ni migration to the bulk anode surface were to have occurred as reported elsewhere, all TPB's would be lost and this stability towards the end would not be seen. Moreover, the formation of secondary Ni phases was not attributed to the overall cell degradation. Figure 13b shows that a porous microstructure is maintained after exposure and Figure 12 shows that no sulfur peak was detected post-test which suggests that no chemical reaction with $\mathrm{Ni}$ was ever formed.

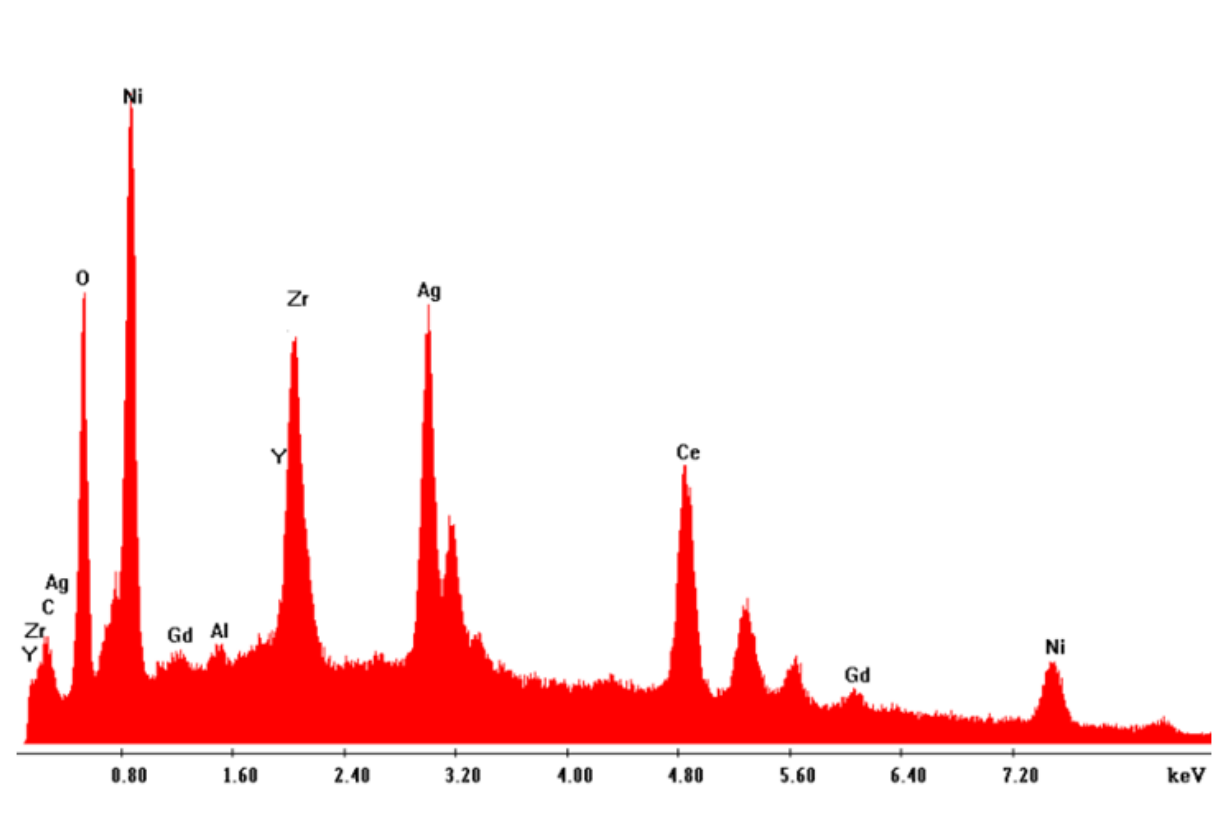

Figure 12: EDS spectra of the Ni-particle of an $\mathrm{H}_{2} \mathrm{~S}$ poisoned Ni/YSZ anode. 

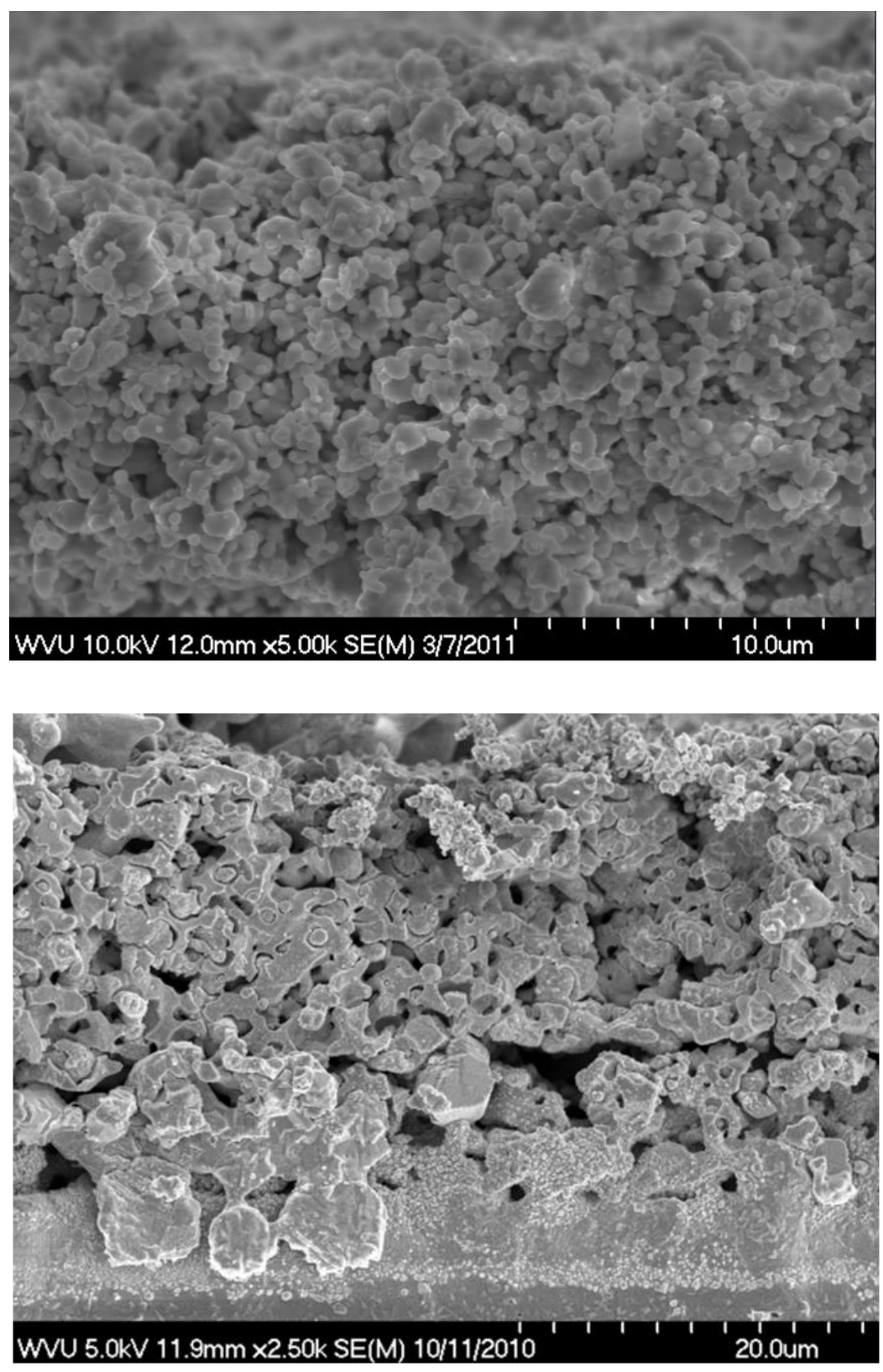

Figure 13: SEM images of Ni/YSZ anode in top) clean syngas and bottom) syngas $+20 \mathrm{ppm} \mathrm{H}_{2} \mathrm{~S}$.

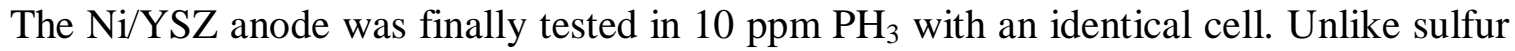
which has that initial steep drop off in potential due to surface adsorption, phosphorus has a steady drop off upon introduction. This sort of response is confirmed by the test seen in Figure 14. 


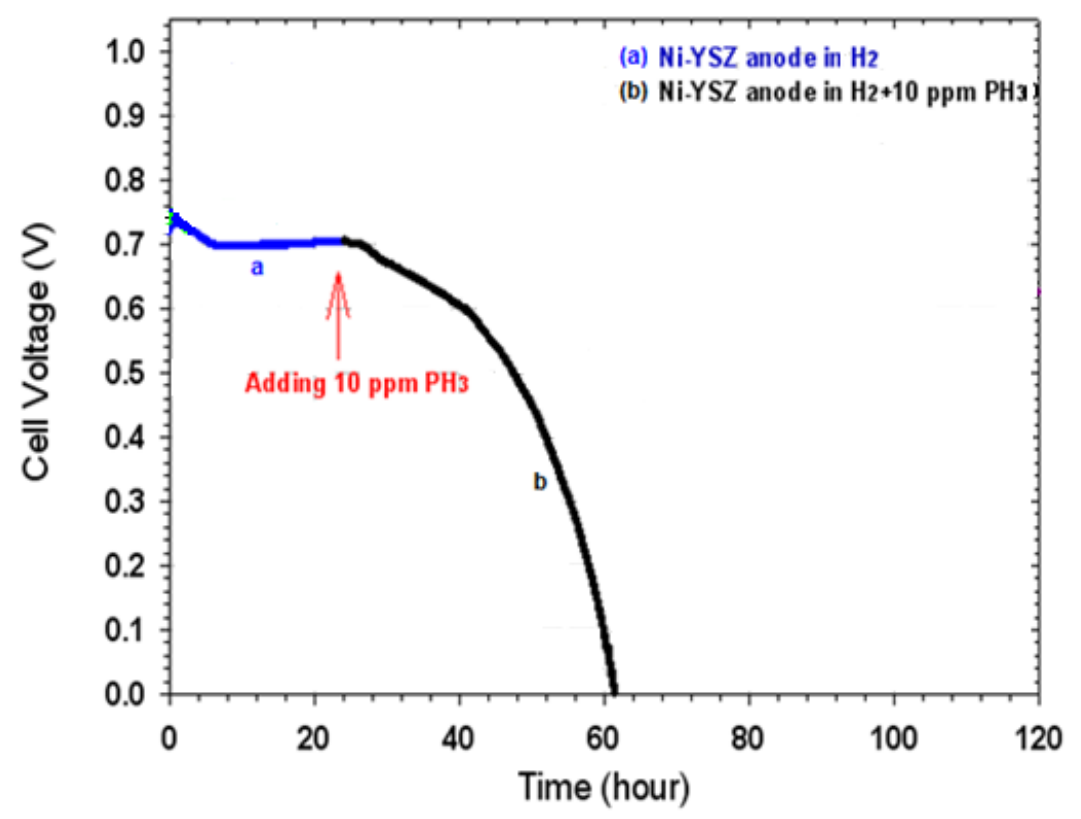

Figure 14: Ni/YSZ anode in response to $10 \mathrm{ppm} \mathrm{PH}_{3}$.

With this test, degradation to the cell was observed immediately following introduction of $10 \mathrm{ppm} \mathrm{PH}_{3}$. This is a similar trend to those described in the literature review where complete failure is seen within a matter of hours for the electrolyte supported platform.

\subsubsection{Conclusions}

There are a few conclusions for the baseline Ni/YSZ anode testing that can be drawn. The first is the importance of a barrier layer for our thick electrolyte supported platform to generate adequate power. Power densities in excess of $300 \mathrm{~mW}-\mathrm{cm}^{-2}$ in wet $\mathrm{H}_{2}$ were seen with the $5 \mu \mathrm{m}$ barrier layer which is competitive with other fuel cell groups given the cell geometry. Power densities in excess of $200 \mathrm{~mW}-\mathrm{cm}^{-2}$ were also achieved in a clean syngas environment, though low concentrations of $\mathrm{H}_{2} \mathrm{~S}$ and $\mathrm{PH}_{3}$ impurities have irreversible impact on the anode as anticipated. This line of testing successfully served to validate findings from previous work and to establish that the testing protocol was sound. 


\subsection{Ni/GDC Anode Testing}

\subsubsection{Experimental Procedure}

\subsubsection{Cell Fabrication}

Cell fabrication and layer dimensions for the Ni/GDC cell were similar to that of the $\mathrm{Ni} / \mathrm{YSZ}$ anode with the following exceptions: the anode sintering condition was found to be $1250^{\circ} \mathrm{C}$ for 2 hours and two different GDC compositions $\mathrm{Gd}_{0.1} \mathrm{Ce}_{0.9} \mathrm{O}_{2}$ (GDC-10) and $\mathrm{Gd}_{0.2} \mathrm{Ce}_{0.8} \mathrm{O}_{2}$ (GDC-20) were synthesized using a co-precipitation method for comparative purposes. The first layer for the anode was a $5 \mu \mathrm{m}$ GDC barrier (printed with a 400 mesh screen) that was sintered onto the YSZ electrolyte at $1400^{\circ} \mathrm{C}$ for $2 \mathrm{~h}$. The active layer was a $50 / 50 \mathrm{wt}-\%$ mixture of $\mathrm{Ni}$ and GDC-10 that was mixed in a polypropylene jar on a mill for 2 hours, dried and sieved, and finally printed as a $10 \mu \mathrm{m}$ layer using a 325 mesh screen. The same procedure was carried out for the current collection layer, which was a 70/30 wt-\% mixture of Ni and GDC. A 230 mesh screen was used and 2 layers were printed and dried to obtain a $40 \mu \mathrm{m}$ total thickness.

\subsubsection{Cell Test Setup}

For testing $\mathrm{H}_{2}$ fuel with the $\mathrm{H}_{2} \mathrm{~S}$ impurity, $\mathrm{H}_{2}$ was humidified with $3 \%$ water (wet $\mathrm{H}_{2}$ ). For testing syngas fuel with the $\mathrm{H}_{2} \mathrm{~S}$ impurity, the syngas was blended with a composition of $\mathrm{H}_{2}$ $34 \%, \mathrm{CO} 31 \%$, and $\mathrm{CO}_{2} 19 \%$ from commercial cylinders. The $\mathrm{H}_{2}$ passed through a temperaturecontrolled water humidifier where it adds up to $16 \% \mathrm{H}_{2} \mathrm{O}$ to the syngas. Prescribed amounts of $2000 \mathrm{ppm} \mathrm{H}_{2} \mathrm{~S}$ in $\mathrm{H}_{2}$ were blended with the syngas or wet $\mathrm{H}_{2}$ to achieve the desired $\mathrm{H}_{2} \mathrm{~S}$ concentration. A platinum reference electrode was incorporated in one of the cell tests. Platinum ink was printed on the cathode side of the electrolyte about $0.5 \mathrm{~mm}$ away from the edge of the cathode electrode. The reference electrode was approximately $0.5 \mathrm{~mm}$ wide and $2 \mathrm{~mm}$ long. The cell contacts were made by using $6 \times 50 \mathrm{~mm}$ platinum mesh ( 80 mesh woven) strips fastened with platinum paste on the cathode and nickel paste on the anode (Figure 15a). The cell was mounted between two alumina flanges with mica washes serving as pressed seals on either side of the cell (Figure 15b). 


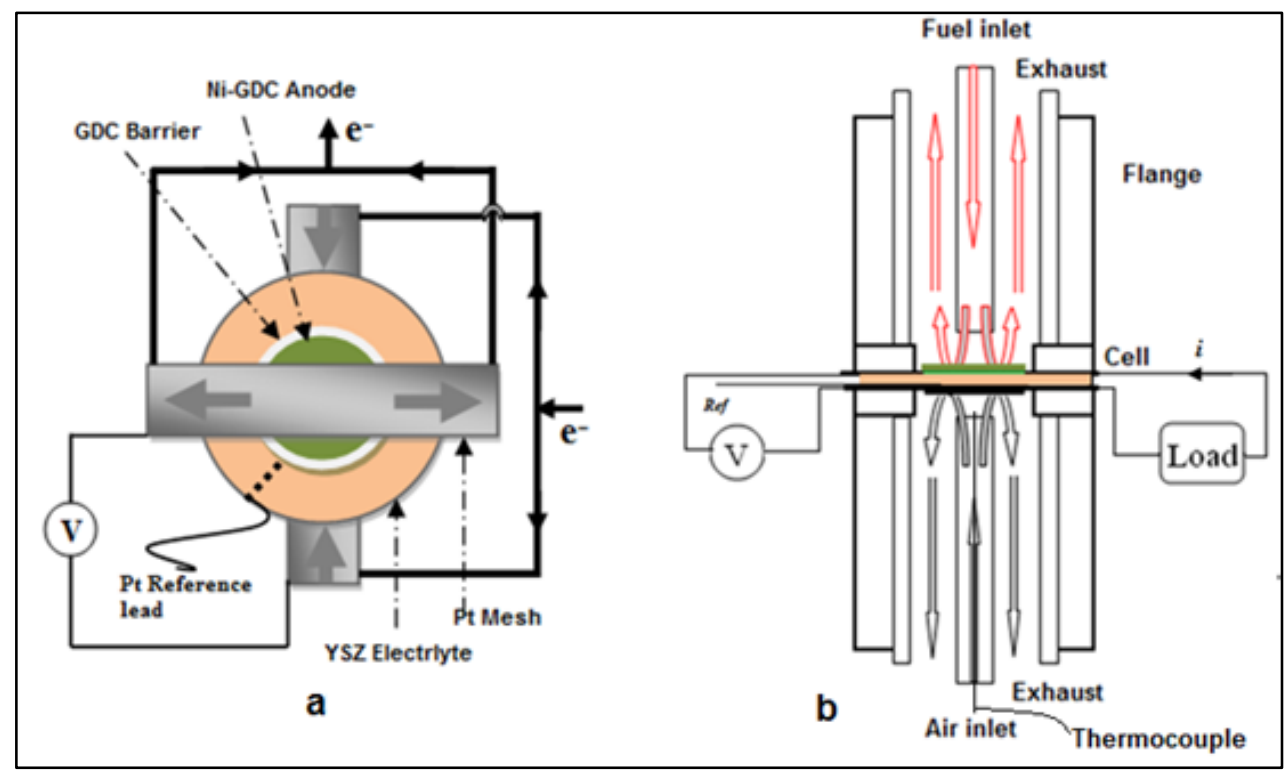

Figure 15: (a) The cell contact configuration and (b) the cell testing setup diagram [112].

Each end of the Pt mesh on an electrode was soldered to a thick sliver wire for the current-collection lead and to a thin silver wire for the voltage-sensing lead. A thin gold wire was contacted with gold paste to the Pt reference electrode pad at the edge of the electrolyte.

The cell was heated to $800^{\circ} \mathrm{C}$ at a heating rate of $2^{\circ} \mathrm{C}$ per minute while flowing $50 \mathrm{SCCM}$ $\mathrm{N}_{2}$ on the anode and air on the cathode. After the cell temperature reached $800^{\circ} \mathrm{C}$, the flow to the cell anode was shifted to $10 \% \mathrm{H}_{2}$ in $\mathrm{N}_{2}$ for $1 \mathrm{~h}$, then $50 \% \mathrm{H}_{2}$ and $\mathrm{N}_{2}$ for another $2 \mathrm{~h}$. A constant current density of $200 \mathrm{~mA} \mathrm{~cm}^{-2}$ was loaded on the reduced cell with a flow of either $100 \mathrm{SCCM}$ wet $\mathrm{H}_{2}$ or 150 SCCM syngas $\left(\mathrm{H}_{2} 34 \%, \mathrm{CO} 31 \%, \mathrm{CO}_{2} 19 \%\right.$ and $\left.\mathrm{H}_{2} \mathrm{O} 16 \%\right)$ to the anode and 200 SCCM air flow to the cathode. After the cell voltage stabilized for $24 \sim 100 \mathrm{~h}$, the cell polarization curve (V-I curve) and electrochemical impedance spectrum (EIS) were taken as a record of the baseline cell performance. The EIS was collected using a Solartron SI-1287 electrochemical interface and an SI-1252 frequency response analyzer with an $\mathrm{AC}$ amplitude of $10 \mathrm{mV}$ at frequencies ranging from $200 \mathrm{kHz}$ to $0.05 \mathrm{~Hz}$. The constant DC current load was supplied by a solid-state load cell (TDI Transistor Devices SD-1103). $\mathrm{H}_{2} \mathrm{~S}$ was added to the syngas fuel immediately upstream of the furnace. The fuel transport tubes were heat-traced to over $120^{\circ} \mathrm{C}$ to 
prevent $\mathrm{H}_{2} \mathrm{O}$ condensation. After testing, the cell was cooled to room temperature while purging $20 \% \mathrm{H}_{2}$ in $\mathrm{N}_{2}$ to the anode.

The microstructure and chemical composition of the cell anode were examined with a Hitachi S-4700 SEM / EDS. To determine the composition of the anode, an XPS (PHI 5000 VerasProbe XPS Microprobe) with a monochromatic Al K-alpha radiation source $(8.34118 \AA$ ) was employed. Depth profiling was performed over an area of $1 \times 1 \mathrm{~mm}$ by means of $2 \mathrm{keV}$ Argon ion sputtering. High-resolution XPS spectra were subsequently obtained by using a focusing X-ray monochromator with a $100 \mu \mathrm{m}$ spot size. The sputtering rate was determined to be $20 \mathrm{~nm} \mathrm{~min}^{-1}$ with reference to a $\mathrm{Ta}_{2} \mathrm{O}_{5}$ layer [79]. The actual sputtering rate may differ for the Ni samples studied here. Thus, it should be noted that the change in depth (nominal depth) rather than the absolute depth of the surface chemical trace layer was the meaningful metric. A MSK Instruments Inc. Cirrus (LM99) residual gas analysis mass spectrometer was connected to the fuel exhaust to monitor the low concentration of exhaust species.

\subsubsection{Results}

\subsubsection{Ni-GDC-10 Anode with/without a GDC Barrier Layer}

A YSZ electrolyte-supported Ni-GDC-10 anode cell with a $5 \mu \mathrm{m}$ GDC-10 barrier layer (cell-1) between the YSZ electrolyte and the anode active layer was tested in syngas with 100 ppm $\mathrm{H}_{2} \mathrm{~S}$ impurity. Cell-1 showed excellent stability and performance in syngas. The voltage of cell-1 was about $0.756 \mathrm{~V}$ under $200 \mathrm{~mA} \mathrm{~cm}^{-2}$ constant current loading in clean syngas. After adding $100 \mathrm{ppm} \mathrm{H}_{2} \mathrm{~S}$ impurity, the voltage of cell-1 quickly dropped to $0.686 \mathrm{~V}$ and was stable for $220 \mathrm{~h}$. Cell-1 was recovered by removing the $\mathrm{H}_{2} \mathrm{~S}$ and flowing wet $\mathrm{H}_{2}$ for about $30 \mathrm{~h}$. Once the cell voltage returned to $0.756 \mathrm{~V}$, it suddenly dropped to $0.740 \mathrm{~V}$ (see the circled area in Figure 16). 


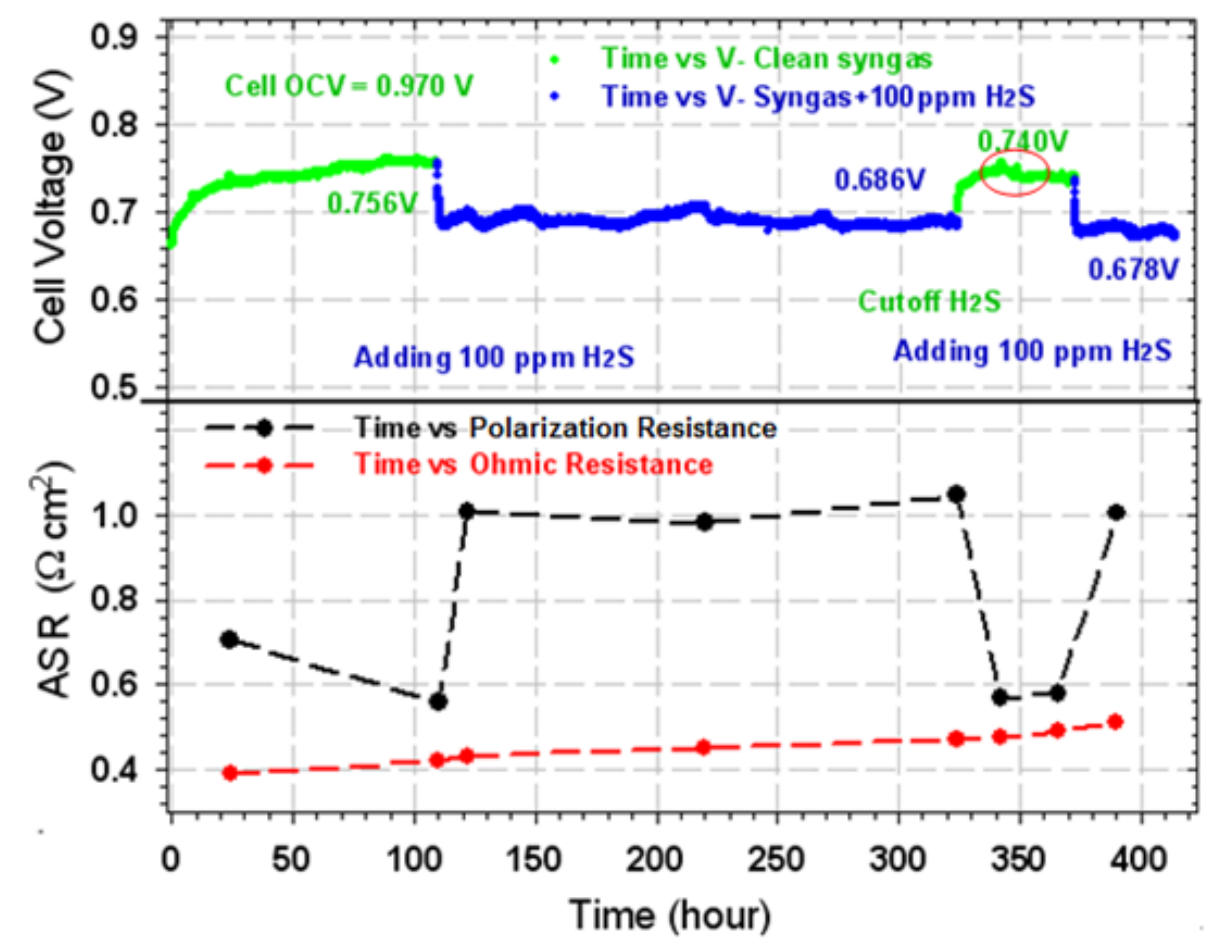

Figure 16: Performance of cell-1 and its area specific resistances (ASR) in clean syngas and syngas with $100 \mathrm{ppm}$ $\mathrm{H}_{2} \mathrm{~S}[112]$.

When the cell voltage leveled off, a second cycle with $100 \mathrm{ppm}_{2} \mathrm{~S}$ in syngas was initiated. The cell voltage dropped to $0.678 \mathrm{~V}$ and stabilized at that point for $40 \mathrm{~h}$ (Figure 16). The ohmic resistance and the polarization resistance of cell-1 derived from impedance spectra are also plotted in Figure 16. The cell ohmic resistance slightly increased with testing time. The cell polarization resistance increased significantly during the periods when $\mathrm{H}_{2} \mathrm{~S}$ was added to the fuel. However, it returned to the original value of $0.685 \Omega \mathrm{cm}^{2}$ after the $\mathrm{H}_{2} \mathrm{~S}$ was removed indicating full cell recovery.

An identical YSZ electrolyte-supported cell with a Ni-GDC-10 anode, but without the GDC-10 barrier layer (cell-2), was tested under similar conditions. As seen in Figure 17, the performance of cell-2 was relatively lower than that of cell-1. 


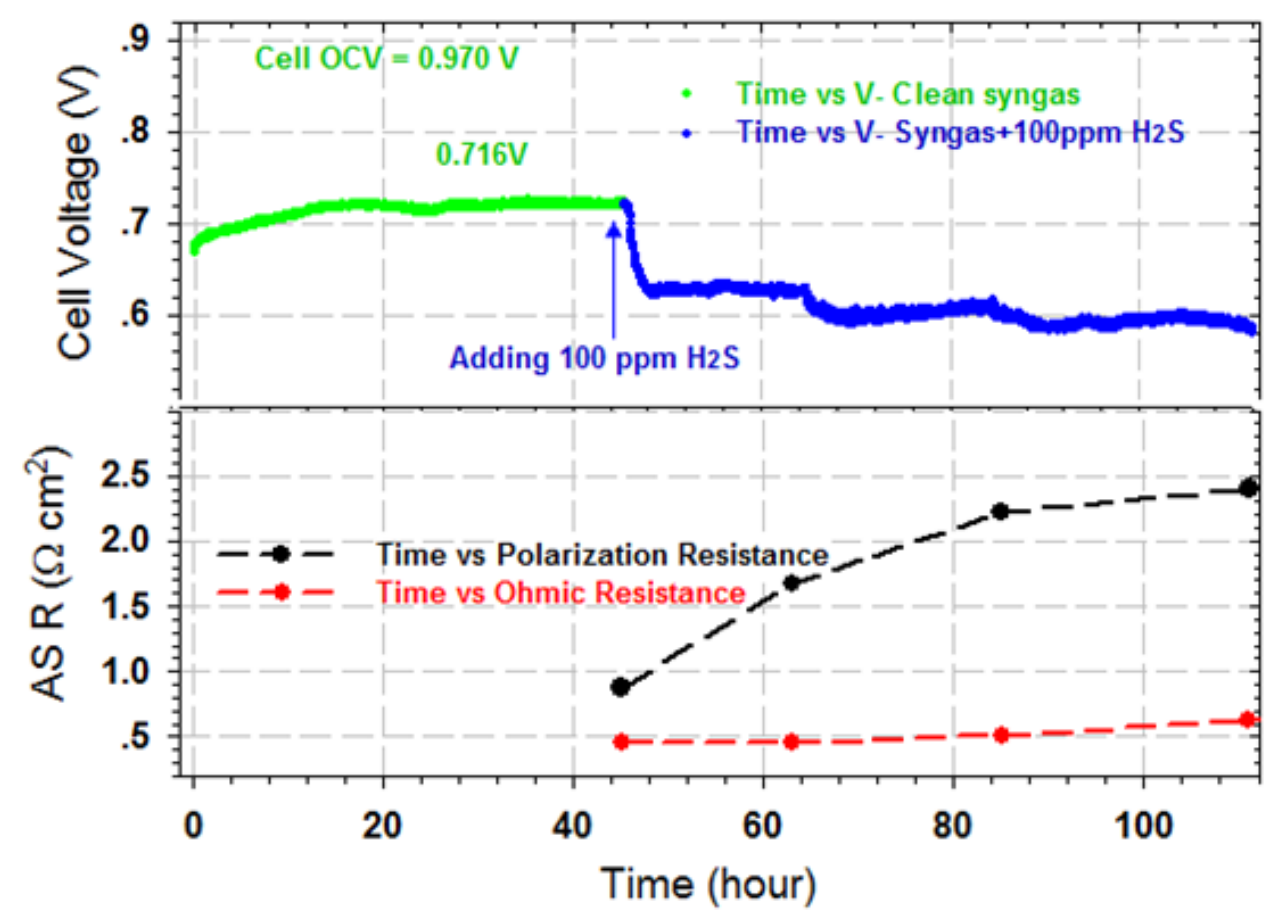

Figure 17: Performance of cell-2 and its area specific resistances (ASR) in clean syngas and synags with $100 \mathrm{ppm}$ $\mathrm{H}_{2} \mathrm{~S}[112]$.

After adding $100 \mathrm{ppm} \mathrm{H}_{2} \mathrm{~S}$ in syngas, the voltage of cell- 2 decreased from $0.716 \mathrm{~V}$ to $0.636 \mathrm{~V}$ during the initial poisoning phase, and then slowly dropped to $0.585 \mathrm{~V}$ over the next 60 h. These two tests confirmed that cell-1, which contained the barrier layer, had significantly higher $\mathrm{H}_{2} \mathrm{~S}$ tolerance than cell-2. Cell-3 which was identical to cell-1 was used to check the limits of the $\mathrm{H}_{2} \mathrm{~S}$ tolerance. Under the same testing conditions as cell-1 and cell-2, cell-3 showed resistance to $100 \mathrm{ppm}_{2} \mathrm{~S}$ in syngas for $6 \mathrm{~h}$, whereupon the cell voltage was recovered after stopping the $\mathrm{H}_{2} \mathrm{~S}$ flow in the syngas for $10 \mathrm{~h}$. (see Figure 18) 


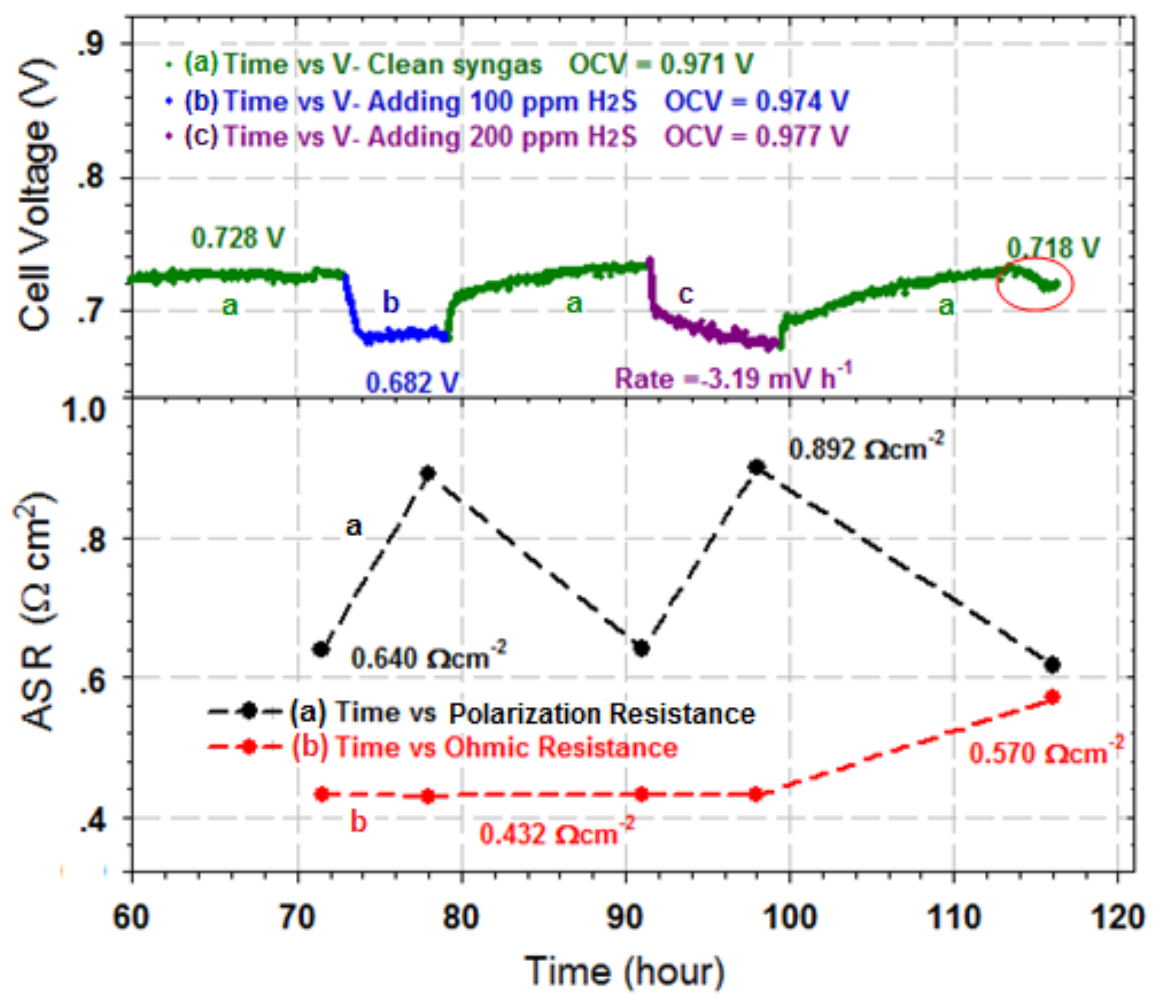

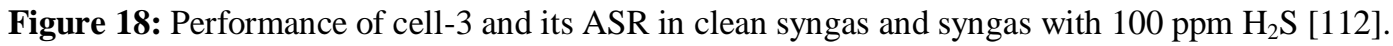

When the $\mathrm{H}_{2} \mathrm{~S}$ concentration was increased to $200 \mathrm{ppm}$ in the syngas, the cell continually lost voltage at a rate of $0.319 \mathrm{mV} \mathrm{h}^{-1}$ during the next $9 \mathrm{~h}$. Although the cell was recovered to the original voltage of $0.728 \mathrm{~V}$, the cell suddenly dropped $15 \mathrm{mV}$ at the end of test (see the circled area in Figure 18). The cell ohmic resistance rapidly increased from 0.432 to $0.570 \Omega \mathrm{cm}^{2}$ during the final recovery period. The Ni-GDC-10 anode with the GDC-10 barrier layer has excellent tolerance for $100 \mathrm{ppm}_{2} \mathrm{~S}$ in syngas. However, when the $\mathrm{H}_{2} \mathrm{~S}$ concentration was increased to $200 \mathrm{ppm}$, the cell tolerance to $\mathrm{H}_{2} \mathrm{~S}$ reached its limit.

To measure the impedance change of the anode, cathode and full cell, cell-4, identical to cell-1 except for the reference electrode on the cathode side as discussed above, was tested both in wet $\mathrm{H}_{2}$, and syngas with/without $100 \mathrm{ppm} \mathrm{H}_{2} \mathrm{~S}$. The cell voltage is shown during the different periods-a, b, c of testing in Figure 19. 


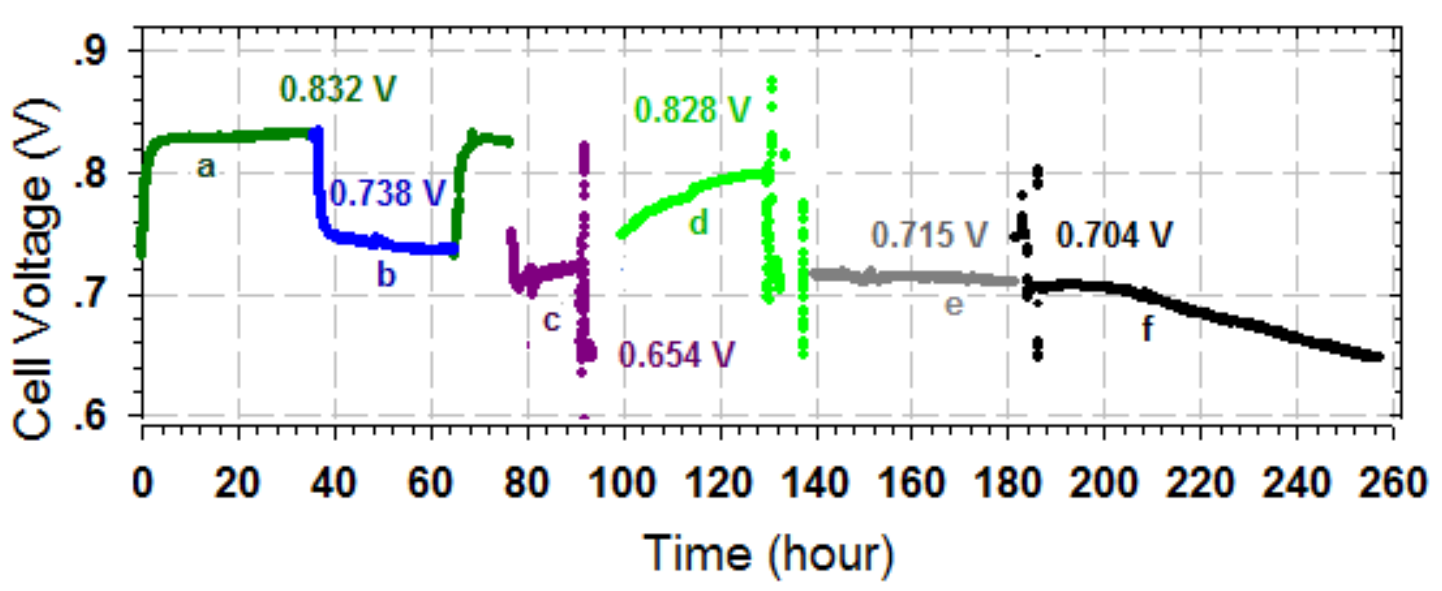

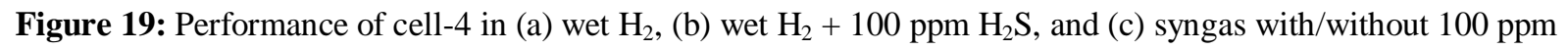
$\mathrm{H}_{2} \mathrm{~S}$ during the first $100 \mathrm{~h}$, then the cell was recovered in $\mathrm{H}_{2}$, and (d) $\mathrm{H}_{2}+\mathrm{N}_{2}, \mathrm{H}_{2}+200 \mathrm{ppm}_{2} \mathrm{~S}$, (e) $\mathrm{H}_{2}+500 \mathrm{ppm} \mathrm{H}_{2} \mathrm{~S}$ and (f) $\mathrm{H}_{2}+1000$ ppm $\mathrm{H}_{2} \mathrm{~S}$ testing [112].

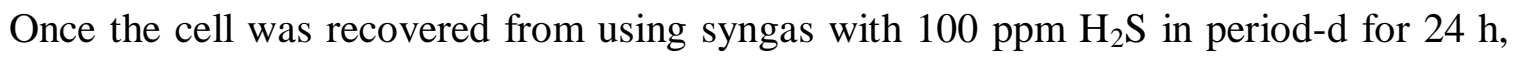
impedance data were obtained from the cell tested in dry $\mathrm{H}_{2}$ with 100, 200, 500 and 1000 ppm $\mathrm{H}_{2} \mathrm{~S}$ concentration and $84 \%, 75 \%, 50 \%, 25 \%$ and $16 \% \mathrm{H}_{2}$ diluted with $\mathrm{N}_{2}$ at 130 hours and 140 hours respectively. Finally, cell-4 exhibited stable operation for 40 h. in dry $\mathrm{H}_{2}$ with 500 ppm $\mathrm{H}_{2} \mathrm{~S}$ which is an $\mathrm{H}_{2} \mathrm{~S}$ impurity level 5 times higher than that tested in syngas (Figure 19e). When the $\mathrm{H}_{2} \mathrm{~S}$ level was raised to $1000 \mathrm{ppm}$ in dry $\mathrm{H}_{2}$, the cell started gradually to lose its performance (Figure 19f). Details of the behavior of this cell are discussed below.

\subsubsection{Ni-GDC-20 Anode with a GDC Barrier Layer}

Increasing the gadolinium doping level in the GDC may change the $\mathrm{H}_{2} \mathrm{~S}$ tolerance of the Ni-GDC anode. GDC-20 was used to modify the Ni-GDC anode in both the active layer and the current collector. A cell (cell-5) with a Ni-GDC-20 anode and a GDC-10 barrier layer was tested by exposure to wet $\mathrm{H}_{2}$ with up to $1000 \mathrm{ppm} \mathrm{H}_{2} \mathrm{~S}$ at $800^{\circ} \mathrm{C}$ under $200 \mathrm{~mA} \mathrm{~cm}^{-2}$ current density load. The results showed that the cell could resist up to about $500 \mathrm{ppm} \mathrm{H}_{2} \mathrm{~S}$ in wet $\mathrm{H}_{2}$ fuel. The cell voltage started its constant decline after the addition of $1000 \mathrm{ppm}_{2} \mathrm{~S}$ (Figure 20). 


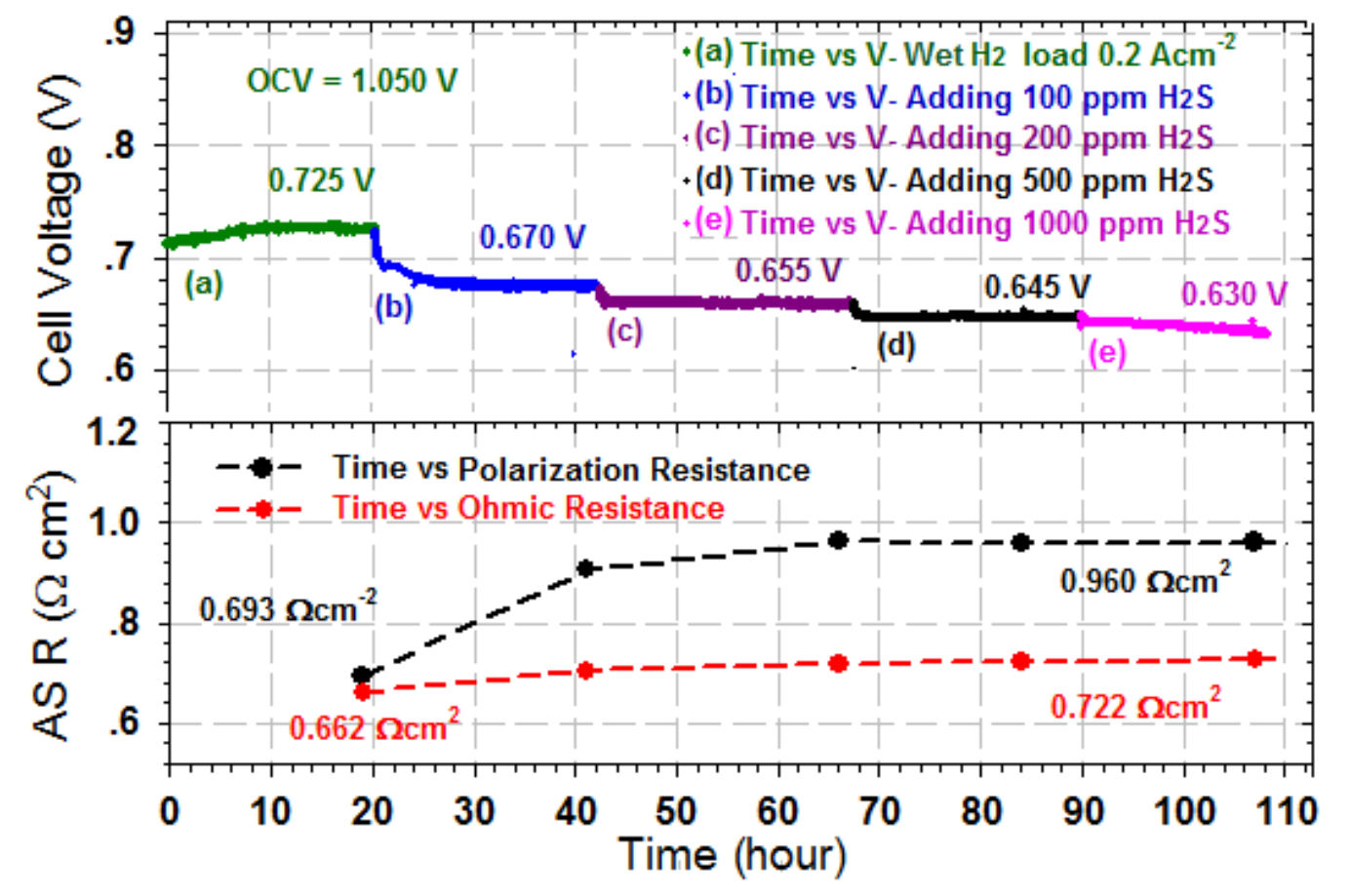

Figure 20: The voltage and ASR of cell-5 versus testing time [112].

The cell ohmic and polarization resistances remained constant at all $\mathrm{H}_{2} \mathrm{~S}$ levels. Another cell (cell-6) with an identical Ni-GDC-20 anode and a GDC-20 barrier layer was tested in wet $\mathrm{H}_{2}$ for comparison. This cell showed a relatively higher tolerance to $1000 \mathrm{ppm}_{2} \mathrm{~S}$ in wet $\mathrm{H}_{2}$. The cell ohmic resistance was stable after adding $\mathrm{H}_{2} \mathrm{~S}$ for the entire $220 \mathrm{~h}$ period. The cell polarization resistance increased slightly after adding $1000 \mathrm{ppm}_{2} \mathrm{~S}$ for $70 \mathrm{~h}$ which caused a 20 $\mathrm{mV}$ voltage drop in the cell (Figure 21). 


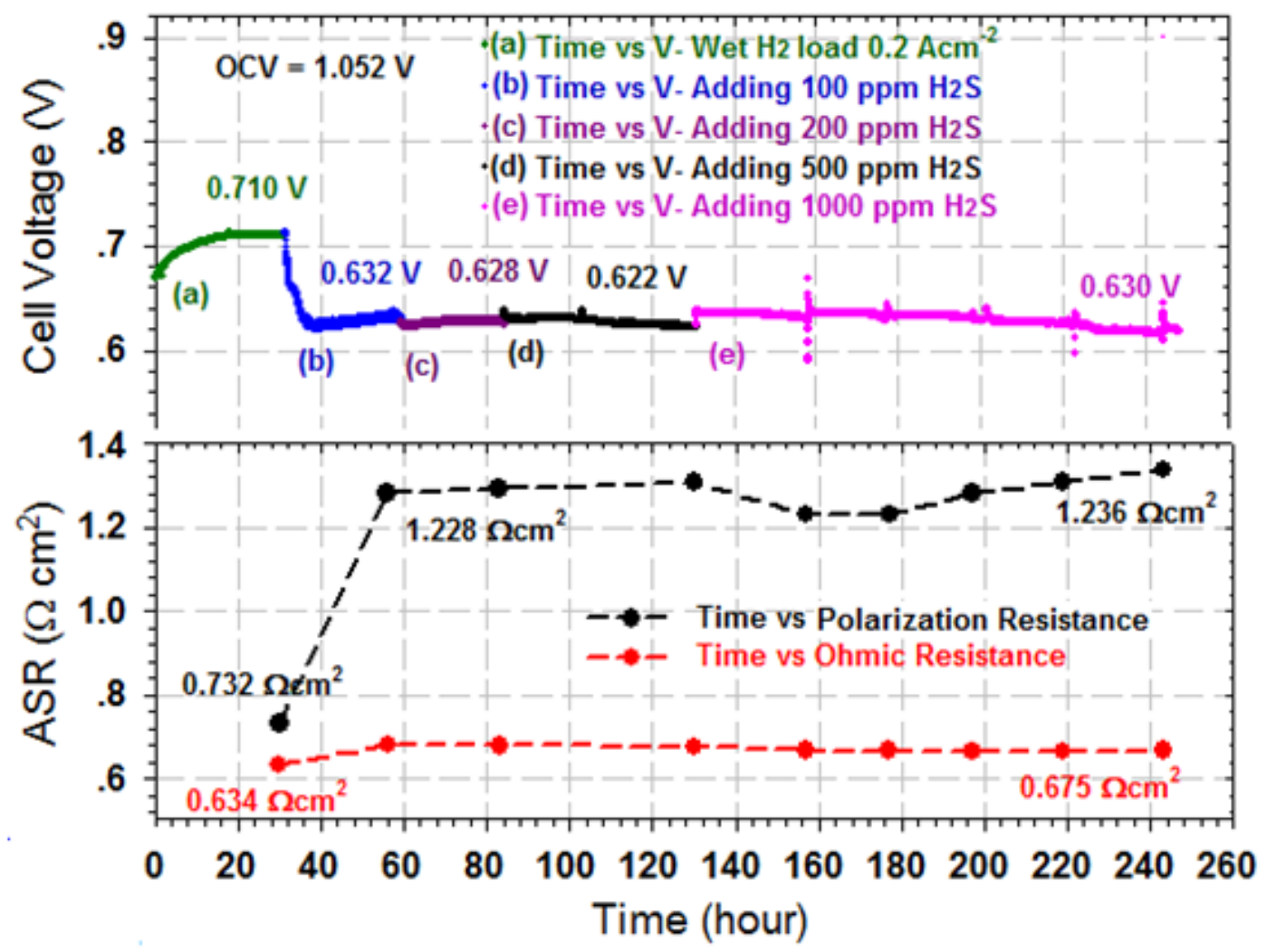

Figure 21: The cell voltage and ASR versus testing time of cell-6 (with the Ni-GDC-20 barrier layer in the anode) [112].

These two tests have a common result which is that the cell ohmic resistance did not significantly increase as a result of $\mathrm{H}_{2} \mathrm{~S}$ addition. There are however a few important differences between cell-5 and cell-6. Cell-5, with a GDC-10 barrier layer, exhibited superior performance than that of cell-6. Additionally, the initial drop in voltage upon $100 \mathrm{ppm}_{2} \mathrm{~S}$ introduction is greater for cell-6. The increase in polarization resistance seen from adding $100 \mathrm{ppm}_{2} \mathrm{~S}$ was only $\sim 0.25 \Omega \mathrm{cm}^{2}$ for cell 5 , while cell-6 saw an increase in polarization resistance of $\sim 0.5 \Omega \mathrm{cm}^{2}$. The changes to the cell polarization resistance are not unlike those seen by Zhang et al [10] and Zha et al [39] with similar anode architectures. This suggests that while there is slightly improved tolerance to high levels of $\mathrm{H}_{2} \mathrm{~S}$ for the GDC-20 barrier layer, the tradeoff comes in the form of decreased power density. After the tests, each cell was cooled to room temperature with a purge of $30 \% \mathrm{H}_{2}$ in $\mathrm{N}_{2}$ over $4 \mathrm{~h}$ and then subjected to post-mortem examination. 


\subsubsection{Reference Electrode and Cell Impedance}

A reference electrode was incorporated in cell-4 to monitor the change of anode and cathode impedances with and without $100 \mathrm{ppm} \mathrm{H}_{2} \mathrm{~S}$ in the fuels. The impedance of the cathode electrode was measured between the platinum reference on the cathode side of the electrolyte surface and the cathode current collector. The impedance of the anode electrode and YSZelectrolyte was measured between the same platinum reference and the anode current collector. Figures 22 and 23 show the resulting impedance data for the entire cell with the Ni-GDC-10 anode and the GDC-10 barrier layer of cell-4 with and without $100 \mathrm{ppm} \mathrm{H}_{2} \mathrm{~S}$ in wet $\mathrm{H}_{2}$ (curve-e and curve-a).

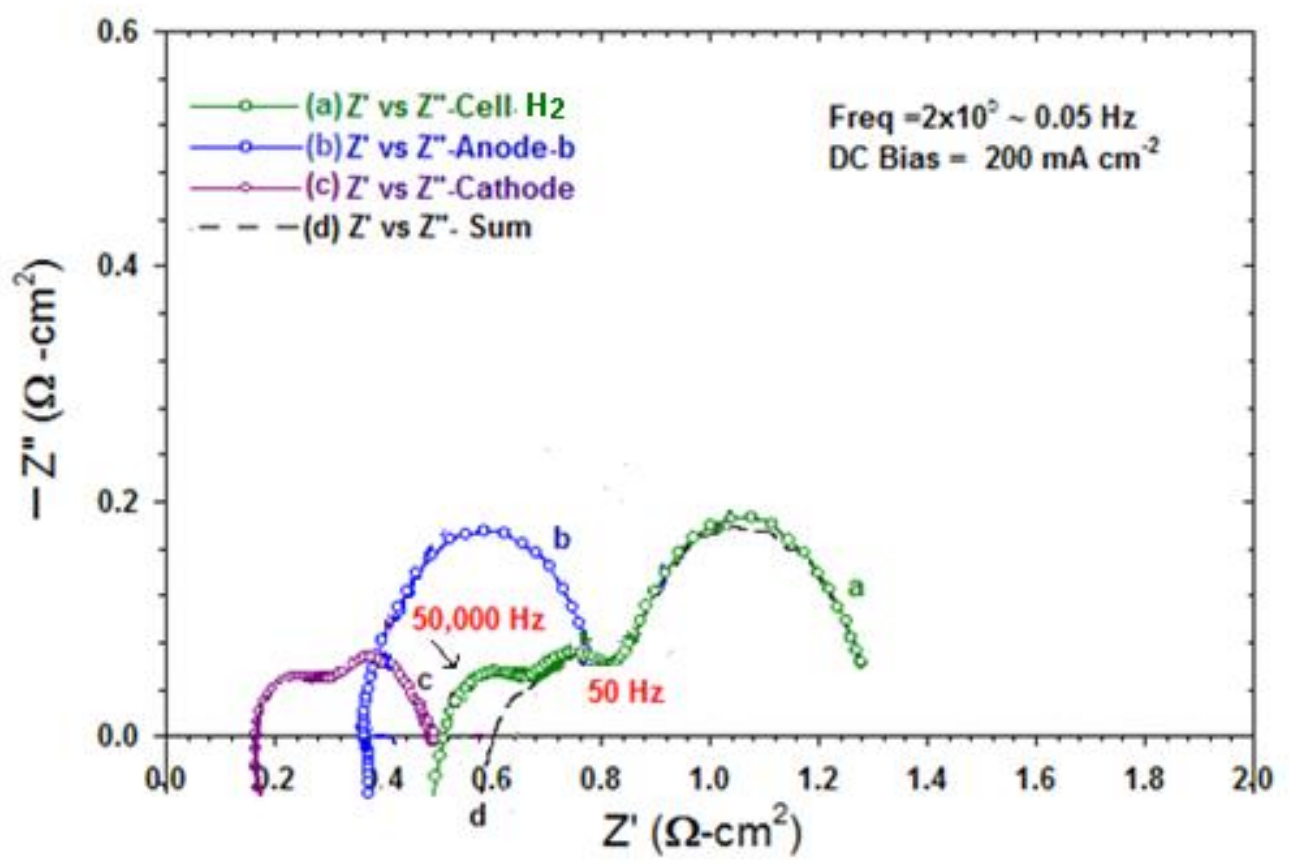

Figure 22: The impedance spectra of cell-4 under $200 \mathrm{~mA} \mathrm{~cm}{ }^{-2}$ current bias in wet $\mathrm{H}_{2}$. 


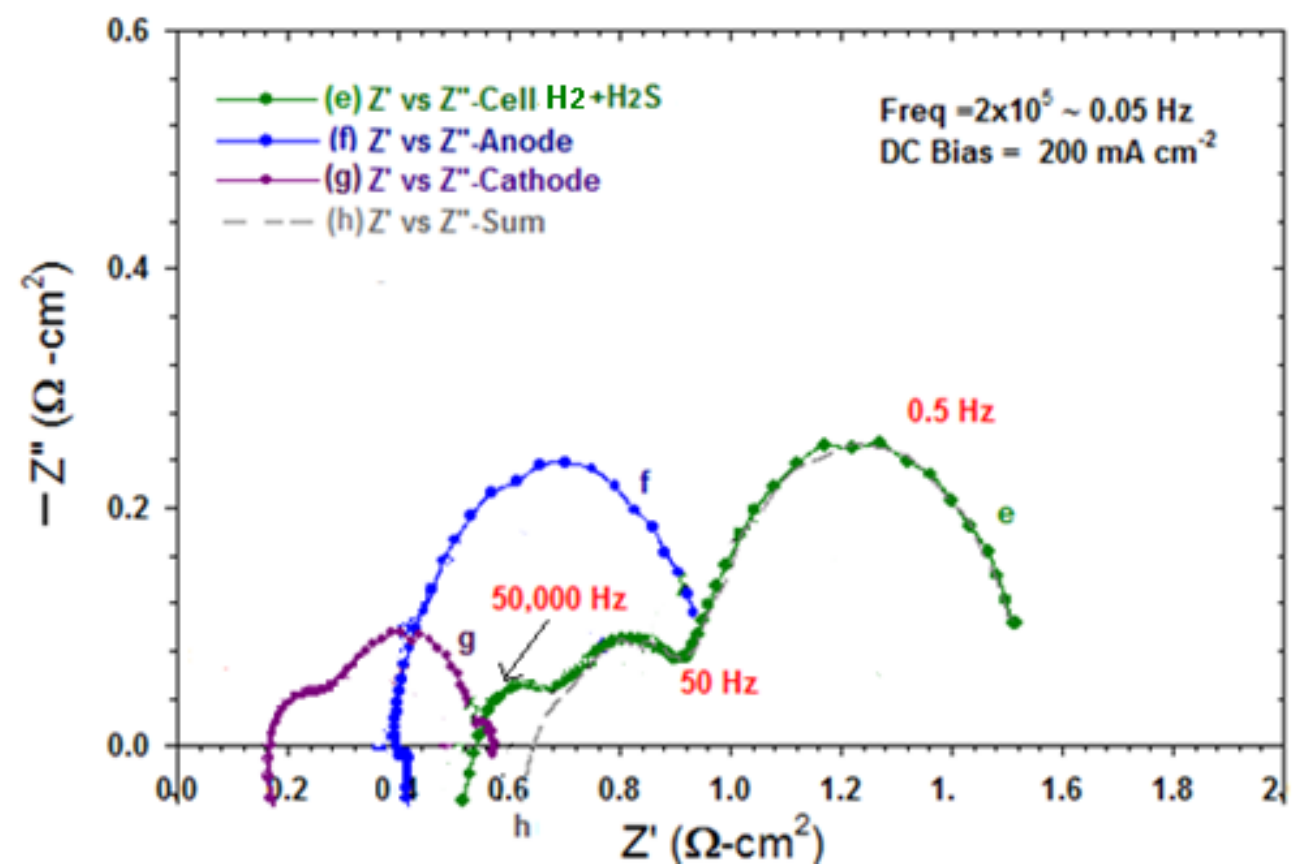

Figure 23: The impedance spectra of cell-4 under $200 \mathrm{~mA} \mathrm{~cm}^{-2}$ current bias in wet $\mathrm{H}_{2}$ with $100 \mathrm{ppm}_{2} \mathrm{~S}$.

The anode polarization resistance in the low frequency range from $50 \mathrm{~Hz}$ to $0.05 \mathrm{~Hz}$ (curve-f and curve-b) significantly increased after the addition of $100 \mathrm{ppm}_{2} \mathrm{~S}$ to the wet $\mathrm{H}_{2}$. The cell cathodic impedance did have a notable change in the high frequency range as seen in curve-g and curve-c (>10000 Hz). The impedance data of curve-h and curve-d are the sum of the anodic and cathode impedances under the exact same frequency for the case of wet $\mathrm{H}_{2}$ with and without $\mathrm{H}_{2} \mathrm{~S}$ respectively. From Table 3 , it can be seen that the change of the cell ohimc resistance, $R_{\Omega}$, is relatively small compared to that of the total polarization resistance, $R_{\text {total }}$,

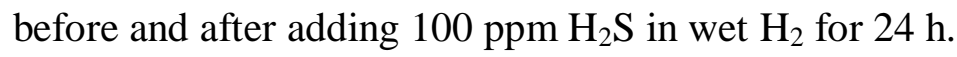


Table 3: Summary of the impedance spectra for cell-4 in $\mathrm{H}_{2}$ and clean syngas [112]

\begin{tabular}{|c|c|c|c|c|c|c|c|c|}
\hline \multirow{2}{*}{$\begin{array}{l}\text { Impedance Source \& } \\
\text { Fuel } \\
\mathrm{H}_{2}+3 \% \mathrm{H}_{2} \mathrm{O} \text { Fuel }^{*}\end{array}$} & \multicolumn{3}{|c|}{$\begin{array}{l}\text { Olmic } \\
R_{Q}\left(\Omega \mathrm{cm}^{2}\right)\end{array}$} & \multicolumn{3}{|c|}{$\begin{array}{l}\text { Total Polarization } \\
R_{p}\left(\Omega \mathrm{cm}^{2}\right)\end{array}$} & \multirow{2}{*}{\multicolumn{2}{|c|}{$\begin{array}{l}\text { Frequency } \\
\text { Range }(\mathrm{Hz})\end{array}$}} \\
\hline & Clean $^{c}$ & $\mathrm{H}_{2} \mathrm{~S}^{d}$ & $\Delta^{*}$ & Clean & $\mathrm{H}_{2} \mathrm{~S}$ & $\Delta$ & & \\
\hline Anode/Reference. & 0.365 & 0.395 & 0.030 & 0.781 & 0.934 & 0.153 & 64.5 & $50 \sim 0.05$ \\
\hline Cathode/Reference. & 0.165 & 0.168 & 0.003 & 0,492 & 0.572 & 0.080 & 33.5 & $50 \mathrm{k} \sim 0.05$ \\
\hline Sum & 0.601 & 0.657 & 0.056 & 1.274 & 1.509 & 0.235 & 99.2 & $50 \mathrm{k} \sim 0.05$ \\
\hline Full Cell in $\mathrm{H}_{2}$ & 0.517 & 0.540 & 0.026 & 1.279 & 1.516 & 0.237 & 100 & $50 \mathrm{k} \sim 0.05$ \\
\hline Syngas Fuel ${ }^{b}$ & Clean & $\mathrm{H} / \mathrm{S}$ & $\Delta$ & Clean & $\mathrm{H} / \mathrm{S}$ & $\Delta$ & $\Delta \%$ & \\
\hline Anode/Reference. & 0.355 & 0.398 & 0.044 & 0.878 & 1.176 & 0.298 & 67.9 & $50 \sim 0.05$ \\
\hline Cathode/Reference. & 0.166 & 0.178 & 0.012 & 0.513 & 0.643 & 0.133 & 32.1 & $50 \mathrm{k} \sim 0.05$ \\
\hline Sum & 0.613 & 0.666 & 0.053 & 1.388 & 1.819 & 0.431 & 99.2 & $50 \mathrm{k} \sim 0.05$ \\
\hline Full Cell in Syngas. & 0.532 & 0.571 & 0.039 & 1.383 & 1.822 & 0.439 & 100 & $50 \mathrm{k} \sim 0.05$ \\
\hline
\end{tabular}

a. $\mathrm{OCV}=1.063 \mathrm{~V}$. b. $\mathrm{OCV}=0.970 \mathrm{~V}$. c. Without $\mathrm{H}_{2} \mathrm{~S}$ in fuel. d. Addition $100 \mathrm{ppm}_{2} \mathrm{~S}$ in fuel. e. the difference between using clean and $\mathrm{H}_{2} \mathrm{~S}$ addition fuels.

The change of $R_{\text {total }}$ is mainly attributed to the change in the cell polarization portion, $R_{p}$, $\left(R_{p}=R_{\text {total }}-R_{\Omega}\right)$ of the total resistance. According to the impedances of each electrode, about $64.5 \%$ and $33.5 \%$ of the overall increase of the cell $R_{\text {total }}$ is contributed by the increase of anodic and cathodic polarization, respectively. There is about $2 \%$ error introduced from the reference electrode. For the case of syngas, the impedance spectra in figures 24 and 25 with and without $100 \mathrm{ppm} \mathrm{H}_{2} \mathrm{~S}$ showed a similarly increasing behavior as that for the wet $\mathrm{H}_{2}$ as displayed in Figures 22 and 23. 


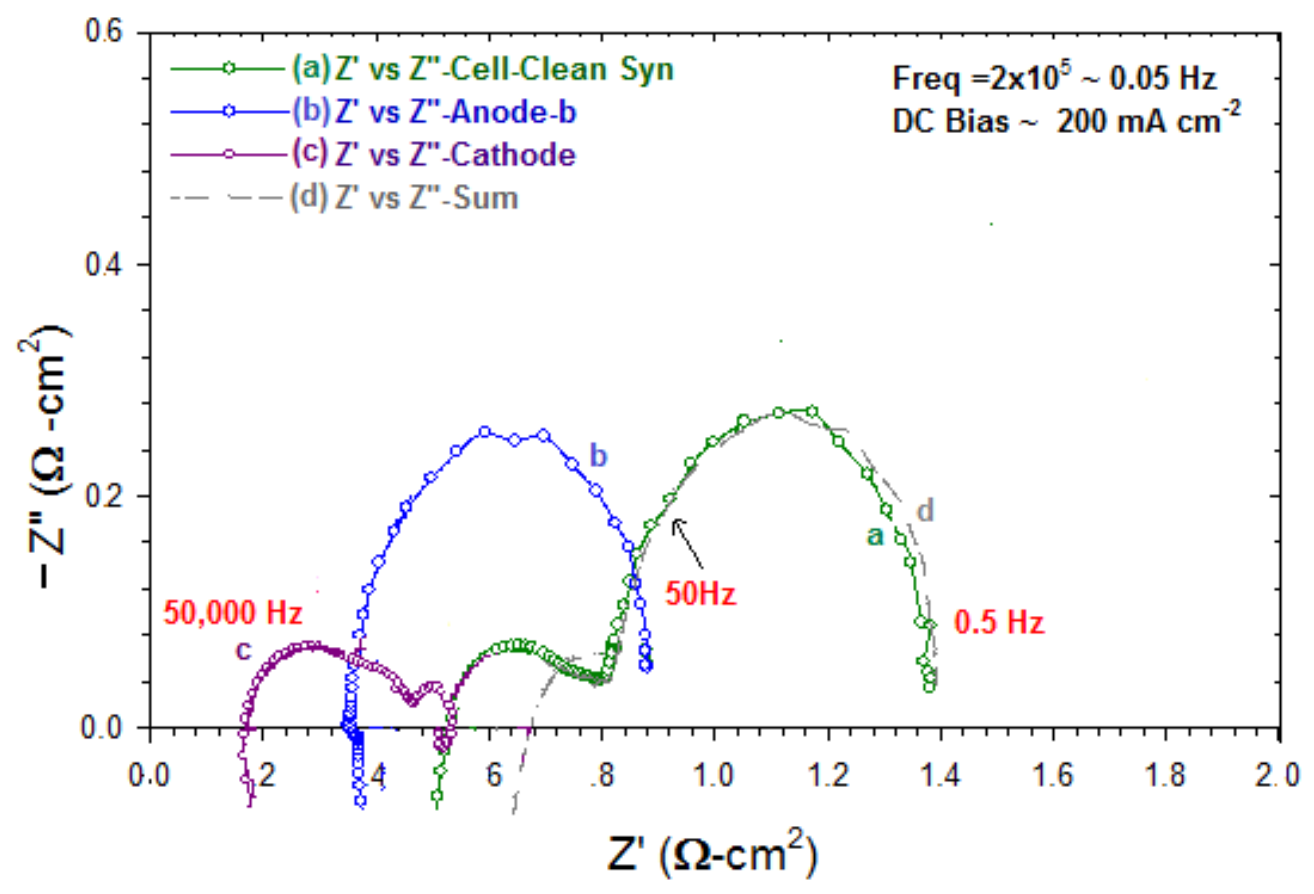

Figure 24: The impedance spectra of cell-4 under $200 \mathrm{~mA} \mathrm{~cm}{ }^{-2}$ current bias in clean syngas.



Figure 25: The impedance spectra of cell-4 under $200 \mathrm{~mA} \mathrm{~cm}^{-2}$ current bias in syngas with $100 \mathrm{ppm}_{2} \mathrm{~S}$. 
The increase of $R_{\text {total }}$ in syngas was larger than the wet $\mathrm{H}_{2}$ case. Both the anodic and cathodic impedances still showed a significant increase of polarization resistance at the lower frequency range which was mostly attributed to an increase of mass transport polarization. This is because the slower processes correspond to lower frequency responses and the large arc in the 0.1-0.5 Hz range would suggest mass diffusion limitations as it is among the slowest processes in a fuel cell.

The changes of overall impedance for cell-4 with increasing $\mathrm{H}_{2} \mathrm{~S}$ concentration (by ppm) in the $\mathrm{H}_{2}$ fuel were measured and plotted in Figure 26.

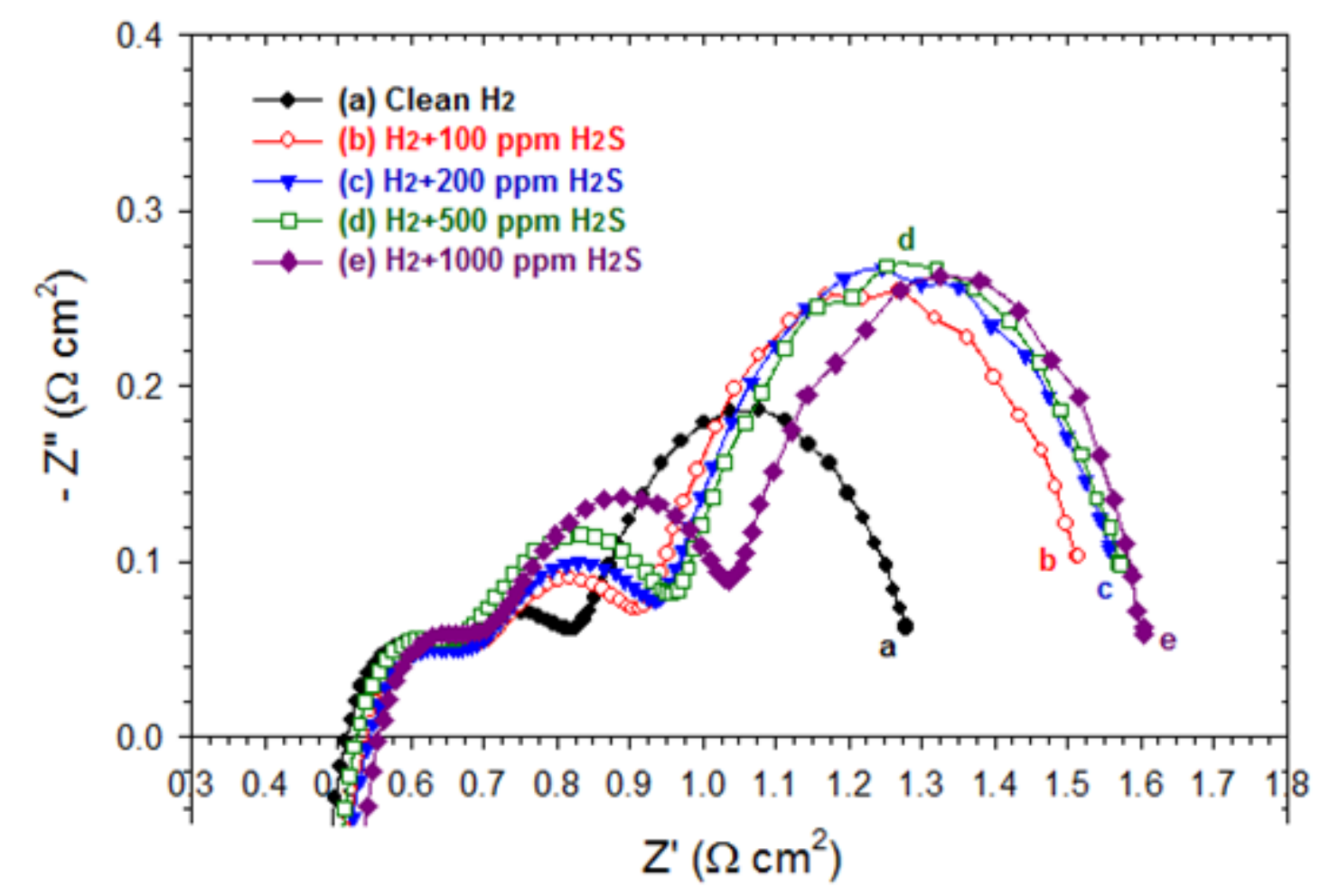

Figure 26: The impedance spectra of cell-4 under $200 \mathrm{~mA} \mathrm{~cm}^{-2}$ current bias in $\mathrm{H}_{2}$ with $0,100 \mathrm{ppm}, 200 \mathrm{ppm}, 500$ ppm and 1000 ppm $\mathrm{H}_{2} \mathrm{~S}$ impurity [112].

Similarly the changes of cell impedance with increasing $\mathrm{N}_{2}$ concentration (by percentage) in the $\mathrm{H}_{2}$ fuel were measured and plotted in Figure 27 for comparison. Both increasing $\mathrm{H}_{2} \mathrm{~S}$ and $\mathrm{N}_{2}$ concentration in the $\mathrm{H}_{2}$ fuel led to an increase in the total polarization resistance, $R_{\text {total }}$, of the cell. However, the increase of $R_{\text {total }}$ with the increasing $\mathrm{H}_{2} \mathrm{~S}$ concentration exhibited a non-linear 
trend which is different from the increase of $R_{\text {total }}$ observed by diluting the $\mathrm{H}_{2}$ fuel with $\mathrm{N}_{2}$ (see Figure 28). The importance of dilution is to try and establish which contribution is related to diffusion in the anode polarization. A comparison of these curves shows that for $\mathrm{N}_{2}$ dilution increases to the polarization are seen primarily with the second arc, which corresponds to concentration or diffusion problems. Whereas for $\mathrm{H}_{2} \mathrm{~S}$ poisoning the changes to the polarization curve are more pronounced with the first arc, or higher frequency processes. In this case, charge transfer problems are likely. So while the quantitative impact of these two variables to the fuel cell performance is similar, the qualitative reasons behind the drops in performance are vastly different.

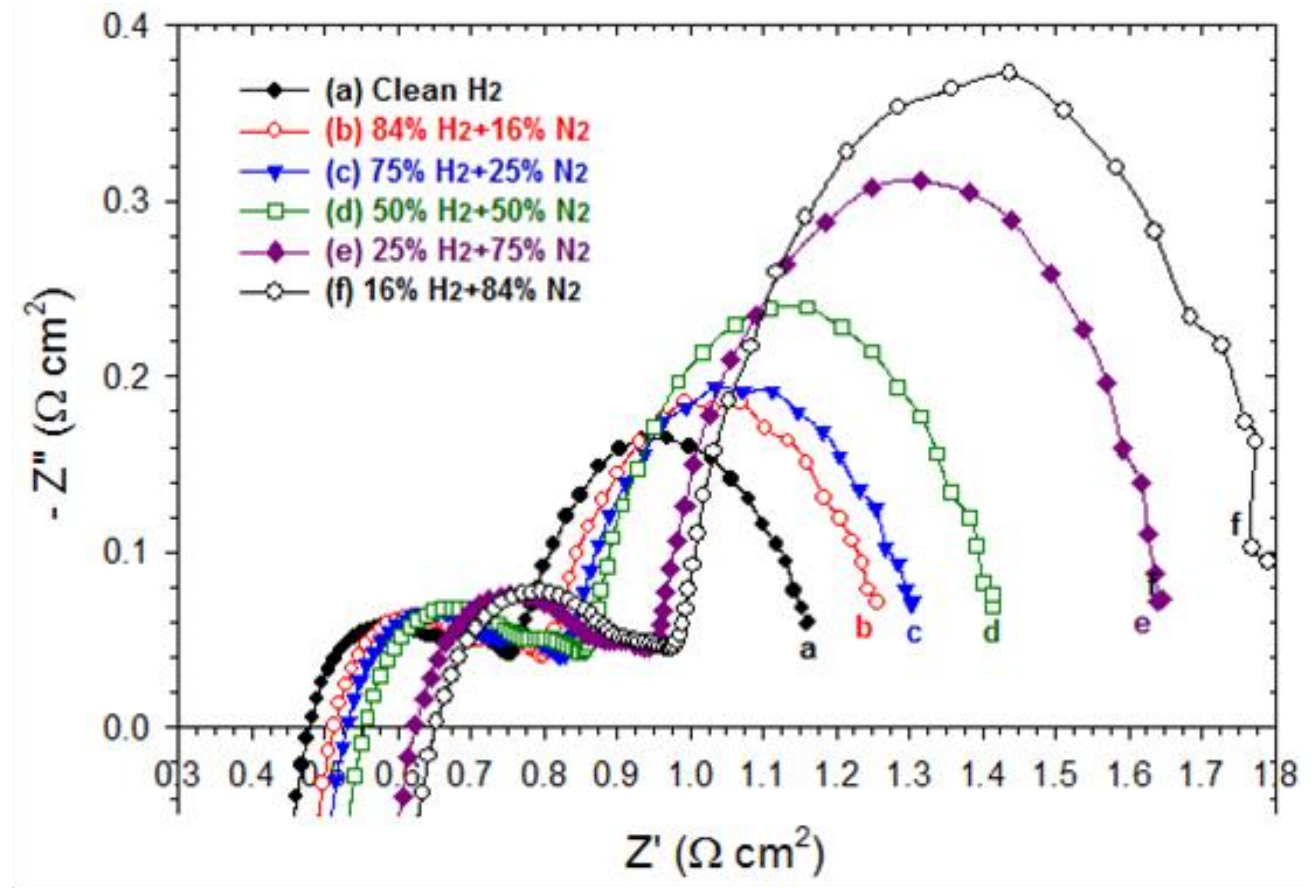

Figure 27: The impedance spectra of cell-4 under $200 \mathrm{~mA} \mathrm{~cm}^{-2}$ current bias in $\mathrm{H}_{2}$ with $0,16 \%, 25 \%, 50 \%, 75 \%$ and $84 \% \mathrm{~N}_{2}[112]$. 


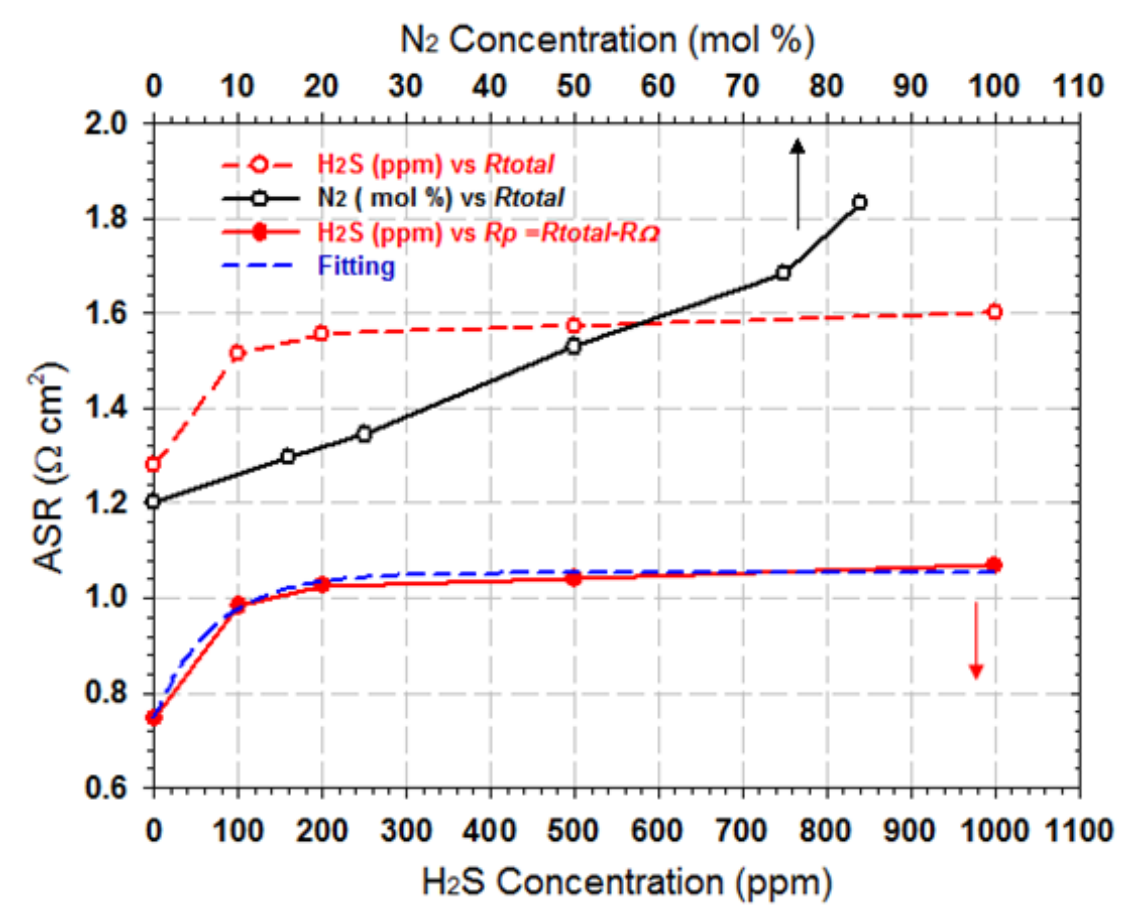

Figure 28: The total polarization resistance $\mathrm{R}_{\mathrm{tp}}$ of the cell- 4 versus $\mathrm{H}_{2} \mathrm{~S}$ concentration (ppm) and $\mathrm{N}_{2}(\mathrm{~mol} \%$ ) concentration in $\mathrm{H}_{2}$ fuel [112].

\subsubsection{Morphology, Structural and Chemical Analysis}

Because cell-6 had been exposed to 1000 ppm $\mathrm{H}_{2} \mathrm{~S}$ in wet $\mathrm{H}_{2}$ for a long-term test without recovery, it was selected for post-mortem analyses. Fig. 13 shows the SEM images of the anode active layer for the $\mathrm{H}_{2} \mathrm{~S}$ - poisoned cell-6 (Figure 29a) compared to a clean reduced anode active layer (Figure 29b). 

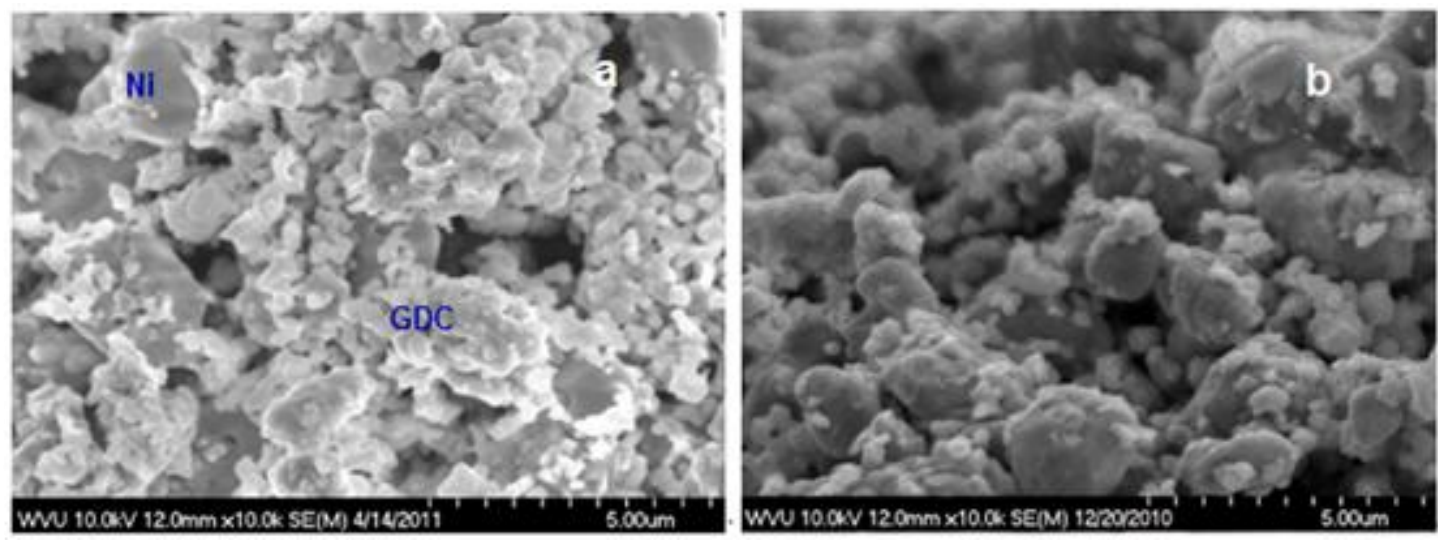

Figure 29: SEM images for cell-6 of (a) the poisoned Ni-GDC in the anode interface, (b) the clean reduced Ni-GDC in the anode interface [112].

The larger particles are $\mathrm{Ni}$ and the small particles are GDC, with approximate particle sizes of $10 \mu \mathrm{m}$ and $2 \mu \mathrm{m}$ respectively. The microstructure in these two images does not show any notable difference. The SEM images of the Ni contact paste of cell-6 on the top of the cell anode for observing the $\mathrm{Ni}$ particle size, grain boundary and $\mathrm{Ni}$ metal surface texture are seen in Figures 30a and 30b. The particle size of the Ni in the Ni paste is about $10 \mu \mathrm{m}$ which matches the size on the $\mathrm{H}_{2} \mathrm{~S}$-poisoned cell image.
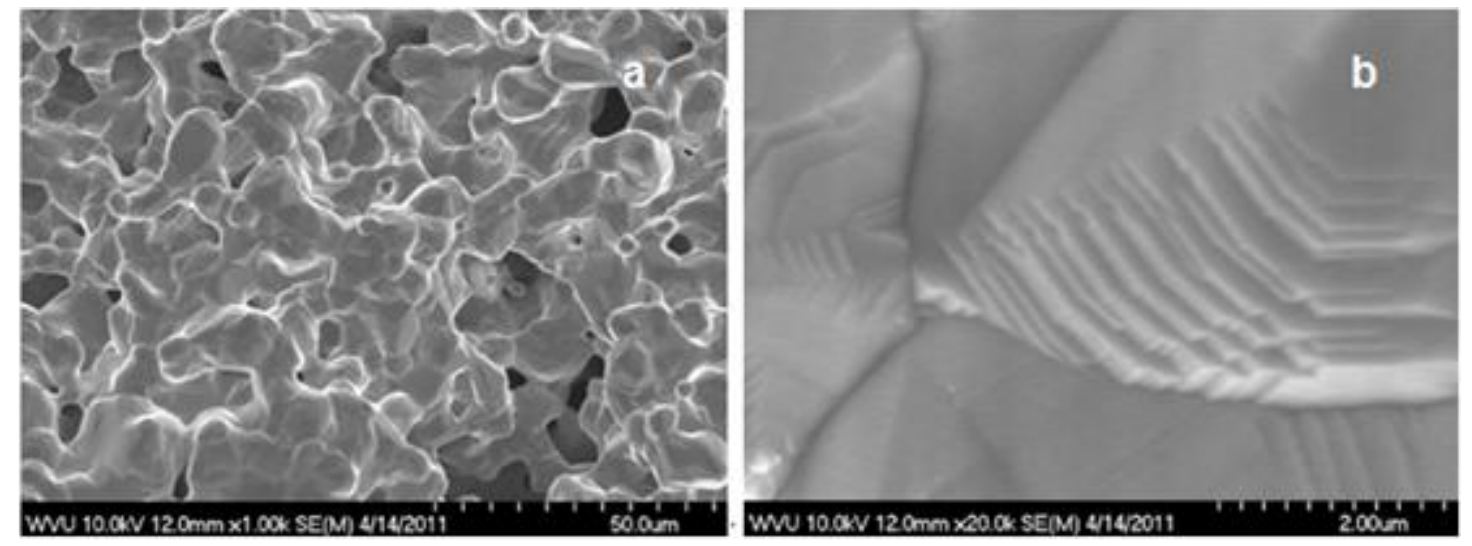

Figure 30: SEM images for cell-6 of the Ni particles in the contact paste on the top surface of the anode: (a) at $1 \mathrm{k}$ magnification and (b) at 20k magnification [112]. 
The clear Ni grain boundary and surface texture imply that there is no significant surface reconstruction on the Ni particle surface. The EDS spectra of the poisoned cell-6 showed that there are sulfur peaks at the cell active layer and GDC particles (Figures 31c and d), but there are no detectable sulfur signals at $2.307 \mathrm{keV}$ on the Ni particles in both the contact paste and the cell anode interface (Figure 31a \& 31b). This h indicates that the sulfur signal is coming from the GDC particles. To detect sulfur traces and changes on the surface of the Ni particles of the poisoned cell, a depth profile of the XPS spectra from the top surface was obtained by using Ar ion sputtering. These pieces of data are shown in Figure 32. Both oxidized S and un-oxidized S signals appeared on the $\mathrm{Ni}$ at the top surface (Figure 32a). But at a distance of $1 \mathrm{~nm}$ under the top surface, the oxidized S peak at 168-170 eV did not exist in the spectrum (Figure 32b).

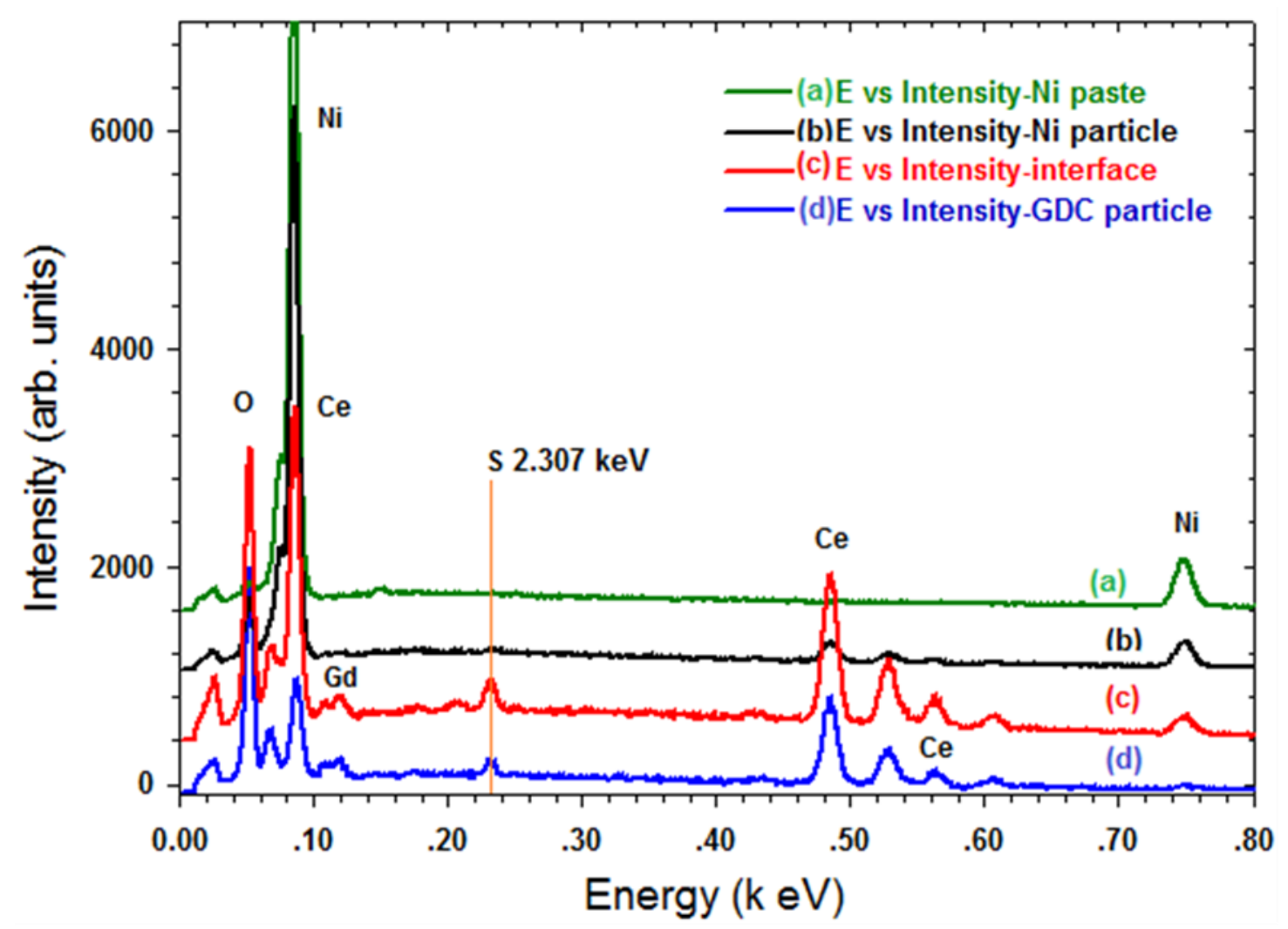

Figure 31: EDS spectra of (a) the Ni paste, (b) Ni particles in the anode interface, (c) Ni-GDC anode interface and (d) GDC particles in the anode interface [112]. 


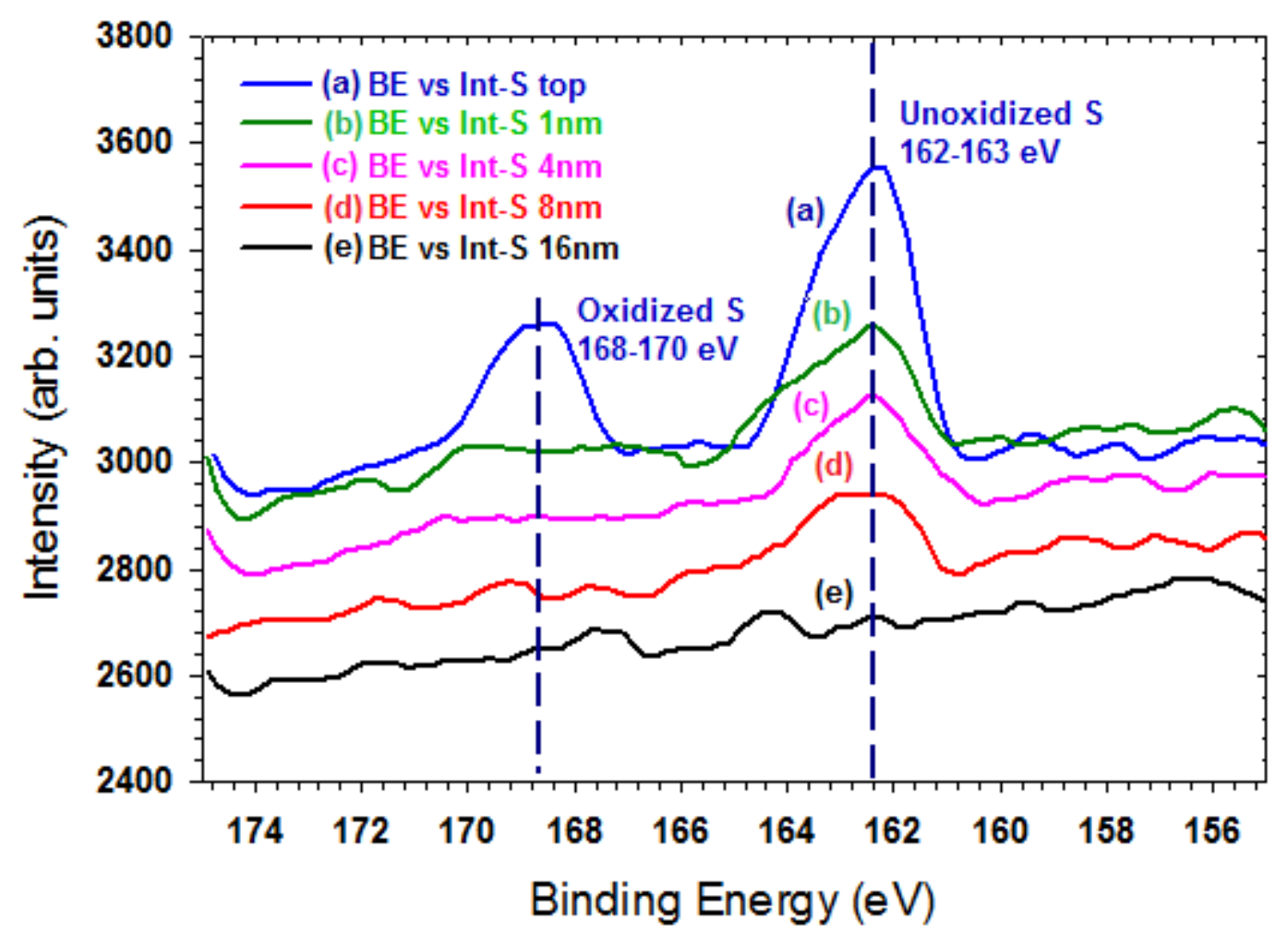

Figure 32: The depth profile of XPS spectra on the Ni surface of the $\mathrm{H}_{2} \mathrm{~S}$ poisoned cell. The oxidized S peak at 169-

$170 \mathrm{eV}$ is only significant on the top Ni surface. The un-oxidized $\mathrm{S}$ peak is detectable at $8 \mathrm{~nm}$ depth from the $\mathrm{Ni}$ surface [112].

Furthermore, Figure 32e shows that the un-oxidized S peak disappeared at about $16 \mathrm{~nm}$ below the top surface. The XPS spectra displayed were smoothed by means of a third-order polynomial. The XPS spectra for the Ni peaks only, Ni $2 \mathrm{p}_{1 / 2}$ and $2 \mathrm{p}_{3 / 2}$, are significant at 869.50 $\mathrm{eV}$ and $852.35 \mathrm{eV}$, respectively. The intensity of the Ni peaks increased with the depth from the top surface (Figure 33). 


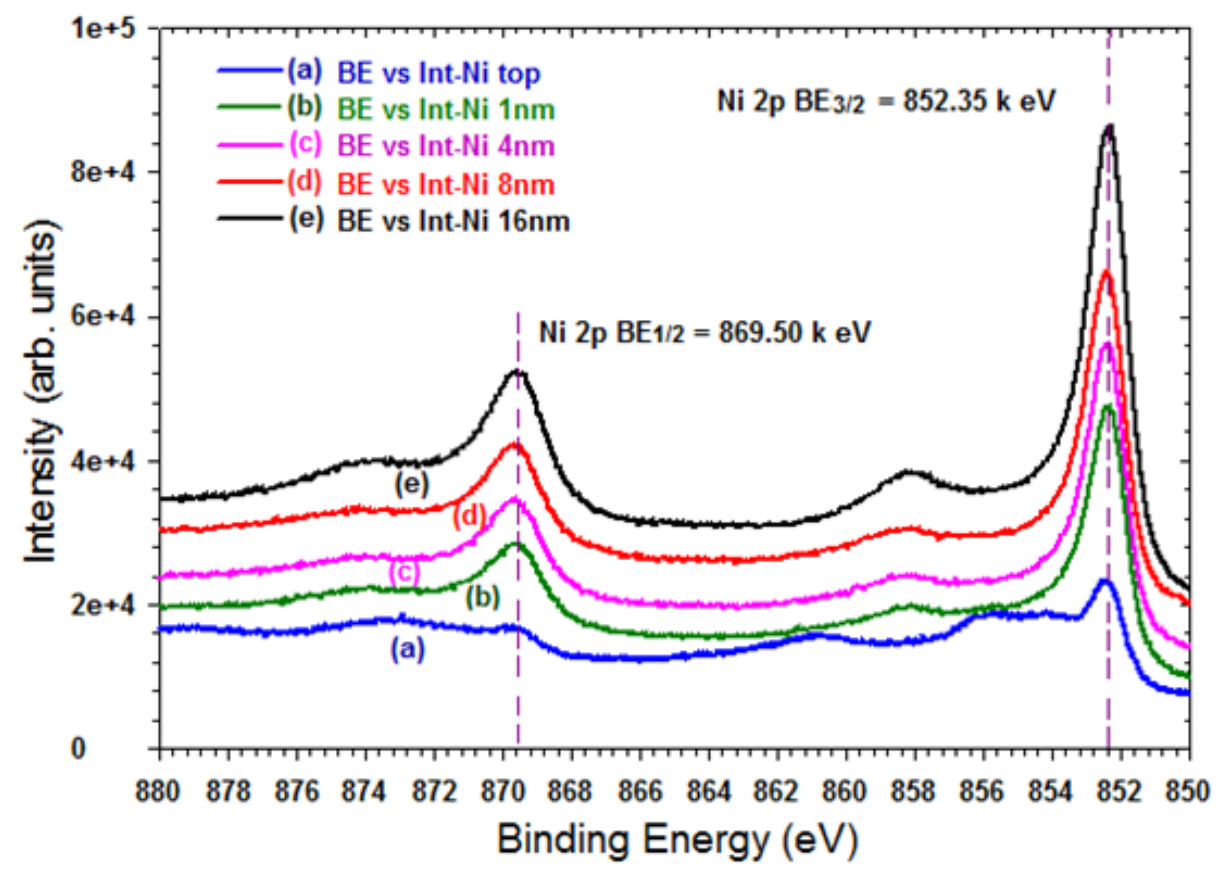

Figure 33: The depth profile of XPS spectra of the $\mathrm{H}_{2} \mathrm{~S}$ poisoned cell Ni surface [112].

However, there was only an oxidized S $2 p$ peak on the GDC barrier layer (Figure 34b). From the observation of the SEM image, and the EDS and XPS spectra of the Ni particles in the anode and the paste, it can be seen that sulfur did not significantly react with $\mathrm{Ni}$. The un-oxidized $\mathrm{S}$ signal existed only in the shallow level about 8 to $16 \mathrm{~nm}$ from the $\mathrm{Ni}$ surface. The un-oxidized $\mathrm{S}$ is most likely chemisorbed $\mathrm{S}$ rather than nickel sulfide. The oxidized $\mathrm{S}$ trace only existed on the top several mono-layers $(1 \mathrm{~nm})$ which could result from the oxidation of adsorbed sulfur after the sample was exposed to ambient air. 


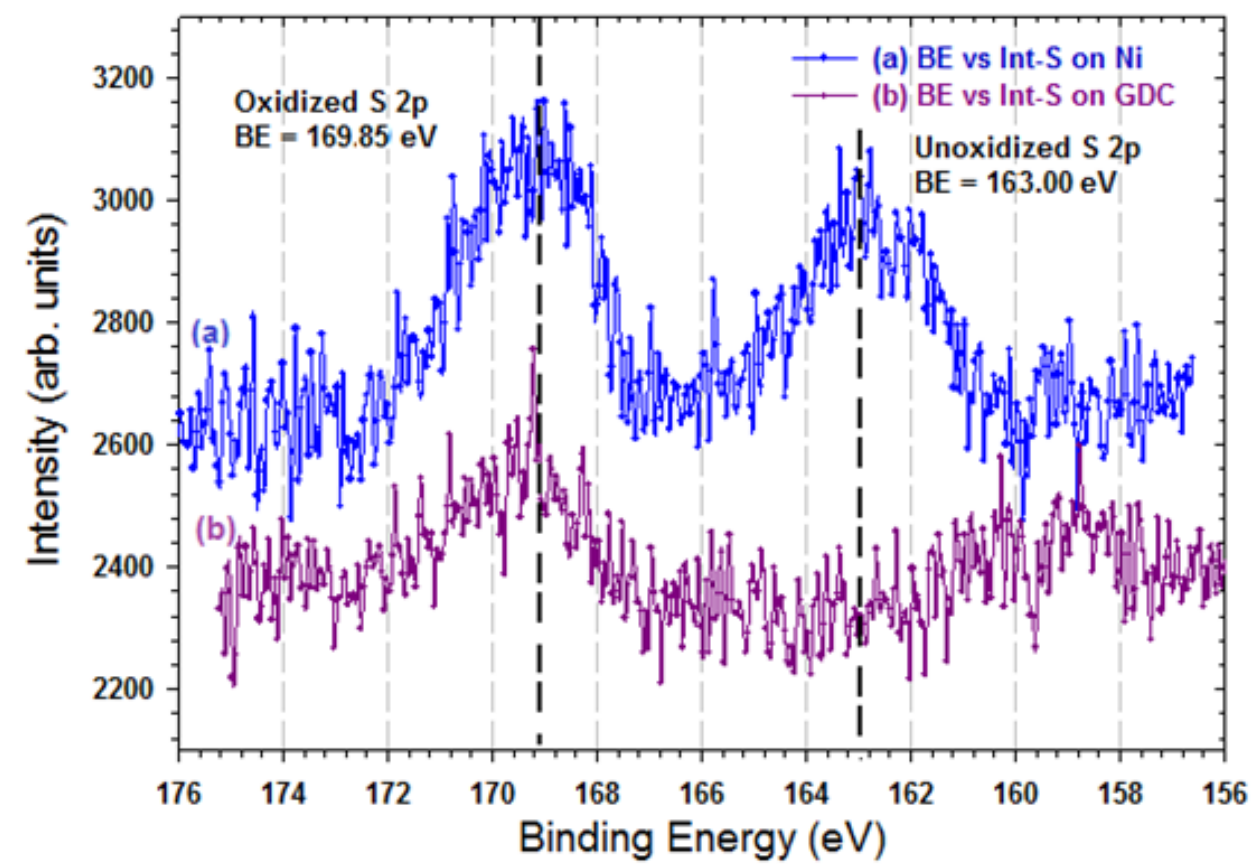

Figure 34: XPS spectra of the $\mathrm{H}_{2} \mathrm{~S}$ poisoned top surface of the Ni paste and (b) GDC-20 barrier layer on the cell. The oxidized S peak at $169.85 \mathrm{eV}$ is only significant on the GDC-20 barrier layer [112].

\subsubsection{Discussion}

Ceria $\left(\mathrm{CeO}_{2}\right)$ is a mixed electronic and ionic conductor in the temperature range of $600^{\circ} \mathrm{C}-1300^{\circ} \mathrm{C}$. The electronic conductivity is contributed by small polaron transport and is proportional to the concentration of reduced defects $\left(\mathrm{CeO}_{2-\mathrm{x}}\right) \mathrm{Ce}^{3+}$ from $\mathrm{CeO}_{2}$. In a reducing environment $\left(P_{O_{2}}<10^{-6}\right)$, it is an n-type semiconductor and its conductivity can be as high as 2.5 $\mathrm{S} \mathrm{cm}^{-1}$ at $1000^{\circ} \mathrm{C}$ [80]. Also the $\mathrm{CeO}_{2}$ grain boundaries do not impede electron transport [81-82]. For $\mathrm{Gd}$ doped $\mathrm{CeO}_{2}$, there are more $\mathrm{Ce}^{3+}$ defects in $\mathrm{GDC}$ than $\mathrm{CeO}_{2}$ which in turn contribute to higher electronic conductivity. GDC is a mixed ionic and electronic conductor.

According to the observed cell degradation for the Ni-GDC anode under $\mathrm{H}_{2} \mathrm{~S}(>100 \mathrm{ppm}$ ) poisoning, the initial degradation which caused the rapid loss of cell voltage of about 60 to 100 $\mathrm{mV}$ is inevitable. The Ni-GDC anode, especially when used in concert with the GDC barrier layer can suppress the continuous cell degradation phase for up to $100 \mathrm{ppm}_{2} \mathrm{~S}$ in syngas and 1000 ppm $\mathrm{H}_{2} \mathrm{~S}$ in wet $\mathrm{H}_{2}$ fuel. From the XPS examination, sulfur traces were identified on the 1000 ppm $\mathrm{H}_{2} \mathrm{~S}$ poisoned anode. The oxidized S signal at $168.00-170.00 \mathrm{eV}$ on the Ni particles 
may be attributed to traces of sulfate produced from adsorbed sulfur on the Ni particles at the top surface of the anode when exposed to ambient air at room temperature after the cell was tested. It only existed in the very shallow top surface layer and was not observed in the XPS spectrum deeper into the anode (see Fig. 16a and b). The unoxidized S signal at 162.00-163.00 eV may belong to two possible traces: chemisorbed sulfur and nickel sulfides, such as $\mathrm{NiS}, \mathrm{Ni}_{2} \mathrm{~S}_{3}$ etc. The consistency of the XPS spectrum of $\mathrm{Ni} 2 \mathrm{p}_{1 / 2}$ at $869.50 \mathrm{eV}$ and $2 \mathrm{p}_{3 / 2}$ at $852.40 \mathrm{eV}$ by the depth profiles suggests that $\mathrm{Ni}$ was not in an oxidized state. So the sulfur trace should not be from nickel sulfide. Moreover, nickel sulfide formation is not significant under the prevailing cell working conditions. The un-oxidized $\mathrm{S}$ trace can only be detected up to approximately $8 \mathrm{~nm}$ from the $\mathrm{Ni}$ particle surface. If nickel sulfides were formed on the $\mathrm{Ni}$ particles during cell operation, they should cause a change in the surface structure of the Ni particles considering the melting point of $\mathrm{Ni}_{2} \mathrm{~S}_{3}$ is lower than $800^{\circ} \mathrm{C}$. However, no such change in structure was observed. So the most probable cause of the unoxidized $S$ is that it came from the chemisorbed sulfur on the Ni surface. This conclusion is in agreement with the thermodynamic calculation reported by Sasaki et al. and experimental reports by Rasmussen and Hagen [9,77]. If the $\mathrm{H}_{2} \mathrm{~S}$ concentration in the fuel becomes very high, say over $10,000 \mathrm{ppm}$, nickel sulfide phases could be produced on the Ni-based anode according to Sasaki's thermodynamic equilibrium calculation. For less than $1000 \mathrm{ppm} \mathrm{H}_{2} \mathrm{~S}$ in wet $\mathrm{H}_{2}$, the cell initial degradation phase results from the chemisorption of sulfur which partially blocks active sites for $\mathrm{H}_{2}$ oxidation on the Ni surface. This is analogous to a reduction of the $\mathrm{H}_{2}$ partial pressure on the Ni-based anode. Thus, it would appear that the initial degradation phase is inevitable and reversible for the $\mathrm{Ni}$-based anode under exposure to a certain level of $\mathrm{H}_{2} \mathrm{~S}$ impurity. The test results of cells-1, 4 and 5 with the GDC barrier layer indicated that the second phase of the observed continual degradation by $\mathrm{H}_{2} \mathrm{~S}$ poisoning was highly suppressed by the GDC barrier layer. It implies that the mechanism of the second phase degradation should not be related to nickel sulfide formation on the cell anode. It should be caused by electrochemical changes at the cell anode/electrolyte active interface or the triple phase boundary (TPB).

Using $\mathrm{H}_{2}$ with a certain level of $\mathrm{H}_{2} \mathrm{~S}$ impurity, sulfur is chemisorbed on the $\mathrm{Ni}$ particles of the anode. The diagram in Figure 35a exhibits a Ni particle (without the GDC) that is oxidized by $\mathrm{O}^{2-}$ at the TPB when sulfur is partially blocking the active sites on the Ni particle. 


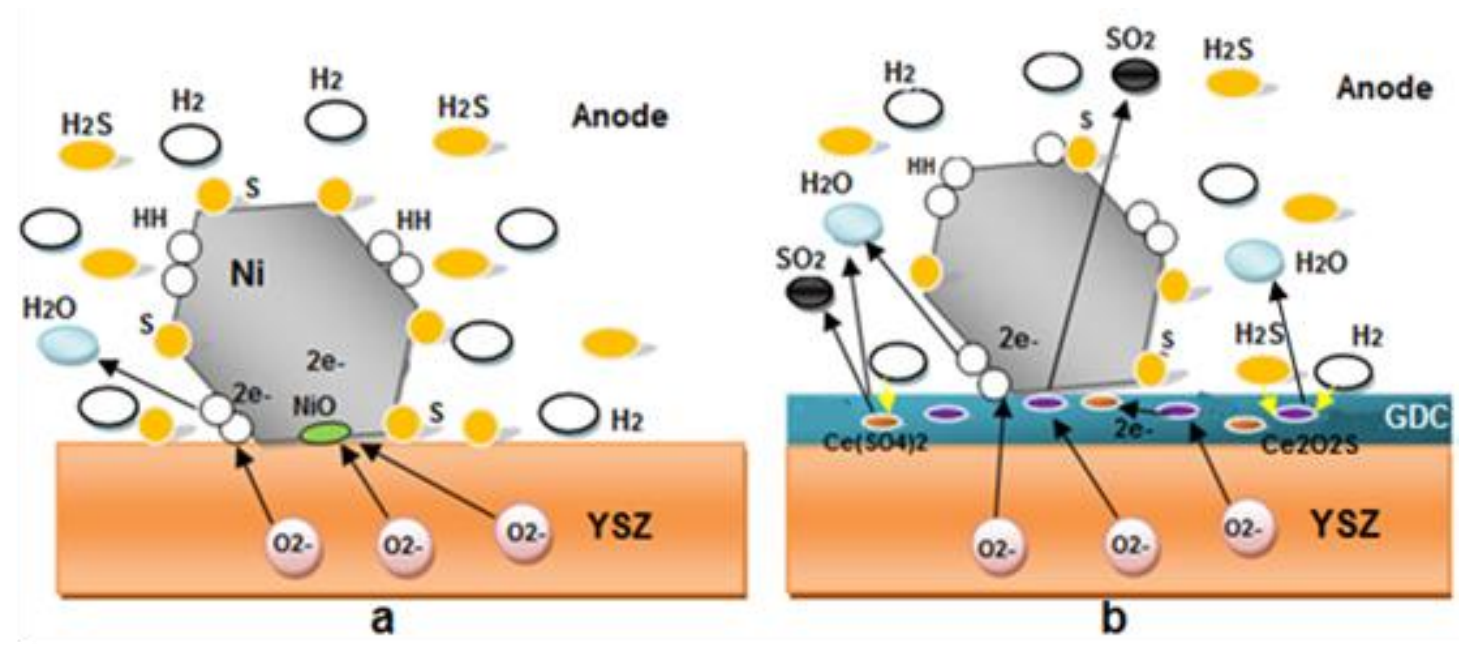

Figure 35: A conceptualization of the cell anode and electrolyte active interface showing that (a) the $\mathrm{Ni}$ is slowly oxidized by $\mathrm{O}^{2-}$ at the active interface and (b) the GDC layer is suppressing the $\mathrm{NiO}$ formation at the active interface [112].

If the $\mathrm{H}_{2}$ does not quickly reverse the $\mathrm{NiO}$ formation, more $\mathrm{NiO}$ would be produced at the local area near the active interface. Under the presence of the $\mathrm{H}_{2} \mathrm{~S}$ impurity, $\mathrm{H}_{2}$ can only be adsorbed on certain planes of nickel with a relatively high adsorption coefficient. On these sites, the reaction $\mathrm{H}_{2}+\mathrm{O}^{2-} \rightarrow \mathrm{H}_{2} \mathrm{O}+2 \mathrm{e}^{-}$is still active. However, some active Ni sites are occupied by sulfur (S). The contact area between Ni and the YSZ electrolyte adjacent to the sites occupied by sulfur becomes inert for hydrogen reduction which leads to the increase in the anode overpotential. Under a constant current load of $200 \mathrm{~mA} \mathrm{~cm}^{-2}$ on the cell, there is a constant $\mathrm{O}^{2-}$ flux across the electrolyte. The $\mathrm{O}^{2-}$ ions could potentially oxidize $\mathrm{Ni}$ particles at the TPB, especially at the interface of the electrolyte and Ni-YSZ anode (Figure 35a). Once NiO is formed, the TPB could be damaged by the microstructural changes caused by the Ni oxidation. The low conductivity of $\mathrm{NiO}$ and the loss of electrical contact between the $\mathrm{Ni}$ and the YSZ electrolyte can cause permanent damage thereby increasing the cell's ohmic resistance, $R_{\Omega}$, which is a possible mechanism for the irreversible cell degradation. However, the GDC barrier layer (Figure 35b) could suppress the direct transport of $\mathrm{O}^{2-}$ to the active interfacial area of the $\mathrm{Ni}$ or the TPB. Under highly reducing conditions, $\mathrm{CeO}_{2}$ in the Ni-GDC and the GDC barrier layer could be reduced to $\mathrm{Ce}_{2} \mathrm{O}_{3}$ which will react with $\mathrm{H}_{2} \mathrm{~S}$ to become cerium oxy-sulfide $\mathrm{Ce}_{2} \mathrm{O}_{2} \mathrm{~S}$ at $800^{\circ} \mathrm{C}$ [83-84]. These reactions are presented in the following equations: 


$$
\begin{aligned}
& 2 \mathrm{CeO}_{2}(\mathrm{~s})+\mathrm{H}_{2}(\mathrm{~g}) \rightarrow \mathrm{Ce}_{2} \mathrm{O}_{3}(\mathrm{~s})+\mathrm{H}_{2} \mathrm{O}(\mathrm{g}) \quad \Delta \mathrm{H}=-1820.8\left(\mathrm{kJmol}^{-1}\right) \\
& 2 \mathrm{Ce}_{2} \mathrm{O}_{3}(\mathrm{~s})+\mathrm{H}_{2} \mathrm{~S}(\mathrm{~g}) \rightarrow \mathrm{Ce}_{2} \mathrm{O}_{2} \mathrm{~S}(\mathrm{~s})+\mathrm{H}_{2} \mathrm{O}(\mathrm{g}) \quad \Delta \mathrm{H}=-1667.8\left(\mathrm{kJmol}^{-1}\right)
\end{aligned}
$$

The GDC layer is porous with relative high electronic conductivity at $800^{\circ} \mathrm{C}$ in the reducing environment [85-86]. According to the analyses of the fuel exhaust by the Cirrus Mass Spectrometer, a small concentration of $\mathrm{SO}_{2}$ is observed in the exhaust gas. Within the GDC barrier layer, the $\mathrm{O}^{2-}$ ion flux transported through the YSZ electrolyte has been held constant under the constant current load.

$$
\begin{aligned}
& \mathrm{Ce}_{2} \mathrm{O}_{3}+\mathrm{O}^{2-} \rightarrow 2 \mathrm{CeO}_{2}+2 \mathrm{e}^{-} \\
& \mathrm{Ce}_{2} \mathrm{O}_{2} \mathrm{~S}+2 \mathrm{O}^{2-} \rightarrow 2 \mathrm{CeO}_{2}+\mathrm{SO}_{2}+2 \mathrm{e}^{-} \\
& 0.2 \mathrm{Ce}_{2} \mathrm{O}_{2} \mathrm{~S}+\mathrm{O}^{2-} \rightarrow 0.1 \mathrm{Ce}\left(\mathrm{SO}_{4}\right)_{2}+0.3 \mathrm{CeO}_{2}+2 \mathrm{e}^{-} \\
& \mathrm{H}_{2}+\mathrm{O}^{2-} \rightarrow \mathrm{H}_{2} \mathrm{O}+2 \mathrm{e}^{-} \\
& 2 \mathrm{Ce}\left(\mathrm{SO}_{4}\right)_{2}+5 \mathrm{H}_{2} \rightarrow \mathrm{Ce}_{2} \mathrm{O}_{3}+4 \mathrm{SO}_{2}+5 \mathrm{H}_{2} \mathrm{O}
\end{aligned}
$$

When adsorbed sulfur partially blocks the local $\mathrm{H}_{2}$ oxidation active sites in the Ni-GDC anode, the electrochemical reactions (17), (18), and (19) could be favored in the GDC barrier layer (see Figure $35 \mathrm{~b}$ ). Moreover, the $\mathrm{H}_{2}$ concentration could be further reduced by the hydrogen oxidation reaction (6) in the GDC barrier layer. Indeed another test reported in the next chapter showed that a pure GDC anode in an SOFC can produce about one third of the power density of a Ni-GDC anode.

Ceria actually is acting as a regenerative catalyst for the oxidation of $\mathrm{H}_{2} \mathrm{~S}$ in these reactions. Reaction rates of (17), (18) and (19) are possibly limited not only by the reaction rates of (15) and (16), but the GDC electronic conductivity and electron transport between the nickel and GDC boundary as well. Reactions (17), (18), (19), and (20) in the barrier layer basically suppress the $\mathrm{Ni}$ oxidation processes by reducing the $\mathrm{O}^{2-}$ ion flux in GDC barrier layer. If either the current loading on the cell or the $\mathrm{H}_{2} \mathrm{~S}$ impurity level in the fuel is too high, $\mathrm{Ni}$ still can be oxidized by $\mathrm{O}^{2-}$ and/or sulfur. The XPS and EDS spectra of GDC in Fig. 31d and Fig. 34b reveal that the sulfur trace in the GDC is oxidized sulfur which could indicate the formation of $\mathrm{Ce}\left(\mathrm{SO}_{4}\right)_{2}$ via reaction (19). Reaction (21) could partially regenerate the $\mathrm{Ce}_{2} \mathrm{O}_{3}$ in a reducing environment. 
The test of cell- 6 with the GDC-20 barrier layer showed a relatively higher tolerance for $\mathrm{H}_{2} \mathrm{~S}$ than that seen with the GDC-10 barrier layer. This may be a result of the GDC-20 barrier layer having a higher electronic conductivity with a higher $\mathrm{Ce}_{2} \mathrm{O}_{3}$ concentration in the reducing environment. This is clearly seen from the data for cell-3 and cell-4 wherein cell-4 had much higher $\mathrm{H}_{2} \mathrm{~S}$ tolerance in $\mathrm{H}_{2}$ fuel than cell-3 in syngas. This could be explained by the difference of $\mathrm{O}_{2}$ partial pressure $\left(P_{\mathrm{O} 2}\right)$ and $\mathrm{H}_{2}$ partial pressure $\left(P_{\mathrm{H}_{2}}\right)$ in the fuels. In the syngas, there is about $16 \% \mathrm{H}_{2} \mathrm{O}$ in the fuel. It is higher than that of wet $\mathrm{H}_{2}$ which is only about $3 \% \mathrm{H}_{2} \mathrm{O}$. Also, $P_{H 2}$ in syngas is 0.34 atm compared to nearly 1 atm in the $\mathrm{H}_{2}$ fuel and the product $\mathrm{H}_{2} \mathrm{O}$ partial pressure is $0.16 \mathrm{~atm}$. The reaction rates of (15) and (20) are reduced by a lower $P_{H 2}$ and higher $P_{H 2 O}$. Reaction (21) may be largely suppressed by the lower $P_{H 2}$ in the syngas fuel too. From experimental observation, the cell overpotential increased about 70 to $100 \mathrm{mV}$ using syngas compared to wet $\mathrm{H}_{2}$. Eventually when the $\mathrm{H}_{2} \mathrm{~S}$ concentration gets as high as 200 ppm in syngas, the formation of $\mathrm{Ce}_{2} \mathrm{O}_{2} \mathrm{~S}$ is favored over that of $\mathrm{Ce}\left(\mathrm{SO}_{4}\right)_{2}$ from the equation (19) thereby reducing the sulfur oxidation processes leading to the formation of $\mathrm{NiO}$ at the $\mathrm{Ni}$ and GDC active interface.

The observation of the sudden drop in cell voltage after the recovery of the $\mathrm{H}_{2} \mathrm{~S}$-poisoned cell to the maximum voltage in the circled areas in Figures 16 and 18 could be explained by $\mathrm{NiO}$ formation during $\mathrm{H}_{2} \mathrm{~S}$ poisoning on the active interface or TPB. Reduction of this $\mathrm{NiO}$ to Ni during recovery could damage the contact between the $\mathrm{Ni}$ and GDC and result in a change in microstructure with an increase in ohmic resistance $R_{\Omega}$. Compared to GDC, YSZ is more stable in $\mathrm{H}_{2}$, and the analogous reactions (15) and (16) for $\mathrm{ZrO}_{2}$ hardly occurs; thus, the YSZ electrolyte-supported Ni-YSZ anode cell has very poor tolerance for $\mathrm{H}_{2} \mathrm{~S}$. But YSZ is still the most stable and cost effective electrolyte in clean fuel at $800^{\circ} \mathrm{C}$. The GDC coating on the YSZ electrolyte-supported Ni-GDC anode is a new architecture for an $\mathrm{H}_{2} \mathrm{~S}$-tolerant cell. The barrier layer of ceria with different doping materials, such as Sm, Nd, Dy, Er and La, may afford $\mathrm{H}_{2} \mathrm{~S}$ protection as well.

The reference electrode placement and configuration used for cell-4 may introduce some error in the anode and cathode impedance measurements [87-89]. But this reference electrode setup is practical to monitor the changes in the anode and cathode impedance before and after introducing the $\mathrm{H}_{2} \mathrm{~S}$ impurity. The sum of the anode and cathode impedances ( $Z^{\prime \prime}$ and $\left.Z^{\prime}\right)$ in the 
same frequency range is very close to that seen for the full cell impedance for both the wet $\mathrm{H}_{2}$ and syngas fuel cases. This implies that the error introduced by the reference electrode is small. The anode polarization appeared in the low frequency range from $50 \mathrm{~Hz}$ to $0.05 \mathrm{~Hz}$. The cathode polarization covered the range from $50 \mathrm{kHz}$ to $0.05 \mathrm{~Hz}$. The increase of cell polarization is contributed by increases both at the anode and cathode after the addition of $100 \mathrm{ppm}_{2} \mathrm{~S}$ in the fuel. The contribution to the increased $R_{\text {total }}$ is proportional to the total polarization of each electrode in the clean fuel. The anode had about $63 \%-67 \%$ of the $R_{\text {total, }}$ and the cathode had $32 \%$ - $37 \%$ of the $R_{\text {total }}$ of the full cell (see Table-3). The proportional contributions to the increased polarization of the cell by both the anode and cathode electrodes indicate that the electrodes have an interaction during $\mathrm{H}_{2} \mathrm{~S}$ poisoning. The electrochemical measurements cannot separate the processes from the two electrodes of the cell. The increase of the ohmic resistance is less than 5\% and mainly comes from the increase of the anode ohmic resistance. This implies that the charge transport polarization resistance was only slightly increased by the $\mathrm{H}_{2} \mathrm{~S}$ poisoning of the cell anode.

Because the ohmic resistance did not significantly change, the increase of the polarization resistance $\left(R_{p}=R_{\text {total }}-R_{\Omega}\right)$ with the increase of $\mathrm{H}_{2} \mathrm{~S}$ concentration showed an exponential rise to a maximum (fitted by equation (22)) which means that the chemisorbed sulfur on Ni-GDC anode becomes saturated for $\mathrm{H}_{2} \mathrm{~S}$ concentrations over $1000 \mathrm{ppm}$.

$$
R_{p}=0.747+0.305\left[1-\exp \left(-0.014 C_{H 2 S}\right)\right]
$$

Here $C_{H 2 S}$ is the $\mathrm{H}_{2} \mathrm{~S}$ concentration in ppm. It also implies that as $R_{p}$ exponentially rises, and the number of active sites for the $\mathrm{H}_{2}$ and $\mathrm{O}^{-2}$ reaction is decreasing. This observation agrees with the initial degradation behavior of $\mathrm{H}_{2} \mathrm{~S}$ poisoning on the Ni-based anode. For the case of the varying $\mathrm{N}_{2}$ concentrations in the $\mathrm{H}_{2}$ fuel, both the ohmic resistance $\left(R_{\Omega}\right)$, and the polarization resistance, $\left(R_{p}\right)$ were observed to increase. The increase of ohmic resistance should be attributed to the proposed $\mathrm{Ni}$ oxidation in the Ni-GDC anode due to decreasing local $\mathrm{H}_{2}$ partial pressure. However, in this case, the total polarization $R_{\text {total }}$ change displays almost a linear trend. Although the initial effect for $\mathrm{H}_{2} \mathrm{~S}$ poisoning and $\mathrm{N}_{2}$ dilution are caused by different mechanisms, the resulting changes in the cell resistance are comparable. 


\subsubsection{Conclusion}

A Ni-GDC anode with a GDC barrier layer has been developed for increased tolerance of $\mathrm{H}_{2} \mathrm{~S}$ in fuels. The test data show that the anode could resist up to $1000 \mathrm{ppm}_{2} \mathrm{~S}$ in wet $\mathrm{H}_{2}$ fuel and $100 \mathrm{ppm} \mathrm{H}_{2} \mathrm{~S}$ in synags fuel. The cell polarization resistance, $R_{p}$, increased whenever the $\mathrm{H}_{2} \mathrm{~S}$ impurity was added to the fuel. The polarization increase came from changes both in the cell anode and cathode polarization resulting from sulfur chemisorption on the $\mathrm{Ni}$ catalyst surface in Ni-GDC anode. The cell ohmic resistance, $R_{\Omega}$, remained nearly constant for the cells with the GDC barrier layer. The initial cell degradation phase after adding $\mathrm{H}_{2} \mathrm{~S}$ is caused by sulfur chemisorption and is recoverable. The continual degradation phase of the cell after the initial voltage loss is caused by an increase of $R_{\Omega}$ due to $\mathrm{Ni}$ oxidation forming $\mathrm{NiO}$ at the TPB. Traces of chemisorbed sulfur were observed on the Ni particles at the very top surface of $\mathrm{H}_{2} \mathrm{~S}$-poisoned $\mathrm{Ni}-\mathrm{GDC}$ anode by XPS. The formation of nickel sulfide was not detectable on the Ni surface and had nothing to do with the second phase of cell degradation. The YSZ electrolyte-supported cell with a Ni-GDC anode and a GDC barrier has high $\mathrm{H}_{2} \mathrm{~S}$ tolerance both in wet $\mathrm{H}_{2}$ and syngas. 


\section{Chapter 4: Phosphine Impurity Evaluations of Alternative Composite SOFC Anodes}

\subsection{Introduction}

Solid Oxide Fuel Cell's (SOFC's) have garnered a great deal of attention in recent years as a potential source of emission-free energy for both small mobile auxiliary power as well as for megawatt scale stationary power [22,36]. Most commercialized SOFC's operate on hydrogen fuel; however, operating SOFC's with fossil fuels is highly desirable due to their low cost and availabilitiy. For example, the use of coal syngas produced through various efficient gasification processes could push energy generation efficiency upwards of 60\% [90]. The most commonly used SOFC anode, a nickel/yttrium-stabilized zirconia (Ni/YSZ) cermet, exhibits an ability to run in various clean syngas compositions [28, 91-92], which has resulted in countless research efforts attempting to demonstrate actual functionality and stability in "dirty" gasified coal. Gasified coal contains $\mathrm{H}_{2}, \mathrm{CO}$, and residual $\mathrm{CH}_{4}$ which serve as the primary fuel for the SOFC. The major limitation is that this same fuel stream is loaded with contaminants such as $\mathrm{S}, \mathrm{P}, \mathrm{Sb}$, $\mathrm{Cl}, \mathrm{Zn}, \mathrm{As}$, and $\mathrm{HCl}$ that react with the Ni-based anodes and quickly degrade the performance of the SOFC at standard operating temperatures. The reaction of nickel with these impurities can ultimately lead to resistive secondary phase formation or other microstructural changes that can hinder the electrochemical reaction rates.

Among the most reactive with nickel is phosphorus. Krishnan et al. [93] and Trembly et al. [94] reported that their loss in cell performance is brought on from zirconia phosphate formation at the anode/electrolyte active interface. Both papers suggest that this results in a loss

of the overall electrolyte ionic conductivity. Zhi et al. [95] report total cell degradation within 20

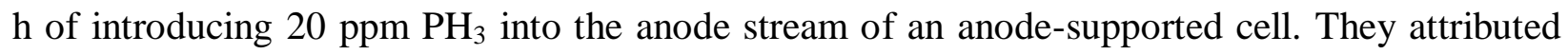
this failure to phosphorus reactions with both $\mathrm{Zr}$ and $\mathrm{Ni}$. Marina et al. [48] conducted similar work, but expanded it to show clear boundaries between reacted and un-reacted Ni particles and also determined that Ni-P formation can occur at impurity concentrations less than $1 \mathrm{ppb}$. This is valuable information since current cleanup technologies display difficulties in removing phosphorus to this level in an economic manner. 
Sulfur has also shown to be harmful to cell performance, though the failure mechanisms were shown to be different than that of phosphorus. The sulfur affects the Ni/YSZ anode first through a surface adsorption process that occurs within a matter of seconds which raises the overall work function of nickel [44,96-97]. That process has been shown to be somewhat reversible upon removal of sulfur from the anode stream. However, solid Ni-S phase formation is also found during long-term operation in fuels containing sulfur, and this process has been proven to be irreversible $[10,98]$.

Some progress has been made in regards to the prevention of sulfur poisoning of the nickel-based anode with the introduction of doped ceria into the anode either in conjunction with or in place of YSZ. In fact, a Ni/GDC (gadolinium doped ceria) anode was observed to withstand up to $200 \mathrm{ppm} \mathrm{H}_{2} \mathrm{~S}$ in syngas with $10-12 \%$ cell degradation after about $570 \mathrm{~h}$ of operation, which is an improvement over the Ni/YSZ anode but not a proven solution [12]. The GDC and other doped ceria compositions have been shown to be good $\mathrm{H}_{2} \mathrm{~S}$ absorbents for the SOFC [51], and GDC appears to react with sulfur to form ceria-sulfides at concentrations higher than 450 ppm from thermodynamic calculations [52,99-101]. This means that a Ni/GDC anode may be suitable for gasified coal as current technologies containing sulfur scrubbers display concentrations much lower than $450 \mathrm{ppm}$.

Another way to address the anode contaminant issue is to remove nickel from the anode entirely. Many different anodes have been developed previously for the investigation of fuel flexibility and impurity tolerance. A popular all-ceramic anode that has demonstrated stability in fuels containing low levels of $\mathrm{H}_{2} \mathrm{~S}$ is $\mathrm{SrTiO}_{3}$. Pillai et al. [57] reported on an anode-supported $\mathrm{SrTiO}_{3}$ anode capable of withstanding up to $100 \mathrm{ppm} \mathrm{H}_{2} \mathrm{~S}$ without appreciable degradation. Kurokawa et al. [102] demonstrated stable cell performance in upwards of $40 \mathrm{ppm}_{2} \mathrm{~S}$ with Asite doping with $\mathrm{Y}$ and $\mathrm{Ce}$ and $\mathrm{Ru}$ infiltration. $\mathrm{La}_{0.75} \mathrm{Sr}_{0.25} \mathrm{Cr}_{1-\mathrm{x}} \mathrm{Mn}_{\mathrm{x}} \mathrm{O}_{3}$ is another anode that has been shown by Zha et al. [103] to resist sulfur poisoning, however the level of $\mathrm{H}_{2} \mathrm{~S}$ tolerance is strongly dependent upon the amount of $\mathrm{Cr}$ in the anode matrix. $\mathrm{A} \mathrm{WS}_{2}$ anode, developed by Yates et al. [104] has shown short term tolerance ( $24 \mathrm{~h})$ to direct $\mathrm{H}_{2} \mathrm{~S}$ fuel. Cheng et al. have recently developed a strontium-doped lanthanum vanadate anode $\left(\mathrm{La}_{1-x} \mathrm{Sr}_{x} \mathrm{VO}_{3}\right)$ that exhibited sulfur tolerance and favorability to a sulfur-containing environment for upwards of $48 \mathrm{~h}$. 
However, the perovskite structure of this anode tends to lose its integrity over longer operation times and secondary phases form which inhibit the cells ability to perform [105].

Several double perovskite structured anode materials $\left(\mathrm{A}_{2} \mathrm{BB}^{\prime} \mathrm{O}_{6}\right)$ have been investigated with $\mathrm{Sr}_{2} \mathrm{MgMoO}_{6-\delta}$ being among the best in terms of resistance to sulfur poisoning. Goodenough et al. [32] and Huang et al. [20,59] have applied this anode to a $\mathrm{La}_{0.8} \mathrm{Sr}_{0.2} \mathrm{Ga}_{0.83} \mathrm{Mg}_{0.17} \mathrm{O}_{2.815}$ (LSGM) electrolyte with the use of a lanthanum-doped ceria (LDC) interlayer to prevent interfacial reactions between the electrodes and electrolytes. They have achieved power densities of $500 \mathrm{~mW} \mathrm{~cm}^{-2}$ in $\mathrm{CH}_{4}$ and $840 \mathrm{~mW} \mathrm{~cm}^{-2}$ in $\mathrm{H}_{2}$ at $800^{\circ} \mathrm{C}$ using $\mathrm{SrCo}_{0.8} \mathrm{Fe}_{0.2} \mathrm{O}_{3-\delta}$ (SCF) as a cathode. This anode also is capable of operating in up to $50 \mathrm{ppm} \mathrm{H}_{2} \mathrm{~S}$ in $\mathrm{H}_{2}$ with minimal performance loss after $200 \mathrm{~h}$ ( $\sim 5 \%$ voltage loss $)$.

Since the SMM anode has been shown to perform well in a variety of fuels and withstand realistic levels of $\mathrm{H}_{2} \mathrm{~S}$, a logical progression would be to investigate how this anode responds to other coal contaminants. Specifically, this study will investigate the response of the cell upon

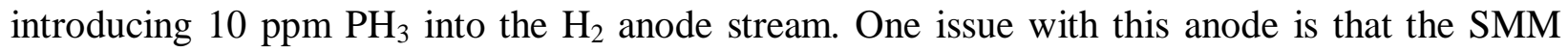
alone exhibits relatively low ionic conductivity in reducing atmospheres [106]; thus, GDC is incorporated into the anode to improve the ionic conduction of the cell.

Additionally, as a means of useful comparison to the Ni-based anode, the last section of this chapter investigates a novel anode composition that is still Ni-based. The wolframite $\mathrm{NiWO}_{4}$ composition will be evaluated to understand the phase evolution upon reduction, its electrochemical performance alone and with different ionic conduction contributors, and its response to $\mathrm{PH}_{3}$ impurity. 


\section{2 $\quad \mathrm{PH}_{3}$ Impurity Tolerance of $\mathrm{Sr}_{2} \mathrm{MgMoO}_{6-\delta} / \mathrm{GDC}$ Composite Anodes}

\subsubsection{Experimental Procedure}

\subsubsection{1 $\mathrm{Sr}_{2} \mathrm{MgMoO}_{6-\delta}$ Powder Preparation}

$\mathrm{Sr}_{2} \mathrm{MgMoO}_{6-\delta}$ powders were synthesized using a standard solid-state method with $\mathrm{SrCO}_{3}$, $\mathrm{MgO}$, and $\mathrm{MoO}_{3}$ (Alfa Aesar, 99.9\% purity for each) as starting reagent materials. The powders were first mixed and then ball milled in ethanol and calcined at $1000^{\circ} \mathrm{C}$ for $4 \mathrm{~h}$ in air to burn off the carbonates. After the initial heat treatment, the powder was sieved and attrition-milled for 4 h. The powder was then calcined at the same temperature and time under a reducing atmosphere $\left(5 \% \mathrm{H}_{2} / \mathrm{N}_{2}\right)$ to form the single-phase SMM material. Previous work on this material suggests that the low melting temperature and high volatility of Mo make it problematic for high thermal treatment temperatures [106], so the lowest possible calcination temperature was sought to minimize this effect.

$\mathrm{X}$-ray diffraction (XRD) spectra were recorded for samples fired at $1000^{\circ} \mathrm{C}, 1100^{\circ} \mathrm{C}$, and $1200^{\circ} \mathrm{C}$ for $4 \mathrm{~h}$ in $5 \% \mathrm{H}_{2} / \mathrm{N}_{2}$ and are shown in Figure 36.

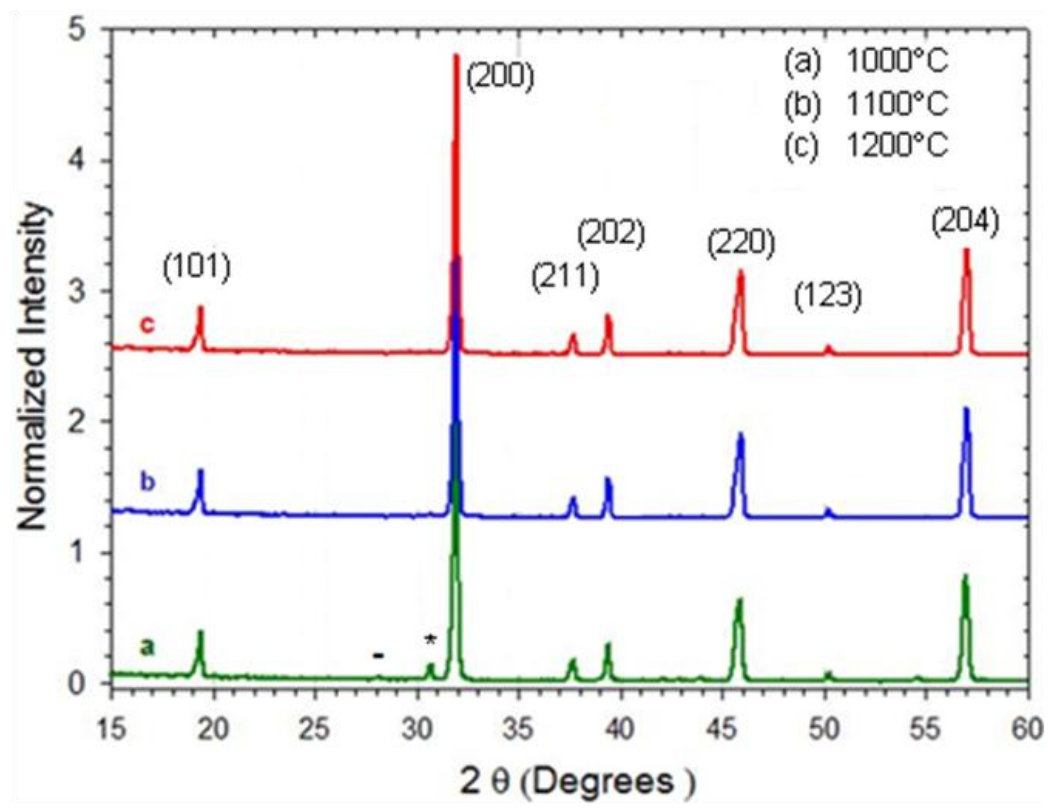

Figure 36: XRD spectra for the $\mathrm{Sr}_{2} \mathrm{MgMoO}_{6-\delta}$ anode calcined at different temperatures in a 5\% $\mathrm{H}_{2} / \mathrm{N}_{2}$ atmosphere.

(*) denotes the secondary $\mathrm{SrMoO}_{4}$ phase [113]. 
At $1000^{\circ} \mathrm{C}$ and $1100^{\circ} \mathrm{C}$, a secondary scheelite phase $\left(\mathrm{SrMoO}_{4}\right)$ was detected at $27.5^{\circ}$ (20). A single phase material was formed at $1200^{\circ} \mathrm{C}$ and the bulk of the powder was calcined at

this temperature. Recent work by Vasala et al. [107] suggests that the $\mathrm{SrMoO}_{4}$ phase is an insulator, but that it becomes $\mathrm{SrMoO}_{3}$ in atmospheres with low partial pressures of oxygen and the reduced structure is conductive. Thus, at $1200^{\circ} \mathrm{C}$, a nearly single phase was achieved, and what traces of $\mathrm{SrMoO}_{4}$ were present $(<1 \%)$ were deemed insignificant in regards to electrode performance. The final step in powder synthesis was attrition milling to achieve unimodal particle size distribution. The BET surface area of this calcined powder was found to be $4.711 \mathrm{~m}^{2}$ $\mathrm{g}^{-1}$, which is greater than SMM powders prepared elsewhere [21].

\subsubsection{Electrolyte/GDC Preparation and Processing}

Most of the previous fuel cell experiments carried out with the SMM anode utilized LSGM as the electrolyte due to its higher ionic conductivity [21]. However, the material is quite brittle and still highly reactive; thus, $8 \mathrm{~mol} \% \mathrm{Y}_{2} \mathrm{O}_{3}-\mathrm{ZrO}_{2}$ (YSZ) electrolyte substrates were used for our anode evaluations. YSZ powder (Daiichi Kigenso Kagaku Kogoyo Co., LTD) was first mixed into a slurry using the appropriate amounts of a 50/50 wt \% xylene/ethanol solvent system and a fish-oil dispersant. After milling for $4 \mathrm{~h}$ the plasticizers (benzyl butyl phthalate and polyalkalene glycol) and poly-vinyl butyral binder were added to the system and milled for $12 \mathrm{~h}$.

The slurry was then tape casted onto mylar sheets to a dried thickness of approximately $50 \mu \mathrm{m}$. Pieces of this tape were cut and layered so that a green thickness of $150 \mu \mathrm{m}$ was achieved. The stacked YSZ sheets were laminated at $100^{\circ} \mathrm{C}$ and $0.4 \mathrm{GPa}$. Laminates were cut into $1 \mathrm{~cm}$ diameter button cells generated by sintering at $1450^{\circ} \mathrm{C}$ for $2 \mathrm{~h}$. The final thickness of the YSZ electrolytes was approximately $120 \mu \mathrm{m}$, which provides a structurally sound support and allows for qualitative and quantitative anode performance comparisons. The GDC used in this study was prepared using a conventional co-precipitation method [108]. 


\subsubsection{Button Cell Assembly}

Button cells were produced by first taking the YSZ electrolytes and applying a GDC buffer layer onto both sides and sintering at $1400^{\circ} \mathrm{C}$ for $2 \mathrm{~h}$ for optimal density. The first set of cells contained an anode approximately $40 \mu \mathrm{m}$ in thickness of SMM and was fired on at $1100^{\circ} \mathrm{C}$ for $2 \mathrm{~h}$. The second set of cells had a different anode composition, where the anode was composed of a $40 \mu \mathrm{m}$ composite anode (50 wt \%. SMM and $50 \mathrm{wt} \%$. GDC). The composite anode was applied to one side and fired at $1150^{\circ} \mathrm{C}$ for $2 \mathrm{~h}$. For both sets, a $\mathrm{La}_{0.85} \mathrm{Sr}_{0.15} \mathrm{MnO}_{3}$ (LSM) based cathode was used. The cathode consists of a $10 \mu \mathrm{m} \mathrm{LSM/GDC} \mathrm{active} \mathrm{cathode} \mathrm{layer}$ which was printed and then dried before adding a $40 \mu \mathrm{m}$ LSM current collector layer. This cathode assembly was sintered at $1100^{\circ} \mathrm{C}$ for $1 \mathrm{~h}$.

\subsubsection{Fuel Cell Testing}

Prior to testing, a pair of $6 \times 50 \mathrm{~mm}$ platinum mesh (80 mesh woven) strips were attached with platinum paste to serve as the current collector. The cells were then mounted between two alumina flanges with mica washers for a compressed seal configuration shown in Figure 37.

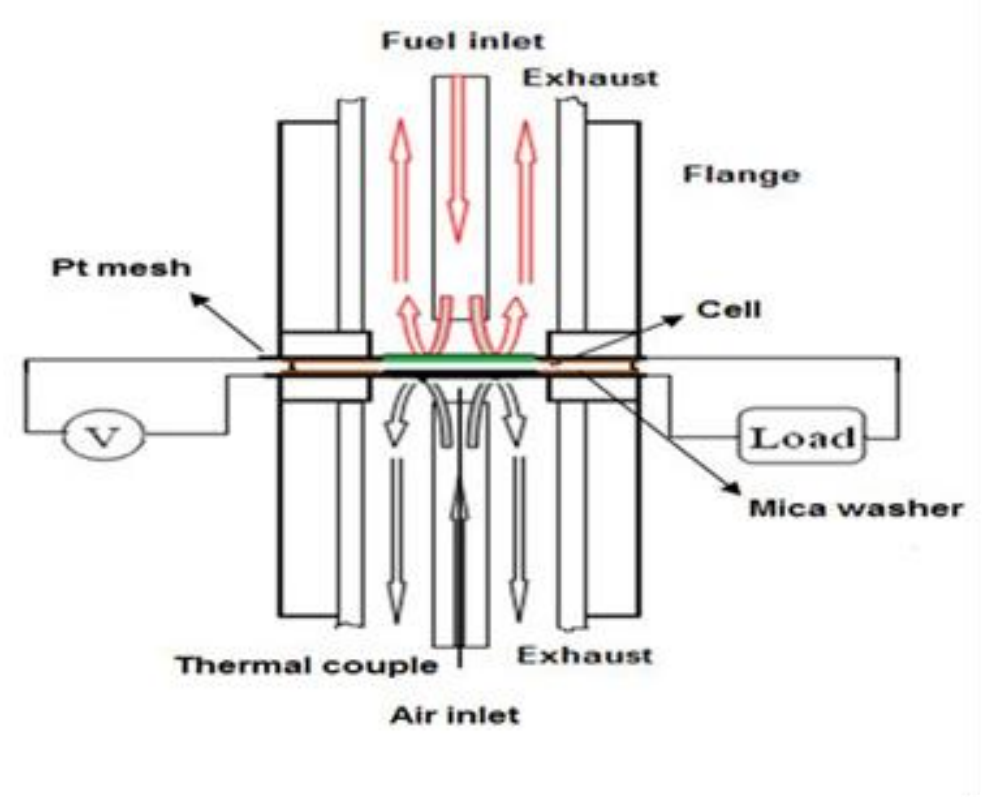

Figure 37: Fuel cell fixture schematic used in current-voltage-power (J-V-P) testing in this work [113]. 
Each end of $\mathrm{Pt}$ mesh at both electrodes was connected to a thick sliver wire for the current lead and a thin wire for the voltage lead. The cell was heated to $800^{\circ} \mathrm{C}$ at a rate $2^{\circ} \mathrm{C} \min ^{-1}$ in $50 \mathrm{sccm} \mathrm{N}_{2}$ on the anode and air on the cathode. After the target $800^{\circ} \mathrm{C}$ was reached, the fuel stream was slowly converted to the wet $\mathrm{H}_{2}$ fuel. A $0.25 \mathrm{~A} \mathrm{~cm}^{-2}$ constant current was loaded on the cell with $100 \mathrm{sccm}$ wet $\mathrm{H}_{2}\left(97 \% \mathrm{H}_{2}\right.$, and $\left.3 \% \mathrm{H}_{2} \mathrm{O}\right)$ to the anode and $150 \mathrm{sccm}$ air flow to the cathode. After the cell voltage stabilized for $20 \mathrm{~h}$, the cell polarization curve ( J-V curve) and electrochemical impedance spectrum (EIS) were taken to establish the cell baseline performance. The EIS were collected using a Solartron SI-1287 electrochemical interface and an SI-1252 frequency response analyzer. An AC amplitude of $20 \mathrm{mV}$ at frequencies ranging from $200 \mathrm{kHz}$ to $0.1 \mathrm{~Hz}$ was applied for the EIS testing. The constant DC current load was supplied by a solidstate load cell (TDI Transistor Device SD-1103). $\mathrm{PH}_{3}$ was added in the fuel downstream before the furnace. The fuel transport tubes were per-heated to over $150^{\circ} \mathrm{C}$. After testing, the cell was cooled to room temperature by purging $30 \% \mathrm{H}_{2}$ and $70 \% \mathrm{~N}_{2}$ to the anode.

\subsubsection{Results and Discussion}

\subsubsection{Initial Performance of the SMM Anode in Clean $\mathrm{H}_{2}$ Fuel}

The goal of the initial tests was to establish a baseline performance for the pure SMM anode in order to later assess the effects of the phosphine additions on the degradation of the anode. Table 4 shows the cell performance for various anode sintering temperatures and indicates that the performance of the cell increases as the sintering temperature decreases.

Table 4: Max power densities for both SMM and GDC anode.

\begin{tabular}{cccc} 
Sample & Sintering temp $\left({ }^{\circ} \mathrm{C}\right)$ & $\mathrm{SMM}\left(\mathrm{mWcm}^{-2}\right)$ & $\mathrm{GDC}\left(\mathrm{mWcm}^{-2}\right)$ \\
\hline 1 & 1350 & 65 & - \\
2 & 1300 & 70 & - \\
3 & 1250 & 85 & - \\
4 & 1200 & 100 & - \\
5 & 1150 & 100 & - \\
6 & 1100 & 110 & 85
\end{tabular}


This would suggest that the higher sintering temperature may alter the porosity level and triple-phase boundary area, and/or may result in potential interfacial reactions between the anode and electrolyte, even with a dense GDC interlayer. Sintering studies at temperatures below $1100^{\circ} \mathrm{C}$ were investigated, but these temperatures were not found to be high enough for proper adherence of the anode to the electrolyte. The cells were found to be stable over the course of 48 $\mathrm{h}$, but the maximum power density achieved was only $110 \mathrm{~mW} \mathrm{~cm}^{-2}$ for the cell with the anode fired at $1100^{\circ} \mathrm{C}$. Figure 38 shows an I-V-P plot for the GDC anode in the sample 6 condition. The OCV for each test in $3 \%$ wet $\mathrm{H}_{2}$ was $1.06 \mathrm{~V}$, which was consistent throughout the experiments outlined in Table 4 indicating consistency in sealing.

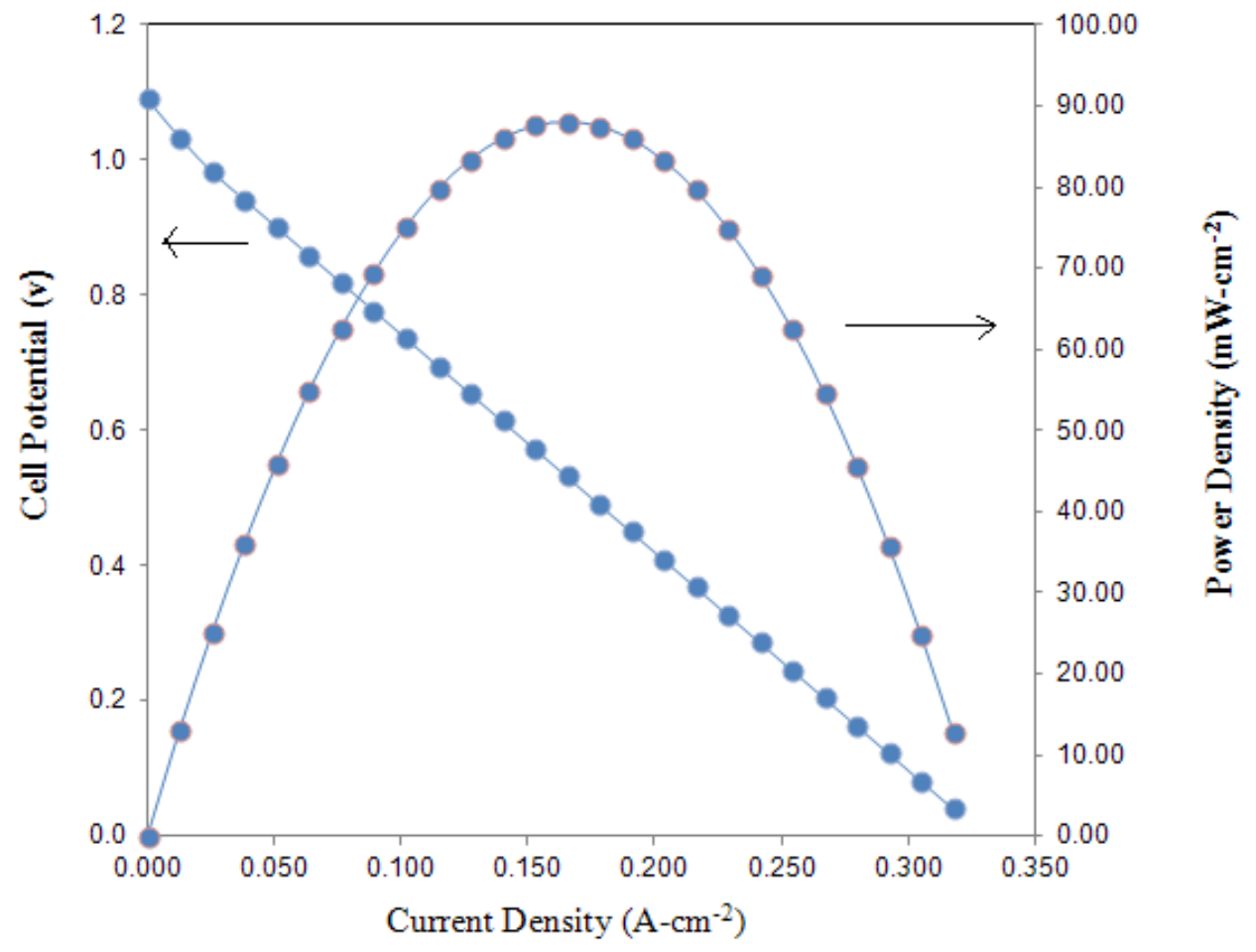

Figure 38: Performance of the pure GDC anode in $3 \%$ wet $\mathrm{H}_{2}$.

This data was recorded at a time $12 \mathrm{~h}$ after reduction where maximum power density was observed. Under reducing environments, the GDC does exhibit low electronic conductivity, which means that it alone could potentially function as an anode. However, this test confirms low performance for a pure GDC anode indicating that it is either primarily an ionic conductor even in a reduced atmosphere or has low catalytic activity towards hydrogen oxidation. In either 
case, these tests confirm that the compositions alone are not sufficient, but that as a composite high performance could be achieved.

\subsubsection{Performance of SMM/GDC Anode in Clean $\mathrm{H}_{2}$ Fuel and Clean Coal Syngas Blend}

In an effort to enhance the performance of the cell, the GDC was added to the anode matrix to form a 50/50 wt $\%$ mixture with SMM. The addition of the GDC within the anode to the baseline cell resulted in a cell performance of $\sim 280 \mathrm{~mW} \mathrm{~cm}^{-2}$ in wet $\mathrm{H}_{2}$. This cell also remained stable for over 4 days without significant degradation ( $0.008 \% / \mathrm{hr}$, time not shown). Previous investigations suggest that structural changes to the ceria in the reducing atmospheres can decrease cell performance over time. The testing conducted in this study showed essentially no loss in performance when operating on pure $\mathrm{H}_{2}$ with the SMM/GDC composite anode. This was important to establish so that the possibility of the cell not deteriorating in the presence of $\mathrm{H}_{2}$ alone might be eliminated. For an electrolyte-supported cell, this performance and stability was found suitable for the contaminant investigation. Figure 39 shows the I-V performance curve for the baseline SMM/GDC cell in wet $\mathrm{H}_{2}$.

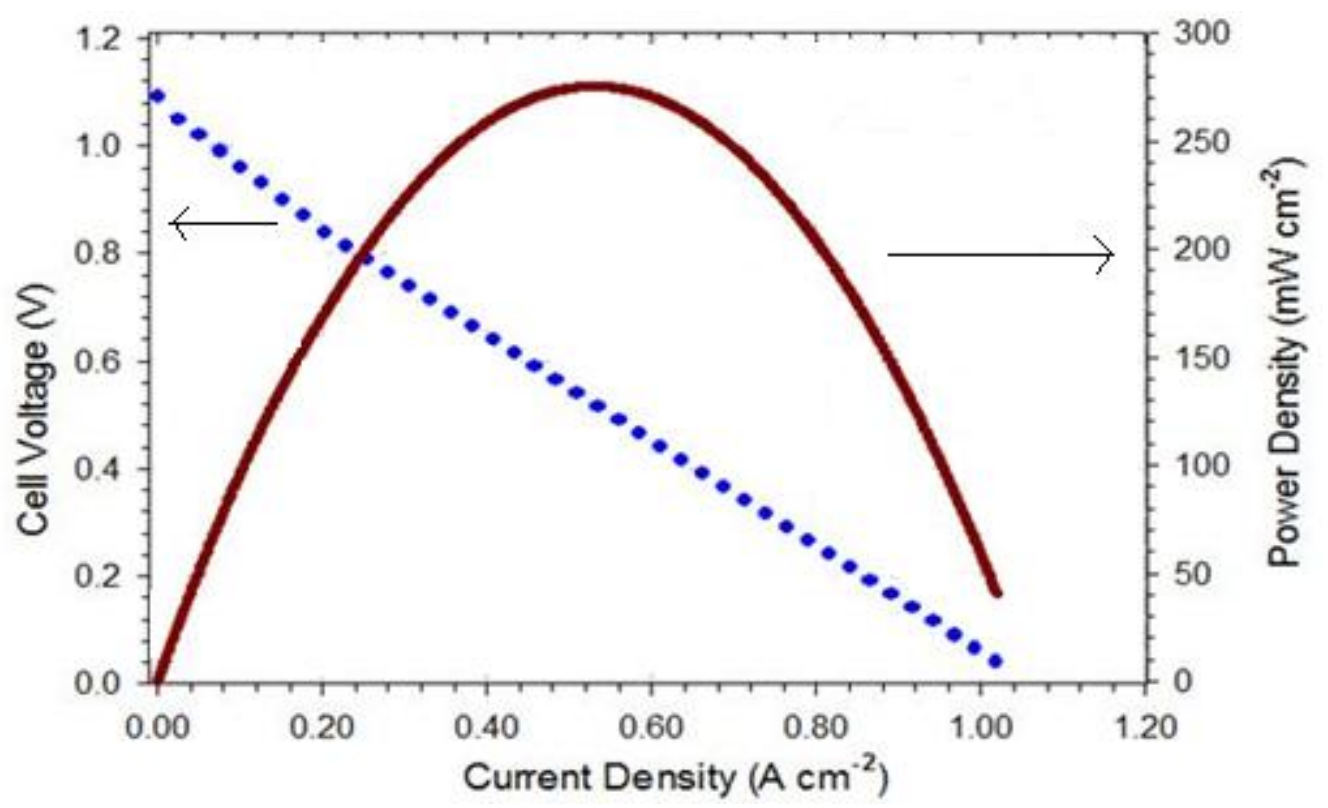

Figure 39: (I-V-P) performance for SMM/GDC composite anode in wet $\mathrm{H}_{2}\left(3 \% \mathrm{H}_{2} \mathrm{O}\right)$ [113]. 
To establish the SMM/GDC anode as suitable for long term power generation in a coal syngas-based fuel stream, the anode must demonstrate reasonable performance in wet syngas with trace levels of impurities. To test the viability of this anode in a coal-based fuel environment, a cell was loaded and stabilized in wet $\mathrm{H}_{2}$. After power stabilization, the cell was exposed to a fuel environment with $34 \% \mathrm{H}_{2}, 31 \% \mathrm{CO}, 19 \% \mathrm{CO}_{2}$, and $16 \% \mathrm{H}_{2} \mathrm{O}$, which simulates a standard coal syngas composition. In Figure 40 the expected decrease in the cell potential can be seen as a result of the syngas fuel composition.

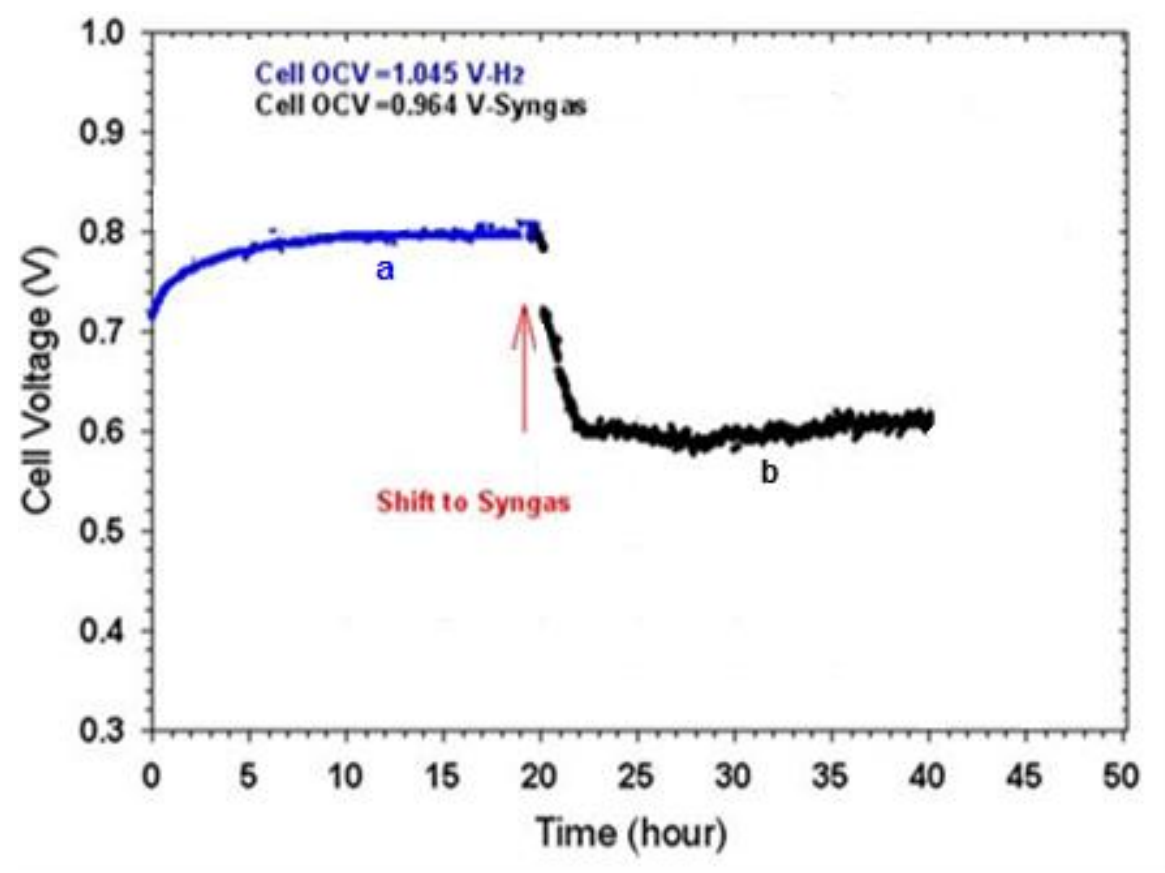

Figure 40: Voltage vs. time for the electrolyte-supported SOFC with a SMM/GDC anode tested at constant current density $\left(0.25 \mathrm{~A} \mathrm{~cm}^{-2}\right)$ in a) $\mathrm{H}_{2}+3 \% \mathrm{H}_{2} \mathrm{O}$ and b) clean syngas at $800^{\circ} \mathrm{C}$ [113].

The maximum power density of this cell in syngas was under $200 \mathrm{~mW} \mathrm{~cm}^{-2}$. The cell demonstrated stability in this syngas blend, which is promising for future application of this composite anode. However, the initial drop in potential upon switching over to syngas is almost $200 \mathrm{mV}$. This is significantly higher than what is seen with the Ni/YSZ or Ni/GDC cermets, which typically experience voltage losses from switching to syngas fuel ranging from 20 to 80 $\mathrm{mV}$, leaving room for future studies on optimizing the performance of this cell in syngas through catalyst incorporation (other than $\mathrm{Ni}$ ) to make the anode commercially competitive. 


\subsubsection{Performance of SMM/GDC Anode in $\mathrm{H}_{2}$ with $10 \mathrm{ppm} \mathrm{PH}_{3}$}

An identical SMM/GDC cell was brought to the $800^{\circ} \mathrm{C}$ testing temperature and $100 \mathrm{sccm}$ wet $\mathrm{H}_{2}$ and $150 \mathrm{sccm}$ air were delivered to the anode and cathode respectively. Once the cell reached temperature, the slow anode reduction in $3 \%$ wet $\mathrm{H}_{2}$ ensued until the open circuit voltage was observed. This voltage was found to be $1.046 \mathrm{~V}$ in wet $\mathrm{H}_{2}$ upon full reduction. A constant current load of $0.25 \mathrm{~A} \mathrm{~cm}^{-2}$ was then applied to the cell. With the load, the corresponding voltage was measured as $0.766 \mathrm{~V}$. Figure 41 shows the initial cell stability in wet

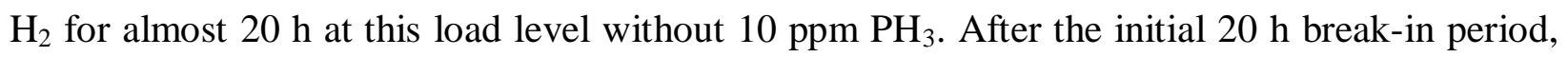
$10 \mathrm{ppm} \mathrm{PH}_{3}$ was introduced into the fuel stream without unloading the cell. Figure 42 also shows a plot of the SMM/GDC composite anode in wet $\mathrm{H}_{2}$ for a period of $\sim 160 \mathrm{~h}$ to demonstrate that changes to the potential are not a result of the anode degrading in a clean environment. The figure shows stability during this time period which means the changes to the voltage seen in Figure 41 are a direct result of phosphine inclusion into the fuel stream.

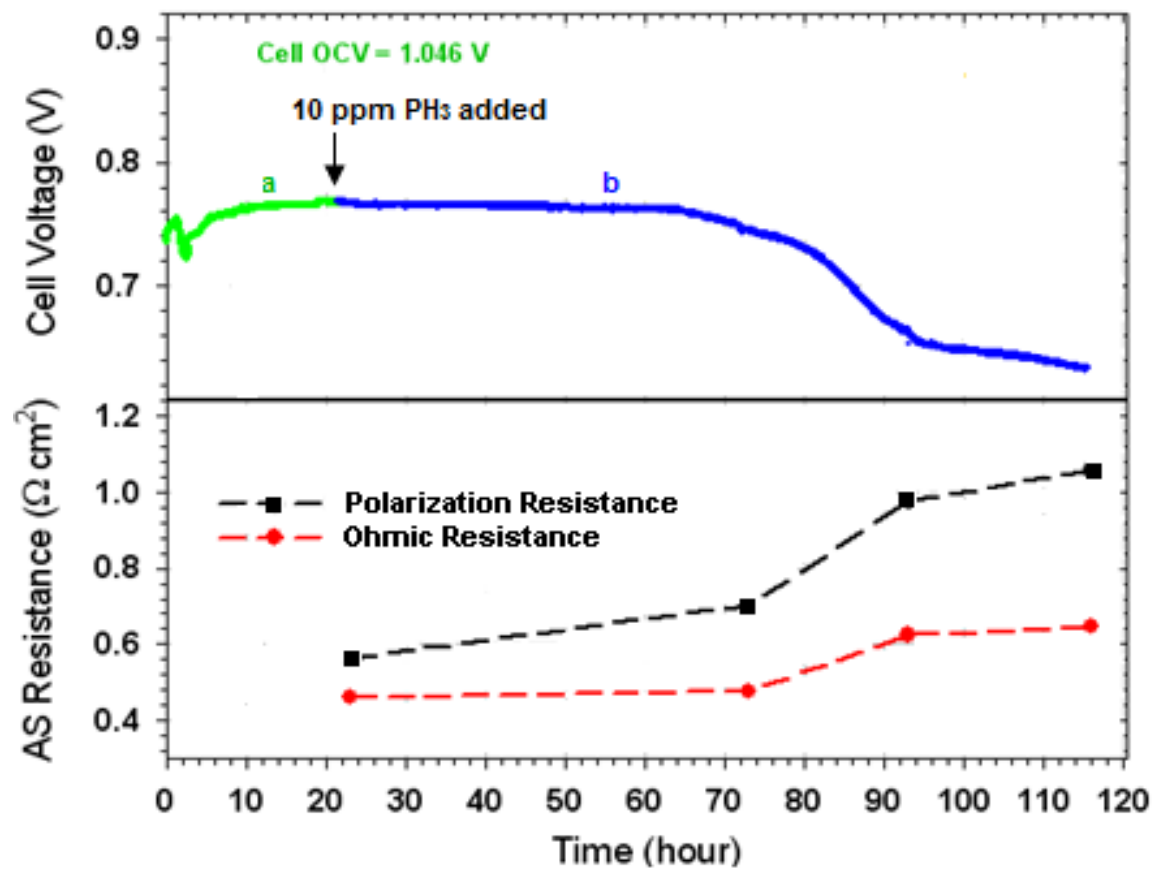

Figure 41: Cell voltage and resistance vs. time for the electrolyte-supported SOFC with a SMM/GDC anode tested at $800^{\circ} \mathrm{C}$ and at constant current density $\left(0.25 \mathrm{~A} \mathrm{~cm}^{-2}\right)$ in a) $\mathrm{H}_{2}+3 \% \mathrm{H}_{2} \mathrm{O}$ fuel and b) $\mathrm{H}_{2}+3 \% \mathrm{H}_{2} \mathrm{O}$ with the addition

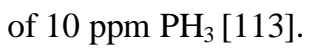




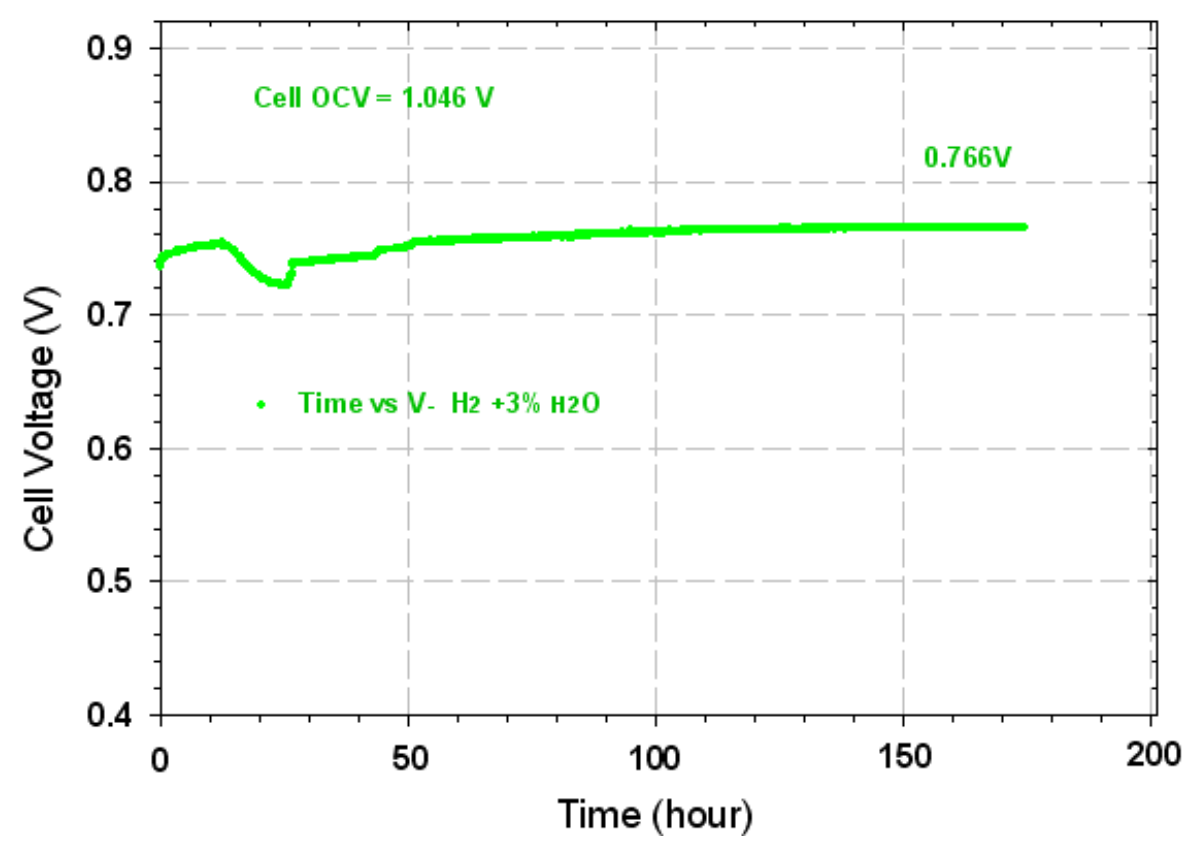

Figure 42: Voltage vs. Time plot for the SMM/GDC composite anode in wet $\mathrm{H}_{2}$ for $\sim 160 \mathrm{~h}$.

The $10 \mathrm{ppm} \mathrm{PH}_{3}$ introduction resulted in an initial 1-2 $\mathrm{mV}$ drop in the cell potential. However, the cell quickly re-stabilized and remained at that potential for approximately $40 \mathrm{~h}$. During that time, the ohmic resistance remained constant at $0.47 \Omega \mathrm{cm}^{2}$, but the polarization resistance increased from $0.55 \Omega \mathrm{cm}^{2}$ to $0.70 \Omega \mathrm{cm}^{2}$, as quantified by the loaded EIS measurement that can been seen in Figure 41.

The values of the ohmic resistance and polarization resistance can be determined through visual inspection of a Nyquist plot. Much research has been done in correlating the geometry of these curves to the individual electrical and electrochemical processes that occur during SOFC operation [109-111]. Using the fundamental theory from these previous works, the ohmic resistance was determined by the intersection of the first arc with the real impedance axis. For thick electrolyte membranes, such as those used in this work, the majority of the ohmic resistance is aligned with the electrolyte membrane, which accounts for the movement of ions across the electrolyte. The magnitude of the polarization resistance was determined by measuring the distance between the first and second intersections with the real axis. This resistance may be attributed to both the high and low frequency processes, such as charge transfer and mass diffusion, respectively. Equation 1 below shows the total resistance of the circuit: 


$$
\Delta \mathrm{R}_{\mathrm{total}}=\Delta \mathrm{R}_{\mathrm{act}}+\Delta \mathrm{R}_{\mathrm{conc}}+\Delta \mathrm{R}_{\Omega}
$$

Where $\Delta \mathrm{R}_{\text {act }}$ is the activation polarization, $\Delta \mathrm{R}_{\text {conc }}$ is the concentration polarization, and $\Delta \mathrm{R}_{\Omega}$ is the ohmic resistance. This fundamental theory was applied to the results to formulate initial conclusions about the performance of the cell over time.

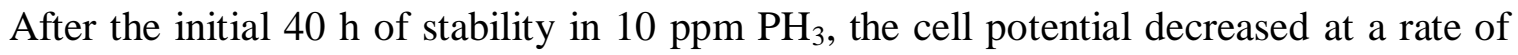
about $2.8 \mathrm{mV} \mathrm{h}^{-1}$ over the course of the next $30 \mathrm{~h}$. The series resistance increased to $0.16 \Omega \mathrm{cm}^{2}$ and the polarization resistance continued to rise as well over this span. However, after $70 \mathrm{~h}$ in 10 ppm $\mathrm{PH}_{3}$, the rate of cell degradation decreased to about $1 \mathrm{mV} \mathrm{h}^{-1}$ and the series resistance remained nearly constant while the polarization resistance increased about another $10 \%$. The cell never re-stabilized beyond this time and continued to degrade at a similar rate. By the time the test was concluded, a 47\% decrease in maximum power density was observed, as displayed in Figure 43. Because the cell failed to re-stabilize over a significant range of time, the test was concluded.

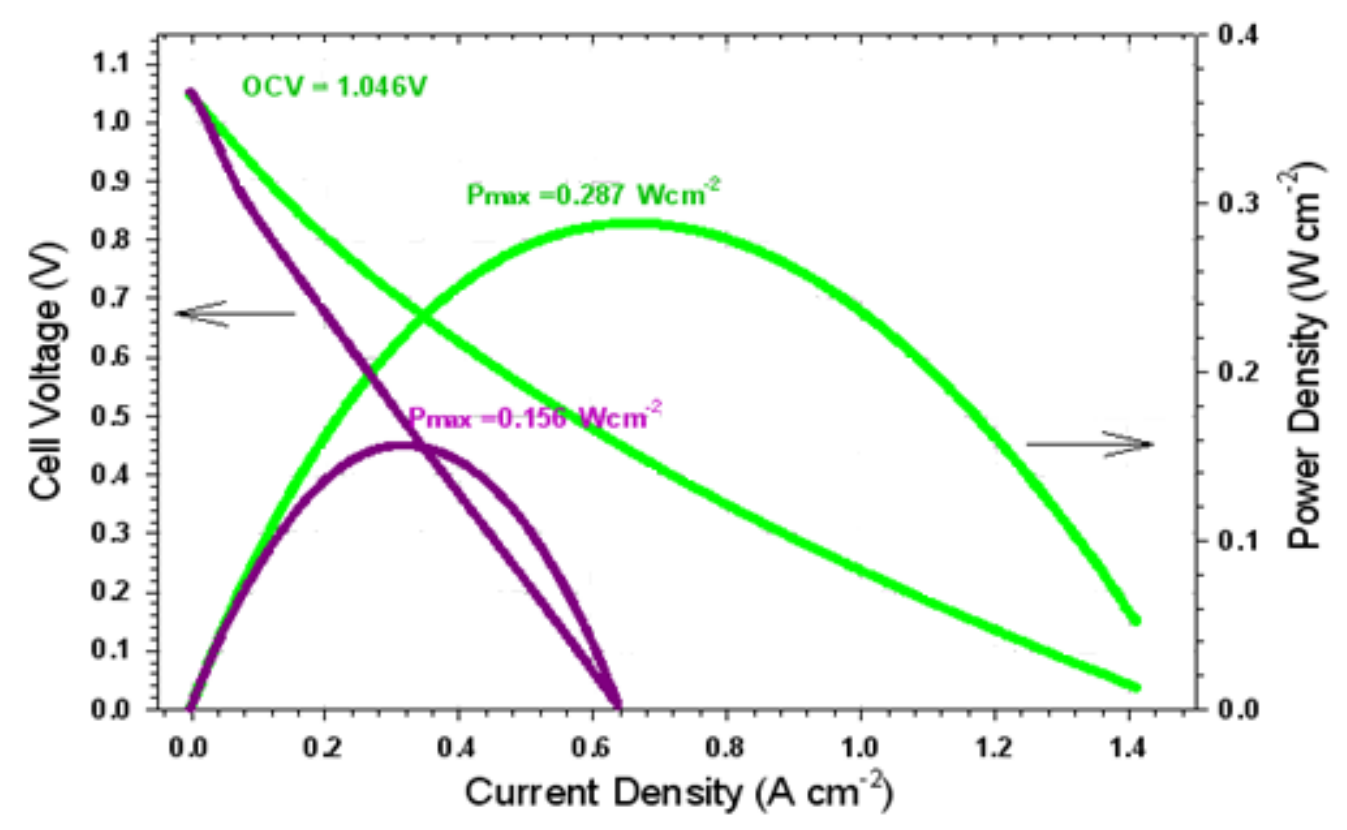

Figure 43: J-V-P performance of SOFC with SMM/GDC anode in wet $\mathrm{H}_{2}$ before $\mathrm{PH}_{3}$ introduction and after $120 \mathrm{~h}$

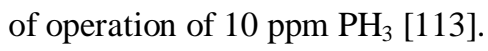


While degradation to this SMM/GDC anode was shown in these tests, it shows much higher resistance to phosphine poisoning compared to the standard Ni/YSZ anode on an electrolyte-supported cell. Of course, we differentiate between anode-supported and electrolytesupported designs, since the rate of anode degradation as a result of poisoning is dependent upon anode thickness. The electrolyte-supported platform was used in this study in order to accelerate degradation of the anode (due to minimal anode thickness) for rapid evaluation purposes. In Figure 44, the voltage versus time comparison can be seen which indicates much stronger tolerance to $\mathrm{PH}_{3}$ for the $\mathrm{SMM} / \mathrm{GDC}$ anode.

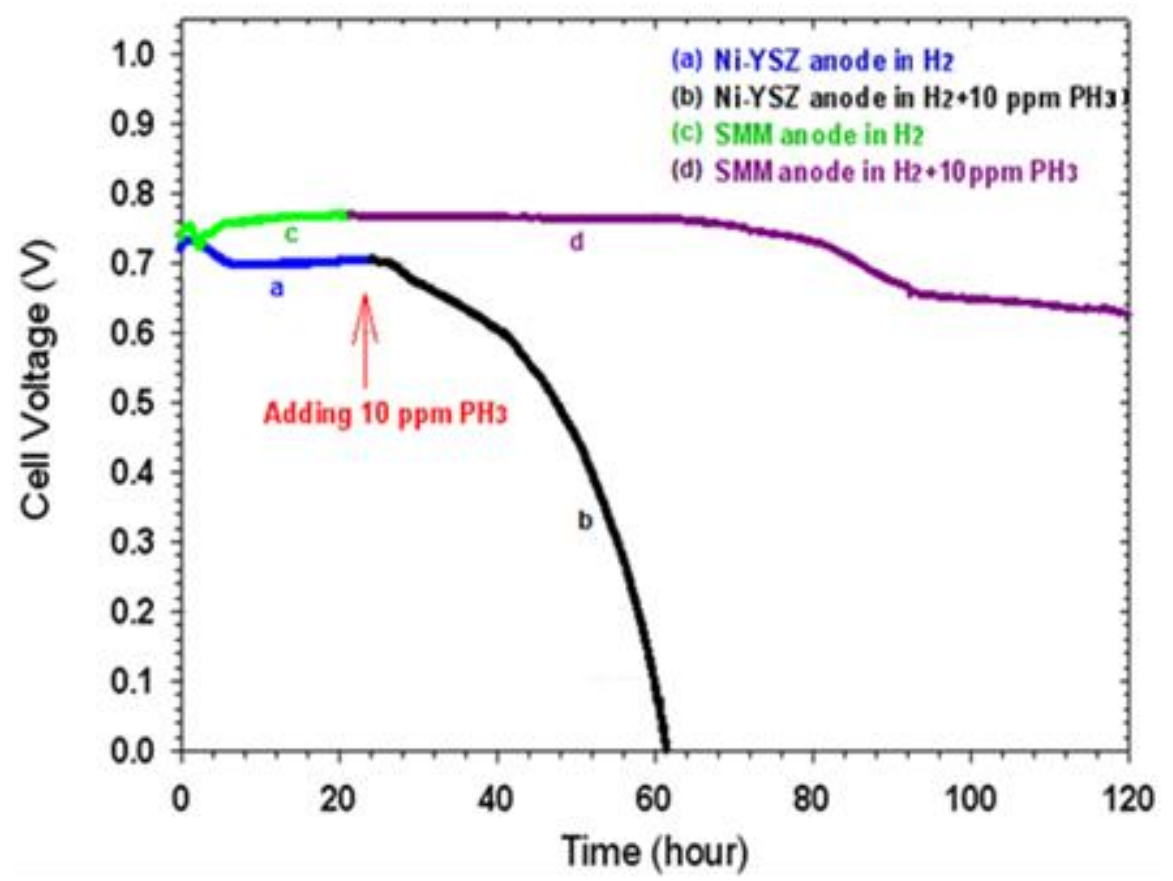

Figure 44: Comparison of the performance at constant current density $\left(0.25 \mathrm{~A}-\mathrm{cm}^{-2}\right)$ in wet $\mathrm{H}_{2}$ and with addition of 10 ppm $\mathrm{PH}_{3}$ between Ni-YSZ anode cell and SMM/GDC anode cell [113].

Within $30 \mathrm{~h}$, the Ni/YSZ cell voltage drops to $0 \mathrm{~V}\left(\sim 3.1 \% \mathrm{~h}^{-1}\right)$ using the same testing protocol and conditions. Extrapolation of the performance curve for the SMM/GDC anode would result in complete cell failure after approximately $750 \mathrm{~h}$. The complete cell failure in this context indicates the point where the cell potential will reach a zero value. Figure 45 shows the detailed progression of the Nyquist plots through the duration of the testing. 


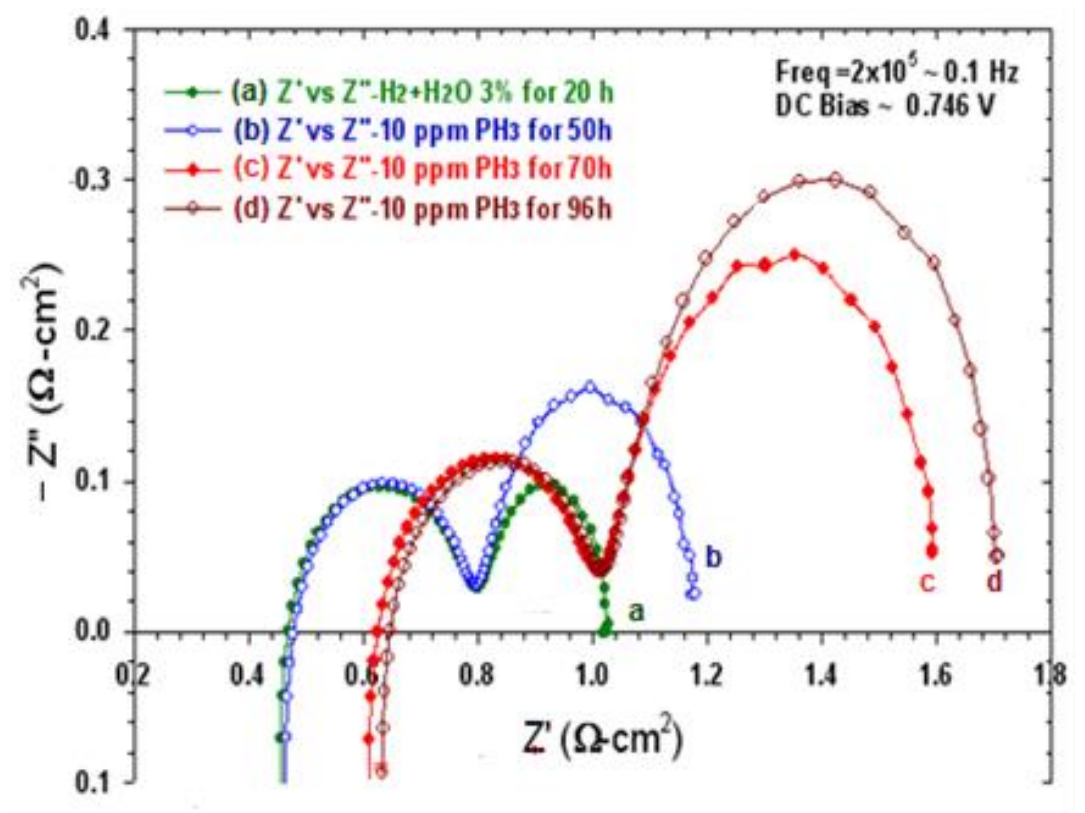

Figure 45: EIS curves at $0.746 \mathrm{~V}$ bias before and after introducing $10 \mathrm{ppm} \mathrm{PH}_{3}$ impurity into the $\mathrm{H}_{2}$ fuel stream [113].

After $50 \mathrm{~h}$, no change in the ohmic resistance and the high frequency arc was observed. The only change during this time was an increase to the second arc. This increase in the second arc did not however affect the cell performance during this time. The images suggest small changes in the bulk anode microstructure throughout the duration of the testing. However, this microstructure is a far contrast from what is typically seen for poisoning of the Ni/YSZ anode, where the formation of phosphide and/or phosphate phases throughout the bulk of the anode results in vast microcracking, anode densification, and microstructural failure [8,50]. Figure 46

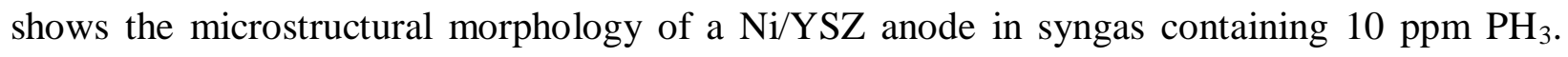
Both particle coarsening and nickel migration to the anode surface are observed. 

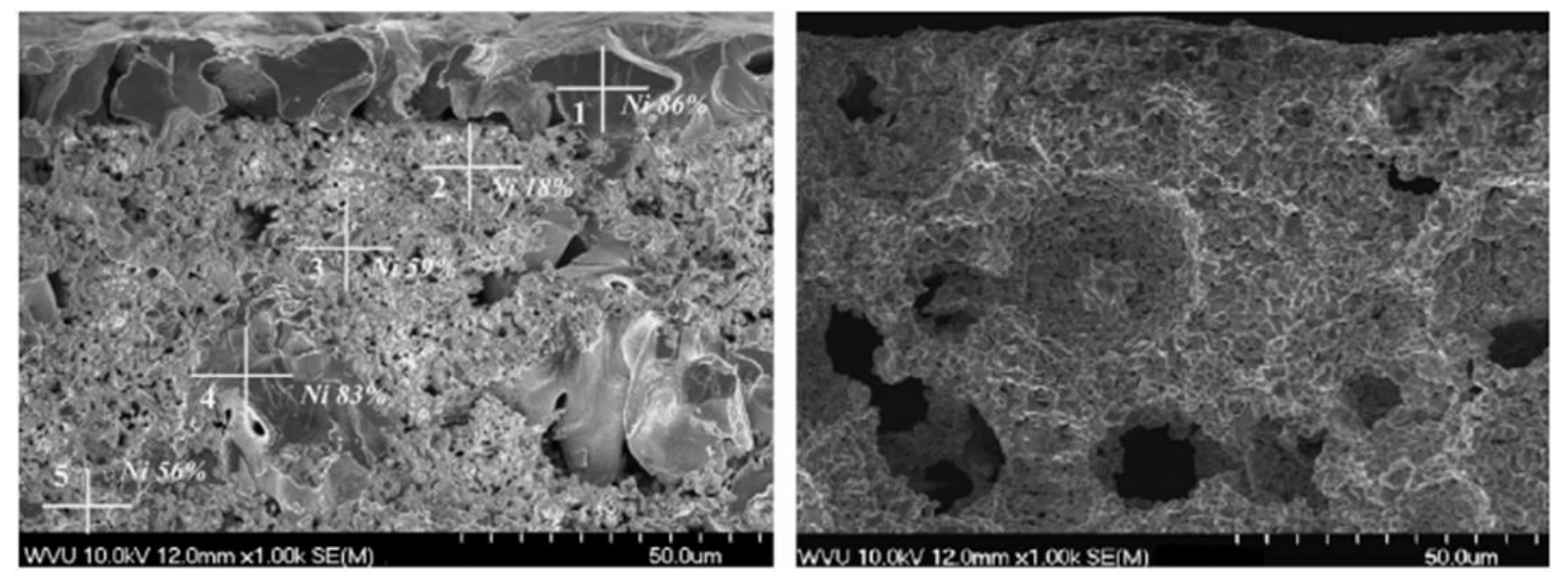

Figure 46: Ni/YSZ anode in left) clean syngas and right) syngas $+10 \mathrm{ppm} \mathrm{PH}_{3}[8]$.

Figure 47 shows the difference in bulk anode microstructures between the poisoned and unpoisoned sample. The images suggest small changes in the bulk anode microstructure throughout the duration of the testing. Therefore, the effect of anode microstructural changes must not be the sole culprit for the performance degradation for the SMM/GDC composite anode. It was identified after post-mortem investigation that the microstructure of the Pt contact was vastly altered. Figure 47 shows that the Pt contact material densified extensively and delamination was shown along the contact area between the anode and the lead wires. Both densification and delamination of these leads may contribute significantly to the restriction of fuel diffusion to the anode surface and current collection. 

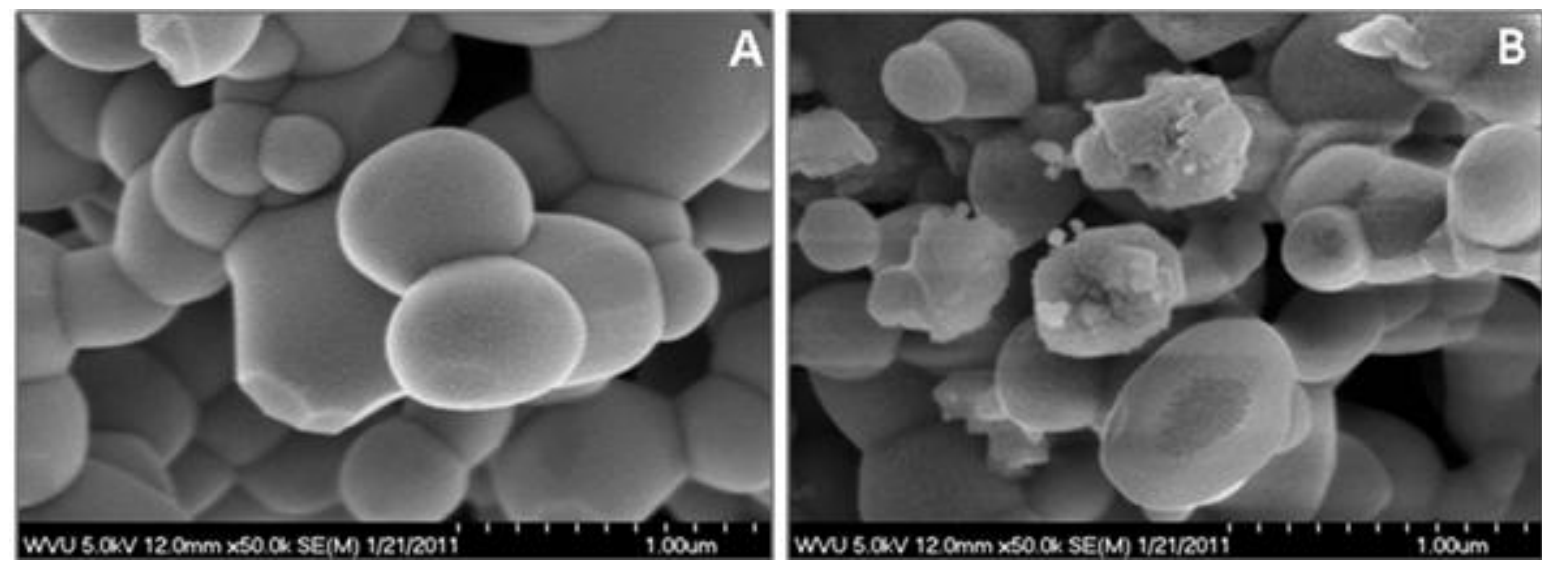

Figure 47: $\mathrm{SEM}$ micrographs of the SMM/GDC anode after testing in A) wet $\mathrm{H}_{2}$ and $\mathrm{B}$ ) wet $\mathrm{H}_{2}$ with $10 \mathrm{ppm} \mathrm{PH}_{3}$.

There appears to be no significant change to the microstructure of the bulk of the anode [113].

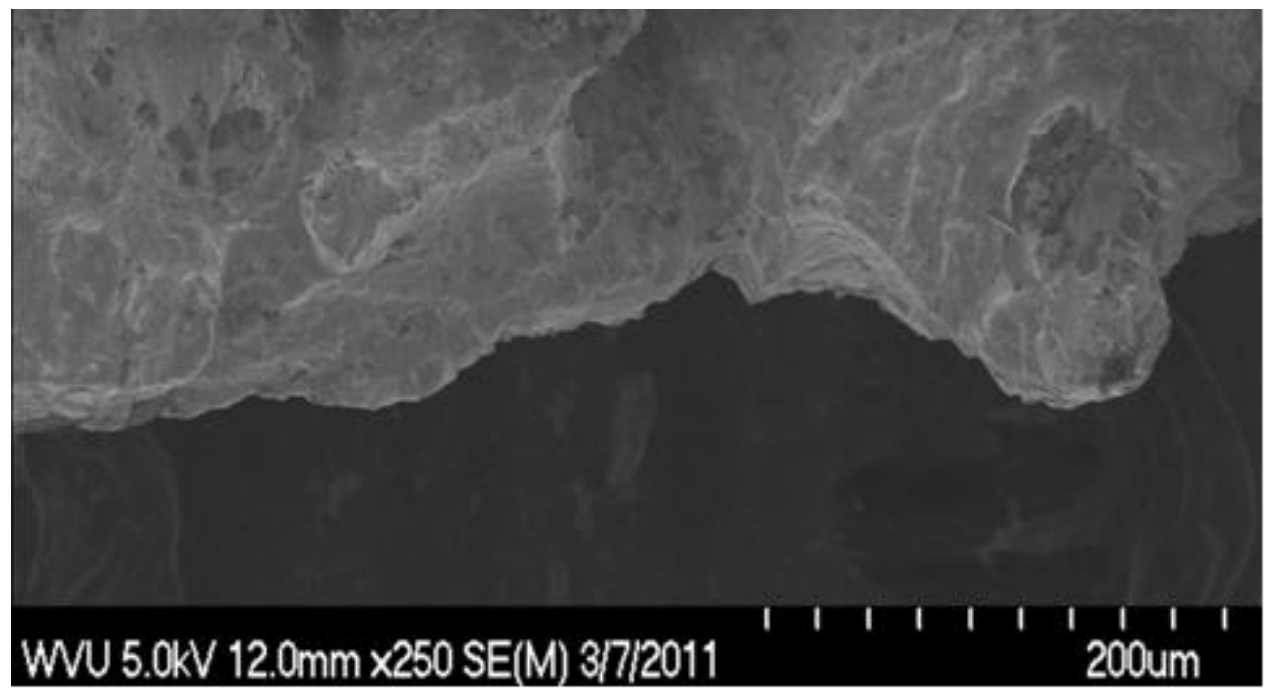

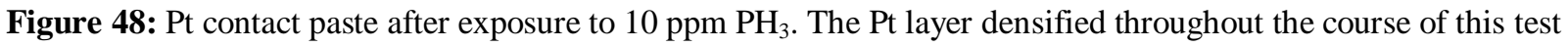
[113].

During the next $20 \mathrm{~h}$, a 34\% increase in the ohmic resistance and another increase in the second arc were observed. From this point to the conclusion of the test, increases to the polarization and series resistance were minimal. Figure 49 indicates that the reasoning for the 
increase in series resistance may be due to slight delamination at the electrode/electrolyte interface, which would suggest that ion and/or current flow is being hindered.

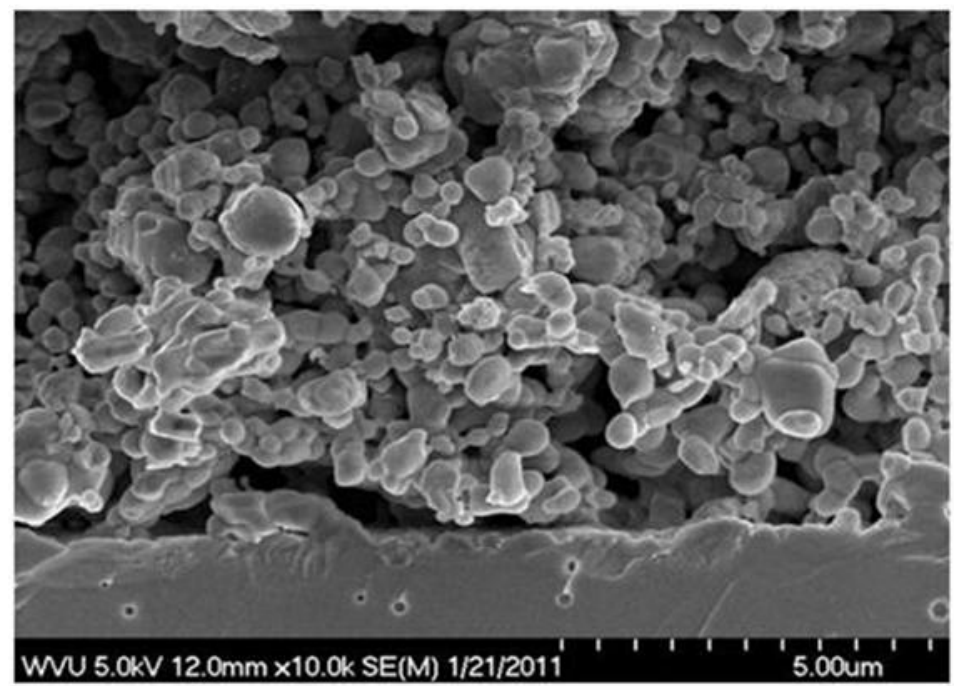

Figure 49: SEM micrograph of the active anode/electrolyte interface after $\mathrm{PH}_{3}$ poisoning test for the SMM/GDC composite anode [113].

By the end of the test, the magnitude of the resistance from the first arc remains about the same, meaning that low frequency processes and increases to the ohmic resistance are ultimately responsible for the decrease in performance of the cell.

\subsubsection{XPS/EDS Analysis}

The XPS spectrum along the anode/electrolyte interface from a cross-sectioned sample was completed to identify the formation of secondary phases, such as phosphide or phosphate compositions. One possibility would be for phosphorus to exist at the interface as either a phosphide or phosphate. Xu et al. [8] showed distinct peaks for P 2s and P 2p at $192 \mathrm{eV}$ and 134 $\mathrm{eV}$, respectively, where the $134 \mathrm{eV}$ peak from their work corresponded to possible phosphate presence in the form of either $\mathrm{P}_{2} \mathrm{O}_{5}$ or $\mathrm{PO}_{4}{ }^{3-}$. Their XPS analysis also indicated potential nickelphosphide phase formation from their Ni 2p 3/2 peaks. These results were obtained using similar testing conditions to the work performed in this study; the only difference being that $\mathrm{Xu}$ et al. 
completed the testing in syngas with $\mathrm{PH}_{3}$, which will be a focal point of future work for this SMM anode.

The XPS results from this fuel cell test show that no P 2s peak was detected near the active interface. Figure 50 shows the overall spectra near the active interface with distinct peaks for each of the key anode components. Figure 51 shows an enhanced view of the range where the P 2s peak would be expected. This lack of a peak is evidence to suggest that the phosphorus is not residing in the active interface. The $\mathrm{P} 2 \mathrm{p}$ peak however is more difficult to classify. Figure 52 is the magnified XPS spectra corresponding to the $\mathrm{P} 2 \mathrm{p}$ peak.

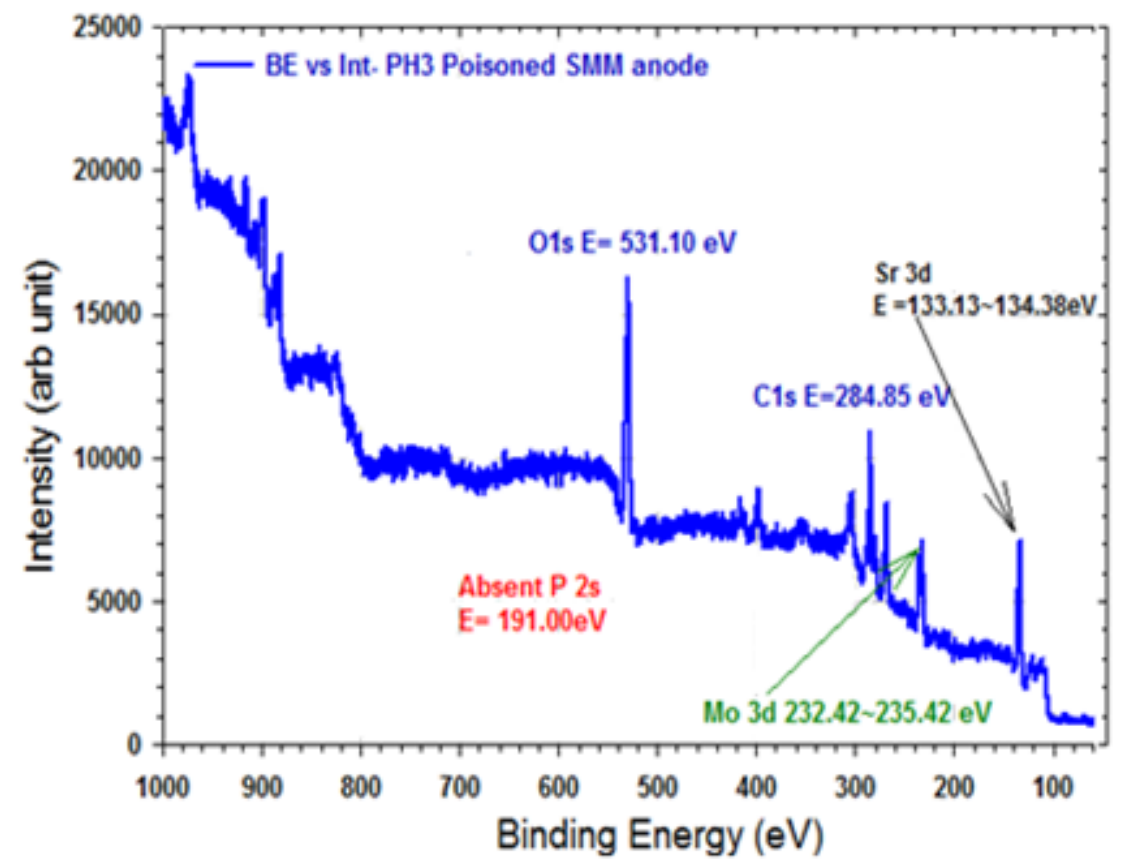

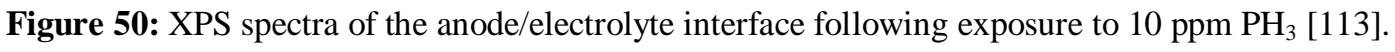




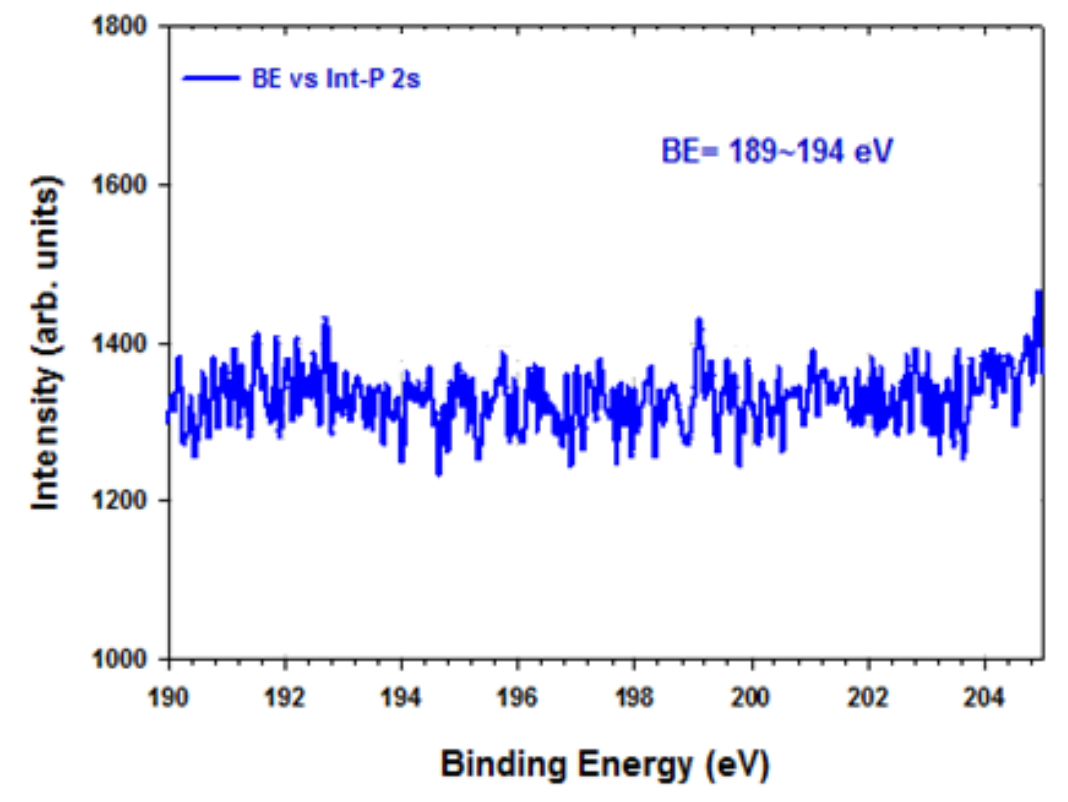

Figure 51: An enhanced view of the XPS spectra with no change in signal at $192 \mathrm{eV}$ where the $\mathrm{P} 2 \mathrm{~s}$ peak would be expected [113].

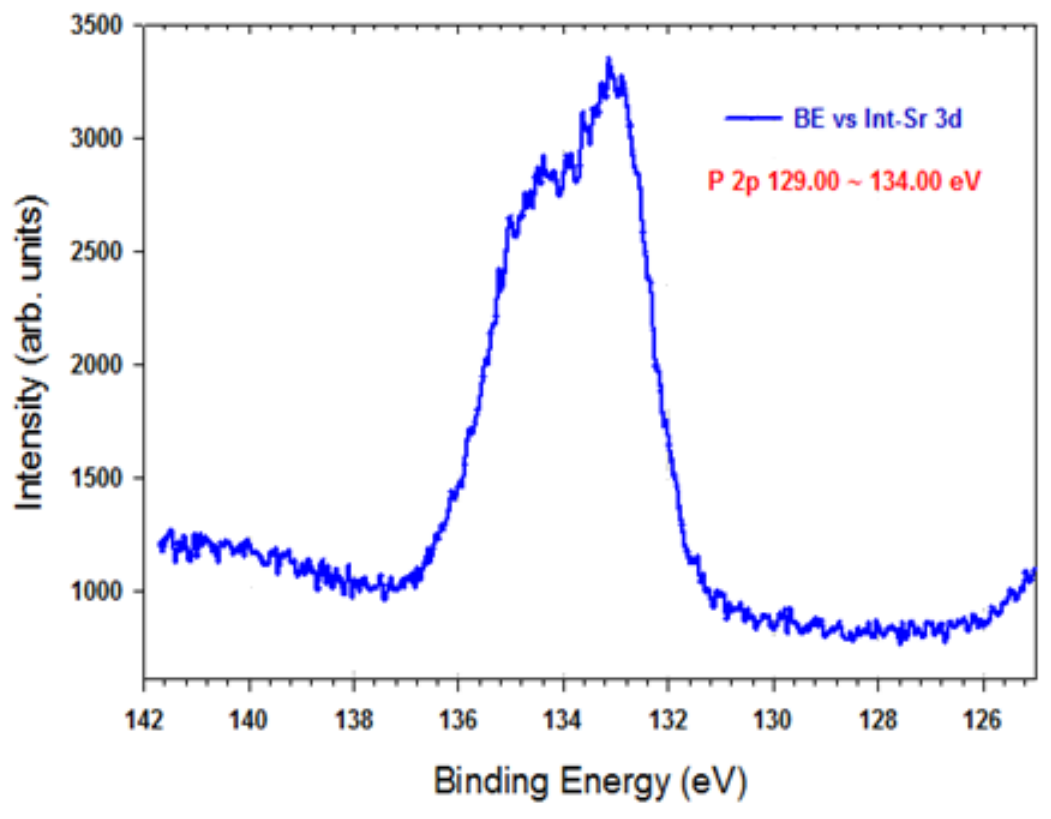

Figure 52: An enhanced view of the XPS signal in the $134 \mathrm{eV}$ range corresponding to the $\mathrm{Sr} 3 \mathrm{~d}$ signal. This signal also corresponds to the $\mathrm{P} 2 \mathrm{p}$ peak and thus is not adequate for elemental qualification [113]. 
A fairly well-defined peak is present in the range of $132-134 \mathrm{eV}$, which could suggest that phosphate compounds were present in our sample. The problem is that this peak coincides with the Sr 3d peak, making it difficult to identify this peak using XPS alone. To help rectify this diagnostic problem, an EDS analysis was conducted in a similar location to distinguish between the two elements. The spectral plot in Figure 53 shows a very distinct Sr peak and a very weak signal for $\mathrm{P}$.

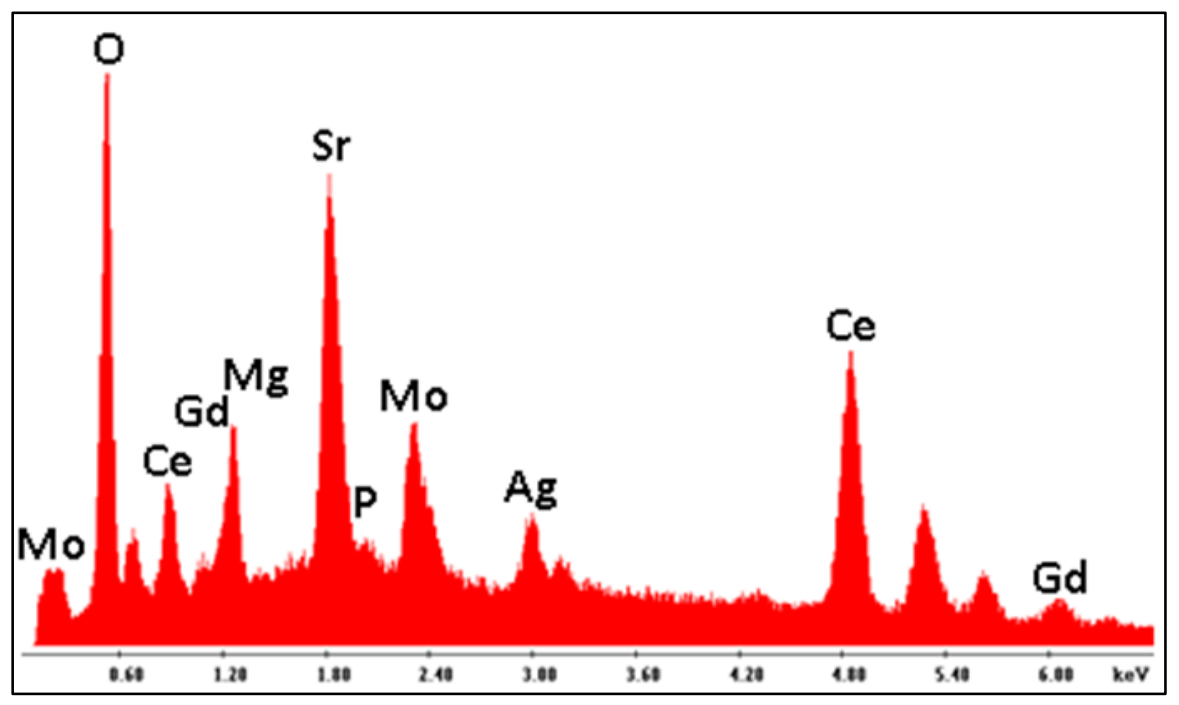

Figure 53: EDS scan of the anode/electrolyte interface. The scan has a well defined Sr peak and a very weak signal for P [113].

This along with the lack of a $\mathrm{P} 2$ s peak cannot rule out that phosphorus is responsible for the degradation, but these results indicate a low P presence in the active region, thus diminishing the potential for microstructural alteration at the anode/electrolyte as the sole degradation mechanism.

Without thermodynamic analysis available, an experimental approach was taken for our testing condition to determine whether or not each of the raw constituents in the SMM structure have any noticeable interaction with P. This set of testing was carried out through exposure tests in the same testing chamber as the fuel cell experiments. The raw powders used in the solid-state synthesis of the SMM powder were all heated to $800^{\circ} \mathrm{C}$ to get them in a state free of carbonates. The powders were then mixed into an ink and coated onto a YSZ substrate, so that the powders 
can be sealed. They were then heated up to the testing temperature of $800^{\circ} \mathrm{C}$ using the identical heating protocol as for the fuel cell tests. Samples in clean $\mathrm{H}_{2}$ and $\mathrm{H}_{2}$ with $10 \mathrm{ppm} \mathrm{PH}_{3}$ were compared to the raw powders using XPS to observe any potential interactions with P. Each of the XPS survey scans for $\mathrm{Sr}, \mathrm{Mg}$, and Mo in clean $\mathrm{H}_{2}$ can be seen in Figures 54, 55, and 56 respectively. These plots all identify the $\mathrm{C} 1 \mathrm{~s}$ peak at $\sim 284 \mathrm{eV}$ indicating that the peaks were properly shifted. The $\mathrm{Sr} 3 \mathrm{~d} 5 / 2$ peak can be seen in a range between $132-135 \mathrm{eV}$ for the clean sample. The fact that 2 peaks are present in this region suggest that both elemental $\mathrm{Sr}$ and $\mathrm{SrO}$ are present in the clean reduced sample.

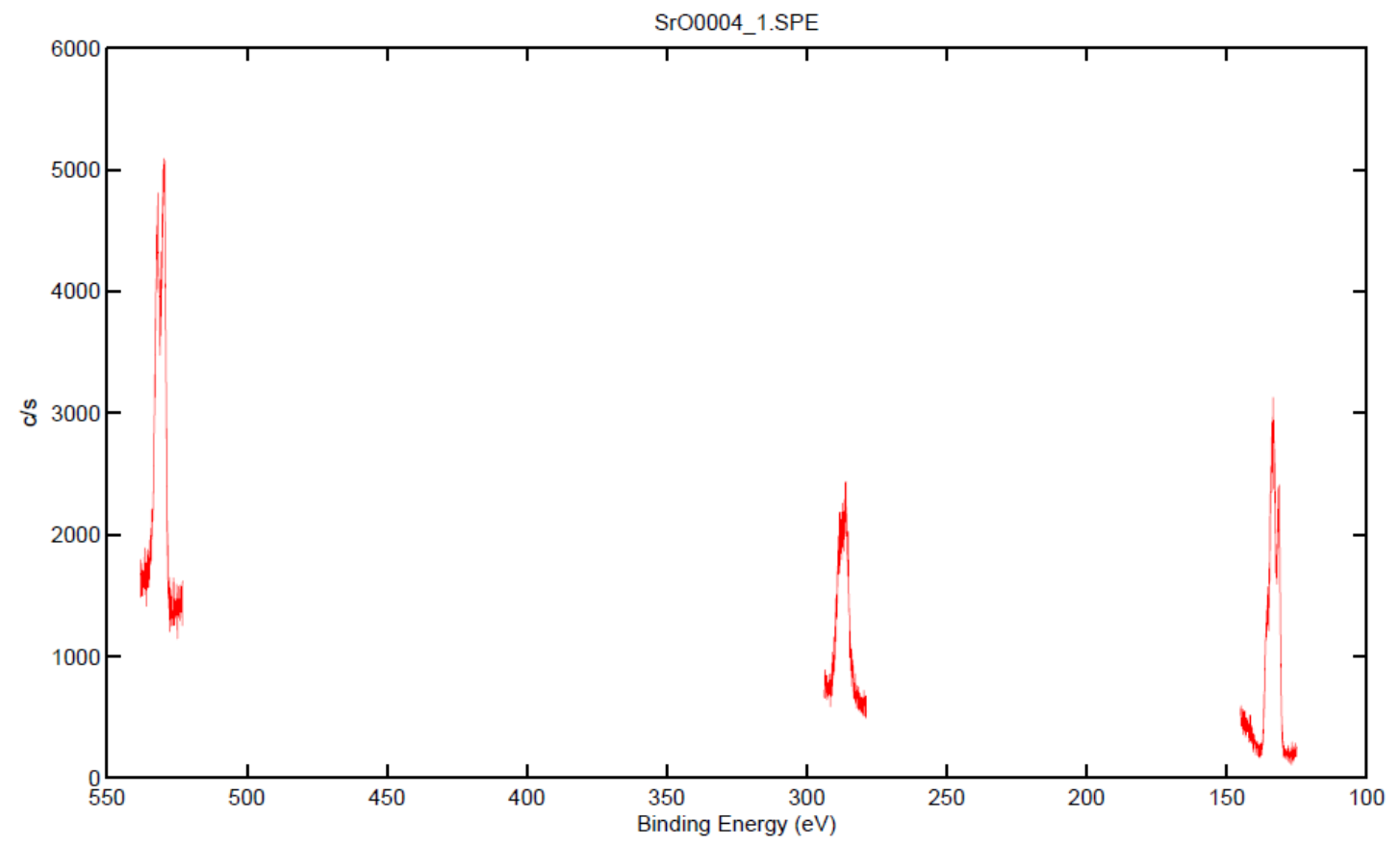

Figure 54: XPS peaks of the clean reduced raw Sr powder.

The peak corresponding to the $\mathrm{Mg} 2 \mathrm{p}$ orbital is seen in Figure 55 at a binding energy of $\sim 49.2 \mathrm{eV}$. This peak is very broad and the presence of a second peak can potentially be detected. Like $\mathrm{Sr}$, this is indicative of a mixture of elemental $\mathrm{Mg}$ and $\mathrm{MgO}$ for the sample after reduction for $48 \mathrm{~h}$. 


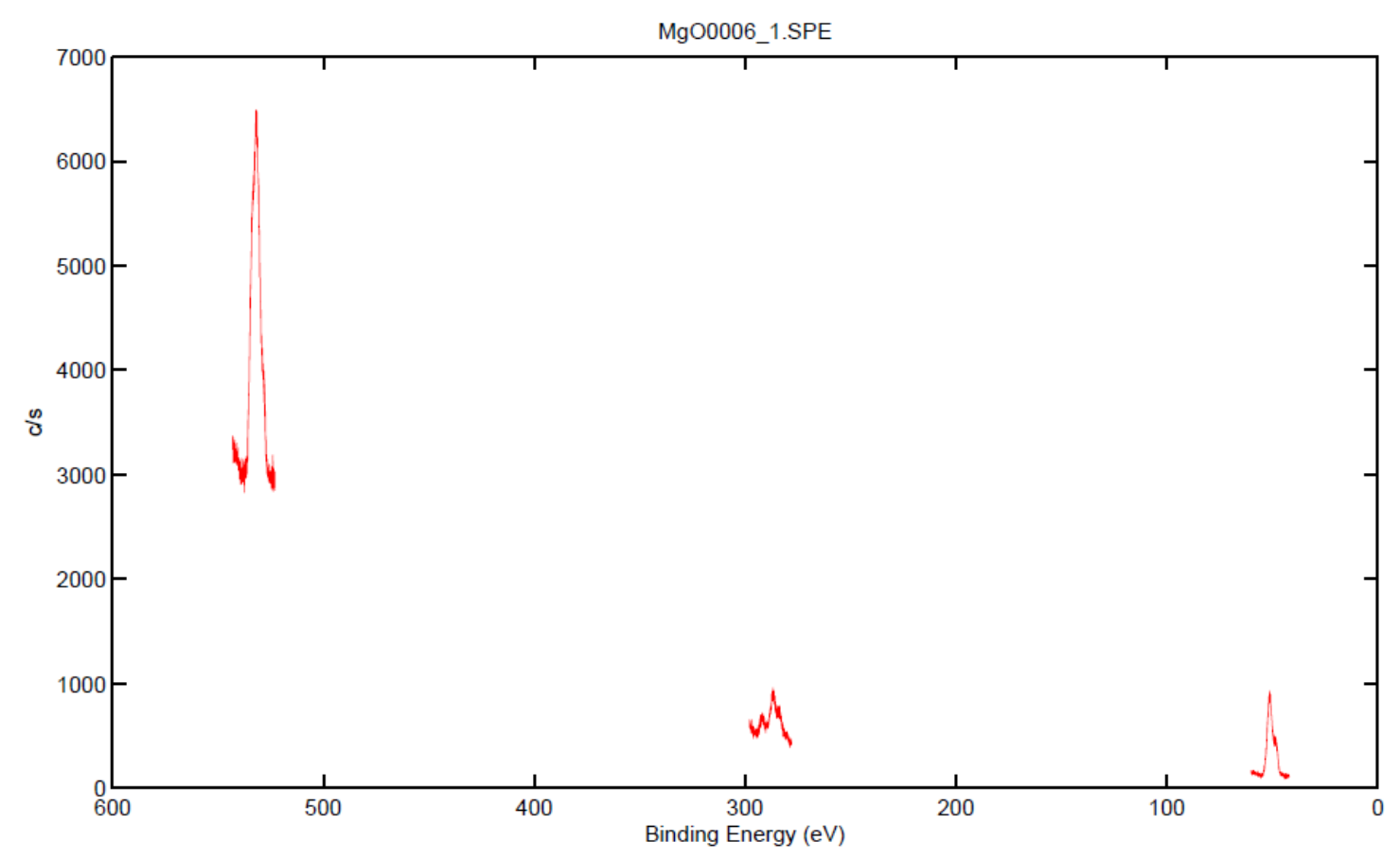

Figure 55: XPS peaks of the clean reduced raw Mg powder.

In the case of the reduced $\mathrm{MoO}_{3}$ powder, there are three peaks present. The peak locations are $236.2 \mathrm{eV}, 232.5 \mathrm{eV}$, and $229.2 \mathrm{eV}$. According to the NIST XPS database, these are closest to $\mathrm{MoO}_{2}$, which is a reduced form of $\mathrm{MoO}_{3}$. While this is not the same redox couple, $\mathrm{Mo}(\mathrm{VI}) / \mathrm{Mo}(\mathrm{V})$, that is seen for the Mo in the SMM structure due to its 6-fold oxygen coordination, this is the type of evolution that would be expected in a wet $\mathrm{H}_{2}$ environment for a pure $\mathrm{MoO}_{3}$ sample. 


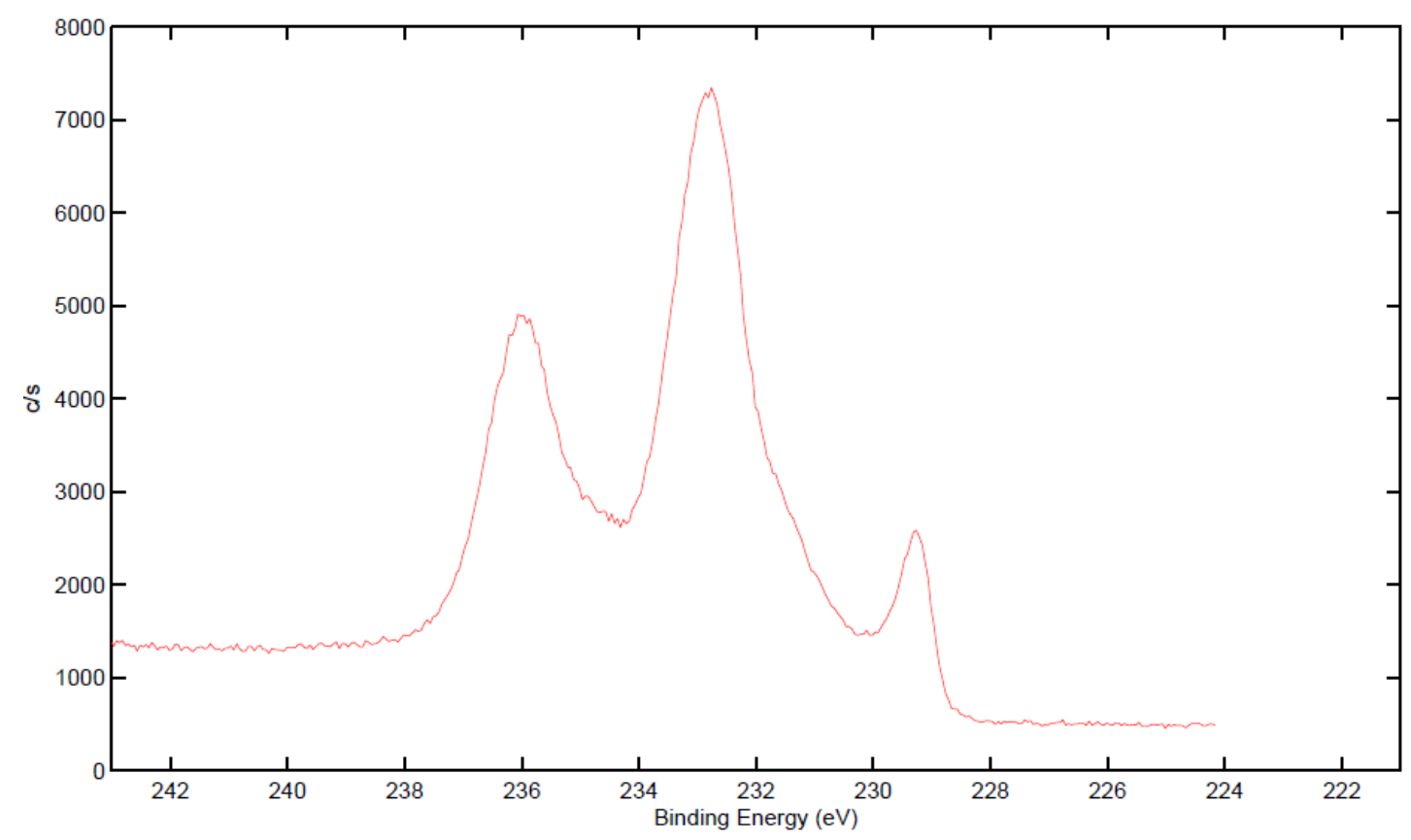

Figure 56: XPS peaks of the clean reduced raw Mo powder.

The peaks in the above figures represent the baseline case where no $\mathrm{PH}_{3}$ impurity is added. These exposure tests were done to $48 \mathrm{~h}$, which is beyond the point where degradation began to set in for the SMM/GDC anode. The same exposure time was carried out for the

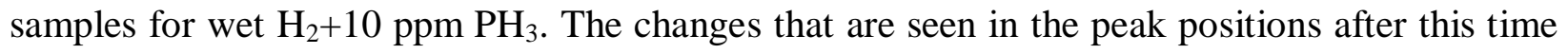
could help assess interactions between each of the raw constituents and the P. In the case of the Sr exposure, the $\mathrm{Sr} 3 \mathrm{~d} 5 / 2$ peak and the P2p peaks overlap so it is difficult to classify. Figure 57 shows the two apparent peaks corresponding to $\mathrm{P} 2 \mathrm{p}$ which both appear to be phosphates. To classify the Sr, the $3 p$ spectra can be used. The Sr peak for this can be seen in Figure 58. This peak is located at a slightly lower binding energy than carbon but they do not overlap. The peak position for $\mathrm{SrO}$ is $\sim 270-271 \mathrm{eV}$, which this peak lies right between $(270.8 \mathrm{eV}$ ). This combined with the $\mathrm{P} 2 \mathrm{p}$ peaks suggests that interactions between $\mathrm{Sr}$ and $\mathrm{P}$ are limitied to surface phosphates, which could easily have been formed during exposure to the ambient. 


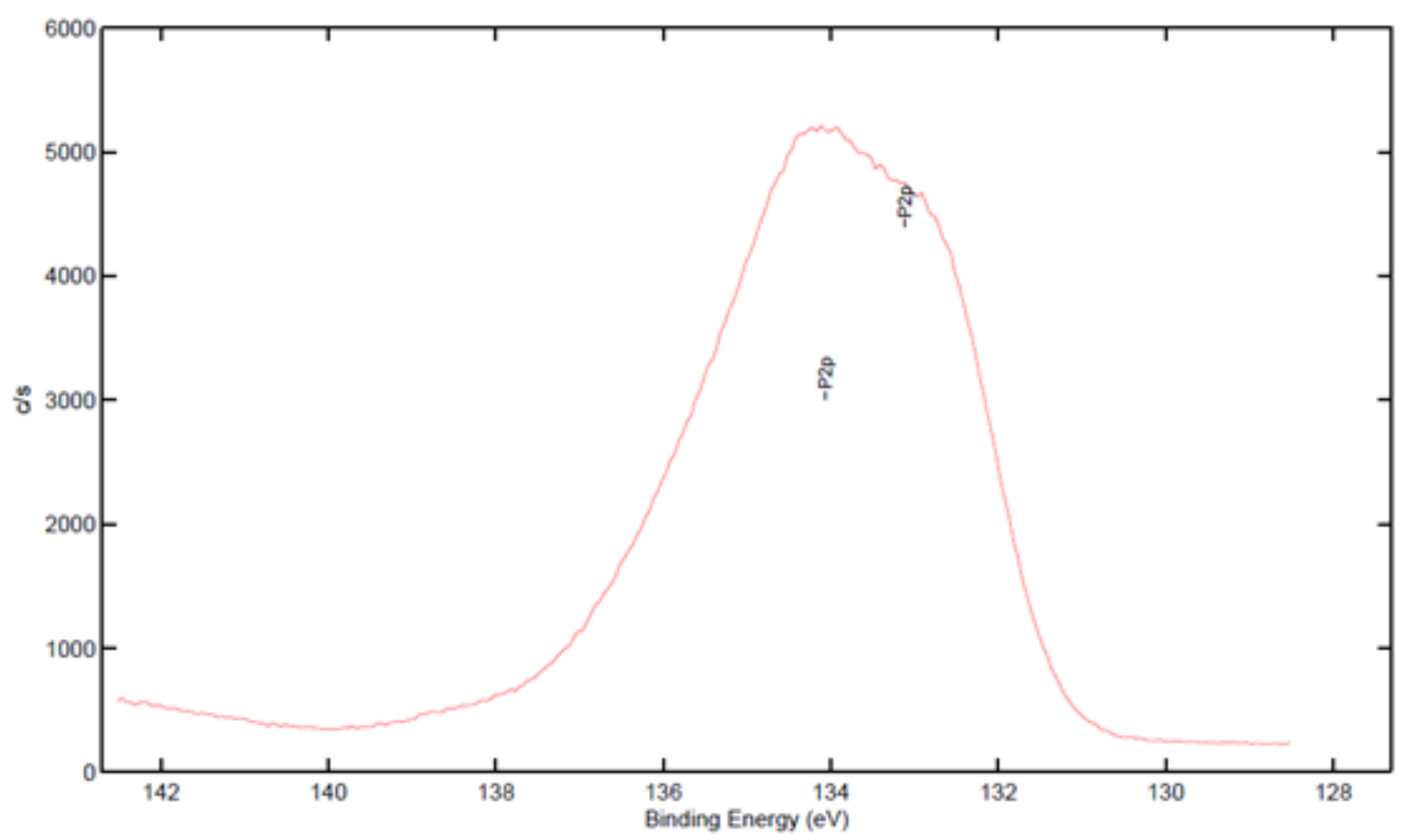

Figure 57: XPS for the overlapped Sr 3d and P 2p peak region.

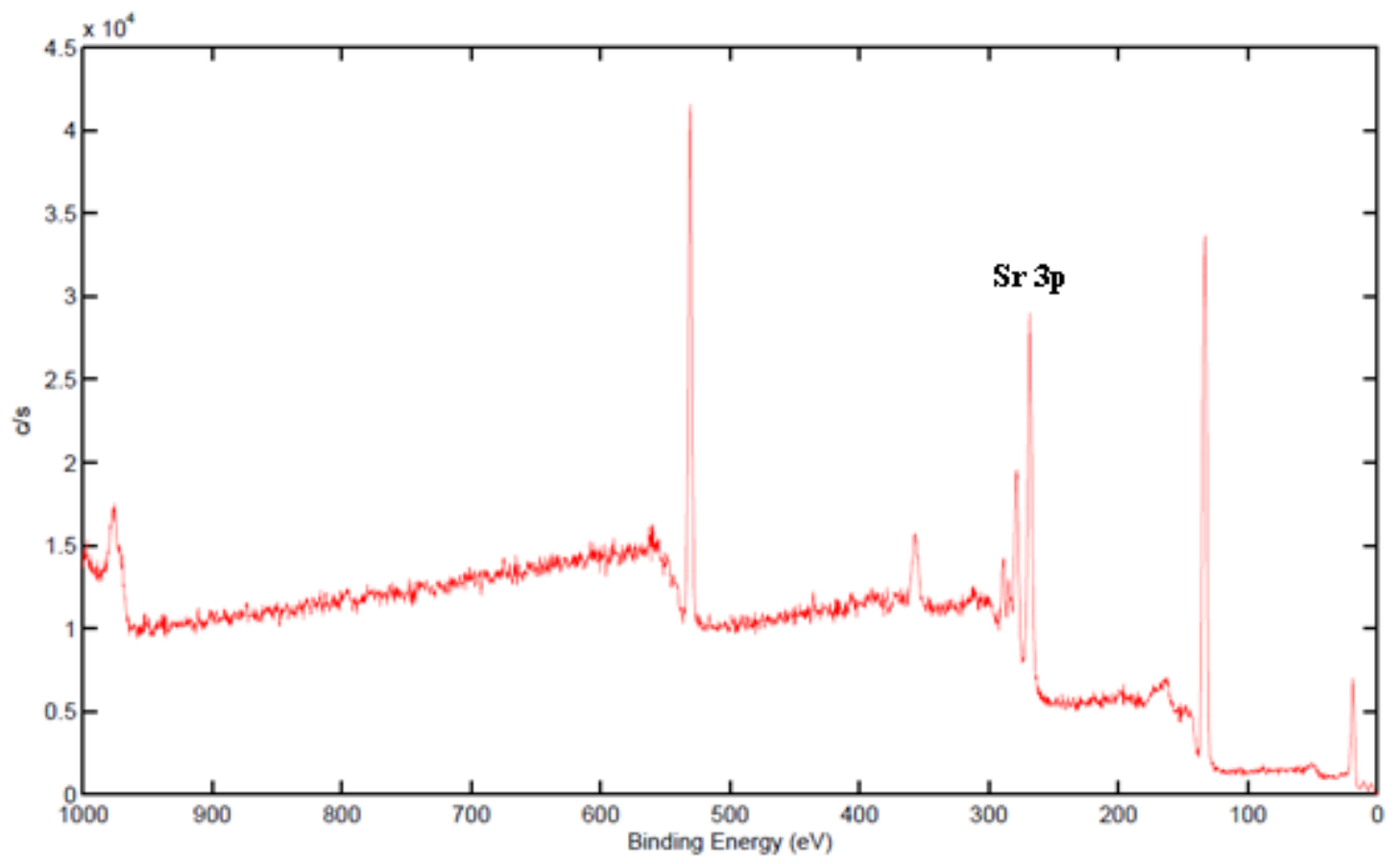

Figure 58: XPS for the Sr 3p spectra for the poisoned sample.

For $\mathrm{Mg}$, there was no observed peak shift between the samples exposed to clean and Pladen fuel. Figure 59 displays the Mg 2P peak. The peak position to of $49.2 \mathrm{eV}$ is nearly identical 
to that of the clean sample in Figure 55. Additionally, the only peak detectible in the P $2 \mathrm{p}$ region is at $134 \mathrm{eV}$ (Figure 60), that of phosphate rather than phosphide formation with $\mathrm{Mg}$.

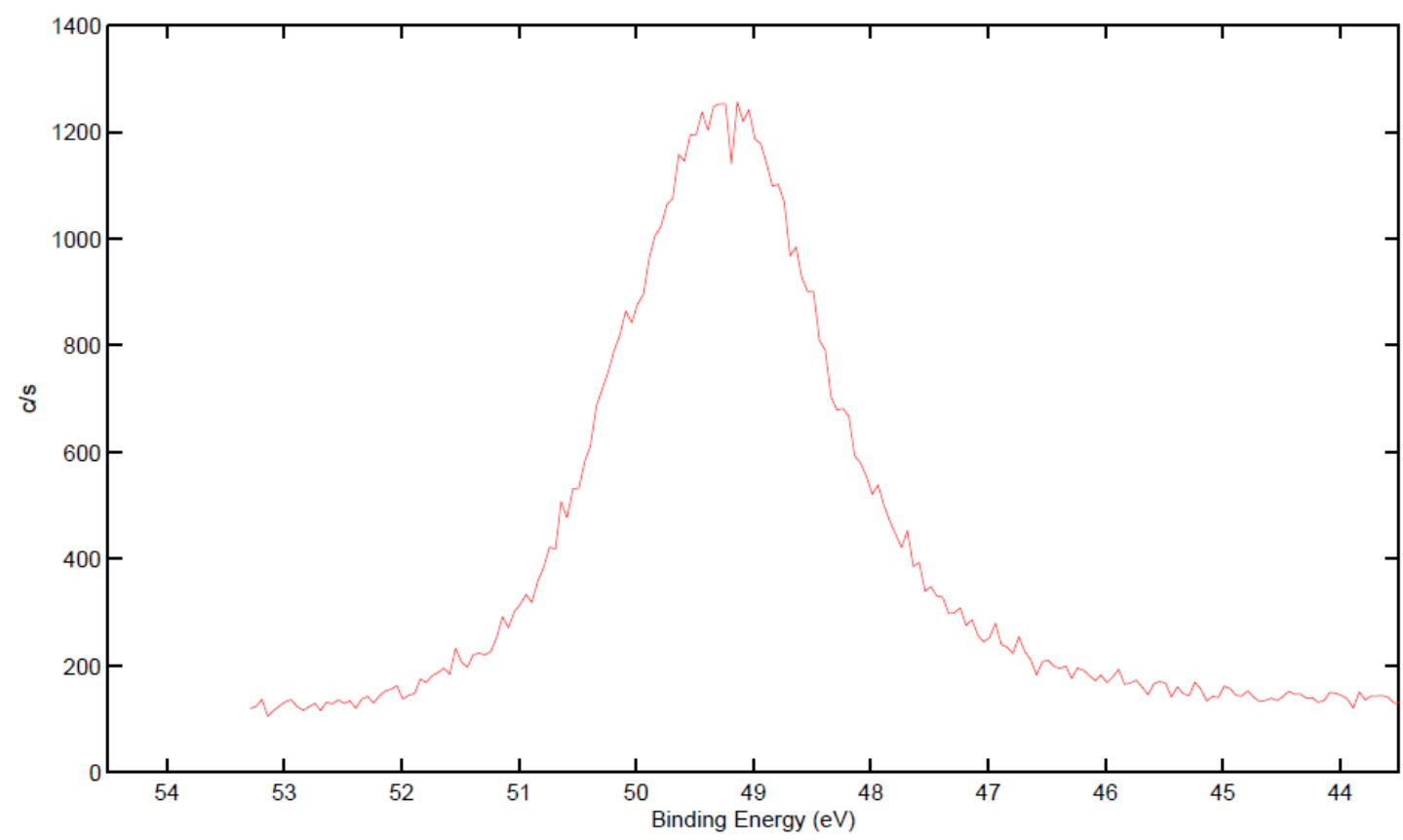

Figure 59: $\mathrm{Mg} 2 \mathrm{p}$ peak for the poisoned $\mathrm{MgO}$ sample.

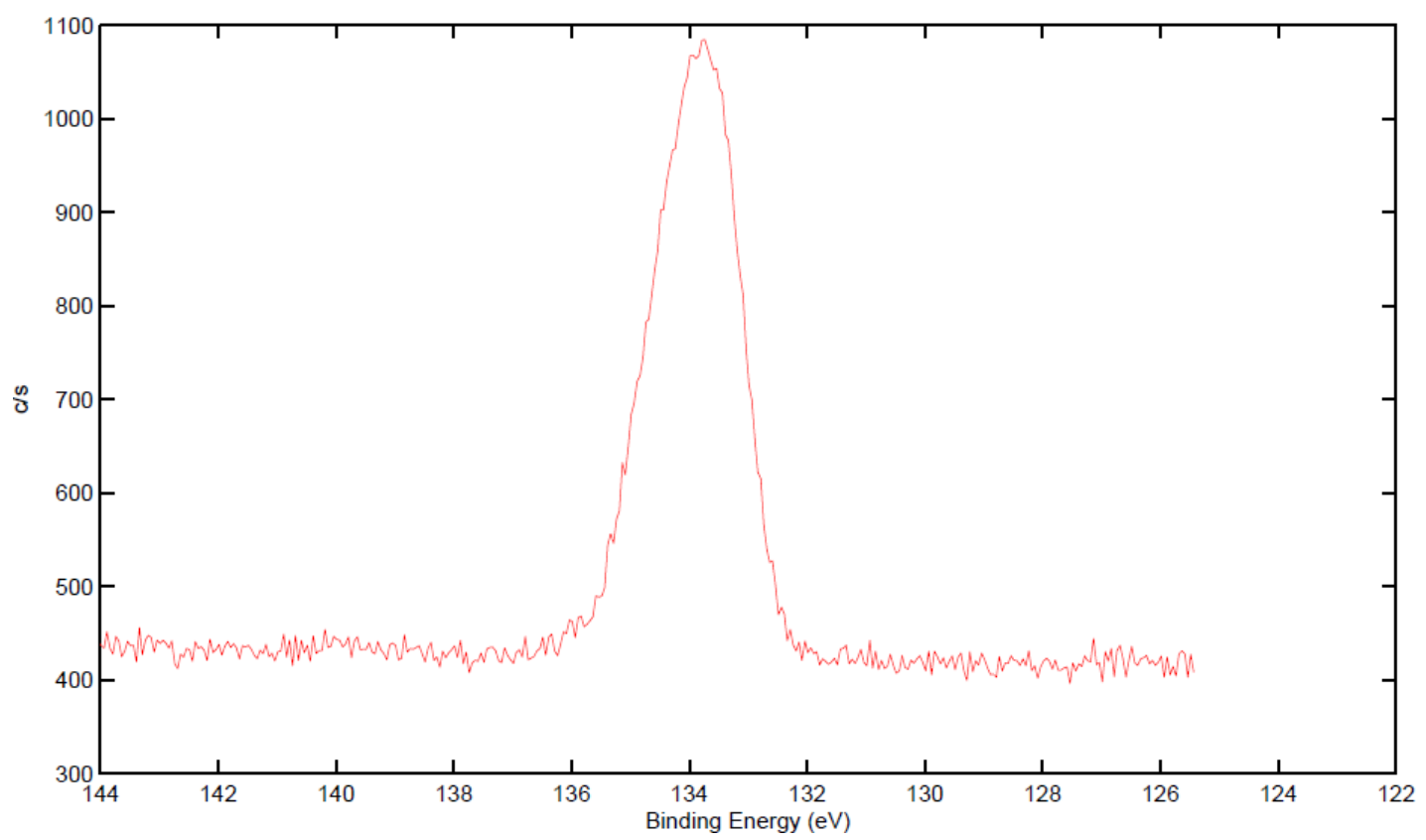

Figure 60: $\mathrm{P} 2 \mathrm{p}$ peak for the poisoned $\mathrm{MgO}$ sample. 
Lastly, changes to the $\mathrm{MoO}_{3}$ sample peaks were compared with and without $\mathrm{PH}_{3}$

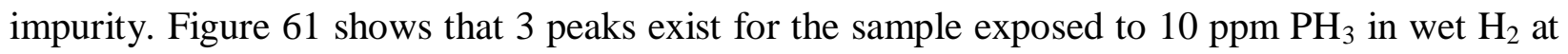
$236.2 \mathrm{eV}, 232.8 \mathrm{eV}$, and $229.3 \mathrm{eV}$.

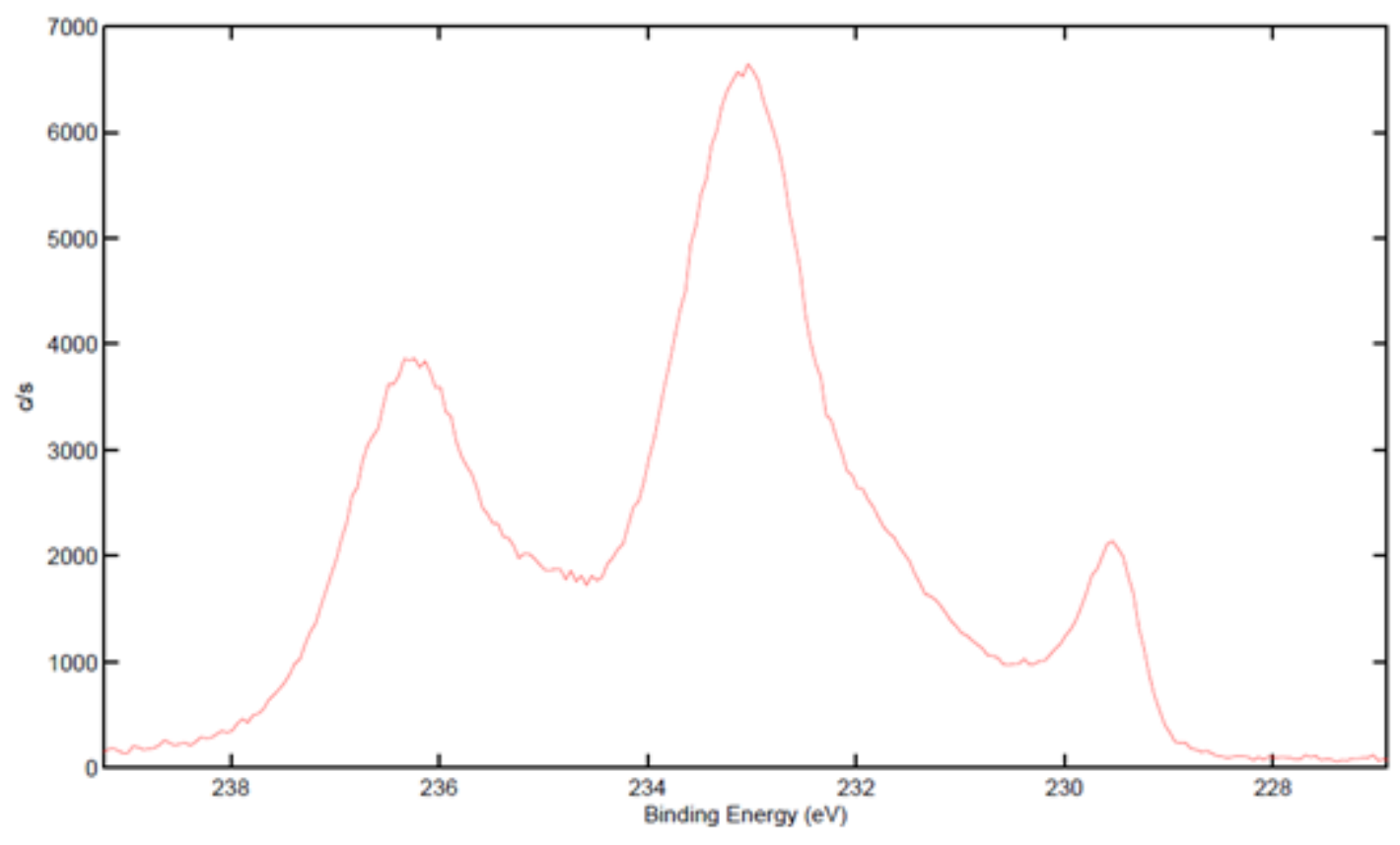

Figure 61: Mo 3d spectra for the poisoned $\mathrm{PH}_{3}$ samples.

Almost no shifts to the 3 peaks were seen when comparing the clean and poisoned samples. Also, a similar phosphate peak was observed as with the $\mathrm{Sr}$ and $\mathrm{Mg}$ samples. To get an idea of what type of XPS peak would form should the Mo and P react chemically to form a solid Mo-P phase, a recent publication by Bai et al. shows their P 2p spectra for their Mo-P hydrodesulfurization catalyst [131]. 


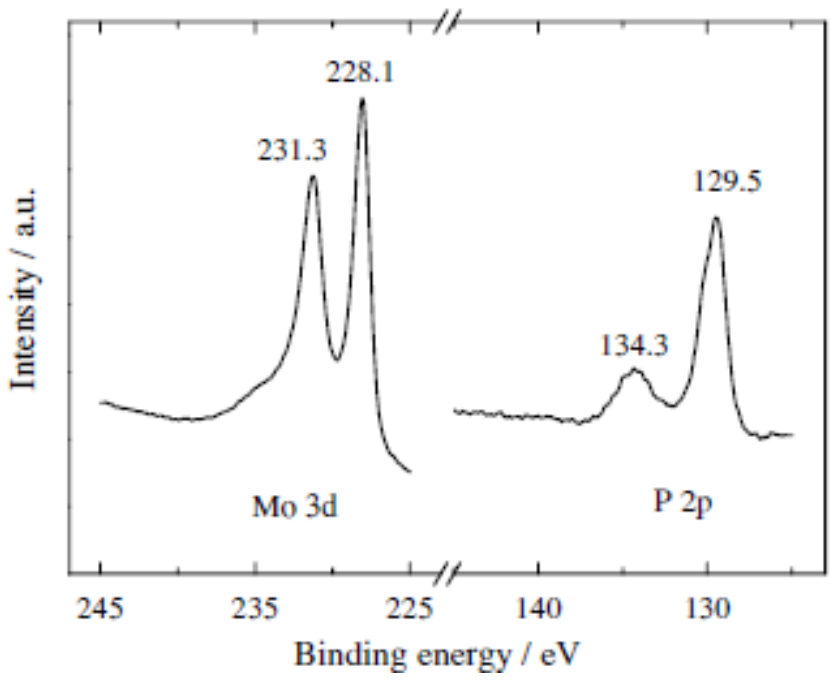

Figure 62: XPS spectra for the Mo 3d and P 2p regions for a solid MoP hydro-desulfurizaiton catalyst [131].

If the Mo were to chemically react with the $\mathrm{P}$ to form a Mo-P phase, a strong peak would be seen at a binding energy around $129 \mathrm{eV}$. This is similar for the other SMM constituents, as this energy range (128-130 eV) corresponds to $\mathrm{P}$ bonding with another metal. This lack of any $\mathrm{P}$ $2 p$ peak in that range for any of the raw powders indicates that for our testing conditions interactions between the $\mathrm{P}$ and the other metals are limited to surface phosphate formation which is consistent with the fuel cell test carried out previously.

\subsubsection{Conclusions}

A SMM/GDC composite SOFC anode composition was fabricated and tested on an electrolyte-supported platform in humidified $\mathrm{H}_{2}$ and coal syngas fuels. The GDC was found to greatly improve the performance of the cell and is primarily aiding in the anode's ionic conduction. The cell exhibited stability in wet hydrogen and the performance of the cell remained the same after the first $50 \mathrm{~h}$ in $10 \mathrm{ppm} \mathrm{PH}_{3}$. After this however, the cell potential decreased and never fully re-stabilized. The rate of degradation of this composite anode was much lower than that of the standard Ni/YSZ anode, which signifies the value of this work. The XPS and EDS spectra of the anode/electrolyte interface did not distinctly confirm the presence of secondary phase formation. This result is in far contrast to that seen for typical Ni/YSZ anodes 
exposed to phosphine. We are initially attributing power degradation to slight anode delamination and mass diffusion limitations from contact paste densification. However, due to the

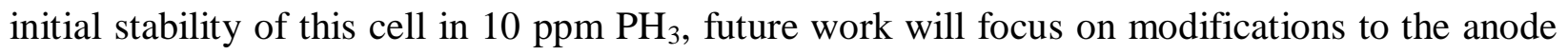
architecture and current collection in order to optimize performance and demonstrate increased contact stability. In addition, fundamental mechanistic studies are required to better understand the lower rate of electrochemical and microstructural degradation for this ceramic composite compared to the typical Ni/YSZ cermet anode. Better understanding of the interaction of the phosphine with this all-ceramic anode will provide valuable information in the pursuit of developing a high-performance anode that may function on coal-syngas fuel with reasonable levels of $\mathrm{H}_{2} \mathrm{~S}$ and $\mathrm{PH}_{3}$ contaminants.

\subsection{In Situ Formation of a Solid Oxide Fuel Cell (SOFC) Cermet Anode by $\mathrm{NiWO}_{4}$ Reduction}

The Ni-cermet compositions, typically Ni combined with YSZ, are the traditionally used anode for solid oxide fuel cell (SOFC) applications over the past few decades. This cermet is conventionally processed by initially creating a composite mixture of micron-sized $\mathrm{NiO}$ and the electrolyte oxide powders. After incorporation within the SOFC microstructure, the Ni-cermet is formed by reduction during the operation of the fuel cell. Although this general process for forming the Ni-cermet SOFC anodes have proven to be economical and resulted in fuel cells with adequate performance characteristics, the overall final anode microstructure can be further optimized. In the end, the stated process results in an inhomogenous mixture of micron-size agglomerates of $\mathrm{Ni}$ and YSZ particles throughout the anode, which limits the overall cell performance by failing to maximize the triple-phase boundary (TPB) sites that control the electrochemical oxidation processes.

In order to improve the dispersion of the metal catalyst throughout the cermet anode structure, researchers developed processes of impregnating porous electrolyte structures with aqueous and non-aqueous solutions containing $\mathrm{Ni}, \mathrm{Co}, \mathrm{Cu}$, and/or precious metals dissolved 
species (or dispersed nano-particulates) to form the cermet [114-116]. After multiple impregnation steps, the anode structure is dried and potentially fired to higher temperatures resulting in the formation of metal precipitates throughout the porous electrolyte structure. Researchers have shown that the incorporation of metal nano-catalyst into the anode structure by impregnation methods resulted in enhanced SOFC performance [117]. Unfortunately, the solution impregnation process typically does not result in homogeneous distribution of the nanoprecipitate due variations in solution wetting and drying characteristics. The final structure usually results in a concentration gradient from the surface into the porous anode interior consisting of agglomerated nanomaterials. Therefore, although the anode performance is increased by the incorporation of the nano-catalyst, the anode structure and cermet homogeneity is still not optimized or ideal.

Catalyst researchers have shown methods of in situ reduction of complex ternary oxide solid-solution to form oxide-supported nano-metal catalyst for various reforming applications. This process is dependent upon forming an oxide compound with base and/or precious metals dissolved into one of the structures sites. For example, Goldwasser et al. formed a perovskite solid solution of $\mathrm{La}_{1-x} \mathrm{Ca}_{x} \mathrm{Ru}_{0.8} \mathrm{Ni}_{0.2} \mathrm{O}_{3}$ [118]. During the methane reforming application, a homogenous mixture of 9-17 $\mathrm{nm} \mathrm{Ni}$ catalyst particles precipitated over the lanthanum ruthenate support particles to enhance catalytic activity. A similar strategy could be utilized for the formation of nano-enhanced SOFC anode structure, where a ternary oxide composition containing $\mathrm{Ni}$ could be in situ reduced to form a $\mathrm{Ni}$ cermet composition. An interesting candidate for this potential process is the $\mathrm{NiWO}_{4}$ composition. The $\mathrm{NiWO}_{4}$ composition has a general wolframite structure that can be readily reduced to $\mathrm{Ni}-\mathrm{WO}_{3-\mathrm{x}}$ mixtures at various oxygen partial pressures. The defective $\mathrm{WO}_{3}$ composition is a known mixed ion-electron conductor (MIEC), which can potentially substitute for the use of doped- $\mathrm{ZrO}_{2}$ and $\mathrm{CeO}_{2}$ typically used within the SOFC anode. At high $\mathrm{H}_{2}$ content and low oxygen partial pressures, the $\mathrm{WO}_{3-\mathrm{x}}$ composition can reduce to $\mathrm{WO}_{2}$ and finally to elemental W. Therefore, depending upon the $\mathrm{H}_{2}$ fuel concentration and current load, the anode may consist of a mixture of nano-Ni supported upon a mixture of $\mathrm{WO}_{3} / \mathrm{WO}_{2} / \mathrm{W}$.

A few researchers tested SOFCs containing tungsten within the anode structure with varying results $[119,120]$. A cermet $\mathrm{Ni}-\mathrm{WO}_{3}$ anode composition for SOFC applications has not 
been reported in literature, although similar $\mathrm{Ni}-\mathrm{W}-\mathrm{O}$ compositions were used as a catalyst for dehydrogenation [121], catalyst for polymer fuel cells [122], $\mathrm{H}_{2} \mathrm{~S}$ and $\mathrm{PH}_{3}$ sensing material [123], and hydro-desulfurization (HDS) [124].

The objective of this work was to evaluate the viability of in situ reducing the $\mathrm{NiWO}_{4}$ composition to form a Ni/WO $\mathrm{WO}_{\mathrm{x}}$ cermet composition for application as a potential SOFC anode. Fuel cell tests (current-voltage-power measurements) were used to measure the electrochemical performance of the initial trial of this anode composition. The incorporation of finite amounts of YSZ and Gd-doped $\mathrm{CeO}_{2}$ (GDC) electrolytes within the $\mathrm{NiWO}_{4}$ composition were also investigated in order to access effects on thermo-mechanical stability and electrochemical performance. Finally, due to previous demonstration by other researchers to increase hydrotreating catalyst performance by incorporation of phosphorus into $\mathrm{Ni}-\mathrm{W}$ composites, the electrochemical stability of the $\mathrm{NiWO}_{4}$ derived anode was tested as a function of time in $\mathrm{H}_{2}$ fuel

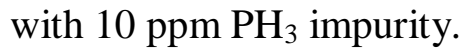

\subsubsection{Experimental procedure}

Although the overall performance of the fuel cell is known to be low, an electrolytesupported SOFC architecture was utilized in order to provide a simple platform to alter the anode composition without requiring alterations to the electrolyte and cathode microstructures. In this work, the active anode layer is considered to be the first $\sim 15-20 \mu \mathrm{m}$ layer (of one specific composition and microstructure) in contact with the electrolyte. The active anodes tested in this work were: 1) pure $\mathrm{Ce}_{0.9} \mathrm{Gd}_{0.1} \mathrm{O}_{2}(\mathrm{GDC})$, 2) pure $\left.\mathrm{NiWO}_{4}, 3\right) \mathrm{NiWO}_{4} / \mathrm{YSZ}$ composite, and 4) $\mathrm{NiWO}_{4} / \mathrm{GDC}$ composite. A $\mathrm{NiWO}_{4}$ current collection layer was printed over all active layers accept the pure GDC layer. Commercial $\mathrm{NiWO}_{4}$ powder (Alfa Aesar, USA) with an average particle size of $\sim 5 \mu \mathrm{m}$ was used within the anode experiments.

The electrolyte-support membranes were fabricated from 8 mol\% YSZ powder (Daiichi Kigenso Kagaku Kogoyo Co., LTD, Japan) by a tapecasting and lamination process. The $1 \mathrm{~cm}$ diameter YSZ button cell membranes were sintered at $1450{ }^{\circ} \mathrm{C}$ for $2 \mathrm{hr}$ to full densification. A 3 $\mu \mathrm{m}$ thick $\mathrm{Ce}_{0.9} \mathrm{Gd}_{0.1} \mathrm{O}_{2}$ (GDC) buffer layer was incorporated between the electrolyte and electrodes by screenprinting for both the anode and cathode in an effort to prevent potential 
interfacial reactions with the $\mathrm{Zr}$. The GDC was processed using a co-precipitation method [10]. This material was then screen-printed and fired onto the electrolyte at $1350^{\circ} \mathrm{C}$. Each of the subsequent anode compositions were sintered at the minimum temperature necessary for adhesion to the electrolyte. A standardized $\mathrm{La}_{0.85} \mathrm{Sr}_{0.15} \mathrm{MnO}_{3}$ (LSM) based cathode was used for each test to keep the anode composition as the primary variable. The cathode consisted of a 10 $\mu \mathrm{m} \mathrm{LSM/GDC} \mathrm{active} \mathrm{cathode} \mathrm{layer} \mathrm{which} \mathrm{was} \mathrm{printed} \mathrm{and} \mathrm{dried} \mathrm{before} \mathrm{adding} \mathrm{a} 40 \mu \mathrm{m}$ LSM current collector layer. The cathode assembly was sintered at $1100^{\circ} \mathrm{C}$ for $1 \mathrm{~h}$.

The current collection contact layer for the anode was comprised of Pt paste on top of a Pt mesh. And upon sealing the system with virgin mica rings and sufficient compression, the cell was heated up to $800^{\circ} \mathrm{C}$ over $4 \mathrm{~h}$ with $50 \mathrm{sccm} \mathrm{N}$ flow for the anode side and $50 \mathrm{SCCM}$ air for the cathode. Once the operating temperature was achieved, the anode stream was slowly reduced over $2 \mathrm{~h}$ by incrementally increasing the flow of $\mathrm{H}_{2} .100 \mathrm{sccm}$ wet $\mathrm{H}_{2}$ was used as the anode testing condition $\left(97 \% \mathrm{H}_{2}, 3 \% \mathrm{H}_{2} \mathrm{O}\right)$ with $100 \mathrm{sccm}$ air for the cathode. Cell polarization curves (I-V curves) and electrochemical impedance spectra were taken for during the test to establish baseline cell performances. This data was collected using a solid state load cell for constant DC load (TDI Transistor Device SD-1103) and a Solatron SI-1287 interface and an SI-1252 frequency response analyzer for the EIS data.

\subsubsection{Results and discussion}

As previously stated, the $\mathrm{NiWO}_{4}$ was deposited by screenprinting onto an electrolytesupport consisting of a $\sim 100 \mu \mathrm{m}$ thick YSZ-supported membrane with a thin, dense GDC coating. The porous $\mathrm{NiWO}_{4}$ was bonded onto the membrane at a temperature of $1000^{\circ} \mathrm{C}$ for $1 \mathrm{~h}$, which is $\sim 300^{\circ} \mathrm{C}$ lower in temperature than typical NiO/YSZ mixtures. This adhesion temperature is close to that utilized for typical lanthanum ferrite and cobaltite cathode compositions, potentially allowing for co-firing of anode and cathode compositions for specific SOFC architectures. After full reduction of the anode in the $3 \%$ wet $\mathrm{H}_{2}$, the anode remained firmly attached to the electrolyte membrane. Figures 63 and 64 display the XRD patterns taken from the top surface of the $\mathrm{NiWO}_{4}$ anode before and after full reduction at the $800^{\circ} \mathrm{C}$ testing conditions. 


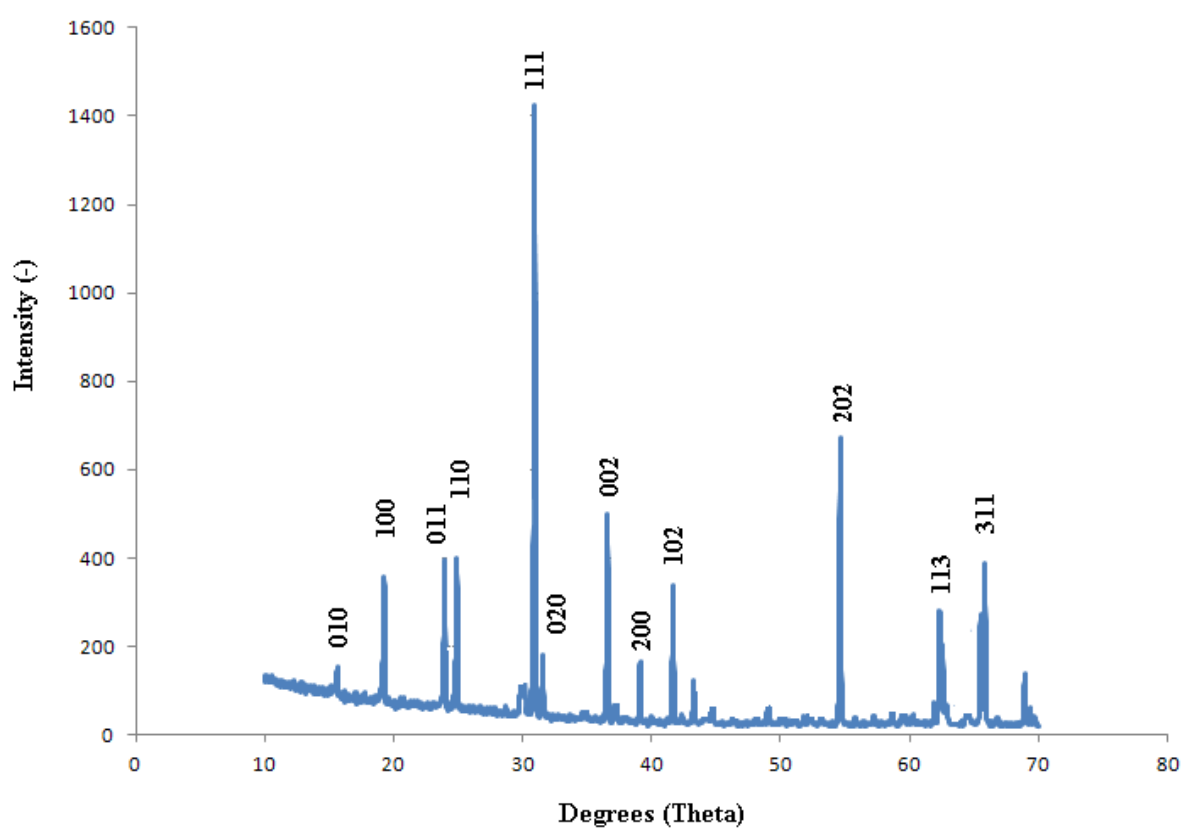

Figure 63: $\mathrm{XRD}$ of the $\mathrm{NiWO}_{4}$ anode surface before reduction.

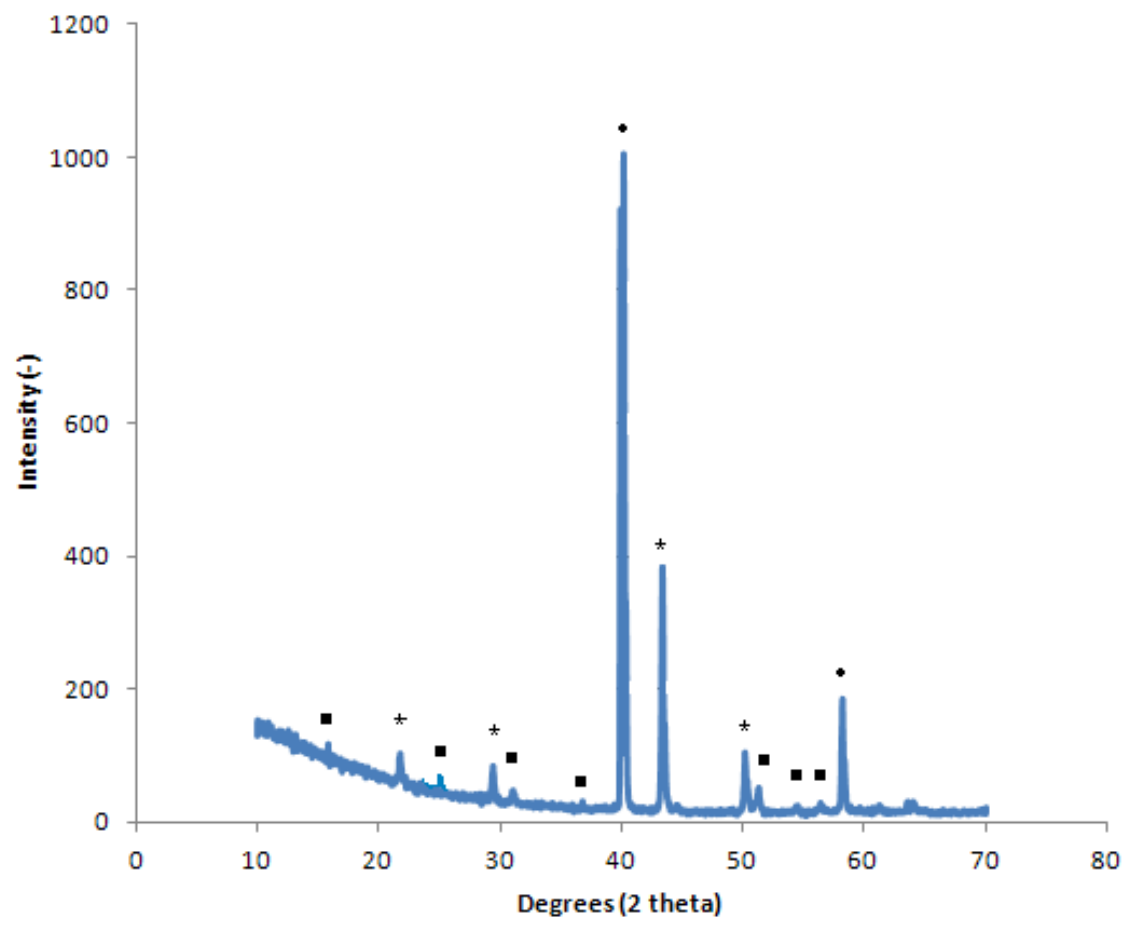

Figure 64: XRD of the reduced anode surface after $48 \mathrm{~h}$ in $3 \%$ wet $\mathrm{H}_{2} .(\cdot)$ corresponds to $\alpha-\mathrm{W},\left(^{*}\right)$ to $\mathrm{Ni}$, and (匹) $\mathrm{WO}_{3}$. 
Figure 63 is that of the pure $\mathrm{NiWO}_{4}$ anode as anticipated after sintering in an oxidizing environment. In Figure 64 however, the peaks corresponded to that of BCC $\alpha-\mathrm{W}, \mathrm{Ni}$, and small peaks corresponding to $\mathrm{WO}_{3}$. Unfortunately, the peak intensities for the mixed-conducting $\mathrm{WO}_{3}$ phase are rather weak indicating that the metallic $\mathrm{W}$ was most prominent near the anode surface. This plot does suggest however that there is some mixed conducting nature to the bulk anode during reduction with a constant current flux.

Figure 65 displays an SEM micrograph of the anode structure before reduction and Figure 66 is after testing in $\mathrm{H}_{2}$ for $48 \mathrm{~h}$. Figure 65 shows that the anode consists of singular phase with well-dispersed porosity throughout the microstructure. As shown in Figure 66, after testing, the level of porosity has decreased. Additionally, some changes to the particle geometry are observed.

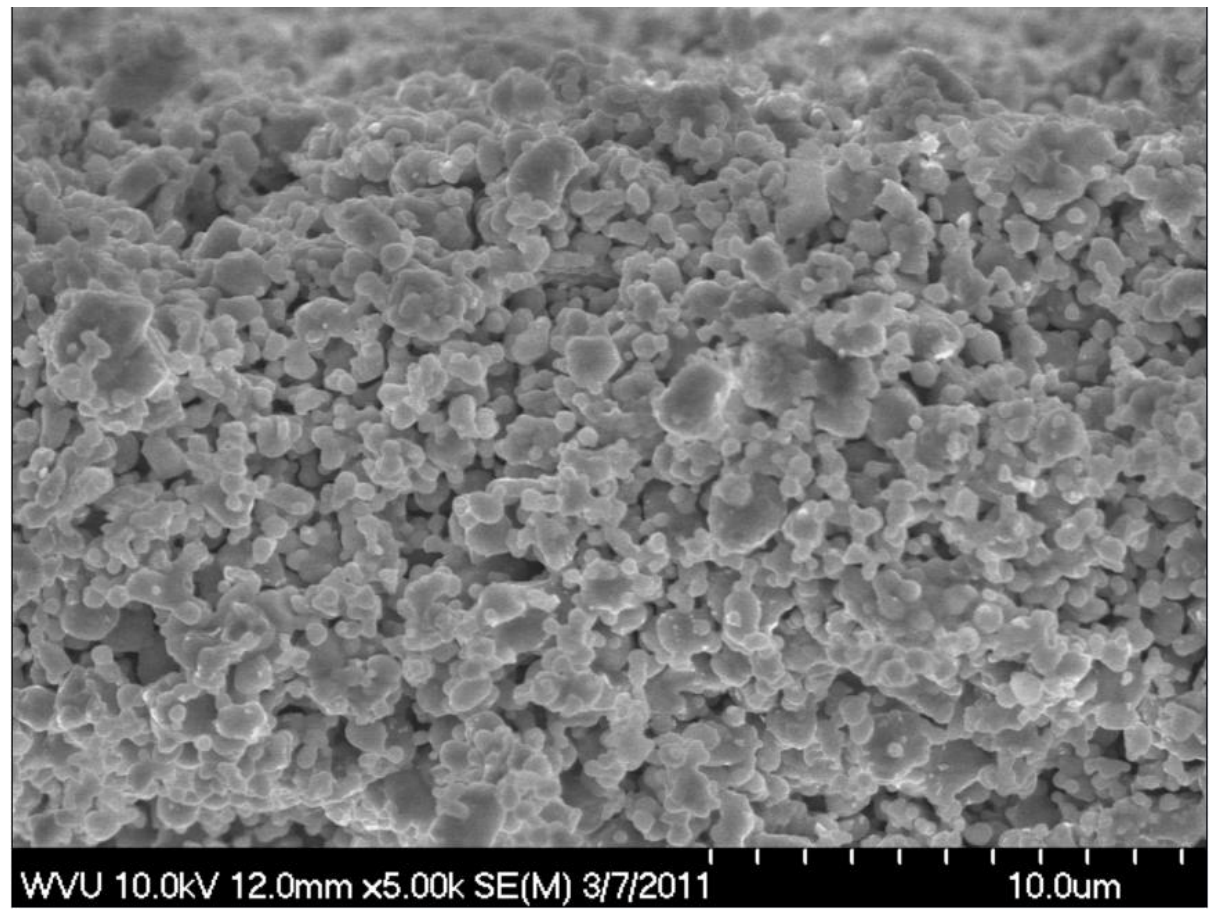

Figure 65: SEM image of a clean un-reduced $\mathrm{NiWO}_{4}$ anode. 


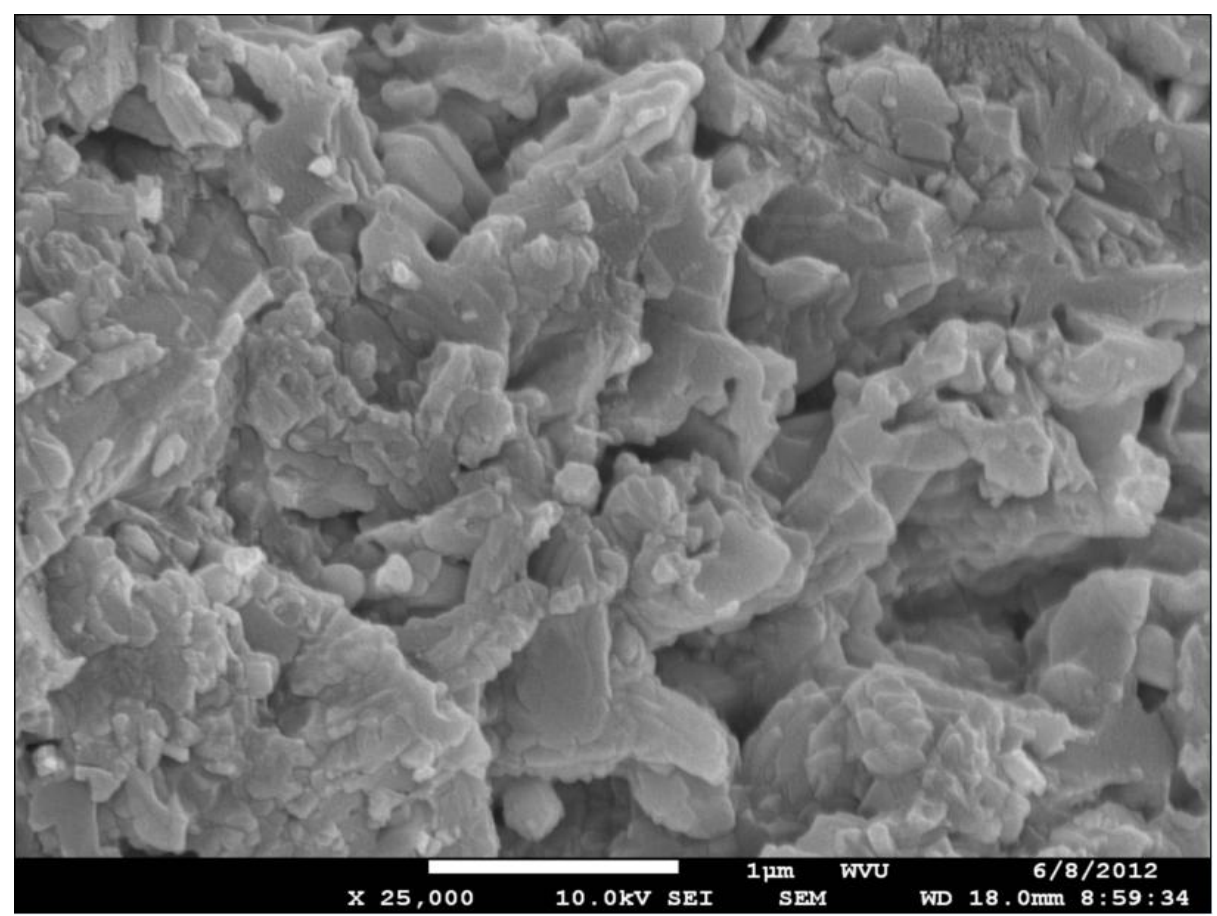

Figure 66: The NI-W anode after $48 \mathrm{~h}$ run in clean $\mathrm{H}_{2}$.

It seems that a dispersion of particulates ( $\mathrm{Ni}$ particulates), though inhomogeneous, decorates the surface of larger granular phase (Figure 66). This micrograph demonstrates that the method of in situ reduction could be utilized to form a cermet anode structure consisting of dispersed nano-metal particulates over a MIEC oxide support structure, but that the high partial pressure of hydrogen makes it difficult to control the microstructure and phase evolution.

The current density-voltage-power (I-V-P) measurement was completed on the fuel cell down to a current density of $\sim 0.3 \mathrm{~A} \cdot \mathrm{cm}^{-2}$ at $800^{\circ} \mathrm{C}$. All fuel cells were test with the same protocol previously described, and after reduction, all cells showed a similar OCV value of $\sim 1.06$ V. Figure 67c shows the I-V-P data collected for one of the electrolyte-supported SOFCs with the reduced $\mathrm{NiWO}_{4}$ anode. 


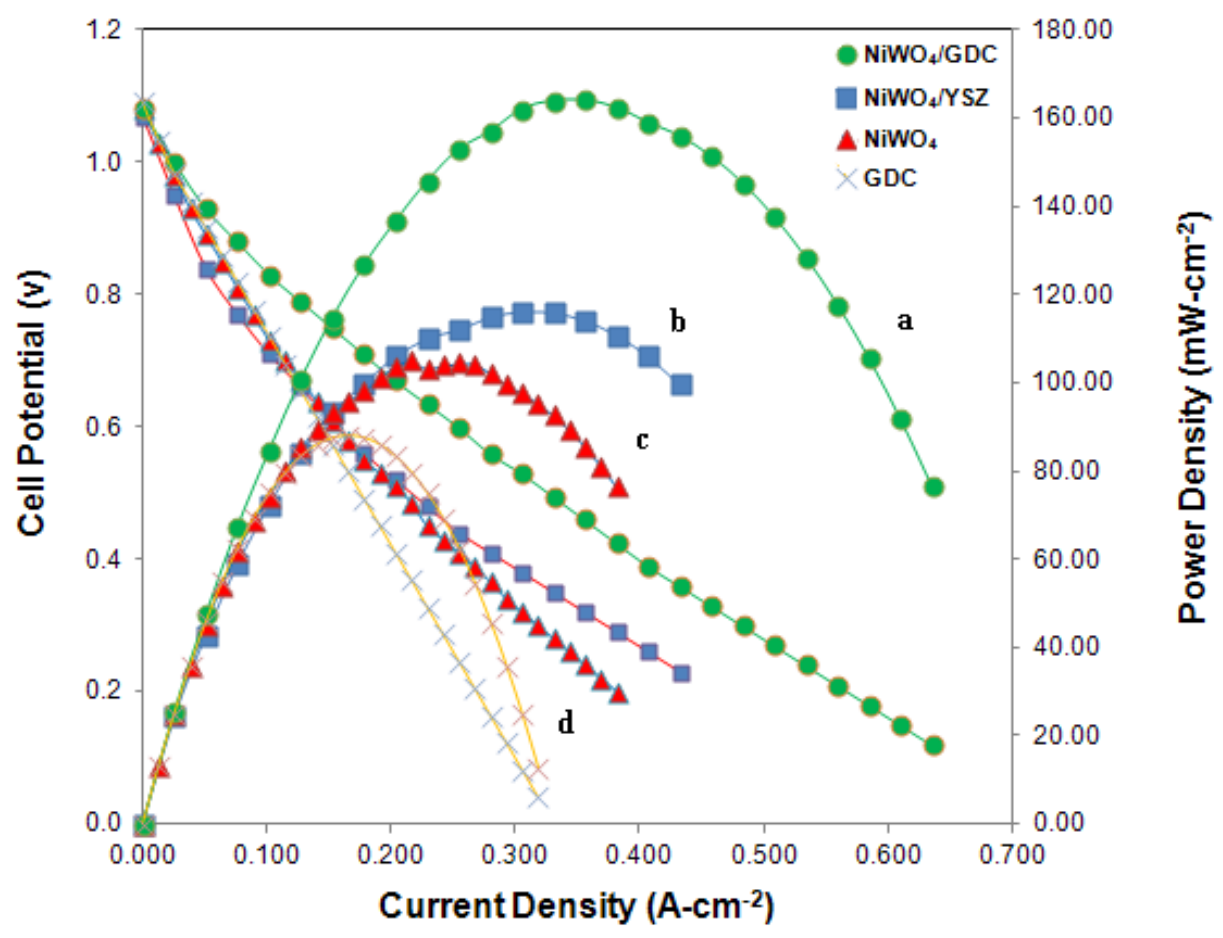

Figure 67: Cell potential -power density-current density performance for an electrolyte-supported SOFC button cell at $800^{\circ} \mathrm{C}$ for the following defined compositions.

From this current sweep, a respectable maximum power density of $\sim 104 \mathrm{~mW} \cdot \mathrm{cm}^{-2}$ was attained. Subsequent tests with this anode composition (and microstructure) yielded similar performance. The power achieved from this cell shows the potential of in situ forming a cermet anode from a singular ternary oxide composition.

In order to compare against the typical NiO/YSZ compositions, a 50/50 vol\% $\mathrm{NiWO}_{4} / \mathrm{YSZ}$ mixture within the active layer was tested. The use of the pure $\mathrm{NiWO}_{4}$ current collection layer was retained for these experiments. Figure $67 \mathrm{~b}$ displays the I-V-P data collected for the testing of this composite anode. The $\mathrm{NiWO}_{4} / \mathrm{YSZ}$ mixture showed a slight increase in performance, with a maximum power density of $116 \mathrm{~mW} \cdot \mathrm{cm}^{-2}$ achieved with this modification. One potential explanation for this slight performance increase would be due to the increase in ion-conducting sites (due to the increase in electrolyte material); but, the increase may also be attributed to a general modification in the microstructure that may affect anything from charge transfer to fuel/steam transport. For this $\mathrm{NiWO}_{4} / \mathrm{YSZ}$ composite, a higher adhesion temperature $\left(150^{\circ} \mathrm{C}\right.$ higher) was required to bond the active layer to the GDC barrier layer. This increased 
temperature led to further densification of the anode which would limit diffusion, and thus, limit electrochemical reaction rates.

In an effort to reduce the sintering temperature needed for sufficient adhesion, the YSZ was replaced in the active anode layer with a nano/micro-GDC mixture. The resultant 50/50 vol\% $\mathrm{NiWO}_{4} / \mathrm{GDC}$ mixture anode sintered onto the electrolyte at $1050^{\circ} \mathrm{C}$. This composite anode generated a maximum power density of $\sim 164 \mathrm{~mW}-\mathrm{cm}^{-2}$ at $800^{\circ} \mathrm{C}$ using wet $\mathrm{H}_{2}$ fuel (Figure $67 \mathrm{a}$ ). In order to better understand the contribution of the GDC, a similar fuel cell consisting of only a porous GDC anode (with no $\mathrm{NiWO}_{4}$ component) was tested at the same conditions. The GDC layer was fired onto the GDC-coated YSZ membrane (of the same thickness) at $1100^{\circ} \mathrm{C}$ for $1 \mathrm{~h}$. Figure 67d shows the I-V-P data collected from testing this cell at the same conditions previously used for the other anode architectures. The cell showed relatively low performance with a maximum power density of $\sim 82 \mathrm{~mW} \cdot \mathrm{cm}^{-2}$ at $800^{\circ} \mathrm{C}$ in $\mathrm{H}_{2}$ fuel. Although the power was relatively low, the pure GDC anode demonstrated $\sim 70 \%$ of the performance of the reduced $\mathrm{NiWO}_{4}$ composition, and nearly $50 \%$ of the $\mathrm{NiWO}_{4} / \mathrm{GDC}$ anode mixture. Therefore, it may be concluded that the reduced $\mathrm{NiWO}_{4}$ anode significantly lacks the contribution of an ionic carrier phase and that the present $\mathrm{W}$-oxide phases are not sufficient for oxygen transport and/or exchange.

Extended loading testing of the $\mathrm{NiWO}_{4} / \mathrm{GDC}$ anode was completed by holding the prereduced sample at a constant load of $0.15 \mathrm{~A}-\mathrm{cm}^{-2}$ for approximately $20 \mathrm{~h}$ at $750^{\circ} \mathrm{C}$ to confirm stability of the anode in pure $\mathrm{H}_{2}$ (Figure 68). The sample shows $<0.2 \%$ power loss over this testing period. The slight fluctuation in the cell voltage during the initial $20 \mathrm{~h}$ run was attributed to the drastic change in temperature and humidity of the ambient overnight. 


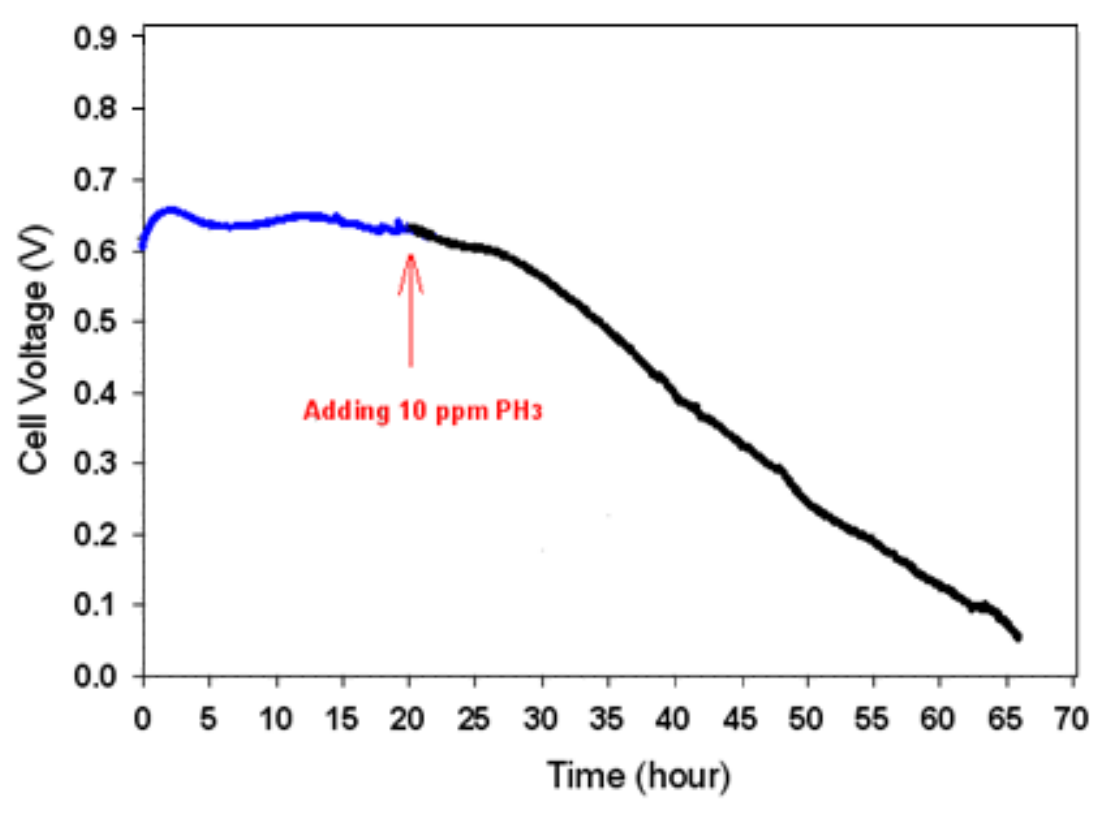

Figure 68: Cell voltage as function of time for an electrolyte-supported SOFC button cell with a $\mathrm{NiWO}_{4} / \mathrm{GDC}^{\circ}$ anode tested at a current density of $0.15 \mathrm{~A}-\mathrm{cm}^{-2}$ at $800^{\circ} \mathrm{C}$.

After $24 \mathrm{~h}, 10$ ppm $\mathrm{PH}_{3}$ was added into the $\mathrm{H}_{2}$ fuel stream. Within a matter of minutes, the cell voltage began to decrease. During the first $5 \mathrm{~h}$ of impurity testing, the rate of degradation was approximated at $0.006 \mathrm{~V}-\mathrm{h}^{-1}$. Beyond that time, the degradation rate increased to $0.015 \mathrm{~V}-\mathrm{h}^{-}$ 1. The cell voltage decreased at this rate until it reached $0.05 \mathrm{~V}$, after which the $\mathrm{PH}_{3}$ impurity was cutoff and the cell was cooled.

The EIS spectrum of the cell in clean $\mathrm{H}_{2}$ showed an ohmic resistance of $\sim 1 \Omega \cdot \mathrm{cm}^{2}$, which is rather high but can be attributed primarily to the thick electrolyte $(\sim 100 \mu \mathrm{m})$. Additionally, the increased ohmic resistance could also be attributed to the poor contact between the ion carriers and the $\mathrm{Ni}$ and $\mathrm{W}$ particles. The initial total polarization resistance was found to be $2.4 \Omega \cdot \mathrm{cm}^{2}$. This elevated resistance in comparison to the traditional Ni/YSZ electrolyte supported cell was attributed to both diffusion limitations and a lack of a homogeneous anode matrix resulting from

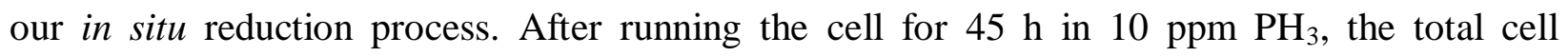
resistance increased to over $10 \Omega \cdot \mathrm{cm}^{2}$. The EIS data for the cell in clean $\mathrm{H}_{2}$ and $\mathrm{H}_{2}+10 \mathrm{ppm} \mathrm{PH}_{3}$ under $300 \mathrm{mV}$ DC bias can be seen in Figure 69. 


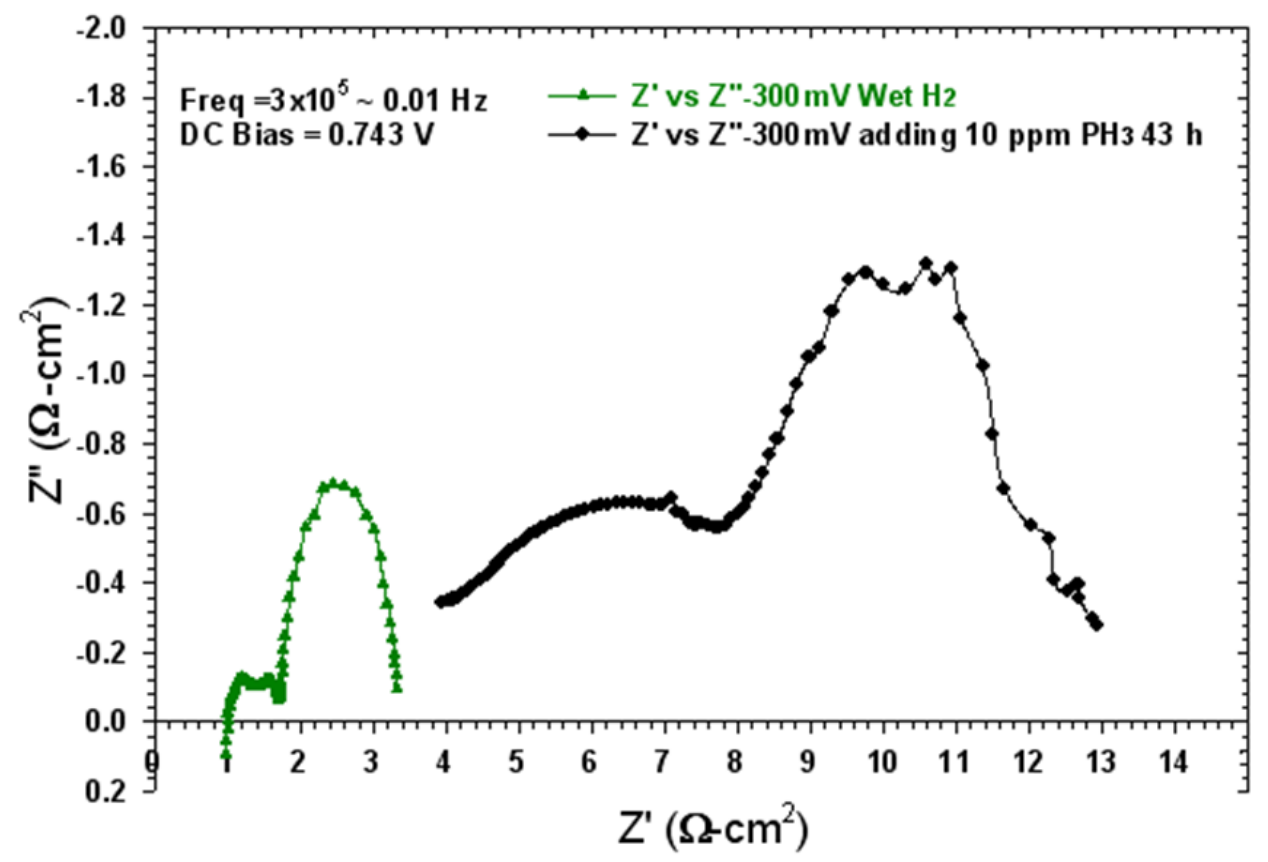

Figure 69: EIS data for the $\mathrm{NiWO}_{4} / \mathrm{GDC}$ anode before and after impurity addition.

Cross-sectional SEM images taken from the cell showed that the realtaively uniform anode microstructure in the clean, reduced environment was replaced with numerous coarse particulates after poisoning. Previous research has shown that this concentration of $\mathrm{PH}_{3}$ in the fuel stream leads to different attack mechanisms for the traditional Ni/YSZ cell. Xu et al [11] found that for an anode supported Ni/YSZ cell operating in syngas with $10 \mathrm{ppm} \mathrm{PH}_{3}, \mathrm{Ni}$ migration to the anode surface in the form of liquid Ni-P phases was the predominant feature of the micro-structure and that $\mathrm{Ni}_{2} \mathrm{P}_{5}$ was the most probable resultant based on post-test characterization and thermodynamic analysis. X-ray photoelectron spectroscopy (XPS) of the anode surface contained strong peaks for the phosphorus $2 \mathrm{~s}$ and $2 \mathrm{p}$ core levels as seen in Figures 70 and 71. Furthermore, and EDS scan of the anode-electrolyte interface of this anode seen in Figure 72 also indicates a strong $\mathrm{P}$ peak. 


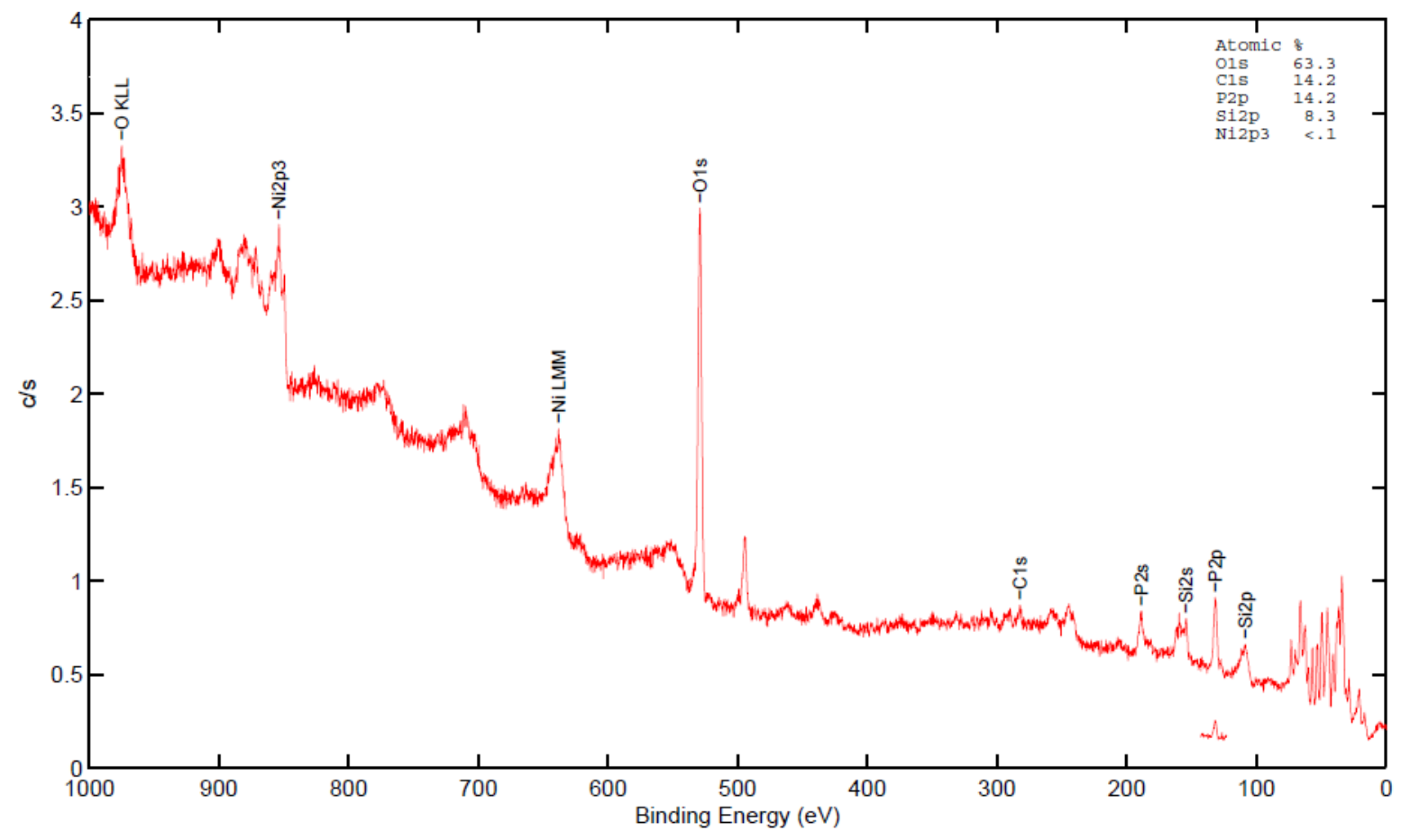

Figure 70: XPS survey scan for the $\mathrm{NiWO}_{4}$ poisoned sample.

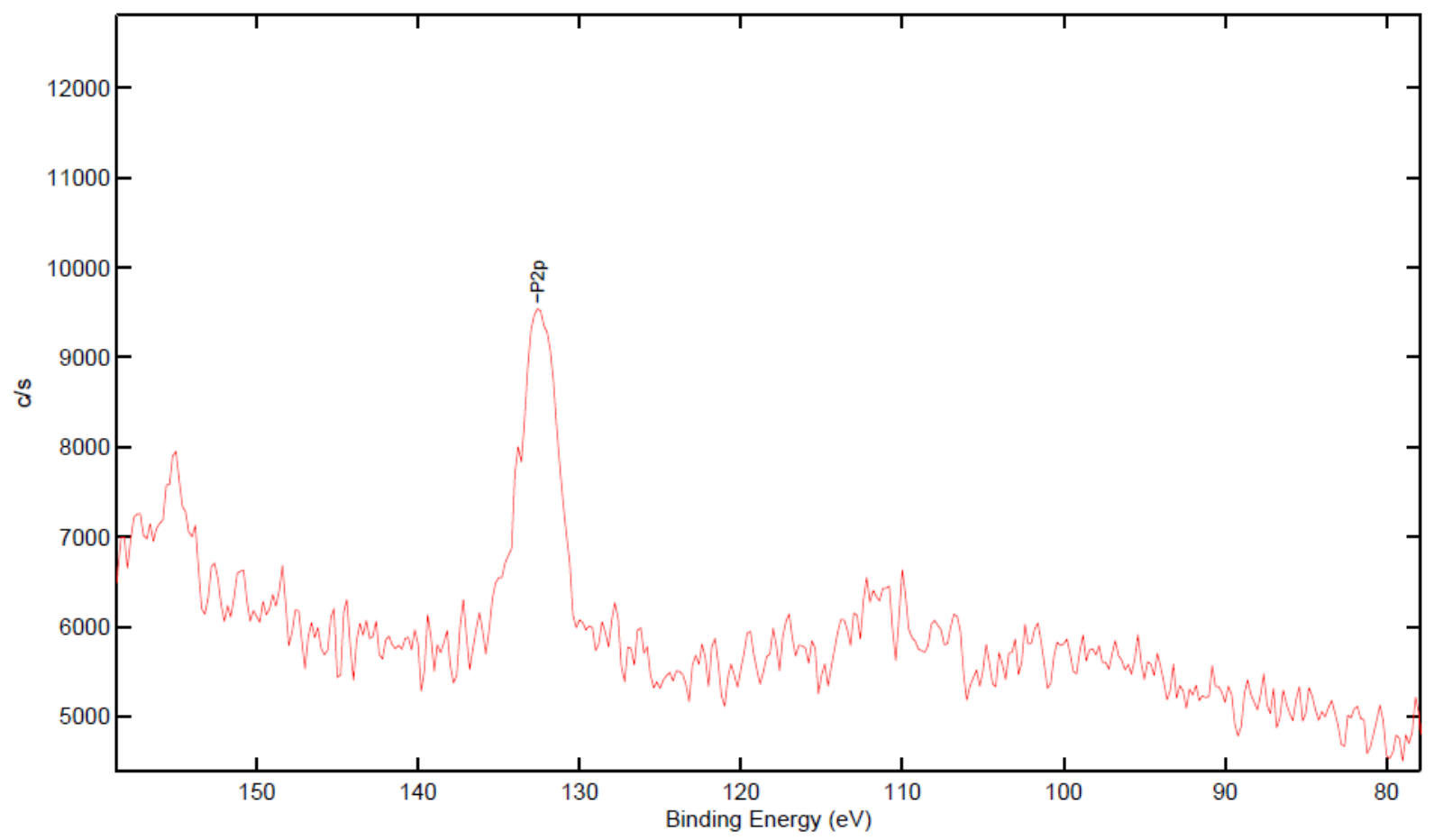

Figure 71: XPS scan for the P2p peak. 


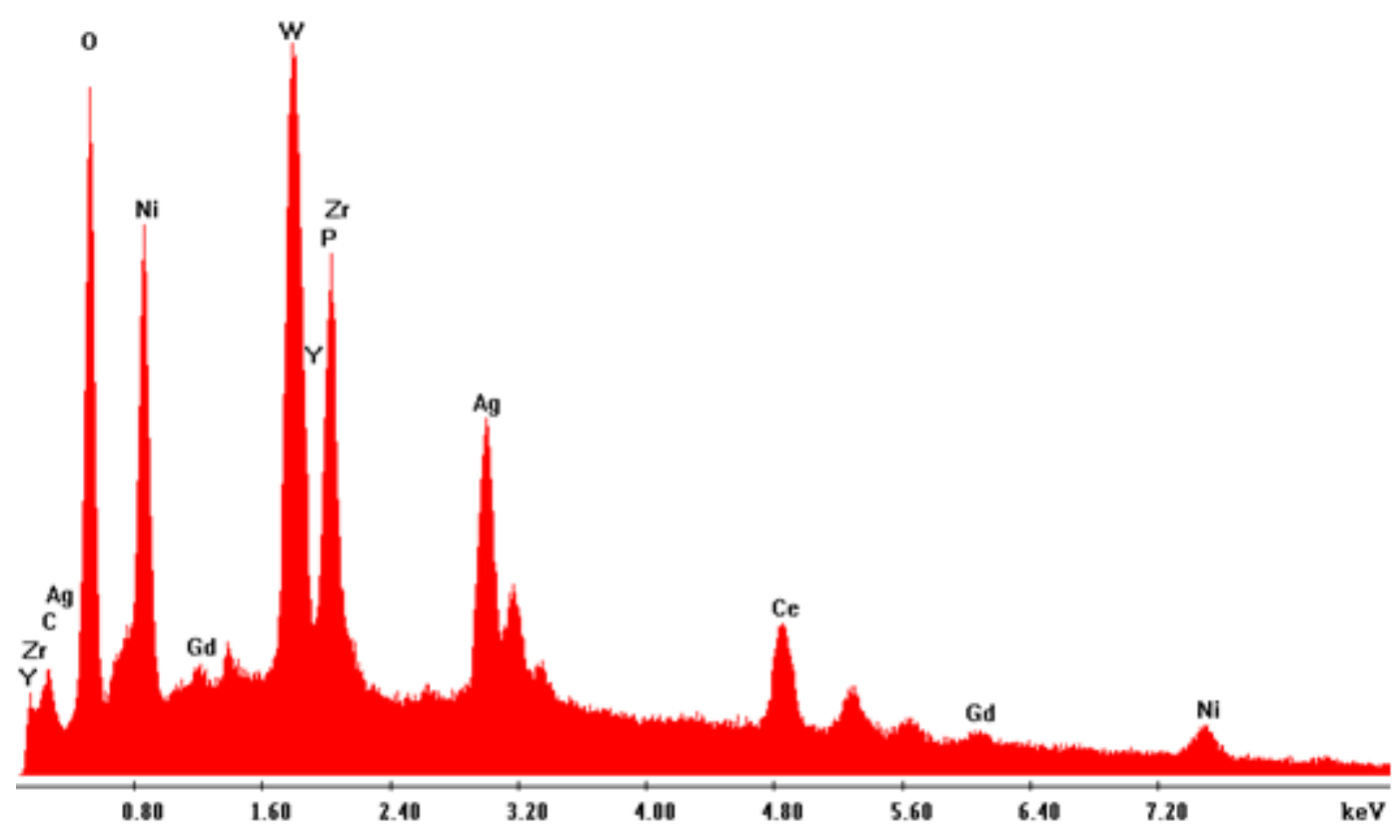

Figure 72: EDS scan of the anode-eletrolyte interface.

The phosphorus $2 \mathrm{p}$ peak positioned at about $133.5 \mathrm{eV}$ suggests that phosphate presence exists on the electrode surface. However, the lack of a peak in the 126-128 eV range indicates that Ni-P and W-P chemisorption did not occur for this fuel condition. The $\mathrm{PH}_{3}$ did however change the microstructure and therefore, it is reasonable to state that the $10 \mathrm{ppm}$ concentration of $\mathrm{PH}_{3}$ for the $\mathrm{NiWO}_{4}$-based anode experiences a similar degradation mechanism to the Ni-YSZ cermet.

\subsubsection{Conclusions}

The work demonstrated the method of in situ reduction of a ternary oxide composition to form cermet composition that may be utilized as a SOFC anode. In this work, the $\mathrm{NiWO}_{4}$ composition was chosen since the reduced oxide would result in a mixture of $\mathrm{Ni}$ metal and a MIEC oxide, which is the typical cermet combination required for the electrochemical reaction within SOFC anodes. The proposed $\mathrm{NiWO}_{4}$ composition successfully demonstrated adequate performance for an un-optimized microstructure on a rather thick YSZ membrane utilizing LSM 
as the cathode. Additionally, the anode sintering temperatures were compatible with conventional SOFC cathodes making co-sintering of the anode with high-performance ferrite and cobaltite cathodes possible. Further testing of the reduced $\mathrm{NiWO}_{4}$ anode indicated that there may be a deficiency in ionic carrier paths and reaction sites within the anode structure, where the performance of the formed cermet was improved with the incorporation of both YSZ and GDC into the anode matrix. GDC in particular increased the power output of a single cell by almost $58 \%$. Although the $\mathrm{NiWO}_{4}$ composition did not result in the optimal performance, the technique of utilizing an in situ reduction process of a ternary oxide (containing base or precious metals) showed great promise and further ternary compositions that result in cermets containing more redox stable MIECs will be attempted. This work also verified that a Ni-WO $-\mathrm{GDC}$ anode demonstrated similar problems to the Ni/YSZ cermets in regards to $\mathrm{PH}_{3}$ tolerance; specifically, a coarsened microstructure and surface phosphate/nickel-phosphate presence caused cell failure within $45 \mathrm{~h}$. 


\section{Chapter 5- $\mathrm{A} \mathrm{Sr}_{2} \mathrm{MgMoO}_{6-\delta} / \mathrm{Gd}_{0.1} \mathrm{Ce}_{0.9} \mathrm{O}_{2}$ Anode Supported SOFC}

\subsection{Introduction}

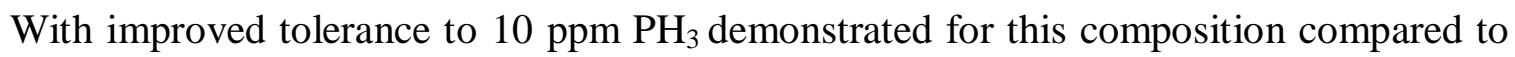
the $\mathrm{Ni} / \mathrm{YSZ}$ anode in the previous chapter, further investigation is warranted. However, there are quite a few things that can be done to the original cell architecture to increase the commercial potential. One issue is the electrolyte-supported platform. As previously described, the ohmic resistance of the cell is comprised of contributions from three parts, the anode, cathode, and electrolyte. For the traditional Ni/YSZ, LSM/YSZ, YSZ electrolyte supported configuration, the anode and cathode ohmic resistances are negligible in comparison to the electrolyte. Part of this is attributable to the material, YSZ, but primarily it is due to the thickness needed for adequate mechanical support from sealing and thermal cycling.

One method to alleviate this is to change the electrolyte material. Most previous literature on this anode has utilized a LSGM electrolyte, which exhibits far superior ionic conductivity at $800^{\circ} \mathrm{C}$ and also has better chemical compatibility than that of YSZ [21]. However, the mechanical strength of this material is only $30 \%$ of YSZ, making it impractical for use [126]. The same composition that has been used as the barrier for $\mathrm{H}_{2} \mathrm{~S}$ tolerance, GDC, has also been used for SOFC electrolytes at intermediate temperatures. It to has higher ionic conductivity than YSZ and also has less likelihood of interactions with the $\mathrm{Sr}$ in the anode. The only drawback to this material is its propensity to reduce from $\mathrm{CeO}_{2}$ to $\mathrm{Ce}_{2} \mathrm{O}_{3}$ in environments containing high partial pressures of $\mathrm{H}_{2}$ at $800^{\circ} \mathrm{C}$ resulting in potential leaking, partial direct combustion, and ultimately cell failure. This fact makes syngas or $\mathrm{CO}$ fuel a far more attractive option than humidified $\mathrm{H}_{2}$. If the reduction of $\mathrm{Ce}$ can be managed through proper fuel selection and reduced operating temperatures, then this electrolyte could prove to be a better fit.

The other way to increase performance is to consider an anode supported configuration. An anode with enough thickness ( $>500 \mu \mathrm{m}$ in most cases) can serve as the mechanical support, making it possible to apply an electrolyte between 10 and $30 \mu \mathrm{m}$ that results in a decrease of the overall ohmic resistance and thus an increase in maximum power density. Specifically, the 
ohmic resistance is linearly related to the thickness of the electrolyte, so an order of magnitude decrease to the electrolyte thickness should greatly improve the overall power production. Leng et al. [127] developed a SOFC with a $10 \mu \mathrm{m}$ GDC electrolyte that was made via solid-state synthesis. Using a Ni/GDC type anode and a LSCF cathode, they showed a maximum power density of $578 \mathrm{~mW}-\mathrm{cm}^{-2}$ at $600^{\circ} \mathrm{C}$ in $3 \%$ wet $\mathrm{H}_{2}$. However, they do note significantly lower OCV at $600^{\circ} \mathrm{C}, 0.86 \mathrm{~V}$, than for the YSZ electrolyte at that temperature and fuel condition which suggests electronic leaking is an issue for their design. For comparison to a GDC electrolyte supported cell, Zha et al. [128] show an increased OCV of $0.95 \mathrm{~V}$ at the same $600^{\circ} \mathrm{C}$ and a performance of only $220 \mathrm{~mW}-\mathrm{cm}^{-2}$ with a $210 \mu \mathrm{m}$ thick electrolyte. While long term stability analysis has not been conducted for this electrolyte, these two works make it seem that the tradeoff for increased performance with the anode support is the increased likelihood of leaking.

There are a few concerns that must be considered with the new SMM/GDC anode and GDC electrolyte setup. First is the CTE match between the SMM and the GDC during co-firing. The further apart the CTE's are the more difficult it will be to preserve a structure that is free of bends and/or cracks. The next is to make sure that sufficient porosity of the support for gas diffusion is maintained after the co-firing stage. As outlined previously, there are several different pore forming options that help to preserve this porous network through all of the firing cycles. The last major concern is the chemical stability of the materials during the high temperature processing. At the typical GDC sintering temperatures $\left(1350-1450^{\circ} \mathrm{C}\right)$, the volatility of Mo is such that it can be lost from the material [21]. The high vapor pressure of $\mathrm{MoO}_{3}$, the raw starting material for SMM synthesis, at its melting point $\left(\sim 800^{\circ} \mathrm{C}\right)$ makes it possible to vaporize at temperatures higher than this and thus escape the structure. As such, the maximum sintering temperature before significant losses in Mo in the double-perovskite structure will have to be identified. However, reducing the maximum allowable sintering temperature comes with a decrease in density of the GDC. So, infiltration techniques using GDC nanopowders that densifies at lower temperatures will be incorporated after initial firing in order to achieve full densification of the electrolyte. The work in this chapter will first define a sound protocol for anode-supported cell fabrication including support processing, electrolyte densification, and cathode application. Future work will include cell sealing and testing using a wide range of fuels as well as coal contaminants. 


\subsection{Experimental Procedure}

The following sections outline the several processing steps required to obtain a full cell that can be evaluated for electrochemical performance and stability.

\subsubsection{Anode Support Fabrication}

\subsubsection{Tape Casting and Hot Pressing}

The raw powders were prepared in an identical fashion to those synthesized in Chapter 4. These materials were each used in a 50/50 volume percent mixture for the tape casting formulation. The pore former selected for this process was Pencook 30 rice starch (surface area of $0.8 \mathrm{~m}^{2} \mathrm{~g}^{-1}$ ). This organic makes up 50 volume percent of the overall solids loading of the slurry. The rest of the system is the same as was used for YSZ tape casting from Chapter 3 utilizing the same volume percentages. The slurry was milled overnight and cast using the doctor blade to approximately $40 \mu \mathrm{m}$ in thickness. 25 layers were then stacked until a green thickness of $1 \mathrm{~mm}$ was achieved. The sample was finally vacuum sealed in preparation for lamination of the layers. Once sealed, the samples can then be pressed. The only difference between the YSZ pressing procedure and this is the role that the pore former has on the lamination process. A study was performed to identify the optimum pressing condition for these samples.

\subsubsection{Sample Bisquing}

With a laminated green support, samples can be cut out and thermally treated to remove organics and increase mechanical strength. This process is known as bisquing, which occurs at a temperature at the onset of particle sintering. To identify the temperature at which all organics are removed from the system, a thermogravimetric analysis (TGA) run was carried out. This made it possible to determine the right heating rates and holds to remove the organics without distorting the sample geometry. After organic removal, the additional temperature increases help to form a substrate strong enough to withstand pressures from electrolyte deposition. 


\subsubsection{Electrolyte/Cathode Application}

With sufficient strength, the bisqued supports can withstand printing of the electrolyte coating. The deposition of the electrolyte ink was completed stensilling the ink over the substrate using a 230 count mesh screen. A rubber blade was used to spread the ink across the sample so that a layer with an approximate thickness of $15 \mu \mathrm{m}$ could be generated. This layer was dried in an oven at $60^{\circ} \mathrm{C}$ and then fired at $1250^{\circ} \mathrm{C}$ for 2 hours in air. This firing step provided sufficient bonding to the anode support, but left some significant porosity within the structure that must be filled in before testing.

To fill in these pores within the electrolyte, a ceria sol gel suspension was developed. The gel was made by mixing appropriate amounts of ethanol, DI $\mathrm{H}_{2} \mathrm{O}$, citric acid, and glycerol. The mixture was then milled for 1 hour then gadolinium and cerium chloride were added and milled for an additional hour. The sol gel coatings were deposited by using a spin coater. Each deposition consisted of 1 drop of the sol gel solution onto the substrate with a pipette. The rotational speed of the spin coater was 2500 RPM and the settling time for each application was 20 seconds. Each sample was dried at $50^{\circ} \mathrm{C}$ in an oven for 5 minutes for each coat. This low temperature helps to prevent nano/micro-cracking throughtout the several deposition iterations. After 5 iterations, the samples were fired to the $800^{\circ} \mathrm{C}$ temperature required for full densification

of these coatings. Comparison of the electrolyte density for 5 coatings and 15 coatings was carried out to determine the impact of additional coatings on filling in the porosity.

The last step in cell processing was the cathode application. A standard $\mathrm{La}_{\mathrm{x}} \mathrm{Sr}_{1-\mathrm{x}} \mathrm{Co}_{\mathrm{y}} \mathrm{Fe}_{1-}$ $\mathrm{y}_{3-\delta}(\mathrm{LSCF}) \mathrm{MIEC}$ cathode was printed onto the electrolyte and fired on at $1100^{\circ} \mathrm{C}$. Though this cathode composition is a mixed ion-electron conductor, additional ionic carrier capability for the electrode can be incorporated by mixing GDC into an active layer. This is mixed into the LSCF in a similar manner to other electrode inks described previously. Both the active layer, consisting of 50/50 vol\% of LSCF/GDC and the LSCF current collector were hand-printed using 325 mesh and 230 mesh screens respectively. The cathode was fired onto the cell at $1100^{\circ} \mathrm{C}$ for 2 $h$ in air. 


\subsection{Results and Discussion}

The first iterative process that was carried out in processing the anode support was the hot pressing condition. The glass transition temperature of the organic system dictates the required pressure/temperature setting for the press. In this scenario, the limiting component is the Pencook 30 starch, which has a glass transition temperature of $\sim 45^{\circ} \mathrm{C}$. Temperatures in excess of this value were tried first and the result was a lamination that melted and did not hold its form. Figure 73 shows the sample pressed at $70^{\circ} \mathrm{C}$ and 70 kips for 15 minutes. Most significant is that the cut sample was a 4" x 4" square and the pressed sample became ovular in shape with more width and less thickness.

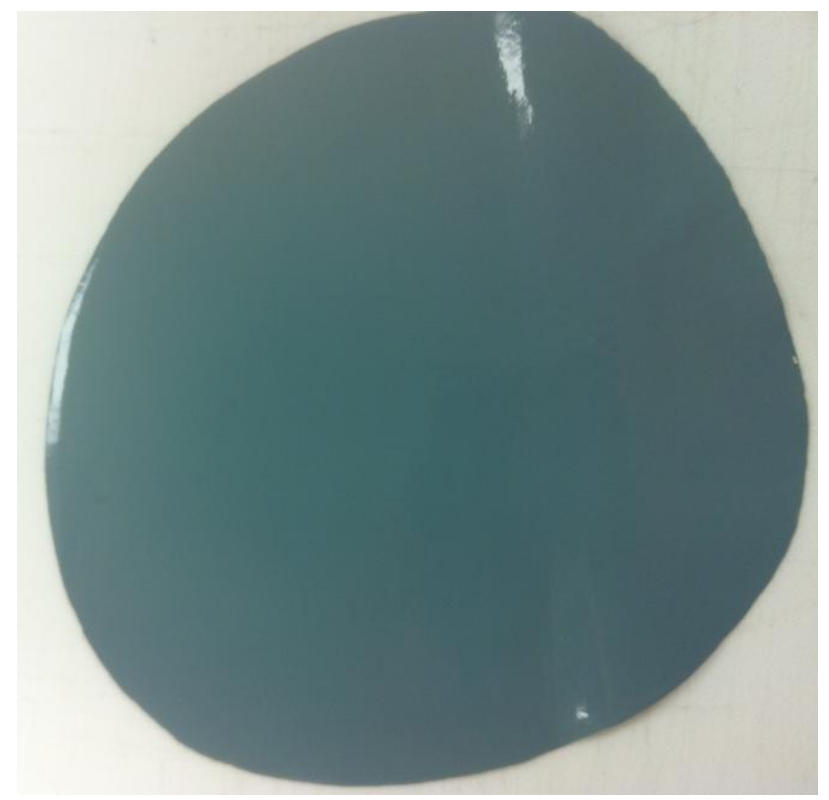

Figure 73: Lamination pressed at $70^{\circ} \mathrm{C}$ and 70 kips for 15 minutes.

The sample thickness shrunk from the $1 \mathrm{~mm}$ starting thickness to $\sim 200 \mu \mathrm{m}$. Nonetheless, these samples were burned out and bisqued to $1100^{\circ} \mathrm{C}$ to determine if this condition would produce a smooth substrate sample. Unfortunately, the result was a sample full of pillowing, as seen in Figure 74. The excessive pressing temperature caused a redistribution of the organic materials which led to inhomogeneous escape of gases during burnout. The pressure gradients that arose from this redistribution caused changes to the inorganic particle arrangement making them unsuitable for further use. 


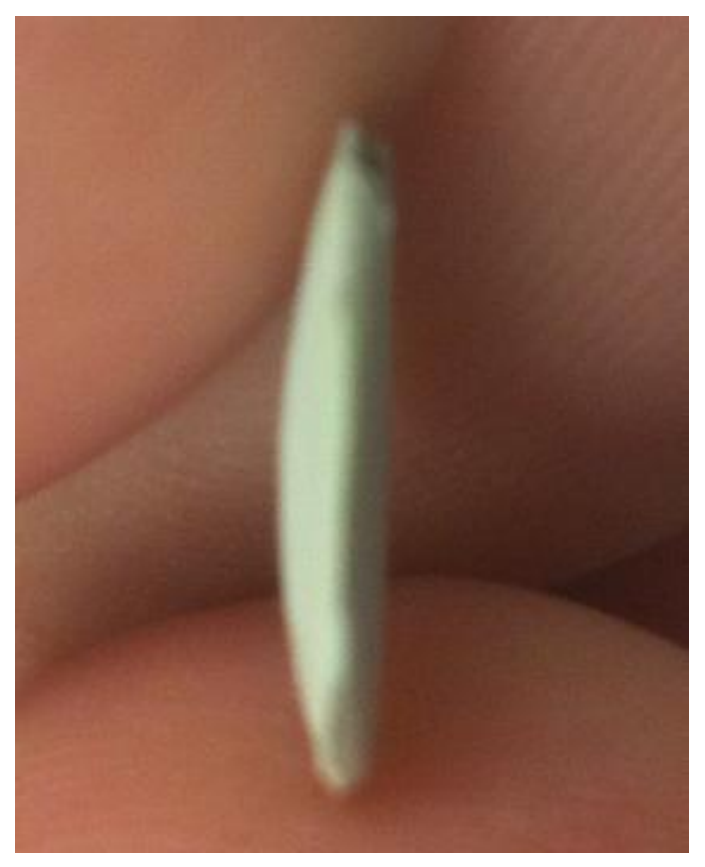

Figure 74: Macroscopic view of 'pillowed' anode support.

At a $40^{\circ} \mathrm{C}$ temperature with the other pressing conditions constant, the sample laminated without significant change to the green thickness. A thickness of approximately $950 \mu \mathrm{m}$ was maintained after the samples were pressed at this condition. Figure 75 shows a macroscopic image of the pressed sample that demonstrates good lamination.

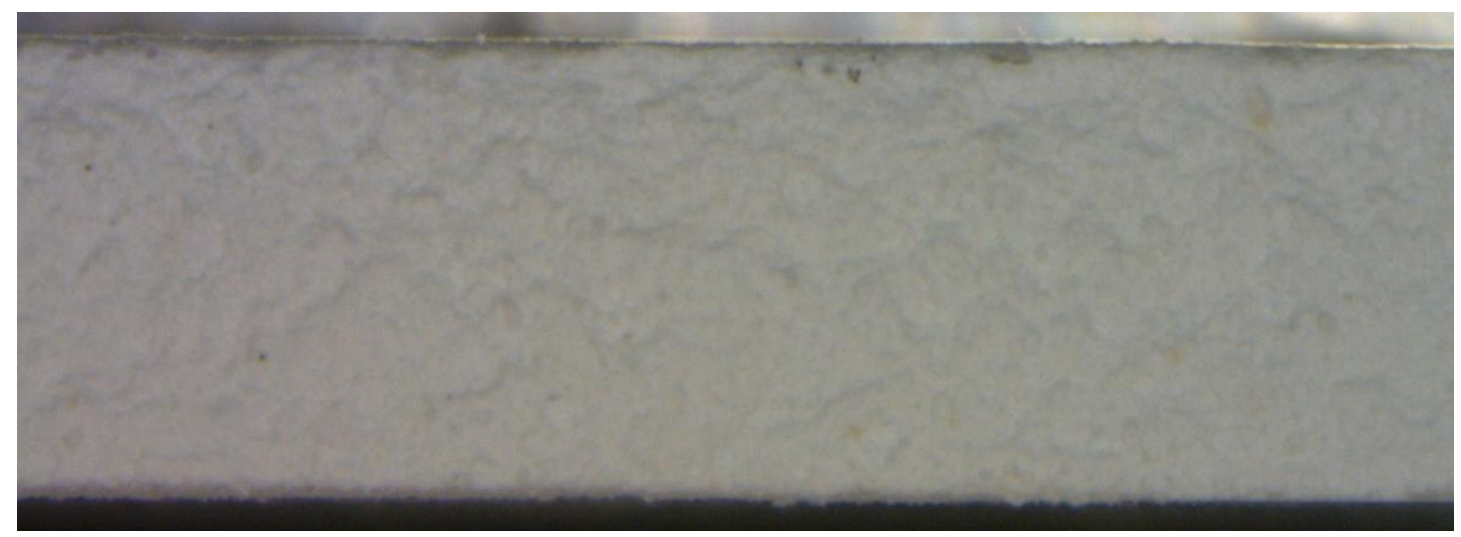

Figure 75: Anode support cross-section demonstrating good lamination.

The samples were then run up to $1100^{\circ} \mathrm{C}$ for bisquing. The same burnout temperature schedule for this lamination was initially used as for the YSZ electrolyte laminations. This burnout schedule was $2^{\circ} \mathrm{C}$ per minute to $600^{\circ} \mathrm{C}$ with a 1 hour hold and then $3^{\circ} \mathrm{C}$ per minute to 
$1100^{\circ} \mathrm{C}$ with a 2 hour hold and finally a $5^{\circ} \mathrm{C}$ per minute cool down rate. After this thermal process, the substrates had a very similar look to those that were pressed at excessive temperature. The TGA run seen in Figure 76 helps to explain why this distortion to the samples occurred.

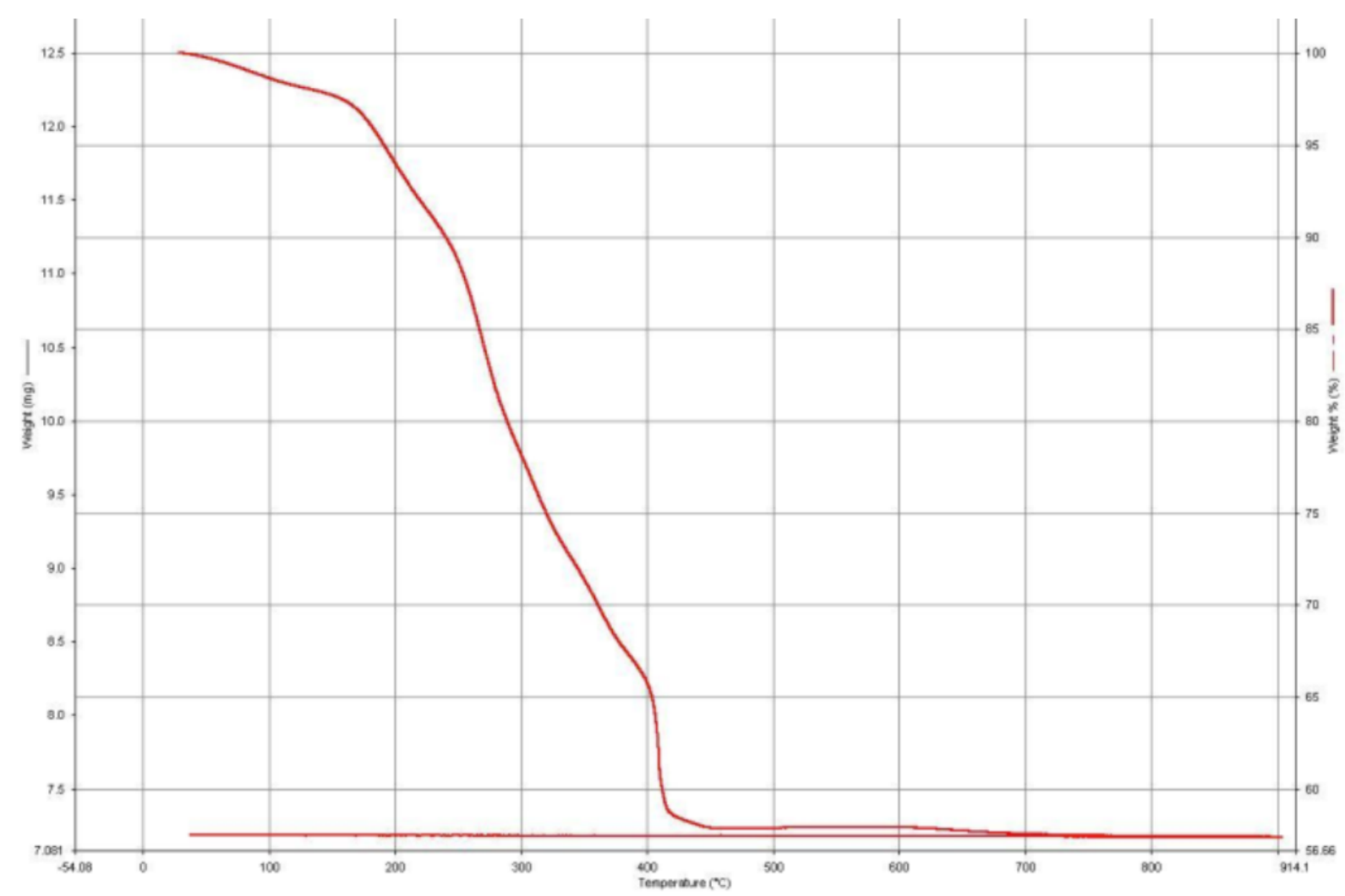

Figure 76: TGA curve for anode support burnout.

In general, when thermal treatment schedules are developed for ceramic processing, TGA analysis is essential in identifying temperature regimes that require slow heating rates or holds. The TGA plot shows locations where the mass of the sample decreases as a function of temperature. Right at the onset of the major losses it is important to hold the temperature for a period of time to initiate the gas release from the sample in a controlled manner. And as the temperature is the driving force for gas release, the temperature ramp rate should be very slow points on the TGA curve where a non-zero slopes are seen. With these considerations, Table 5 shows the final temperature schedule clear up through bisquing. 
Table 5: Final burnout temperature profile for the SMM/GDC anode support.

\begin{tabular}{|c|c|c|}
\hline Rate $\left({ }^{\circ} \mathrm{C}-\mathrm{min}^{-1}\right)$ & Temperature $\left({ }^{\circ} \mathrm{C}\right)$ & Hold (hours) \\
\hline 1 & 60 & 1 \\
\hline 0.5 & 150 & 1 \\
\hline 0.5 & 225 & 1 \\
\hline 0.5 & 400 & 1 \\
\hline 1 & 600 & 2 \\
\hline 1.5 & 1100 & 2 \\
\hline 5 & 25 & - \\
\hline
\end{tabular}

Figure 77 shows the bisqued sample free of pillowing or macroscopic imperfections. It is noteworthy that temperatures lower than $1100^{\circ} \mathrm{C}$ did not produce a substrate with the proper mechanical strength to withstand the electrolyte deposition pressure. As seen in Figure 78, there was not enough mechanical strength to handle the substrate without macroscopic fracture when only fired to $1050^{\circ} \mathrm{C}$.

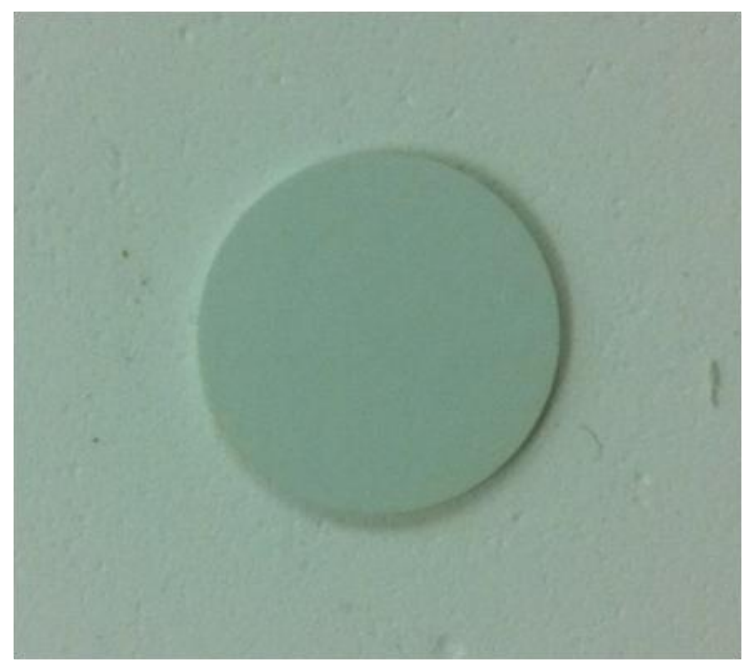

Figure 77: Bisqued anode support at $1100^{\circ} \mathrm{C}$. 


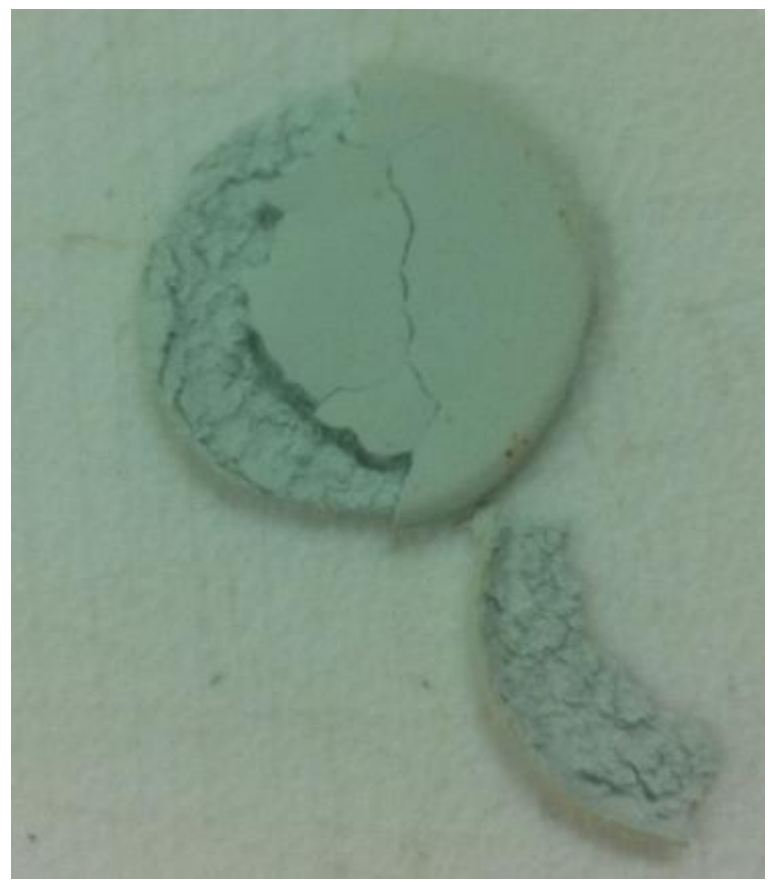

Figure 78: Sample Bisqued to $1050^{\circ} \mathrm{C}$.

With the samples bisqued, the initial GDC print can be deposited. As previously stated, Mo loss at high temperatures prevents a single layer of GDC from achieving full density. Experimentally, this was determined by simply obtaining initial weights of samples bisqued to $1100^{\circ} \mathrm{C}$ and then incrementally weighing them from temperatures ranging from $1150-1400^{\circ} \mathrm{C}$ in $50^{\circ} \mathrm{C}$ intervals. Four samples were examined to establish some statistical significance. The percent loss of mass can be seen in Table 6.

Table 6: Mass loss of molybdenum $(\%)$ in the anode for different bisquing temperatures.

\begin{tabular}{|c|c|c|c|c|c|c|}
\hline & \multicolumn{6}{|c|}{ Temperature $\left({ }^{\circ} \mathrm{C}\right)$} \\
\hline Sample & 1150 & 1200 & 1250 & 1300 & 1350 & 1400 \\
\hline 1 & 0 & 0.176 & 0.352 & 1.76 & 6.5122 & 13.0243 \\
\hline 2 & 0 & 0.1083 & 0.2166 & 1.949 & 6.0636 & 12.3437 \\
\hline 3 & 0 & 0.1231 & 0.3692 & 1.5999 & 6.2767 & 12.7996 \\
\hline 4 & 0 & 0.1608 & 0.3217 & 1.9302 & 6.5947 & 14.1546 \\
\hline
\end{tabular}

With all of the organic material out of the system by $700^{\circ} \mathrm{C}$, any loss in mass at higher temperatures must be from an inorganic within the system. Magnesium oxide exhibits good 
stability at temperatures up to $3600^{\circ} \mathrm{C}$, which corresponds to its boiling point. Likewise, strontium oxide remains stable up to $3200^{\circ} \mathrm{C}$ before any type of decomposition takes place. Knowing that GDC does not fully sinter until between $1350^{\circ}-1400^{\circ} \mathrm{C}$ from our previous work, it can be assumed that losses would not be from this part of the composite. This leaves only the molybdenum oxide. Though the molybdenum has 6-fold oxygen coordination within the double perovskite structure, molybdenum oxide itself has a boiling point of $\sim 1200^{\circ} \mathrm{C}$. The results in Table 6 suggest that this double perovskite coordination prevents the vaporization of Mo until higher temperatures. Specifically, at temperatures below $1250^{\circ} \mathrm{C}$, molybdenum losses to the samples were less than $0.5 \%$ and not deemed too significant for processing considerations. However, by $1300^{\circ} \mathrm{C}$ losses approaching $2 \%$ are seen and by $1400^{\circ} \mathrm{C}$ the losses are around $13 \%$. While these findings suggest that the 6-fold coordination suppresses molybdenum volatility, it shows that processing temperatures for the anode support should be limited to $1250^{\circ} \mathrm{C}$ at to prevent alterations to the composition.

After establishing the processing criteria, the initial $15 \mu \mathrm{m}$ GDC electrolyte layer can be printed onto the substrate. Hand-printing was selected over screen-printing to ensure that excessive pressures on the bisqued sample were prevented. Figure 79 is an SEM image of the initial GDC electrolyte layer onto the anode support after firing at $1250^{\circ} \mathrm{C}$ for 2 hours. 


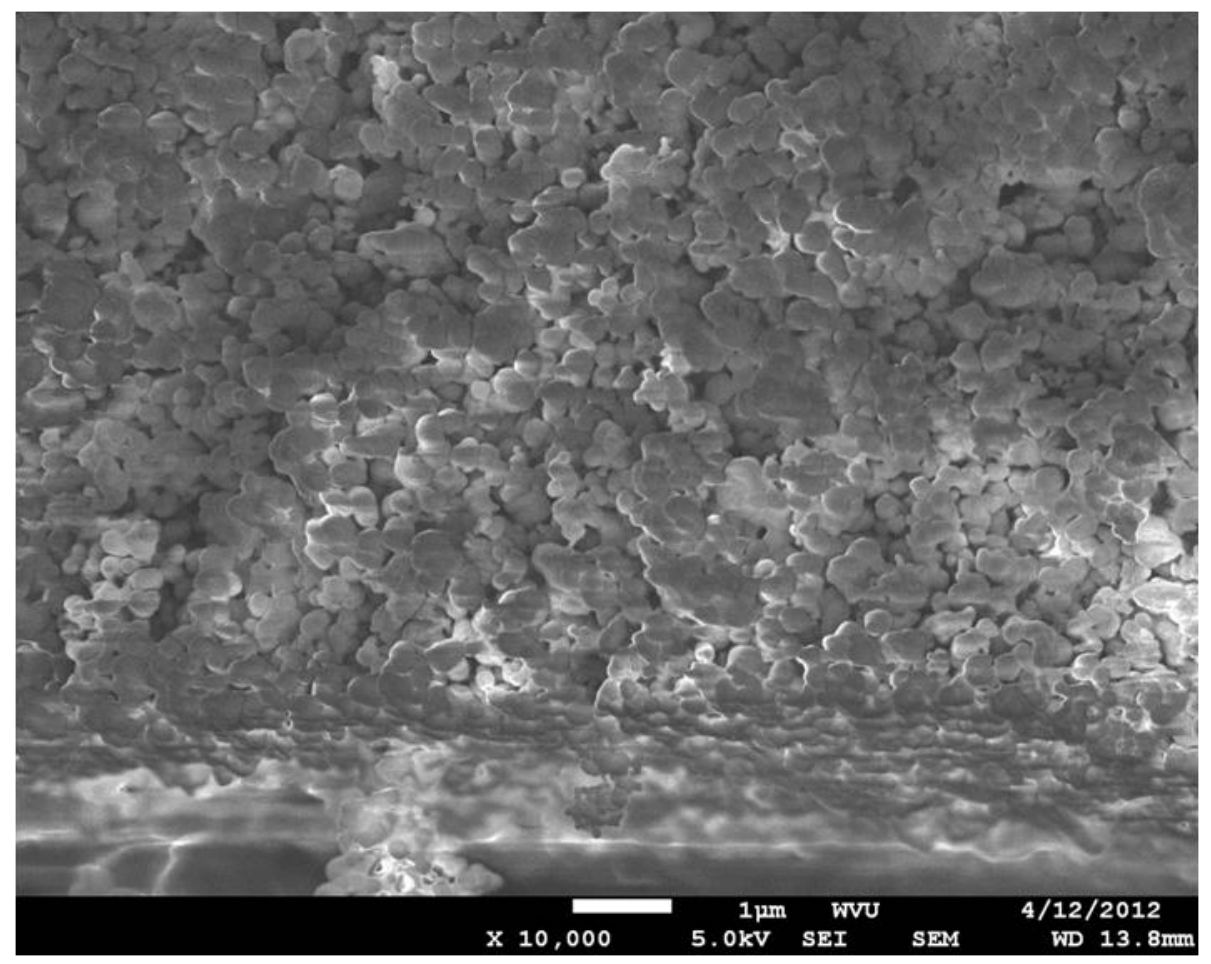

Figure 79: The handprinted GDC electrolyte layer after firing to $1250^{\circ} \mathrm{C}$ for $2 \mathrm{~h}$.

A lack of density is evident from this image. In chapter 3 , it was established that $1400^{\circ} \mathrm{C}$ was required for full densification of the GDC. Another issue with this hand printed layer is diffusion into the anode support. Figures $80 \mathrm{a}$ and $\mathrm{b}$ show the change in porosity of the anode support at different locations from the electrolyte. 


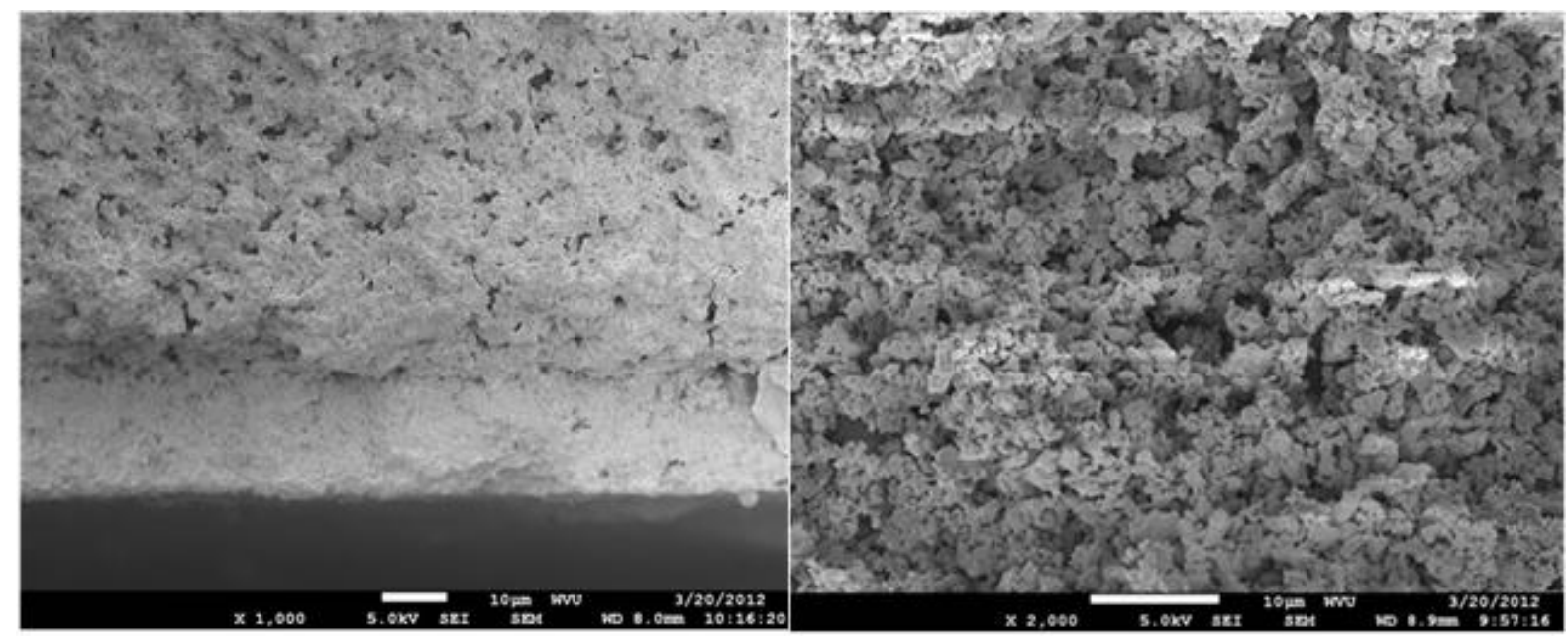

Figure 80: The SEM images showing density of the anode support at a) the interface (left) and b) the bulk of the support (right).

Figure 80a is the area at the anode/electrolyte interface and Figure 80b is at a distance $400 \mu \mathrm{m}$ from the interface which corresponds to the middle of the support. The decreased porosity near the interface can be attributed to either electrolyte material diffusion during the drying/firing process or the first couple of sol-gel depositions seeping through the open porosity before the drying stage. Figure 81 shows the densification of the GDC electrolyte after the first 5 deposition iterations. The bridging of the particles is clearly demonstrated for this procedure, however, additional coatings are needed to fully densify. When comparing Figure 81 with Figure 79 , it can be seen that the sol-gel coatings are in fact filling the gaps that are needed to fully seal the cell. There are still some micro-cracks visible after 5 coatings and firing to $800^{\circ} \mathrm{C}$, which can be filled with further sol-gel depositions and sintering stages. 


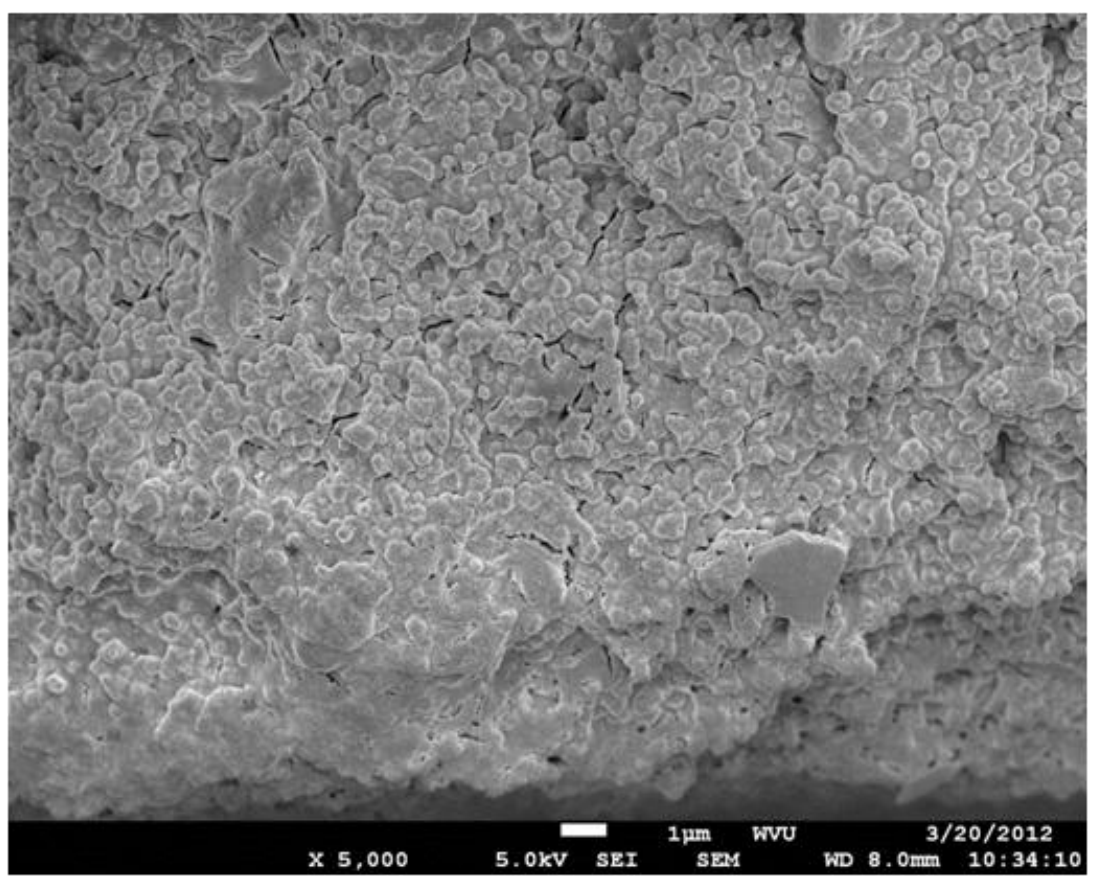

Figure 81: SEM image of the GDC electrolyte after 5 sol-gel coatings and firing to 800C.

Figure 82 shows full densification of the electrolyte after 10 additional coatings and an additional thermal sintering run to $800^{\circ} \mathrm{C}$ for $2 \mathrm{~h}$. This complete densification allows for a good electrical seal which could ultimately result in enhanced electrochemical properties. 


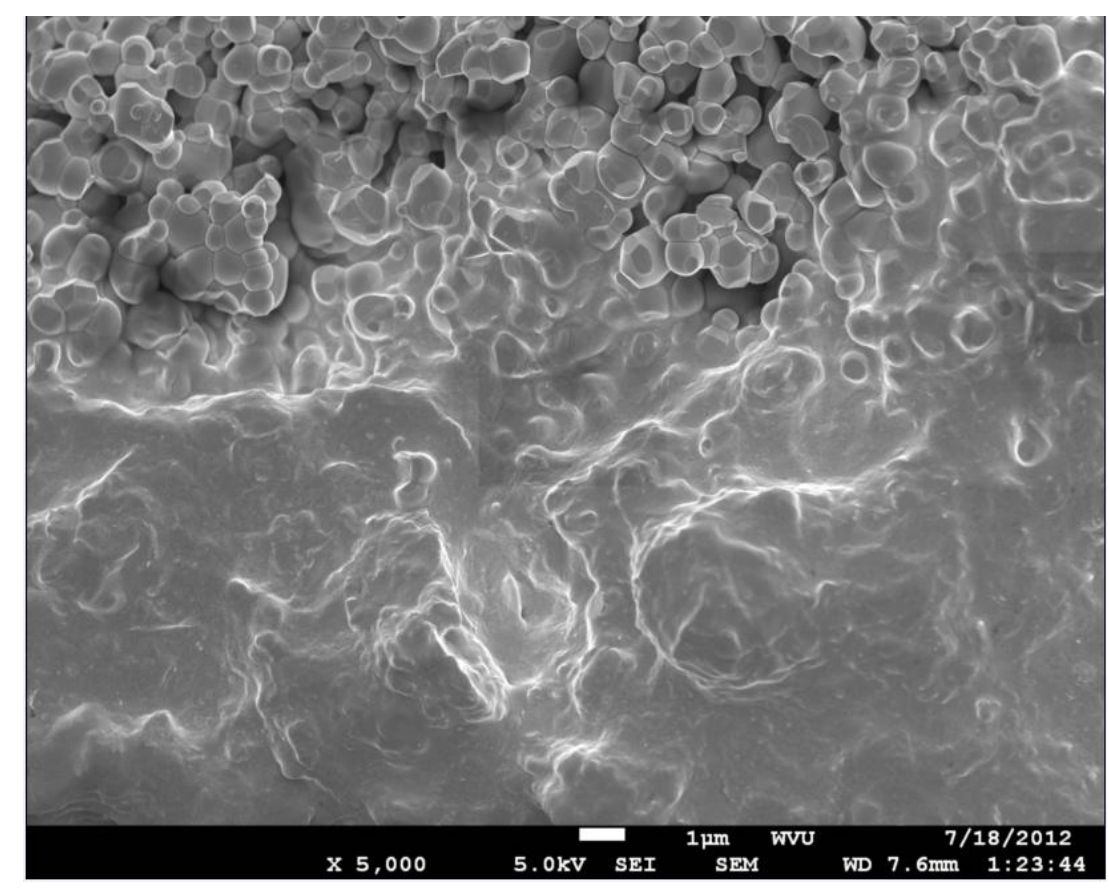

Figure 82: Electroyte after 15 coatings and 2 sintering runs to $800^{\circ} \mathrm{C}$.

\subsection{Conclusions}

The work in this chapter helped to develop a sound processing protocol for a novel SMM/GDC anode-supported cell. The potential volatility of molybdenum made thermal processing at lower temperatures a necessity. The sol-gel GDC solution helped to sufficiently bridge the gaps between the pores of the initial hand-printed layer. The porosity resulted from the $1250^{\circ} \mathrm{C}$ electrolyte sintering temperature, which prevented significant loss of molybdenum in the supports. It was found that 15-20 depositions with 2 sintering stages resulted in a sample dense enough to prevent direct combustion in the fuel cell testing chamber. The next stage of this work will be to test this anode in different fuels to determine performance, stability, the cells propensity towards electronic leaking, and impurity tolerance. 


\section{Chapter 6 - Thesis Conclusions and Future Work}

The work presented in this thesis resulted in several new pieces of information for the fuel cell community with regards to anode materials. The $\mathrm{Sr}_{2} \mathrm{MgMoO}_{6-\delta}$ anode, when combined with a GDC ion conductor, generates power densities approaching $300 \mathrm{~mW}-\mathrm{cm}^{-2}$ using a YSZ electrolyte-supported platform. This is quire a reasonable value considering the thick electrolyte platform that contributes a high ohmic resistance. Additionally, it shows much improved

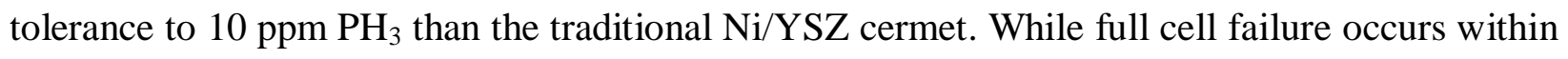
$30 \mathrm{~h}$ for the $\mathrm{Ni} / \mathrm{YSZ}$ anode, extrapolation predicts that cell failure will not occur for the SMM/GDC anode until almost $750 \mathrm{~h}$ and this anode was stable in this impurity for the first 40 hours. Rather than changes to the bulk anode microstructure being the cause for degradation, losses in potential are assigned to slight delamination at the anode/electrolyte interface and densification of the contact paste. Also, to potentially increase the commercial potential of this anode for operation on coal-derived fuels, a processing procedure was experimentally developed using GDC as the electrolyte material. A novel sol-gel method was used to fully densify the electrolyte without using excessive sintering temperatures as to suppress molybdenum volatility.

The other portion of this thesis focused on assessing the importance of a GDC barrier layer on $\mathrm{H}_{2} \mathrm{~S}$ impurity tolerance for a $\mathrm{Ni} / \mathrm{GDC}$ anode. Without the barrier layer, performance of the cell in both wet $\mathrm{H}_{2}$ and syngas was lower and gradual losses to the cell potential under fixed loading were observed. However with the GDC barrier layer, the cell exhibited good stability in syngas plus $100 \mathrm{ppm} \mathrm{H}_{2} \mathrm{~S}$ for over $400 \mathrm{~h}$. The limit for $\mathrm{H}_{2} \mathrm{~S}$ impurity was found to be between 100 and $200 \mathrm{ppm}$ and degradation has been assigned to microstructural changes to the triple phase boundary sites as a result of Ni-oxidation. The tolerance level was found to be between 500 and $1000 \mathrm{ppm}$ in wet $\mathrm{H}_{2}$. Increasing the gadolinium doping level slightly improved $\mathrm{H}_{2} \mathrm{~S}$ tolerance, but resulted in lower power performance. Lastly, a novel $\mathrm{NiWO}_{4}$ composition was evaluated as a potential SOFC anode and generated over $160 \mathrm{~mW}-\mathrm{cm}^{-2}$ when combined with GDC in wet $\mathrm{H}_{2}$ fuel, though problems similar to the Ni/YSZ anode with $\mathrm{PH}_{3}$ impurity were seen.

In the future, knowing that an anode with much improved tolerance has been identified, the anode supported architecture will need to be further explored through testing to analyze its 
viability in terms of testing in fuels containing multiple coal contaminants. Unlike the Ni/YSZ cermet, this composition did not form solid phases with phosphorus nor did its microstructure drastically change suggesting that reactions between the constituents are not favorable for our testing conditions. A sound series of thermodynamic models would be important in the future to see what, if any, ranges of temperatures and oxygen partial pressures would result in reaction between the $\mathrm{Sr}, \mathrm{Mg}$, or Mo in the SMM structure. The ultimate goal is to better understand why the SMM anode showed some tolerance to $\mathrm{PH}_{3}$ and then utilize the electrochemical reaction and method of stability to other energy-related oxide systems. Also, knowing the propensity for electronic leaking of GDC across the cell in environments containing higher partial pressures of hydrogen, evaluations of this anode in $\mathrm{CO}$ fuel would be of interest. 


\section{REFERENCES}

[1] NETL Clean Coal Power Initiative Fact Sheet. http://www.fossil.energy.gov/programs/powersystems/cleancoal/ccpi/Prog052.pdf.

[2] http://wboy.com/story.cfm?func=viewstory\&storyid=85704.

[3] S.C Singhal. "Advances in solid oxide fuel cell technology." Solid State Ionics 135 (2000): 305-313.

[4] D.J.L. Brett, P. Aguiar, N.P. Brandon, R.N. Bull, R.C. Galloway, G.W. Hayes, K. Lillie, C. Mellors, C. Smith, A.R. Tilley. "Concept and system design for a ZEBRA batteryintermediate temperature solid oxide fuel cell hybrid vehicle." Journal of Power Sources 157 (2006): 782-798.

[5] Y. Yi, A.D. Rao, J. Brouwer, G.S. Samuelsen. "Fuel flexibility study of an integrated 25 kW SOFC reformer system.” Journal of Power Sources 144 (2005): 67-76.

[6] T. Kivisaari, P. Bjornbom, C. Sylwan, B. Jacquinot, D. Jansen, A DeGroot. "The feasibility of a coal gasifier combined with a high-temperature fuel cell." Chemical Engineering Journal 100 (2004): 167-180.

[7] J.W. Stevenson, O.A. Marina, L.R. Pederson, C.A. Coyle, E.C. Thomsen, and D.J. Edwards. "SOFC Tolerance Limits for Phosphorus and Arsenic." 11th Annual SECA Workshop, Pittsburgh, PA, 2010.

[8] C. Xu, J.W. Zondlo, H. Finklea, O. Demircan, M. Gong, X. Liu. "The effect of phosphine in syngas on Ni-YSZ anode-supported solid oxide fuel cells." Journal of Power Sources 193 (2009): 739-746.

[9] J.F.B. Rasmussen, A. Hagen. "The effect of $\mathrm{H}_{2} \mathrm{~S}$ on the performance of Ni-YSZ anodes in solid oxide fuel cells." Journal of Power Sources 191 (2009): 534-541. 
[10] L. Zhang, S.P Jiang, H.Q. He, X. Chen, J. Ma, X.C. Song. "A comparative study of $\mathrm{H}_{2} \mathrm{~S}$ poisoning on electrode behavior of $\mathrm{Ni} / \mathrm{YSZ}$ and $\mathrm{Ni} / \mathrm{GDC}$ anodes of solid oxide fuel cells." International Journal of Hydrogen Energy 35 (2010): 12359-12368.

[11] F. Cayan, M. Zhi, S.R. Pakalapati, I. Celik, N. Wu, R. Gemmen. "Effects of coal syngas impurities on anodes of solid oxide fuel cells.” Journal of Power Sources 185 (2008): 595-602.

[12] J.P. Trembly, A.I. Marquez, T.R. Ohrn, D.J. Bayless. "Effects of coal syngas and $\mathrm{H}_{2} \mathrm{~S}$ on the performance of solid oxide fuel cells: Single-cell tests." Journal of Power Sources 158 (2006): 263-273.

[13] A. Hagen, J.F.B. Rasmussen, K. Thydén. "Durability of solid oxide fuel cells using sulfur containing fuels.” Journal of Power Sources 196 (2011): 7271-7276.

[14] T. Huang, M. Huang. "Electrochemical promotion of bulk lattice-oxygen extraction for syngas generation over Ni-GDC anodes in direct-methane SOFC's." Chemical Engineering Journal 135 (2008): 216-223.

[15] C. Ding, H. Lin, K. Sato, T. Kawada, J. Mizusaki, T. Hashida. "Improvement of electrochemical performance of anode-supported SOFC's by $\mathrm{NiO}-\mathrm{Ce}_{0.9} \mathrm{Gd}_{0.1} \mathrm{O}_{1.95}$ nanocomposite powders." Solid State Ionics 181 (2010): 1238-1243.

[16] Andres I. Marquez, Ted R. Ohrn, Jason P. Trembly, David C. Ingram, David J. Bayless. "Effects of coal syngas and $\mathrm{H}_{2} \mathrm{~S}$ on the performance of solid oxide fuel cells Part 2. Stack tests." Journal of Power Sources 164 (2007): 659-667.

[17] M. Gong, X. Liu, J. Trembly, C. Johnson. "Sulfur-tolerant anode materials for solid oxide fuel cell application." Journal of Power Sources 168: (2007) 289-298.

[18] J.A. Bustnes, D. Sichen, and S. Seetharaman. "Kinetic studies of the reduction of $\mathrm{FeO}$ and $\mathrm{FeWO}_{4}$ by hydrogen." Metallurgical and Materials Transactions B 29 (1998): 613618.

[19] B. Fruhberger, M. Grunze, D.J. Dwyer. "Surface chemistry of $\mathrm{H}_{2} \mathrm{~S}$-sensitive tungsten oxide films." Sensors and Actuators B31 (1996): 167-174. 
[20] Y.H. Huang, R.I. Dass, Z.L. Xing, J.B. Goodenough. "Double Perovskites as Anode Materials for Solid-Oxide Fuel Cells.” Science 312 (2006): 254-257.

[21] D. Marrero-López, J. Peña-Martínez, J.C. Ruiz-Morales, M. Gabás, P. Núñez, M.A.G. Aranda, J.R. Ramos-Barrado. "Redox behaviour, chemical compatibility and electrochemical performance of $\mathrm{Sr}_{2} \mathrm{MgMoO}_{6-\delta}$ as SOFC anode." Solid State Ionics 180 (2010): 1672-1682.

[22] S. M. Haile. "Fuel cell materials and components." Acta Materialia 51 (2003): 59816000 .

[23] P. Nehter. "A high fuel utilizing solid oxide fuel cell cycle with regard to the formation of nickel oxide and power density." Journal of Power Sources 164 (2007): 252-259.

[24] J.H. Yu, G.W. Park, S. Lee, S.K. Woo. "Microstructural effects on the electrical and mechanical properties of Ni-YSZ cermet for SOFC anode." Journal of Power Sources 163 (2007): 926-932.

[25] P.A. Ramakrishna, S. Yang, C.H. Sohn. "Innovative design to improve the power density of a solid oxide fuel cell." Journal of Power Sources 158 (2006): 378-384.

[26] R. Barrera, S. De Biase, S. Ginocchio, S. Bedogni, L. Montelatici. "Performance and life time test on a $5 \mathrm{~kW}$ SOFC system for distributed cogeneration." International Journal of Hydrogen Energy 33 (2008): 3193-3196.

[27] K. Ahmed, K. Foger. "Kinetics of internal steam reforming of methane on Ni/YSZ-based anodes for solid oxide fuel cells.” Catalysis Today 63 (2000): 479-487.

[28] H. Miao, W.G. Wang, T.S. Li, T. Chen, S.S. Sun, C. Xu. "Effects of coal syngas major compositions on Ni/YSZ anode-supported solid oxide fuel cells." Journal of Power Sources 195 (2010): 2230-2235.

[29] H. Apfel, M. Rzepka, H. Tu, U. Stimming. "Thermal start-up behaviour and thermal management of SOFC's.” Journal of Power Sources 154 (2006): 370-378.

[30] barnett.mccormick.northwestern.edu. 
[31] H.S. Spacil, US Patent 3,558,360; filed October 30, 1964, modified November 2, 1967, granted March 31, 1970.

[32] J.B. Goodenough, Y. Huang. "Alternative anode materials for solid oxide fuel cells." Journal of Power Sources 173 (2007): 1-10.

[33] D.R. Gaskell. "Introduction to Thermodynamics of Materials." Taylor and Francis. 1995.

[34] C.H. Hamann, A. Hamnett and W. Vielstich. "Electrochemistry." J. Wiley \& Sons. 1998.

[35] J.W. Kim, A. Virkar, K. Fung, K. Mehta, and S. Singhal. "Polarization Effects in Intermediate Temperature, Anode-Supported Solid Oxide Fuel Cells." Journal of the Electrochemical Society 146 (1999): 69-78.

[36] S.C. Singhal, K. Kendall. "High Temperature Solid Oxide Fuel Cells.” Elsevier. 2003.

[37] X. Ye, S.R. Wang, J. Zhou, F.R. Zeng, H.W. Nie, T.L. Wen. "Assessment of the performance of Ni-yttria-stabilized zirconia anodes in anode-supported Solid Oxide Fuel Cells operating on $\mathrm{H}_{2}-\mathrm{CO}$ syngas fuels." Journal of Power Sources 195 (2010): 72647267.

[38] NETL, Fuel Cell Handbook, 7th ed., 2004.

[39] S. Zha, Z. Cheng, M. Liu. "Influence of Cell Voltage and Current on Sulfur Poisoning Behavior of Solid Oxide Fuel Cells." Journal of the Electrochemical Society 154 (2007): 688-693.

[40] Z. Cheng, S. Zha, M. Liu. "Influence of cell voltage and current on sulfur poisoning behavior of solid oxide fuel cells." Journal of Power Sources 172 (2007): 688-693.

[41] P. Lohsoontorn, D.J. Brett, N.P. Brandon. "Thermodynamic predictions of the impact of fuel composition on the propensity of sulfur to interact with $\mathrm{Ni}$ and ceria-based anodes for solid oxide fuel cells.” Journal of Power Sources 175 (2008): 60-67.

[42] D.G. Ivey, E. Brightman, N. Brandon. "Structural modifications to nickel cermet anodes in fuel cell environments." Journal of Power Sources 195 (2010): 6301-6311. 
[43] E. Brightman, D.G. Ivey, D.J.L. Brett, N.P. Brandon. "The effect of current density on $\mathrm{H}_{2} \mathrm{~S}$-poisoning of nickel-based solid oxide fuel cell anodes." Journal of Power Sources 196 (2011): 7182-7187.

[44] A. Lussier, S. Sofie, J. Dvorak, Y.U. Idzerda. "Mechanism for SOFC anode degradation from hydrogen sulfide exposure." International Journal of Hydrogen Energy 33 (2008): 3945-3951.

[45] J. Kuhn, N. Lakshminarayanan, U. Ozkan. "Effect of hydrogen sulfide on the catalytic activity of Ni-YSZ cermets." Journal of Molecular Catalysis A: Chemical 282 (2008): 921.

[46] A. Martinez, K. Gerdes, R. Gemmen, J. Poston. "Thermodynamic analysis of interactions between Ni-based solid oxide fuel cells (SOFC) anodes and trace species in a survey of coal syngas." Journal of Power Sources 195 (2010): 5206-5212.

[47] M. Zhi, H. Finklea, N. Madhiri, I. Celik, B. Kang, X. Liu, N.Q. Wu. Proceedings of the 212th ECS Meeting, Washington, DC, 2007.

[48] O.A. Marina, C.A. Coyle, E.C. Thomsen, D.J. Edwards, G.W. Coffey, L.R. Pederson. "Degradation mechanisms of SOFC anodes in coal gas containing phosphorus." Solid State Ionics 181 (2010): 430-440.

[49] O.A. Marina, L.R. Pederson, D.J. Edwards, C.W. Coyle, J. Templeton, M. Engelhard, Z. Zhu. Proceedings of the 8th Annual SECAWorkshop, San Antonio, TX, 2007.

[50] C. Xu, J.W. Zondlo, M. Gong, X. Liu. "Effect of $\mathrm{PH}_{3}$ poisoning on a Ni-YSZ anodesupported solid oxide fuel cell under various operating conditions." Journal of Power Sources 196 (2011): 116-125.

[51] M. Flytzani-Stephanopoulos, M. Sakbodin, Z. Wang. "Regenerative adsorption and removal of $\mathrm{H}_{2} \mathrm{~S}$ from hot fuel gas streams by rare earth oxides." Science 312 (2006): $1508-1510$.

[52] H. Devianto. "The effect of a ceria coating on the $\mathrm{H}_{2} \mathrm{~S}$ tolerance of a molten carbonate fuel cell." Journal of Power Sources 159 (2006): 1147-1152. 
[53] O.A. Marina, C. Bagger, S. Primdahl, M. Mogensen. "A solid oxide fuel cell with a gadolinia-doped ceria anode: preparation and performance." Solid State Ionics 123, (1999): 199-208.

[54] L. Aguilar, S. Zha, S. Li, J. Winnick, M. Liu. "Sulfur-Tolerant Materials for the Hydrogen Sulfide SOFC.” Electrochemical Solid State Letters 7 (2004): A324.

[55] S. Zha, Z. Cheng, M. Liu. Electrochemical Solid State Lett. 8 (2005): A406.

[56] O.A. Marina, N.L. Canfield, J.W. Stevenson. "Thermal, electrical, and electrocatalytical properties of lanthanum-doped strontium titanate.” Solid State Ionics 149 (2002): 21-28.

[57] M.R. Pillai, I. Kim, D.M. Bierschenk, Scott A. Barnett. "Fuel-flexible operation of a solid oxide fuel cell with $\mathrm{Sr}_{0.8} \mathrm{La}_{0.2} \mathrm{TiO}_{3}$ support.” Journal of Power Sources 185 (2008): 10861093.

[58] J. Canales-Vasquez, S.W. Tao, J.T.S. Irvine. "Electrical properties in $\mathrm{La}_{2} \mathrm{Sr}_{4} \mathrm{Ti}_{6} \mathrm{O}_{19}$ : a potential anode for high temperature fuel cells." Solid State Ionics 159 (2003): 159-165.

[59] Y.H. Huang, R.I. Dass, J.C. Denyszyn, J.B. Goodenough. "Synthesis and Characterization of $\mathrm{Sr}_{2} \mathrm{MgMoO}_{6-\delta}$ : An Anode Material for the Solid Oxide Fuel Cell.” Journal of Electrochemical Society 153 (2006): A1266.

[60] Y. Ji, Y.H. Huang, J.R. Ying, J.B. Goodenough. "Electrochemical performance of Ladoped $\mathrm{Sr}_{2} \mathrm{MgMoO}_{6}$ in natural gas." Electrochemical Communications 9 (2007): 18811885.

[61] D. Marrero-López, J. Peña-Martinez, J.C. Ruiz-Morales, M.C. Martin-Sedeño, P. Núñez. "High temperature phase transition in SOFC anodes based on $\mathrm{Sr}_{2} \mathrm{MgMoO}_{6}$." Journal of Solid State Chemistry 182 (2009): 1027-1034.

[62] M.N. Rahaman, Ceramic Processing and Sintering $2^{\text {nd }}$ Edition, Marcel Dekker Inc.

[63] P.D. Calvert, E.S. Tormy, R.L. Pober. "Fish Oil and Triglycerides as Dispersants for Ceramics Processing.” American Ceramic Society Bulletin 65 (1986): 669-672. 
[64] X.G. Capdevila, J. Folch, A. Calleja, J. Llorens, M. Segarra, F. Espiell, J.R. Morante. "High-density YSZ tapes fabricated via the multi-folding lamination process." Ceramics International 35, (2009): 1219-1226.

[65] A. Mukherjee, B. Maiti, A. Das Sharma, R.N. Basu, H.S. Maiti. "Correlation between slurry rhealogy, green density and sintered density of tape cast yttria stabilized zirconia." Ceramics International 27 (2001): 731-739.

[66] M. Han, X. Tang, H. Yin, S. Peng. "Fabrication, microstructure, and properties of a YSZ electrolyte for SOFCs.” Journal of Power Sources 165 (2007): 757-763.

[67] R.N. Basu, A. Das Sharma, A. Dutta, J. Mukhopadhyay. "Processing of highperformance anode-supported planar solid oxide fuel cell." International Journal of Hydrogen Energy 33 (2008): 5748-5754.

[68] A. Hauch, M. Mogensen. "Ni/YSZ electrode degradation studied by impedance spectroscopy Effects of gas cleaning and current density." Solid State Ionics 181 (2010): 745-753.

[69] A. Hauch, S.D. Ebbesen, S.H. Jensen, M. Mogensen. "Solid Oxide Electrolysis Cells: Microstructure and Degradation of the Ni/Yttria-Stabilized Zirconia Electrode.” Journal of the Electrochemical Society 155 (2008): B1184-1193.

[70] A. Sanson, P. Pinasco, E. Roncari. "Influence of pore formers on slurry composition and microstructure of tape cast supporting anodes for SOFCs." Journal of the European Ceramic Society 28 (2008): 1221-1226.

[71] S.P. Jiang, and S.H. Chan. "A review of anode materials development in solid oxide fuel cells.” Journal of Material Science 39 (2004): 4405-4439.

[72] J.P. Trembly, R.S. Gemmen, and D.J. Bayless. "The effect of IGFC warm gas cleanup system conditions on the gas-solid partitioning and form of trace species in coal syngas and their interactions with SOFC anodes." Journal of Power Sources 163 (2007) 986996. 
[73] M. D. Dolan, A. Y Iiyushechkin, K.G McLennan, S. D. Sharma. Asia-Pacific Journal of Chemical Engineeing (2010).

[74] T. Ko, H. Chu, L. Chaung. "The sorption of hydrogen sulfide from hot syngas by metal oxides over supports." Chemosphere 58 (2005): 467-474.

[75] J. Dong, Z. Cheng, S. Zha, M. Liu. "Identification of nickel sulfides on Ni-YSZ cermet exposed to $\mathrm{H}_{2}$ fuel containing $\mathrm{H}_{2} \mathrm{~S}$ using Raman spectroscopy." Journal of Power Sources Short Communication 156 (2006): 461-465.

[76] J.H. Wang, M. Liu. "Surface regeneration of sulfur-poisoned Ni surfaces under SOFC operation conditions predicted by first-principles-based thermodynamic calculations." Journal of Power Sources 176 (2008): 23-30.

[77] K. Sasaki, K. Susuki, A. Iyoshi, M. Uchimura, N. Imamura, H. Kusaba, Y. Teraoka, H. Fuchino, K. Tsujimoto, Y. Uchida, N. Jingo. " $\mathrm{H}_{2} \mathrm{~S}$ poisoning of Solid Oxide Fuel Cells." Journal of the Electrochemical Society 153 (2006): A2023-A2029.

[78] H. Devianto, S. P. Yoon, S. W. Nam, J. Han, T. Lim. "The effect of a ceria coating on the $\mathrm{H}_{2} \mathrm{~S}$ tolerance of a molten carbonate fuel cell." Journal of Power Sources 159 (2006): $1147-1152$.

[79] J.M. Sanz, S. Hofmann. "Quantitative evaluation of AES-depth profiles of thin anodic oxide films." Surf. Interf. Anal. 5 (1983) 210.

[80] M. Mogensen, N. M. Sammes, G.A. Tompett. "Physical, chemical and electrochemical properties of pure and doped ceria." Solid State Ionics (2000): 63-94.

[81] F.S. Brugner, R. N. Blumenthal. Journal of America Ceramic Societies 54 (1971): Discussions and notes.

[82] Y.M. Chiang, E.B. Lavik, I. Kosacki, H.L. Tuller, J.M. Ying. "Defect thermodynamics and electrical properties of nanocrystalline oxides: pure and doped $\mathrm{CeO}_{2}$." Applied Physics Letters 69 (1996): 633-642. 
[83] R.M. Ferrizz, R.J. Gorte, J.M. Vohs. "Determining the $\mathrm{Ce}_{2} \mathrm{O}_{2} \mathrm{~S}-\mathrm{CeO}_{x}$ phase boundary for conditions relevant to adsorption and catalysis." Applied Catalysis B: Environmental 43 (2003): 273-280.

[84] H. Karjalainen, U. Lassi, K. Rahkamaa-Tolonen, V. Kroger, R.L. Keiski. "Thermodynamic equilibrium calculations of sulfur poisoning in $\mathrm{Ce}-\mathrm{O}-\mathrm{S}$ and $\mathrm{La}-\mathrm{O}-\mathrm{S}$ systems." Catalysis Today 100 (2005): 291-295.

[85] H. Yoo, S. Park, J. Chun. "Suppression of Electronic Conductivity of $\mathrm{CeO}_{2}-\mathrm{Based}$ Electrolytes by Electron Traps." Journal of the Electrochemical Society. 157 (2010): B215-B219.

[86] S. Park, H. Yoo. "Thermoelectric behavior of a mixed ionic electronic conductor, Ce(1x)Gd(x)O(2-x/2-delta).” Physical Chemistry Chemical Physics 11 (2009): 391-401.

[87] S. B. Adler. "Reference Electrode Placement in Thin Solid Electrolytes," Journal of The Electrochemical Society 149 (2002): 166-172.

[88] J. Rutman, I. Riess. "Placement of reference electrode in solid electrolyte cells." Electrochimica Acta 52 (2007): 6073-6083.

[89] J. Winkler, P. V. Hendriksen, N. Bonanos, M. Mogensen. "Geometric requirements of solid electrolyte cells a reference electrode." Journal of the Electrochemical Society 145 (1998): 1184-1192.

[90] M. Li, A.D. Rao, J. Brouwer, G.S. Samuelsen. "Design of highly efficient coal-based integrated gasification fuel cell power plants.” Journal of Power Sources 195 (2010): 5707-5718.

[91] R.S. Gemmen, J. Trembly. "On the mechanisms and behavior of coal syngas transport and reaction within the anode of a solid oxide fuel cell." Journal of Power Sources 161 (2006): 1084-1095.

[92] E.H. Pacheco, M.D. Mann, P.N. Hutton, D. Singh, K.E. Martin. “A cell-level model for a solid oxide fuel cell operated with syngas from a gasification process." International Journal of Hydrogen Energy 30 (2005): 1221-1233. 
[93] G. Krishnan, Proc. 9th Annual Solid State Energy Conversion Alliance Workshop, Pittsburgh, PA USA, August 5-7 2008.

[94] J.P. Trembly, R.S. Gemmen, D.J. Bayless, Proc. 5th International fuel cell science, Engineering, and technology conference, New York, NY, 2007.

[95] M.J. Zhi, X.Q. Chen, H. Finklea, I. Celik, N.Q Wu. "Electrochemical and microstructural analysis of nickel-yttria-stabilized zirconia electrode operated in phosphorus-containing syngas." Journal of Power Sources 183 (2008): 485-490.

[96] E.L. Hardegree, P. Ho, J.M White. "Sulfur adsorption on Ni(100) and its effect on CO chemisorption: I. TDS, AES and work function results.” Surf Sci. 165 (1986): 488-506.

[97] M. Blaszczyszyn, R. Blaszczyszyn, R. Meclewski. "Interactions of sulfur with nickel surfaces: adsorption, diffusion, and desorption.” Surf. Sci. 131 (1983): 433-447.

[98] C.M Grgicak, R.G. Green, J.B. Giorgi. "SOFC anodes for direct oxidation of hydrogen and methane fuels containing $\mathrm{H}_{2}$ S." Journal of Power Sources 179 (2008): 317-328.

[99] R.J. Gorte, H. Kim and J.M. Vohs. "Novel SOFC anodes for the direct electrochemical oxidation of hydrocarbon.” Journal of Power Sources 106 (2002): 10-15.

[100] Z.F. Zhou, C. Gallo, M.B. Prague, H. Schobert, S. Lvov. "Direct oxidation of jet fuels and pennsylvania crude oil in a solid oxide fuel cell." Journal of Power Sources 133 (2004): 181-187.

[101] H. He, R.J. Gorte and J.M. Vohs. "Highly sulfur tolerant Cu-ceria anodes for SOFCs." Electrochem. Solid State Lett. 8 (2005): 279-280.

[102] H. Kurokawa, L. Yang, C.P. Jacobson, L.C. De Jonghe, S.J. Visco. "Y-doped $\mathrm{SrTiO}_{3}$ based sulfur tolerant anode for solid oxide fuel cells." Journal of Power Sources 164 (2007): 510-518.

[103] S. Zha, P. Tsang, Z. Cheng, M. Liu. "Electrical properties and sulfur tolerance of $\mathrm{La}_{0.75} \mathrm{Sr}_{0.25} \mathrm{Cr}_{1-\mathrm{x}} \mathrm{Mn}_{\mathrm{x}} \mathrm{O}_{3}$ under anodic conditions." Journal of Solid State Chemistry 178 (2005): 1844-1850. 
[104] C. Yates, J. Winnick. "Anode material for hydrogen sulfide solid oxide fuel cell." Journal of the Electrochemical Society. 146 (1999): 2841-2844.

[105] Z. Cheng, S. Zha, L. Aguilar, M. Liu. "Chemical, electrical, and thermal properties of strontium doped lanthanum vanadate." Solid State Ionics 176 (2005): 1921-1928.

[106] D. Marrero-Lopez, J. Pena-Martınez, J.C. Ruiz-Morales, D. Perez-Coll, M.A.G. Aranda, P. Nunez. "Synthesis, phase stability and electrical conductivity of $\mathrm{Sr}_{2} \mathrm{MgMoO}_{6-\mathrm{d}}$ anode." Materials Research Bulletin 43 (2008): 2441-2450.

[107] S. Vasala, M. Lehtimaki, S.C. Haw, J.M. Chen, R.S. Liu, H. Yamauchi, M. Karppinen. "Isovalent and aliovalent substitution effects on redox chemistry of $\mathrm{Sr}_{2} \mathrm{MgMoO}_{6-\delta} \mathrm{SOFC}-$ anode material." Solid State Ionics 181 (2010): 754-759.

[108] D.H. Prasad, H.R. Kim, J.S. Park, J.W. Son, B.K. Kim, H.W. Lee, J.H. Lee. "Superior sinterability of nano-crystalline gadolinium doped ceria powders synthesized by coprecipitation method." Journal of Alloys and Compounds 495 (2010): 238-241.

[109] Q.A. Huang, R. Hui, B. Wang, J. Zhang. "Mechanism and kinetics of oxygen reduction on porous $\mathrm{La}_{1-\mathrm{x}} \mathrm{Sr}_{\mathrm{x}} \mathrm{CoO}_{1-\delta}$ electrodes." Electrochem Acta. 52 (2007): 8144-8164.

[110] S.B. Adler. "Mechanism and kinetics of oxygen reduction on porous $\mathrm{La}_{1-x} \mathrm{Sr}_{x} \mathrm{CoO}_{1-\delta}$ electrodes.” Solid State Ionics 111 (1998): 125-134.

[111] S.B. Adler, B.T. Henderson, M.A. Wilson, D.M. Taylor, R.E. Richards. "Limitations of charge-transfer models for mixed-conducting oxygen electrodes.” Solid State Ionics 135 (2000): $35-42$.

[112] C. Xu, P. Gansor, K. Sabolsky, J.W. Zondlo, E.M. Sabolsky. " $\mathrm{An}_{2} \mathrm{H}_{2} \mathrm{~S}$-tolerant Ni/GDC anode with a GDC barrier layer." Journal of Electrochemical Society 158 (2012): 14051416.

[113] P. Gansor, C. Xu, K. Sabolsky, J.W. Zondlo, E.M. Sabolsky. "Phosphine impurity tolerance of $\mathrm{Sr}_{2} \mathrm{MgMoO}_{6-\delta}$ composite SOFC anodes." Journal of Power Sources 198 (2012): 7-13. 
[114] S. Jung, C. Lu, H. He, K. Ahn, R.J. Gorte, J.M. Vohs. "Influence of composition and Cu Impregnation method on the performance of $\mathrm{Cu} / \mathrm{CeO}_{2} / \mathrm{YSZ} \mathrm{SOFC}$ anodes." Journal of Power Sources 154 (2006): 42-50.

[115] S.P. Jiang. "A review of wet impregnation-an alternative method for the fabrication of high performance and nano-structured electrodes of solid oxide fuel cells." Materials Science and Engineering A 418 (2006): 199-210.

[116] J. Qiao, K. Sun, N. Zhang, B. Sun, J. Kong, D. Zhou. 'Ni/YSZ and Ni-CeO $2 / Y S Z$ anodes prepared by impregnation for solid oxide fuel cells." Journal of Power Sources 169 (2007): 253-258.

[117] Z. Liu, D. Ding, B. Liu, W. Guo, W. Wang, C. Xia. "Effect of impregnation phases on the performance of Ni-based anodes for low temperature solid oxide fuel cells.” Journal of Power Sources 196 (2011): 8561-8567.

[118] M.R. Goldwasser, M.E. Rivas, E. Pietri, M.J. Pérez-Zurita, M.L. Cubeiro, L. Gingembre, L. Leclercq, G. Leclercq. "Perovskites as catalysts precursors: $\mathrm{CO}_{2}$ reforming of $\mathrm{CH}_{4}$ on $\mathrm{Ln}_{1-x} \mathrm{Ca}_{x} \mathrm{Ru}_{0.8} \mathrm{Ni}_{0.2} \mathrm{O}_{3}$ (Ln = La, Sm, Nd).” Applied Catalysis A: General 255 (2003): 4557.

[119] S. Wang, Y. He, J. Zo, Y. Wang, H. Huang. Journal of Alloys and Compounds 482 (2009): 61-66.

[120] C. Yates, J. Winnick. "Anode material for hydrogen sulfide solid oxide fuel cell." Journal of Electrochemical Society 146 (1999): 2841-2844.

[121] B. Solsona, J.M. López Nieto, P. Concepción, A. Dejoz, F. Ivars, M.I. Vázquez. "Oxidative dehydrogenation of ethane over $\mathrm{Ni}-\mathrm{W}-\mathrm{O}$ mixed metal oxide catalysts." Journal of Catalysis 280 (2011): 28-39.

[122] E. Antolini, E.R. Gonzalez. "Tungsten-based materials for fuel cell applications." Applied Catalysis B: Environmental 96 (2010): 245-266.

[123] B.Fruhberger, M. Grunze, D.J. Dwyer. "Surface Chemistry of $\mathrm{H}_{2} \mathrm{~S}$-sensitive tungsten oxide films." Sensors and Actuators B31 (1996): 167-174. 
[124] P. Atanasova, T. Tabakova, C. Vladov, T. Halachev, A. Lopez Agudo. "Effect of phosphorus concentration and method of preparation on the structure of the oxide form of phosphorus-nickel-tungsten/alumina hydrotreating catalysts. Applied Catalysis A: General 161 (1997): 105-119.

[125] J. A. Kilner and S. J. Skinner. "Oxygen ion conductors." Materials Today 6 (2003): 3037.

[126] S. Pathak, D. Steinmetz, J. Kuebler, E. Andrew Payzant, N. Orlovskaya. "Mechanical behavior of $\mathrm{La}_{0.8} \mathrm{Sr}_{0.2} \mathrm{Ga}_{0.8} \mathrm{Mg}_{0.2} \mathrm{O}_{3}$ perovskites." Ceramics International 35 (2009): 1235-1241.

[127] Y.J Leng, S.H Chan, S.P Jiang, K.A Khor. "Low-temperature SOFC with thin film GDC electrolyte prepared in situ by solid-state reaction.” Solid State Ionics 170 (2004): 9-15.

[128] S. Zha, W. Rauch, M. Liu. "Ni-Ce ${ }_{0.9} \mathrm{Gd}_{0.1} \mathrm{O}_{1.95}$ anode for GDC electrolyte-based lowtemperature SOFCs." Solid State Ionics 166 (2004): 241-250.

[129] W.G. Bessler, S. Gewies, M. Vogler. "A new framework for physically based modeling of solid oxide fuel cells." Electrochemical Acta 53 (2007): 1782-1800.

[130] P. Hofmann, K.D. Panopoulos. "Detailed dynamic Solid Oxide Fuel Cell modeling for electrochemical impedance spectra simulation." Journal of Power Sources 195 (2010): $5320-5339$.

[131] J. Bai, X. Li, A. Wang, R. Prins, Y. Wang. "Hydrodesulfurization of dibenzothiophene and its hydrogenated intermediates over bulk MoP." Journal of Catalysis 287 (2012): 161-169. 